WHC-SD-W026-TI-009, Rev.0

\title{
Batching Alternatives for Phase I Retrieval Wastes to Be Processed in WRAP Module 1
}

\footnotetext{
Prepared for:

Westinghouse Hanford Company

P.O. Box 1970

Richland, WA

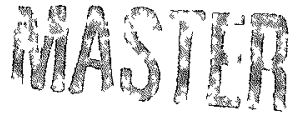

DSTRIBUTION OF THS DOCUMENT IS UMLMIER

Prepared by:

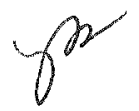

Los Alamos Technical Associates

8633 Gage Blvd.

Kennewick, WA
} 


\section{DISCLAIMER}

This report was prepared as an account of work sponsored by an agency of the United States Government. Neither the United States Government nor any agency Thereof, nor any of their employees, makes any warranty, express or implied, or assumes any legal liability or responsibility for the accuracy, completeness, or usefulness of any information, apparatus, product, or process disclosed, or represents that its use would not infringe privately owned rights. Reference herein to any specific commercial product, process, or service by trade name, trademark, manufacturer, or otherwise does not necessarily constitute or imply its endorsement, recommendation, or favoring by the United States Government or any agency thereof. The views and opinions of authors expressed herein do not necessarily state or reflect those of the United States Government or any agency thereof. 


\section{DISCLAIMER}

Portions of this document may be illegible in electronic image products. Images are produced from the best available original document. 


\section{EXECUTIVE SUMMARY}

Since 1944, the production of defense related material at the Hanford Site has generated radioactive wastes. The bulk of these wastes have been disposed or stored in the Hanford 200 East and 200 West Area burial grounds and waste storage facilities. During the next two decades, the transuranic (TRU) waste now sorted in the 200 Area burial trenches and storage buildings is to be retrieved, processed in the Waste Receiving and Processing (WRAP) Module 1 facility, and shipped to a final disposal facility.

The purpose of this document is to identify the criteria that can be used to batch suspect TRU waste, currently in retrievable storage, for processing through the WRAP Module 1 facility. These criteria are then used to generate a batch plan for Phase I Retrieval operations, which will retrieve the waste located in Trench 4C-04 of the 200 West Area burial ground. The reasons for batching wastes for processing in WRAP Module 1 include reducing the exposure of workers and the environment to hazardous material and ionizing radiation: maximizing the efficiency of the retrieval, processing, and disposal processes by reducing costs, time, and space throughout the process; reducing analytical sampling and analysis; and reducing the amount of cleanup and decontamination between process runs.

Waste stored in the Trench $4 \mathrm{C}-04$ is classified as contact handled (CH) suspect TRU waste and is organized in modules 12 drums wide by 12 drums long, stacked on the asphalt trench bottom four drums high. There are nineteen modules in this trench in a single row each continuous with the adjacent modules. The trench was backfilled, and the top of the modules has an overburden of approximately four feet of native soil. The total number of containers reported to be in Trench $4 \mathrm{C}-04$ is 9,989 lapproximately 9,894 208.2-L and 57 416.4-L drums, 37 metal boxes, and 1 fiberglass reinforced polyester (FRP)plywood box] and total volume of waste is $2.397 \mathrm{~m}^{3}$. Emplacement of waste in Trench 4C-04 began in 1978 . and the last waste package was placed into the trench in 1985.

The criteria selected for batching the drums of retrieved waste entering WRAP Module 1 are based on the available records for the wastes sent to storage as well as knowledge of the processes that generated these wastes. The batching criteria identified in this document include the following:

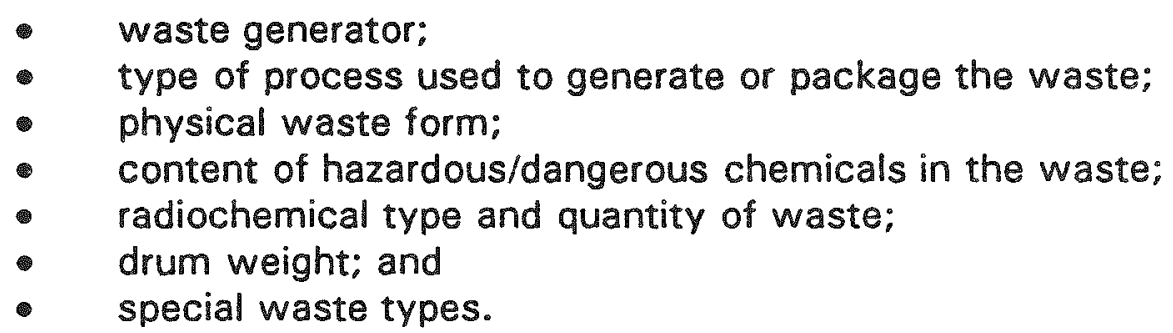

These criteria were applied to the waste drums currently stored in Trench $4 \mathrm{C}-0.04$ to obtain the batches defined in Section 5.0. At least one batching scheme is shown for each of the criteria listed above. The choice of an optimal scheme will depend on the module being retrieved as well as the operational needs of the WRAP Module 1 process at a given time.

It is unlikely that one batching plan will be optimal for all drums retrieved over the life of WRAP Module 1. Rather than batching all waste by a pre-ordained set of criteria, it may be more practical to build the capability for dynamically batching the waste in response to real-time processing needs. This concept uses any combination of the above criteria to 
determine a batch at any given time. An Automated Storage and Retrieval Computer Control System may be used to store and direct the necessary data to accomplish this function. Since the Phase $V$ storage facility employs an Automatic Stacker/Retriever System, the control system and pallet selection and retrieval system can be designed to dynamically create "on-demand" batches. Potential benefits of dynamic batches include random storage of material , minimization of staging materials, maximum flexibility of batch types, optimization of operating process, customer control of their work, and increased inventory control and tracking of containers and contents. 


\section{CONTENTS}

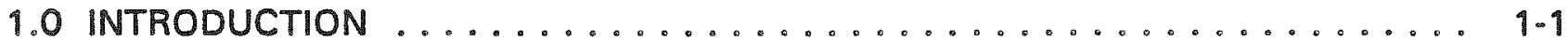

1.1 PURPOSE AND NEED $\ldots \ldots \ldots \ldots \ldots \ldots \ldots \ldots$

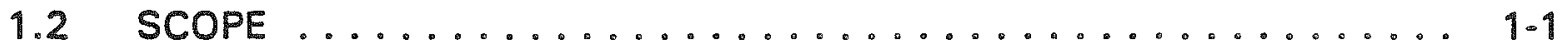

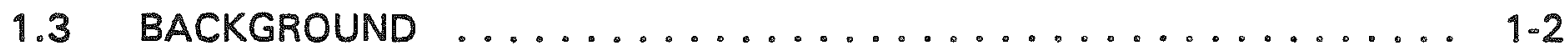

1.4 UNCERTAINTIES AND ASSUMPTIONS ................. 1.4

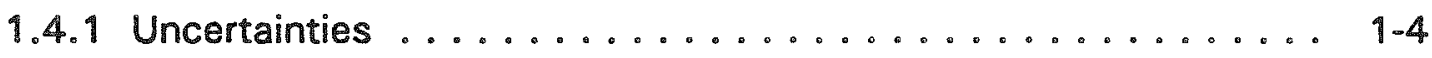

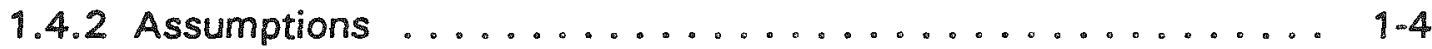

2.0 PROCESS OVERVIEW ................................... 2.1

2.1 PHASE I RETRIEVAL ......................... 2 .

2.2 PHASE V STORAGE ........................... 2.2

2.3 WRAP MODULE 1 PROCESSING $\ldots \ldots \ldots \ldots \ldots \ldots \ldots$

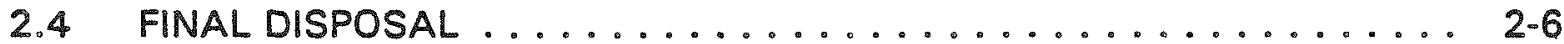

2.4.1 SHIPMENT OF TRU WASTE TO WIPP ............. 2-8

2.4 .2 DISPOSAL OF LLW WASTE ................. 2...

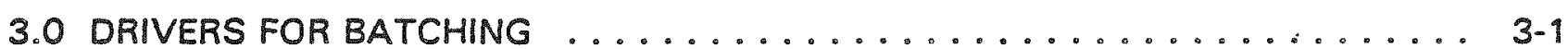

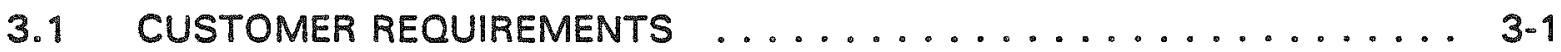

3.1 .1 Protection of the Public/Environment ............... 3-1

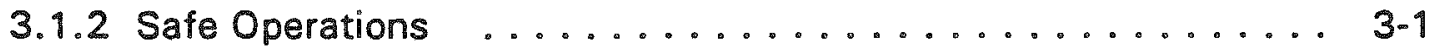

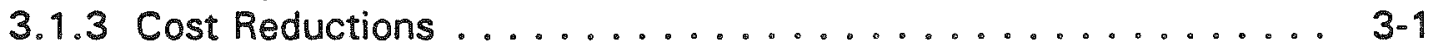

3.2 LOW LEVEL WASTE REDESIGNATION .................. . . $3-2$

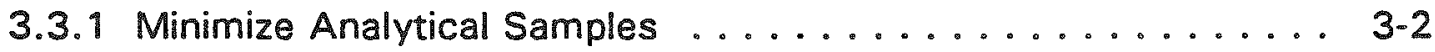

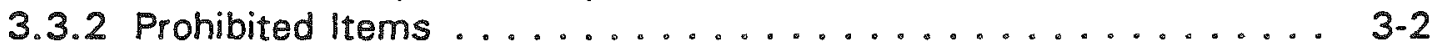

3.3.3 Process Efficiency ........................ 3-3

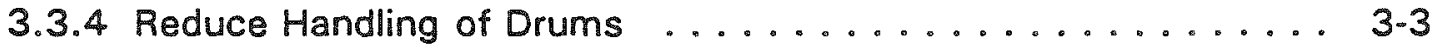

3.3.5 Efficient Handling of Non-compliant Items ............ 3-3

3.3.6 WRAP Module 1 Gram Loading Limits ................. 3-3

3.3.7 Categorization of Low Level Waste (Category 1, III, GTC3) . . . 3-3

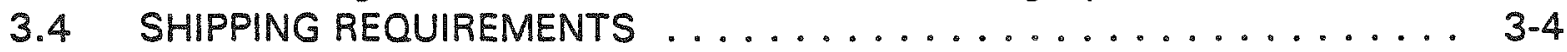

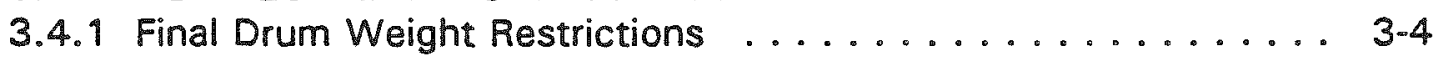

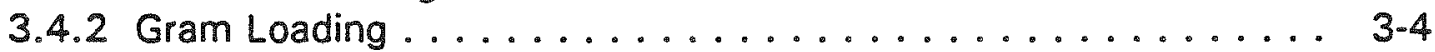

3.4.3 WIPP Waste Acceptance Criteria ................ 3-4

4.0 EVALUATION OF POTENTIAL CRITERIA FOR BATCHING ............. .4

4.1 WASTE GENERATOR ........................... 4-1

4.2 TYPE OF PROCESS USED TO GENERATE OR PACKAGE THE WASTE $.4-2$

4.3 PHYSICAL WASTE FORM $\ldots \ldots \ldots \ldots \ldots \ldots \ldots \ldots \ldots \ldots \ldots$

4.4 HAZARDOUSIDANGEROUS CHEMICALS $\ldots \ldots \ldots \ldots \ldots \ldots$

4.5 RADIOCHEMICAL TYPE AND QUANTITY ............... $\ldots .6$

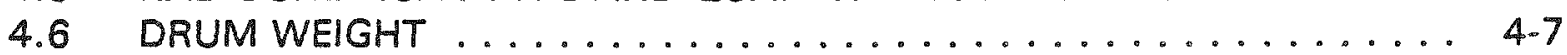

4.7 SPECIAL WASTE TYPES ..................... 4.7

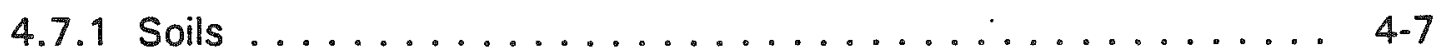

4.7.2 Animal Carcasses .................... 4.7

4.8 TIME FRAME OF RETRIEVAL FROM TRENCH 4 MODULES ........ 4-7 
5.0 POTENTIAL BATCHING OF TRENCH 4 C-04 $\ldots \ldots \ldots \ldots \ldots \ldots \ldots \ldots$ 5-1

5.1 WASTE GENERATOR ..................... 5.1

5.2 TYPE OF PROCESS USED TO GENERATE OR PACKAGE THE WASTE 5-24

5.3 PHYSICAL WASTE FORM ................. 5.46

5.4 HAZARDOUSIDANGEROUS CHEMICALS ............ 5-71

5.5 RADIOCHEMICAL TYPE AND QUANTITY .............. 5 .8.

5.5.1 Total Dose Rate . . . . . . . . . . . . . . . . . . . . 5-80

5.5 .2 Neutron Dose ......................... 5.101

5.5.3 Thermal Power...................... 5-101

5.5 .4 Isotope and Quantity ............... 5-102

5.6 DRUM WEIGHT ..................... 5.154

5.7 SPECIAL WASTE TYPES . . . . . . . . . . . . 5.174

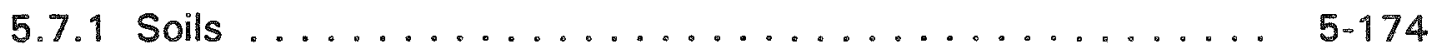

5.7 .2 Animal Carcasses ................... 5.174

6.0 DYNAMIC BATCHING ALTERNATIVE .................. 6-1

6.1 BACKGROUND ......................... 6.1

6.1 .1 Material Receipt ................... 6.1

6.1 .2 Material Storage ................... 6.2

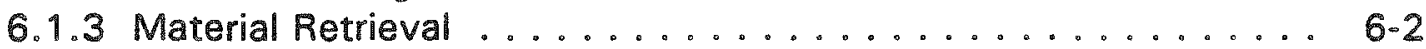

6.2 POTENTIAL OPERATIONAL DESCRIPTION ............ $6-2$

6.2 .1 Expected Containers .................. 6-2

6.2.2 Material Identification and Induction ............ 6-3

6.2 .3 Material Storage .................... 6.3

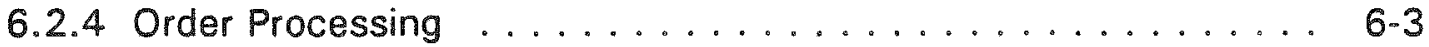

6.2 .5 Material Retrieval ................. 6-3

6.3 POTENTIAL BENEFITS $\ldots \ldots \ldots \ldots \ldots \ldots \ldots . \ldots . \ldots . \ldots .6 . \ldots$

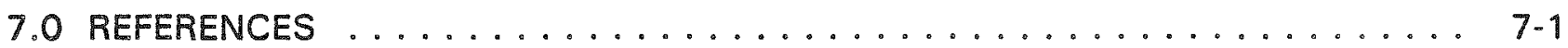




\section{LIST OF TERMS}

\begin{tabular}{|c|c|}
\hline AMHS & Automated Material Handling System \\
\hline AEC & Atomic Energy Commission \\
\hline Al & automatic identification \\
\hline ASRCCS & Automated Storage and Retrieval Computer Control System \\
\hline AS/RS & automated stacker/retriever system \\
\hline B \& W & Babcock and Wilcox (Apollo, PA) \\
\hline BMI & Battelle Memorial Institute (Columbus, OH) \\
\hline $\mathrm{CH}$ & contact handled \\
\hline $\mathrm{Ci}$ & curie \\
\hline CIN & container identification number \\
\hline D\&D & decontamination and decommissioning \\
\hline DOE & U.S. Department of Energ.y \\
\hline Ecology & Washington State Department of Ecology \\
\hline EDI & electronic data interchange \\
\hline EPA & U.S. Environmental Protection Agency \\
\hline ESG & Energy Systems Group (Canoga Park, CA) \\
\hline FFTF & Fast Flux Test Facility \\
\hline FRP & fiberglass reinforced polyester (plywood box) \\
\hline 9 & gram \\
\hline GE & General Electric \\
\hline GTC3 & greater than category 3 (LLW or LLMW) \\
\hline HLW & high-level waste \\
\hline JIT & just-in-time \\
\hline L & liter \\
\hline LLW & low-level waste \\
\hline LLMW & low-level mixed waste \\
\hline MFP & mixed fission products \\
\hline NOA & non-destructive assay \\
\hline NDE & non-destructive examination \\
\hline PC & personal computer \\
\hline PFP & Plutonium Finishing Plant \\
\hline PNL & Pacific Northwest Laboratories (Battelle) \\
\hline RCRA & Resource Conservation and Recovery Act of 1976 \\
\hline RF & radio frequency \\
\hline $\mathrm{RH}$ & remote handled \\
\hline RHO & Rockwell Hanford Operations \\
\hline R-SWIMS & Richland Solid Waste Information Management System \\
\hline RWM & Restricted Waste Management (in WRAP Module 1) \\
\hline SWITS & Solid Waste Information and Tracking System \\
\hline TRU & transuranic \\
\hline TRUMW & TRU mixed waste \\
\hline TSD & treatment, storage and disposal \\
\hline VNC & Vallecitos Nuclear Center (CA) \\
\hline VDT & video display terminal \\
\hline
\end{tabular}


WHC-SD-W026-TI-009, Rev. O

WAC

WARD

WHC

WIPP

WIPP-WAC

WNFD

WRAP
Washington Administrative Code

Westinghouse Advanced Reactor Division (Cheswick. PA)

Westinghouse Hanford Company

Waste Isolation Pilot Plant

WIPP Waste Acceptance Criteria

Westinghouse Nuclear Fuels Division (Cheswick, PA)

Waste Receiving and Processing Facility 


\subsection{INTRODUCTION}

\subsection{PURPOSE AND NEED}

The purpose of this document is to identify and evaluate the criteria that can be used to batch the suspect transuranic (TRU) waste currently in retrievable storage for processing through the Waste Receiving and Processing (WRAP) Module 1 facility. These criteria are then used to generate a batch plan for the retrieval of waste located in Trench $4 \mathrm{C}-04$ located in the 200 West Area burial grounds. The process of batching drums is intended to accomplish the following:

- Reduce the exposure of workers and the environment to hazardous materials and ionizing radiation;

- Maximize the efficiency of the retrieval, processing, and disposal processes by reducing costs, time and space throughout the process:

- Reduce analytical sampling and analysis; and

- Reduce the amount of cleanup and decontamination between process runs.

Consideration of a batching process involves the evaluation of general and detailed information. This evaluation includes the following:

- Why is batching necessary and is it feasible?

What types of waste can be batched?

- How can the waste be batched?

- At which point in the process can batching be optimized and will sub-batching be necessary?

- What is the optimum batch size(s) or range that would satisfy the requirements of each facet of the operation?

\subsection{SCOPE}

This document identifies and evaluates batching criteria for the processing of suspect TRU waste from Trench 4C-04 in WRAP Module 1. The topics covered in this document are described below.

- Section 1.0 presents the purpose, background, assumptions and uncertainties, and scope of the batching study. 
WHC-SD-W026-TI-009, Rev. O

- Section 2.0 gives an overview of the current plans for the retrieval. storage, processing, and shipping of the suspect TRU wastes at Hanford. Particular emphasis has been given to the determination of requirements for batching that are implicit in the current designs for these processes.

- Section 3.0 looks at the drivers for batching from the standpoint of customer (DOE) requirements, redesignation of TRU wastes as LLW at the trench, WRAP Module 1 process, and shipment of the designated wastes to WIPP.

- Section 4.0 evaluates potential criteria for the batching of retrieved wastes.

- Section $\mathbf{5 . 0}$ uses the criteria discussed in Section 4.0 to batch trench 4 C-04, which is the first trench slated for retrieval.

- Section 6.0 considers an alternative to the traditional batching approach presented in the preceding sections: dynamic batching. The concept of dynamic batching allows the criteria for batching to evolve from the specific needs of the WRAP Module 1 process at a given time and allows the facility to respond to changes in the drivers for batching.

- Section 7.0 lists the references used in the compilation of this report.

\subsection{BACKGROUND}

Since 1944, the production of defense related materials at the Hanford Site has generated radioactive wastes. The bulk of these wastes have been disposed of or stored in the 200 East and 200 West Area burial grounds and waste storage facilities.

The Department of Energy (DOE) Order 5820.2A (DOE 1988) divides radioactive waste into three categories:

- transuranic (TRU) includes waste with a concentration of greater than 100 $\mathrm{nCi} / \mathrm{g}$ of long-lived alpha emitting radionuclides with atomic numbers greater than 92;

- high-level waste (HLW) primarily includes waste produced by the primary reprocessing of spent nuclear fuel and contains both transuranic radionuclides and mixed fission products; and

- low-level waste (LLW) includes everything that is not TRU, HLW, spent nuclear fuel, or mill tailing material.

In April 1970, the predecessor to the DOE, the Atomic Energy Commission (AEC), issued /mmediate Action Directive, Number 0511-21 (AEC 1970), which directed all AEC sites to begin the temporary storage of all suspect TRU solid waste "in such a fashion that they can be readily retrievable as contamination-free packages within an interim period of 20 years." Initially, the definition of TRU included any waste with suspected alpha contamination. In 1972, this definition was changed to include only those wastes containing waste with a radioactive concentration of $10 \mathrm{nCi} / \mathrm{g}$ of alpha-emitting isotopes with half-lives greater than 
20 years. In 1982, this definition was changed to include only those wastes with TRU concentrations greater than $100 \mathrm{nCi} / \mathrm{g}$ (DOE 1982).

Before 1970, TRU wastes were not segregated and were buried commingled with LLW. Since 1970 , it has been the policy of the DOE that TRU wastes will be retrieved, treated as required, certified, and sent to a deep geologic repository. Because the existing technology in the 1970's could not determine the concentration of radionuclides at 10 (or even 100) nCi/g, any solid waste that was suspected to be TRU was placed in retrievable storage.

In addition to radioactive materials, Hanford production plants and support operations used a wide variety of chemicals. Many of these chemicals are currently classified as hazardous by the U.S. Environmental Protection Agency (EPA) or dangerous by the Washington State Department of Ecology (Ecology). When hazardous or dangerous chemicals are found in radioactive wastes, the wastes are referred to as "mixed".

During the time much of the mixed wastes at Hanford was generated, there were no definitions or regulations governing the storage, disposal, or documentation of mixed wastes. In 1987, the DOE issued a mixed by-product ruling stating that the hazardous components of mixed waste are regulated by the Resource Conservation and Recovery Act of 1976 (RCRA) (DOE 1987). In November 1987, the EPA authorized Ecology to regulate the hazardous constituents of mixed waste at Hanford.

Storage of suspect TRU waste at the Hanford Site began in May 1970. During the next two decades these wastes, which are primarily stored in the 200 Area burial trenches and storage buildings, are to be retrieved, processed in the WRAP Facility, and shipped to a final disposal facility.

Transuranic wastes will be shipped to the Waste Isolation Pilot Plant (WIPP) in Carlsbad, New Mexico. Before acceptance at WIPP, each TRU waste package must be certified by the shipper to be in compliances with WIPP's established Waste Acceptance Criteria (WIPP-WAC). Low-level wastes will be treated, if necessary, and sent to a Hanford facility for disposal. The DOE Order 5820.2A requires that each LLW package be characterized to identify treatment and disposal methodologies and be certified as meeting all transportation and disposal requirements.

The primary mission of WRAP Module 1 is to characterize and certify contact handled (CH) waste in 208.2-L (55-gallon) and 321.8-L (85-gallon) drums for disposal. Its secondary function is to certify $\mathrm{CH}$ standard waste boxes and boxes of similar size for disposal. It is projected that WRAP Module 1 will receive 6,825 drums $(2,625$ drums of retrieved wastes and 4,200 drums of newly generated wastes) of CH waste annually (Carlson et al. 1994). Both retrieved and newly generated wastes are anticipated to be composed of approximately $50 \%$ of TRU and $50 \%$ LLW containers (Olson et al. 1994). 


\subsection{UNCERTAINTIES AND ASSUMPTIONS}

\subsubsection{Uncertainties}

The uncertainties associated with the batching of retrieved wastes destined for WRAP Module 1 fall into three categories: regulatory, historical records, and plans for the treatment, storage, and disposal (TSD) of retrieved wastes. These areas are discussed briefly below.

1.4.1.1 Regulatory Uncertainties. Suspect TRU wastes to be retrieved from Trench $4 C-04$ may be pre-batched to support redesignation of the waste as LLW at the trench. The viability of trenchside redesignation in light of the current regulations has not been determined.

One of the major drivers for batching of wastes to enter WRAP Module 1 is the reduction of samples that need to be analyzed. The regulatory requirements for characterization of solid waste are dependent on whether WRAP Module 1 is considered to be a generator or a TSD facility. This determination has not been made at the current time.

1.4.1.2 Historical Records. Although records have been maintained for each container of suspect TRU waste sent to retrievable storage, the information required to be on the record as well as the degree of detail has changed considerably over the years. For examples, physical contents were not required prior to 1978, and hazardous chemicals did not need to be listed until 1986.

1.4.1.3 TSD Planning. Future changes in the handling of solid wastes by the TSD facilities will impact the need for and the definition of batches.

An example might be the current discussion over the palletizing of drums in Phase $V$ storage. If drums are not palletized in groups of four then there is no reason to batch drums prior to shipment to storage.

\subsubsection{Assumptions}

The determination of the batching process will be based on the following assumptions:

- Waste projections and process knowledge are sufficiently accurate to safely, accurately, and efficiently retrieve, transport, and sort the waste.

- The non-destructive examination (NDE)/non-destructive assay (NDA) data are sufficient to accurately assay the waste containers.

- The throughput and flow for each process have been determined, integrated, and optimized.

- Sufficient laboratory analytical resources or in-process analytical capabilities can provide the required analyses. 
WHC-SD-W026-TI-009,Rev. O

\subsection{PROCESS OVERVIEW}

The following sections provide a brief description and overview of the processes that retrieved suspect TRU wastes will be subject to prior to their final disposal. These processes include activities that are included as parts of Project W113, Phase I Retrieval; Project W-112. Enhanced Radioactive Mixed Waste Storage; Project W-026, WRAP Module 1; and eventual shipment to a final disposal site.

Each of these projects has been reviewed in order to determine if there are any requirements for batching implicit in the design or operations planned for that project. Each project also was reviewed to consider whether batching might interfere with operations.

\subsection{PHASE I RETRIEVAL}

Project W-113, the Solid Waste Retrieval Facility, Phase 1, will provide retrieval of intact waste containers stored in Trench 4 of Burial Ground $218-W-4 \mathrm{C}$ located in the 200 West Area of the Hanford Site. Waste stored in this trench is classified as CH suspect TRU waste and is contained in units, or modules, generally 12 drums wide by 12 drums long and stacked four drums high on the asphalt trench bottom. Each tier of drums covered with plywood, and the sides and the top of the module covered with polyvinyl tarpaulin. There are nineteen modules in this trench forming a single contiguous row. The trench was backfilled. and the top of the modules has an overburden of approximately four feet of native soil.

The majority of the waste in Trench 4C-04 is contained in 208.2-L drums; however, a variety of containers will be encountered. The total number of containers reported to be in this trench is 9,989 lapproximately 9,894 208.2-L and $57416.4-\mathrm{L}$ drums, 37 metal boxes, and 1 FRP plywood box), and the total volume of waste is $2.397 \mathrm{~m}^{3}$. Emplacement of waste in Trench 4C-04 began in 1978, and the last waste package was placed into the trench in 1985. All information in this section is from the Engineering Study for the Solid Waste Retrieval, Project W-113 (WHC 1991).

Phase 1 retrieval operations will be in compliance with all appropriate laws, regulations, policies, and orders issued by the EPA, Ecology, and the DOE. Phase 1 retrieval is expected to take up to three and one-quarter years, at an estimated rate of 20 drums or one-third of a box per day. The waste containers in this trench are expected to be intact with no significant risk of questionable structural integrity which could cause contamination of the environment. No facilities or equipment for clean-up, disposal, treatment, or storage of contaminated soil are included in this project. Head gas samples will be taken in the trench and waste containers will be overpacked as part of the retrieval process.

In order to comply with the requirements of the Washington Administrative Code (WAC) 173-303 and RCRA, the waste will need to be characterized before it can be received into Phase $V$ storage or WRAP Module 1. To supplement the historical records for the contents of the waste drums and boxes in Trench 4C-04, the Phase 1 Retrieval Facility will include NDE/NDA equipment. This equipment will provide the characterization required for acceptance of the waste into Phase $V$ storage and WRAP Module 1. The NDE/NDA equipment will include one head gas sampling system, one passive-active-neutron system, and one NDE system. Data obtained during head gas sampling and NDE/NDA will not impede waste packages from being shipped to Phase $V$ storage and, subsequently, processed in 
WRAP Module 1. These data are obtained to meet storage requirements for processing later and are not a factor with respect to shipping.

Transport of the loaded overpacks will utilize currently available equipment lan enclosed van similar to the Plutonium Finishing Plant (PFP) process trucks). Expected capacity per vehicle trip is 14 drums. Travel will take place on Hanford Site (not public) roadways.

No batching requirements were identified for Phase 1 retrieval per se. The ability to identify wastes that could be redesignated as LLW before these containers are retrieved, however, could result in significant cost savings. This issue is discussed further in Section 3.2.

\subsection{PHASE V STORAGE}

Project W-112, the Enhanced Radioactive Mixed Waste Storage Facility, often referred to as Phase $V$ Storage, will provide the appropriate mitigating features to permit safe storage of the following waste streams:

(1) Category 3 low level mixed waste (LLMW) storage;

(2) Greater than category 3 (GTC3) LLW and LLMW storage;

(3) recovered suspect TRU waste storage:

(4) newly generated TRU and TRU mixed waste (TRUMW) storage; and

(5) WRAP Facility process support storage.

Phase $V$ storage requires that head gas be vented and that samples be taken prior to acceptance for storage. It also requires that all materials pass through the NDE/NDA provided as part of the retrieval operations before storage.

The activities of Phase $V$ storage can be classified into lag storage, surge storage, and long-term storage for GTC3 LLW. Lag storage is defined as the Phase $V$ waste container storage provided for WRAP processing activities. Lag storage is distinguished by both waste package availability (first-in-first-out capabilities) and short duration (days or weeks) storage. Phase $V$ storage will provide lag storage for waste containers from WRAP Module 1 awaiting subsequent laboratory test results or treatment in WRAP Module 2. Lag storage is limited by space constraints to 208 drums.

Surge storage is defined as the Phase $V$ waste container storage provided before or following WRAP processing activities. Surge storage is designed to provide continuity of operations for the treatment and shipping of TRU and LLMW containers. Surge storage is planned to house waste for up to 60 days prior to processing and up to 60 days after processing. Phase $V$ storage will provide surge storage for waste containers awaiting entry into WRAP Module 1 and containers awaiting shipment to WIPP from WRAP Module 1.

Long-term storage is defined as waste storage for wastes that require storage time frames longer than surge storage. Typical waste types stored in long-term storage are GTC3 LLW or LLMW that have no approved treatment or disposal methods, and remote handled (RH) 
waste, which requires treatment in WRAP Module 2B. Phase $V$ storage also will provide longterm storage for mixed wastes awaiting treatment in WRAP Module $2 \mathrm{~A}$.

Phase V storage includes a waste handling automated stacker/retriever system (AS/RS). The AS/RS is designed to store 7,000 drums, stacked and retrieved on pallets of 4 drums, to support lag storage requirements. The computer controlled AS/RS provides container traceability and the ability to assemble batches of waste drums which may be stored on several different pallets. The computer is able to track drums, pallets, and batches.

Phase V storage will have a capacity of $27,000208.2-\mathrm{L}$ drum equivalents $\left(5,662 \mathrm{~m}^{3}\right)$. No batching requirements were identified for Phase $V$ storage; however, batches identified for WRAP Module 1 processing will be more easily handled if all 4 drums on a given pallet belong to the same batch and can be handled as a unit.

\subsection{WRAP MODULE I PROCESSING}

WRAP Module 1 will process suspect TRU waste that can be handled without radiation shielding (CH wastes with radioactive dose rates less than 200 millirem/hr at any point on the waste container). It will be able to process a total of 6.825 drums per year, with an anticipated split of 2,625 drums of retrieved wastes and 4.200 drums of newly generated waste (and a $50 \%$ split on LLW and TRU), and 70 boxes per year. At 175 planned operating days per year, WRAP Module 1 shipping and receiving areas will be capable of handling 40 drums per day and two boxes per week. The process flow of retrieved wastes and newly generated waste within WRAP Module 1 is shown in Figure 2.3-1.

Waste container receiving and storage operations occur in the shipping and receiving area of the WRAP Module 1. Waste drums and boxes, and associated documentation and records, are received, unloaded, and then transported either to temporary storage or directly to NDA/NDE.

Nominally, 40 waste drums and 2 waste boxes are received on a daily and weekly basis, respectively. Newly generated drums (208-L) and retrieved drums in 322-L overpacks are received 4 to a pallet. Each incoming waste drum and waste box has a bar code label already attached on its top and side. If a bar code label is not present on an incoming container, a bar code label is generated and attached in the shipping and receiving area after this discrepancy has been resolved and the container has been accepted for processing.

Incoming waste drums can either be placed into lag storage in the shipping and receiving area or sent directly to the NDA/NDE area. Waste boxes can be stored temporarily in the shipping and receiving area or sent directly to the NDA/NDE area.

Before entering the NDA/NDE area, waste drums are removed from the pallets, each waste drum is weighed, and its bar code is read. A weight label is attached to each waste drum. Each waste box is weighed and its bar code read after entering the NDA/NDE area before starting NDA/NDE operations. 
WHC-SD-W026-TI-009, Rev. 0

Figure 2.3-1. WRAP Module 1 Top Level Flowsheet

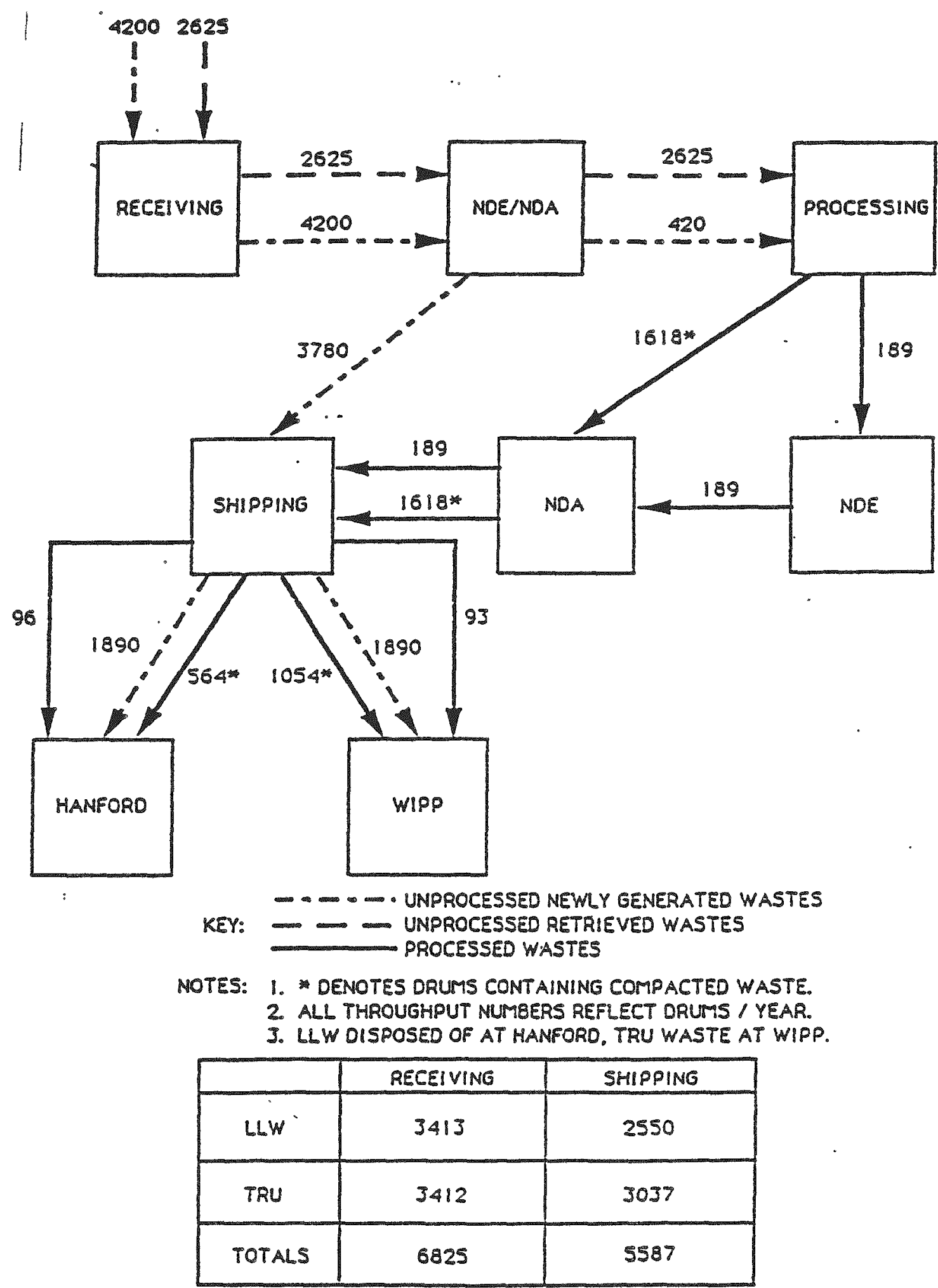


Applicable information pertaining to the received waste containers is entered into the WRAP Module 1 data management system. Weight information is used to calculate specific TRU activity and also is used to identify containers that exceed weight limits established in the waste acceptance criteria.

All waste drums and boxes received at WRAP Module 1 are subjected to NDA/NDE as part of verifying compliance with waste certification requirements and to determinate appropriate methods for processing noncompliant waste present in the received waste drums. Wastes processed in WRAP Module 1 will meet the following four requirements of the WIPP. WAC:

(1) no free liquids are allowed;

(2) pyrophorics must be stabilized;

(3) explosives or compressed gases are not allowed; and

(4) corrosives must be neutralized.

If an incoming waste container has completed NDA/NDE assessment and has been found to contain certified waste, it can be returned to the shipping and receiving area, and prepared for shipment. All incoming waste drums found from the NDA/NDE operation to contain noncompliant (restricted) waste are sent to the waste processing area. In addition, those waste drums which contain certified waste which are to be characterized and supercompacted are sent to waste processing.

In waste processing, incoming waste drums which do not meet the appropriate disposal criteria are opened and sorted in two process glovebox lines to remove the noncompliant (restricted) waste, and are then supercompacted and repackaged. Waste drums that meet the appropriate disposal criteria can be directly supercompacted to reduce the waste volume. Two glovebox lines (with associated heating, ventilating, and air conditioning systems) are provided to perform waste processing operations, one dedicated to TRU waste and the other to LLW. The two glovebox lines and their associated equipment are segregated to prevent cross-contamination of LLW with TRU waste material.

Items that are not certifiable in WRAP Module 1, such as LLMW, LLW class III, and other regulated waste in drums $\{e . g$. lead bricks, PCBs $\}$, that cannot be processed to a certifiable form are either left in the drum or are removed from the drum in the appropriate waste process line and repackaged in the restricted waste management (RWM) glovebox. In either case, the drums containing the noncertifiable materials are then palletized and sent to continued storage pending treatment at another facility.

If noncertifiable newly generated materials are found by the WRAP 1 NDE/NDA, they will be handled in the same manner as retrieved hazardous materials or return to the generator.

Noncompliant (restricted) waste items that are segregated, containerized, and transferred from the two waste process gloveboxes are received at the two RWM gloveboxes. One RWM glovebox is dedicated to LLW and the other to TRU waste materials to avoid the possibility of cross-contamination. Samples of restricted waste items are obtained for analysis at other DOE Hanford Site analytical laboratories. THE RWM gloveboxes also provide limited restricted waste treatment capabilities.

After processing, all outgoing waste drums are subjected to NDA (and some to NDE) 
necessary for certification before shipment. The WRAP Module 1 overall process is pictorially depicted in Figure 2.3-2.

Criticality in the WRAP Module 1 and in any glovebox will be precluded through the imposition of administrative controls that restrict the inventory to $200 \mathrm{~g}$ TRU or less in any drum or glovebox (Olsen et al. 1994). Criticality controls/specifications include the following:

- The individual contents of routinely handled drums everywhere within the facility will typically be much less but shall be limited to $200 \mathrm{~g}$ TRU.

- The TRU processed in WRAP Module 1 gloveboxes shall be batched into sets of drums containing $200 \mathrm{~g}$ TRU or less. After each batch is processed, the glovebox shall be cleaned out, including removal of cakestand items and residual material on glovebox and equipment surfaces. (This control is designed to ensure that the TRU inventory of the glovebox, including residual material, will never exceed a critical mass).

Before processing the next batch, the product drums and restricted articles removed from the previous batch will be assayed to determine the amount of residual TRU remaining in the glovebox. A final clean out and survey of the glovebox will provide assurance that the drum contents from the batch have been removed. These same batch controls apply to inventories within the TRU restricted waste glovebox.

The WRAP Module 1 design and proposed operations currently require that similar waste containers be batched to reduce the number of samples required for waste characterization. Other operations that may benefit from the batching of wastes are discussed in Section 3.3.

\subsection{FINAL DISPOSAL}

In the shipping and receiving area, shipments of waste drums and boxes are sent out on a daily and weekly basis, respectively, after the waste containers have completed all required NDA/NDE and waste processing operations.

All LLW and TRU waste drums that have been sampled are shipped to external lag storage (W-112 Storage Facility) outside of WRAP Module 1 awaiting sample analysis results before shipment to disposal.

Shipment for disposal includes visually inspecting each waste container for integrity and proper lid closure, radiologically surveying waste containers, and reading the container bar-code. Waste container documentation generated by the WRAP Module 1 data management system. 
WRAP Module 1

Pictorial Flow Diagram

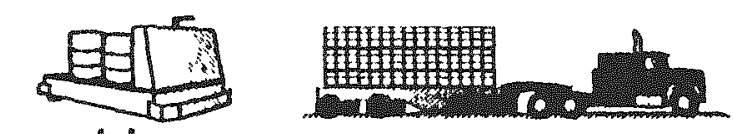

1

11

$\stackrel{n}{a}$
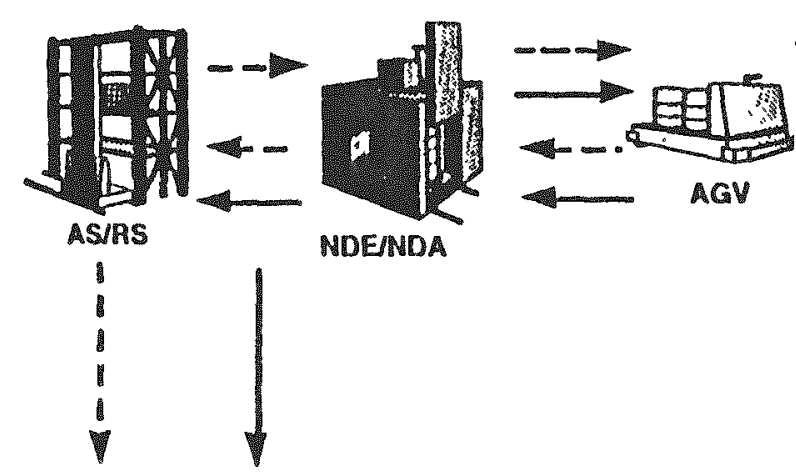

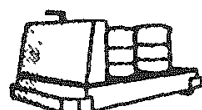

To Storage and LLW Disposal

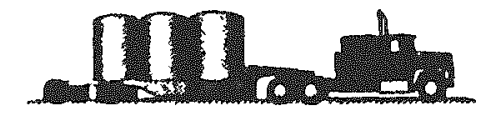

To WIPP

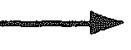

- - - Lowtovol wasto

Transuranle

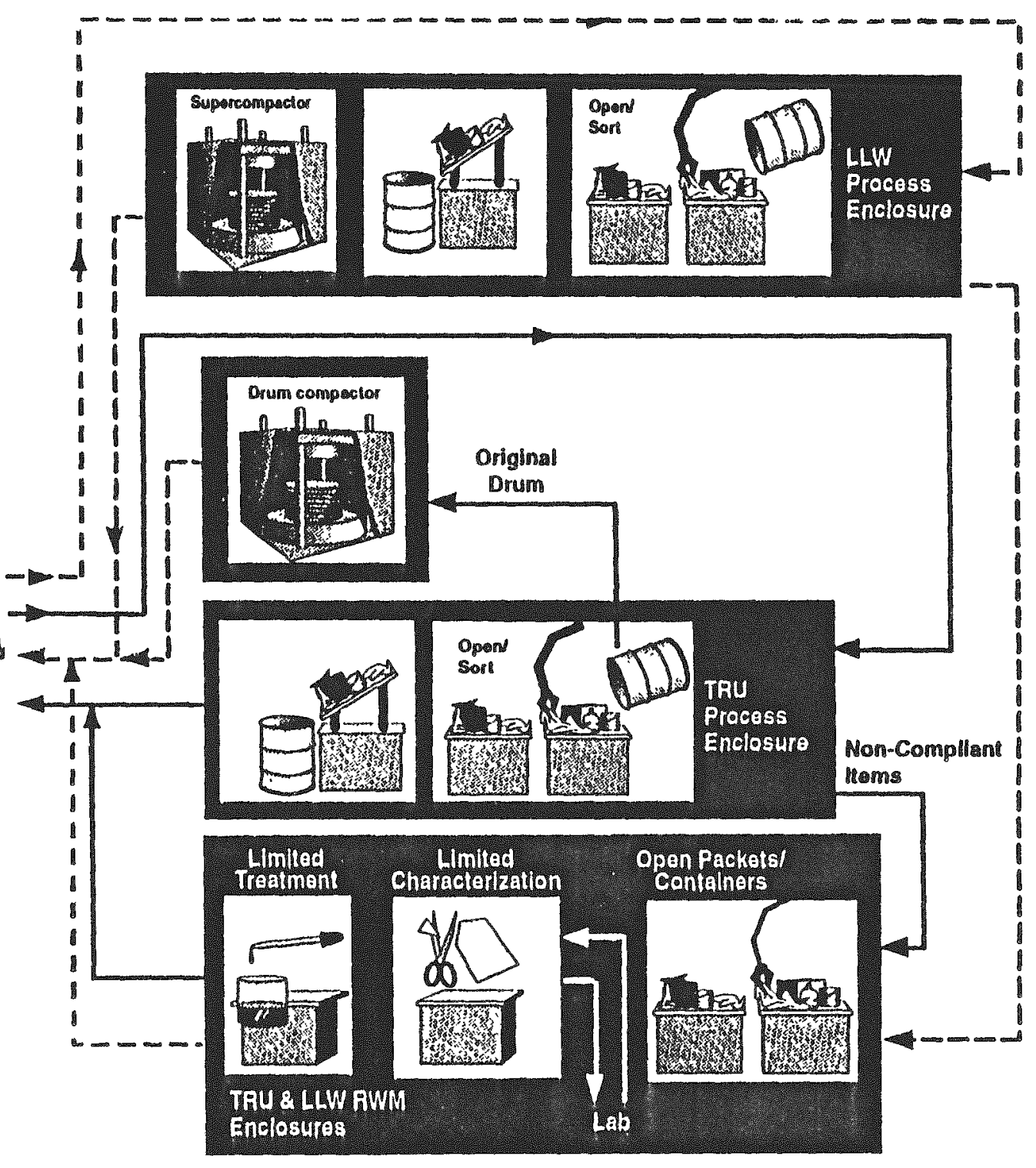

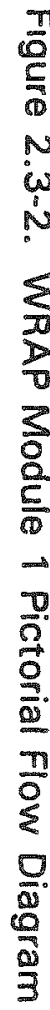




\subsubsection{SHIPMENT OF TRU WASTE TO WIPP}

Certified TRU waste containers (208-L drums and SWBS) are assembled and loaded into TRUPACT-ll transportation casks and sent to WIPP in New Mexico for disposal. The waste drums are placed on pallets and stretch-wrapped before TRUPACT-ll loading; SWBS are assembled, but not stretch-wrapped.

Shipping requirements for the waste relate to the requirements affecting the amount of radioactivity and hazardous contents permitted to be shipped at one time by the U.S. Department of Transportation. Some requirements may also be imposed by the use of TRUPACT-II containers.

\subsubsection{DISPOSAL OF LLW WASTE}

Certified LLW waste containers in 208-L and 322-L drums and boxes are placed on pallets and loaded onto flatbed trucks or enclosed vans and sent to onsite disposal. Noncertified LLW and TRU waste containers (208-L and 322-L drums and boxes) are palletized and loaded onto flatbed trucks or enclosed vans and sent to onsite storage, pending processing at another WRAP. 


\subsection{DRIVERS FOR BATCHING}

The following discussion provides some of the drivers for batching the retrieved wastes that will be processed in WRAP Module 1. The rationale for batching is based on the following needs:

- Customer requirements for protection of the public environment, safe operations, and reasonable costs.

- Redesignation of suspect TRU waste as Low-level waste.

- Operational requirements of WRAP Module 1.

- Shipping requirements for sending the repackaged waste from WRAP Module

- 1 to a permanent disposal site:

\subsection{CUSTOMER REQUIREMENTS}

\subsubsection{Protection of the Public/Environment}

Protection of the workers and the environment is of primary concern in the consideration of batching waste containers for processing in WRAP Module 1. The reduction of the exposure of workers to hazardous materials, ionizing radiation, and the reduction of the risk of criticality are of the utmost importance.

\subsubsection{Safe Operations}

Process batching will ensure the safe operation of the facility during the process run by reducing the concentration of hazardous and radioactive materials. This will also reduce the effort required for cleanup and decontamination of WRAP Module 1 gloveboxes and other processing areas.

\subsubsection{Cost Reductions}

Processing the wastes entering WRAP Module 1 as batches may result in reductions in the operational cost due to the following:

- more efficient process runs and optimization of equipment utilization,

- reduced analytical sampling and analysis, and

- reduced equipment and facility decontamination. 


\subsection{LOW LEVEL WASTE REDESIGNATION}

In 1970, the AEC mandated that TRU waste be retrievably stored pending a decision concerning its final disposition. From 1970 to 1973, segregation of TRU waste was based on generator practices, without any concentration limit. In 1973, the TRU definition was changed to include a concentration limit of greater than or equal to $10 \mathrm{nCi} / \mathrm{g}$. The concentration limit for TRU waste was changed to $100 \mathrm{nCi} / \mathrm{g}$ in 1982.

Because TRU waste definitions have undergone the changes described above. there is a significant amount of waste stored as TRU that would be classified as LLW under the current definition. Redesignation and batching of these wastes prior to treatment at WRAP Module 1 will substantially reduce the costs associated with waste treatment and disposal.

\subsection{WRAP MODULE 1 OPERATIONS}

WRAP Module 1 operations do not specifically require that waste be batched in a specific way; however, batching of waste to exclude certain items or to group waste according to some characteristic may result in more efficient operations.

\subsubsection{Minimize Analytical Samples}

Currently, the estimated costs associated with the sampling and analysis of wastes that require additional characterization are high. A scientifically and statistically defensible sampling plan must be approved before retrieved wastes can be sampled. The samples should be batched in accordance with the definition of an analytical batch as defined by SW- 846 (EPA 1986):

Analytical Batch: The basic unit for laboratory quality control is the analytical batch. The analytical batch is defined as the samples which are analyzed together with the same method sequence and the same lots of reagents and the same manipulations common to each sample within the same time period or in continuous sequential time periods. Samples in each batch should be of similar composition.

\subsubsection{Prohibited Items}

Prohibited items for WRAP Module 1 include items such as soils and animal carcasses as well as drums weighing greater than $454.5 \mathrm{~kg}(1,000 \mathrm{lbs})$. Remote-handled wastes are also excluded from WRAP Module 1. WRAP Module 1 will process only TRU waste that can be handled without radiation shielding $(\mathrm{CH}$ wastes with radioactive dose rates less than 200 $\mathrm{mrem} / \mathrm{hr}$ at any point on the waste container). 


\subsubsection{Process Efficiency}

Equipment set-up and decontamination, analytical sampling and analysis, and process and analytical batching. will be required in order to optimize the efficiency of WRAP Module 1.

\subsubsection{Reduce Handling of Drums}

In order for the entire process to operate efficiently and cost effectively, the handling and processing of drums should be kept to a minimum. Process knowledge and storage records should enable most trenches to be excavated and retrieved in an efficient continuous manner. Holding times and turn-around-times should be established in order to efficiently sample, batch, and ship waste containers for processing though WRAP Module 1.

Drums awaiting processing in WRAP will be stored in Phase $V$ on pallets. Each pallet will hold $1,2,3$, or 4 drums. The storage facility will be most efficient if the number of pallets with fewer than 4 drums is kept to a minimum and if all the drums on aiven pallet are dispositioned together.

\subsubsection{Efficient Handling of Non-compliant Items}

It may be advantageous to batch non-compliant items so that similar items can be processed in RWM at the same time. Non-compliant items to be handled in RWM include aerosol cans; reactive materials; chelating compounds; chemically incompatible materials; corrosive materials; explosives; gas cylinders that are not permanently vented; HEPA filters; lead: organic liquids; aqueous liquids; mercury; powders, cakes and particulate material; and pyrophorics (Olson et al. 1994).

\subsubsection{WRAP Module 1 Gram Loading Limits}

Criticality in WRAP Module 1 and in any glovebox will be precluded through the imposition of administrative controls that restrict the inventory to $200 \mathrm{~g}$ TRU or less in any drum of glovebox. The $200 \mathrm{~g}$ TRU limit is set to assure that the safe mass limit of $450 \mathrm{~g}$ (assuming ${ }^{239}$ Pu based on ANSI 16.1 as directed by DOE Order 5480.5 ) is not exceeded by a single batching error (Olson et al. 1994).

The safety classification approved for WRAP Module 1 places a limit on the amount of fissionable material permitted within the facility at any one time of $5 \mathrm{~kg}$.

\subsubsection{Categorization of Low Level Waste (Category I, III, GTC3)}

The LLW handled in WRAP Module 1 will need to be classified according to LLW category. Category I and category III LLW may need to be segregated for disposal in separate near-surface facilities, while GTC3 LLW cannot be disposed of in near-surface facilities.

\subsection{SHIPPING REQUIREMENTS}




\subsubsection{Final Drum Weight Restrictions}

Current waste package limits are $454.5 \mathrm{~kg} / 208-\mathrm{L}$ drum; heavy drums may require repackaging into several drums. Identifying batches of heavy drums may be helpful for planning the numbers of new drums that will be required during processing.

\subsubsection{Gram Loading}

The TRU and LLW drums shipped from WRAP Module 1 will be required to meet certain specific gram loading limits. Drums which are over gram loaded will require repackaging into new drums.

\subsubsection{WIPP Waste Acceptance Criteria}

Items prohibited from disposal at WIPP include aerosol cans, compressed gases, chelating agents. These items must be removed, vented and/or processed appropriately for ultimate disposal. 


\subsection{EVALUATION OF POTENTIAL CRITERIA FOR BATCHING}

There are many different criteria that can be used to batch the drums of retrieved waste that enter WRAP Module 1. At the present time, these criteria must be based on the available records of the wastes sent to storage as well as knowledge of the processes that generated these wastes. Once Phase I retrieval has begun, however, this information will be augmented with data gathered via NDE, NDA, and Head-gas Sampling.

This section focuses on the presently available information that can be used to sort the drums that will be retrieved from Trench 4C-04 into processing batches for WRAP Module 1. The criteria examined for identifying similar type waste batches include:

- the waste generator,

- the generation process, of packaging.

- the physical form,

- the content of hazardous/dangerous chemicals

- the type and quantity of radiochemicals

- the drum weight

- the special waste types, and

- the timing of retrieval.

In order to evaluate each type of data for potential use in sorting, the following assumptions about the resultant batches were made:

- The drums will contain similar wastes.

- The expected probability of finding hazardous waste material through sampling is equal for all drums.

- The drums can be dispositioned together.

\subsection{WASTE GENERATOR}

Since the generator and facility were virtually always included on the solid waste burial records, this information is arguably the easiest and most consistent information to be attached to a given waste container. In most cases, the generating facility is also expected to be marked on the drum itself. As noted above, characterization documents have been completed for the seven largest generators of suspect TRU solid wastes stored at Hanford. Process knowledge, personnel recollections, and facility tracking and packaging documents were used to supplement the information found in the Solid Waste Information Tracking System (SWITS) database. The SWITS database incorporates the older Richland Solid Waste information Management System (R-SWIMS) that was used to track wastes during the period 
from 1970 to 1992.

The disadvantages associated with using only the generator designation solely to batch wastes destined for WRAP Module 1 stem from several sources. First of all, several large facilities were designated during different time frames to be the collection or acceptance point for wastes coming from other generators. In the 300 Area, for example, it is known that wastes from the 325 building were designated as coming from the 340 building because the wastes from the 300 Area were shipped to the burial grounds from this facility. Similarly, it is known that wastes generated elsewhere in the 200 West Area were sometimes designated as PFP wastes (234-5Z). At least one offsite generator's waste (Babcock and Wilcox) is known to have been buried occasionally as waste from $234-5 \mathrm{Z}$.

A second drawback is the recognition that not all waste from a given generator is similar in physical form or chemical character. The largest generator of waste, 234-5Z, sent wastes from glovebox lines, the analytical laboratory, maintenance, and general housekeeping in addition to some decontamination and decommissioning (D\&D) wastes from the removal of the Remote Mechanical A line. In addition, this facility also packaged contaminated scrap items from all over the DOE complex because of Hanford's role as a repository for material managed by the Scrap Management Organization. Trench 4 is known to contain scrap from this program that was never processed but which was sent to the burial grounds as waste from $234-5 z$.

\subsection{TYPE OF PROCESS USED TO GENERATE OR PACKAGE THE WASTE}

In some cases, wastes from two or more generators may be sufficiently similar to warrant their wastes being placed in the same batch. For example, Babcock and Wilcox, Westinghouse's Advanced Reactors and Nuclear Fuels Divisions, and General Electric's Vallecitos Facility all generated the wastes sent to Hanford as a result of D\&D activities. In all three cases, the D\&D wastes resulted from the research or production of fuels for the Breader Reactor Program. Babcock and Wilcox and Westinghouse's wastes were even more similar as they both resulted from fabrication or research on fuels for the Fast Flux Test Facility (FFTF) at Hanford. (Note that Kerr McGee, which does not have waste in Trench 4. also made fuel elements for FFTF and could be batched with these generators during later campaigns.)

Other batches based on process type might include analytical laboratories, the D\&D activities at the 200 Area fuel reprocessing canyon facilities, and biological research facilities.

In addition to the similarities in the generation of wastes from different generators, packaging was sometimes very similar, especially for offsite generators. All three of the larger offsite generators in this trench, for example, used a high density foam to stabilize the contents of waste packages during shipment to Hanford. These foams may present a unique problem during WRAP Module 1 processing that may make batching of these wastes desirable. Consideration should also be given to restricting containers packaged using foam from processing in WRAP Module 1. 


\subsection{PHYSICAL WASTE FORM}

Waste form data were not entered into the R-SWIMS database until 1978. Prior to that date, much of the waste was described only as miscellaneous process waste. The R-SWIMS database, and its successor, SWITS, include information on the waste contents description as well as special SWIMS codes that were applied to the wastes. These categories are described below:

- Waste Contents Description - Beginning in 1978, the physical contents of waste containers were required on solid waste burial records. The more recent records contain a greater level of detail than do the older records. Table 4-1 lists some of the content description that were found in R-SWIMS (most were retained in the transition to SWITSI. The waste content codes are often accompanied by the weight of that content (in $\mathrm{kgs}$ ) or the volume \% that content occupies. Containers with contents such as animal waste and dirt may be excluded from processing in WRAP Module 1.

- SWIMS Waste Category - SWIMS waste categories are listed in Table 4-2. The majority of drums with SWIMS categories are listed as "NC" or not classified. 
WHC-SD-W026-T1-009, Rev. O

Table 4-1. R-SWIMS Waste Code Contents.

\begin{tabular}{|c|c|c|c|}
\hline $\begin{array}{l}\text { Content } \\
\text { Code }\end{array}$ & Content Description & $\begin{array}{l}\text { Content } \\
\text { Code }\end{array}$ & Content Description \\
\hline ABSOR & Absorbent/Kitty Litter/Vermiculite & LIOU! & Liquid \\
\hline $\mathrm{ACID}$ & Acid & LOORG & Liquid Organic \\
\hline AIR & Air & MARBL & Marble \\
\hline ALUMNI & Aluminum & MATRX & Various Solutions Solidified \\
\hline ANIMA & Animal Waste & MERCU & Mercury \\
\hline ANIF & Antifreeze & METAL & Metal/Iron/Galvanized Sheet \\
\hline ASBES & Asbestos & MISC & Miscellaneous/Unknown/Other \\
\hline ASH & Ashes & MOLYB & Molyboedum \\
\hline ASPHA & Asphalt/Blacktop & OIL & Oils \\
\hline BALLA & Ballast & OILW & Oil and Water \\
\hline BATTE & Batteries & ORGAN & Organics \\
\hline BORON & Boron & OXALI & Oxalic Crystals \\
\hline BRASS & Brass Metal & OXIDE & Oxides/Powders \\
\hline BRICK & Brick/Firebrick & PAINT & Paint/Lucite \\
\hline CADMI & Cadmium & PAPER & Paper/Cardboard \\
\hline CARBO & Carborundum & PCB & Polychlorinated Biphenyl \\
\hline CEMENT & Cement & PCBNB & PCB Non-Regulated \\
\hline CERAM & Ceramics & PLAST & Plastic/Polyurathane \\
\hline CHARC & Charcoal & PLEXI & Plexiglass \\
\hline CHEMI & Chemicals & PLSTR & Plaster \\
\hline CHEMS & Chemsearch & PORGE & Porcelain \\
\hline CLAY & Clay & QUENC & Quench bath \\
\hline CLOTH & Cloth/Rags/Nylon & RESIN & Resins \\
\hline CONCR & Concrete & ROCK & Rock/Gravel \\
\hline CONCS & Concrete Shields & ROOFI & Roofing Material \\
\hline CONTA & Contaminates & RUBBE & Rubber \\
\hline CONWE & Conweb & SALT & Salt Bath \\
\hline COPPE & Copper Metal & SAND & Sand \\
\hline CORK & Cork & SHEET & Sheetrock \\
\hline COTTO & Cotton/Kotex & SILIC & Silica Sel \\
\hline CREOS & Creosote & SLUDG & Sludges \\
\hline DIRT & Dirt/Soil/Diatomite & SOAP & Soap \\
\hline EPOXY & Epoxy/Paint/Oilbase & SOLID & Solidified Aqueous Solution \\
\hline EQUIP & Equipment & SOLVE & Solvents/Thinners \\
\hline FECES & Feces & STAIN & Stainless Steel \\
\hline FIBER & Fiberglass & STRAW & Straw/Hay \\
\hline FILTE & Filters & SWEEP & Floor Sweeps \\
\hline FOAM & Foam/Styrofoam & TAR & Tar \\
\hline FUEL & Fuel/Pins or Rods & TEFLO & Teflon \\
\hline GLASS & Glass & TILE & Floor Tile \\
\hline GRAPH & Graph & TOLUE & Toluene \\
\hline GREAS & Grease & TRANS & Transite \\
\hline GROUT & Grout & TUMBL & Tumbleweeds \\
\hline HAZAR & Hazardous Constituents & WATER & Water \\
\hline HEXAN & Hexanol & WAX & Wax \\
\hline HYDRA & Hydraulic Fluid W/PCB & WEEDS & Weeds/Vegetation \\
\hline INSUL & Insulation Non-Asbestos & WIRE & Wire \\
\hline LEAD & Lead & WOOD & Wood/Lumber.Plywood \\
\hline LEADS & Lead Shielding & XYLEN & Xylene \\
\hline LEATH & Leather & ZIP & Zip Strip Paint Remover \\
\hline LIME & Lime/Slaked Lime & ZIRCO & Zircoy \\
\hline
\end{tabular}


Table 4-2. R-SWIMS Waste Categories.

\begin{tabular}{|l|c|}
\hline \multicolumn{1}{|c|}{ Waste Category } & Code \\
\hline Biological Waste & BW \\
\hline Contaminated Equipment & CE \\
\hline Decontamination Debris & DD \\
\hline Dry Solids & DS \\
\hline Solidified Sludge & SS \\
\hline Not Classified & NC \\
\hline
\end{tabular}

\subsection{HAZARDOUSIDANGEROUS CHEMICALS}

Hazardous constituents were not required to be listed on the solid waste burial records until 1986. (Keep in mind that all of the drums in Trench 4 were emplaced prior to that date. It may be possible to interpolate information about the pre-1986 drums from containers from the same generator that were stored after 1986.) During the R-SWIMS re-entry program in the late $1980^{\prime} \mathrm{s}$, an attempt was made to add any additional information that was on the burial records but which was not in the database; however, this information was scanty.

Data about hazardous constituents can be found in a number of R-SWIMS fields. A brief description of the information contained in these fields follows.

- Mixed Waste - If the waste container had any hazardous constituents present in State reportable quantities it is classified as radioactive mixed waste and has a SWITS primary waste code $M$ (mixed) associated with it.

- Hazardous Constituents - This R-SWIMS field listed the constituent name along with the quantity of that constituent present in the container. These fields were retained in SWITS.

- Waste Designation, Dangerous Waste Number - Mixed waste is designated as dangerous waste or extremely hazardous waste based on the quantity and identity of the hazardous constituents listed on the waste manifest. The dangerous waste numbers associated with a given waste constituent according to RCRA or WAC 173-303 is also recorded in both the R-SWIMS and SWITS databases.

In addition to the information found in the R-SWIMS and SWITS databases, many of the burial records for mixed wastes are accompanied by a waste manifest. The manifest number is generally recorded in the database. This manifest may contain additional information about the dangerous/hazardous wastes contents, but is only available via a manual search of hard copy or microfilmed records. 
Process knowledge, interviews with cognizant personnel, and procurement records for various generators may also be useful in batching wastes with similar mixed wastes. Process knowledge is currently summarized in characterization documents for only the largest seven waste generators: 234-5Z, 202-A, 325, 231-Z, General Electric (GE) Vallecitos Nuclear Center, Westinghouse Advanced Reactors Division (WARD) and Westinghouse Nuclear Fuels Division (WNFD) and Babcock and Wilcox (B \& W).

\subsection{RADIOCHEMICAL TYPE AND QUANTITY}

There are a number of data fields in the SWITS database that contain information about the radioactive constituents of each waste container. The fissile content of each container has been required on the burial records since 1972.

- Total Dose Rate - This data field gives the dose rate at $1 \mathrm{~cm}$ from the container surface in mrem/hr. The dose rate for pre-1982 waste was entered on a per shipment basis and only the measurement from the container with the highest radiation level was recorded.

- Neutron Dose - The total neutron dose (in $\mathrm{mrem} / \mathrm{hr}$ ) at $1 \mathrm{~cm}$ from the outer drum surface was recorded in this field.

- Thermal Power - This field contained the thermal power generation of the waste package in watts per cubic foot.

- Isotope and Quantity - Radionuclide content is listed in this field along with the mass (in g) and/or the radioactivity level (in Ci). Specifically identified are the TRU radionuclides, which at Hanford was often broadened to include U-233 and radium in addition to the transuranium elements. Criticality specifications for drums were non-existent prior 1975. Between 1975 and 1978 TRU constituents were limited to $250 \mathrm{~g}$ per drum. After 1978, this limit was reduced to $200 \mathrm{~g}$.

Except for $\mathrm{N}$-Reactor (105-N) and B-Plant waste, all beta and gamma waste was assumed to be mixed fission products (MFP) if specific nuclides were not provided in the burial records. The calculation used to determine the MFP quantity was based on the fuel processed at PUREX. Beta-gamma emitters that are below lead in the periodic chart are decayed using a decay calculation program. TRU radionuclides and several other isotopes, such as uranium and thorium, are not decayed due to their long half-lives.

Based on the number of grams of TRU isotopes listed in the burial records for a given drum, it is possible to estimate if that container is likely to be reclassified as LLW. Since WRAP Module 1 has both TRU and LLW process and RWM gloveboxes, this information may be valuable in the scheduling of operations to fully utilize the facility and to avoid glovebox downtime. 


\subsection{DRUM WEIGHT}

Heavy drums may reflect the presence of lead or concrete shielding for highly radioactive contents. During or prior to processing in WRAP Module 1 these wastes my be declared to remote-handled (RH).

Drum weights have been recorded since 1982. Drums generated prior to this date have and average drum weight of $68 \mathrm{~kg}(150 \mathrm{lb})$ listed on their records.

\subsection{SPECIAL WASTE TYPES}

\subsubsection{Soils}

Soils are to be specifically excluded from processing in WRAP Module 1. It is expected that NDE at the trench will be able to identify these drums.

\subsubsection{Animal Carcasses}

A number of laboratory facilities used animals in radiation research. Carcasses are found in the suspect TRU drums, generally packaged in lime. It is not always possible to tell which drums contain carcasses from the records, nor is it likely that NDE will be able to distinguish the skeletal remains due to the length of time these containers have been stored. For containers generated post-1978, animal waste may be listed on the burial record.

\subsection{TIME FRAME OF RETRIEVAL FROM TRENCH 4 MODULES}

Batching of the drums from Trench 4C-04 may also be done according to the order in which they are retrieved. Retrieval will proceed from the most recently emplaced modules to the oldest modules, and the drums from various generators are not evenly distributed among the modules. It may be impractical to batch drums that are not stored in the same module in the trench or even to batch drums that are not located in the same area within the module. 



\subsection{POTENTIAL BATCHING OF TRENCH 4C-04}

The criteria that can be used to batch the drums of retrieved waste that enter WRAP Module 1, were discussed previously in Section 4. The following section contains the results of applying these batching criteria to the drums to be retrieved during Project W-113 Phase I retrieval.

Project $W-113$ will retrieve the approximately 10,000 suspect TRU containers that are currently stored in trench 4 of burial ground $4 \mathrm{C}$, which is located in the 200W Area. The containers in this trench were emplaced between 1978 and 1984 in 19 modules. A module is approximately $12208-\mathrm{L}$ drums wide by 12 drums long and either 4 or 5 tiers. Since retrieval will proceed from the most recently emplaced modules to the oldest modules, Module 19 will be discussed first and Module 1 last in the sections that follow.

The data used to produce the batches discussed in this section were derived primarily from the SWITS database. Some of the limitations of this database were discussed briefly in the previous section; specific limitations of the data used in this section are listed where appropriate. The queries used to generate the SWITS data can be found in Appendix A.

\subsection{WASTE GENERATOR}

The wastes in Trench 4C-04 which were generated by 4 onsite and 6 offsite companies, are summarized in Table 5.1-1. Note that PFP (234-5Z) accounts for almost $67 \%$ of the total number of drums. This facility's waste was characterized in detail in WHC-EP0621 (Duncan et al. 1993). In addition to 234-5Z, wastes from the PUREX Plant (202-A), $231-Z$, and the 325 Radiochemistry Building have also been characterized in detail (Pottmeyer et al., 1993a; Pottmeyer et al. 1993b; Pottmeyer et al. 1993c). In Trench 4C-04 the total percentage of waste stored in drums from 234-5Z, 202-A, 325 (both Westinghouse Hanford (WHC) and Pacific Northwest Laboratory (PNL)), and $231-Z$ is approximately $83 \%$. Other, more minor, onsite waste generators accounted for about $5 \%$ of the total number of drums in this trench.

Drums from offsite generators accounted for about $12 \%$ of the total number of $208-L$ (55-gallon) drums in Trench 4. Of these drums, approximately $61 \%$ were sent from Babcock and Wilcox's (B \& W) Park Township. PA facility; $31 \%$ were sent from Westinghouse Electric's Advanced Reactors Division (WARD) and Nuclear Fuels Divisions (WNFD), which were co-located in Cheswick, PA; and $0.5 \%$ were sent from General Electric's Vallecitos Nuclear Center (GE VAL). The wastes sent from these generators have also been characterized in some detail (Duncan 1994: Duncan et al. 1994: Vejvoda et al. 1993). 
Table 5.1-1. Generators with Waste Stored in Trench 4C-04.

\begin{tabular}{|c|c|c|c|}
\hline GENERATOR & FACILITY & DRUMS & $\begin{array}{l}\text { OTHER } \\
\text { CONTAINERS }\end{array}$ \\
\hline \multicolumn{4}{|c|}{ ONSITE GENERATORS } \\
\hline J. A. Jones & & & 5 metal boxes \\
\hline \multirow{4}{*}{$\begin{array}{l}\text { Westinghouse Hanford Company } \\
\text { (WHC) }\end{array}$} & 308 & & 1 metal box \\
\hline & 324 & 85 & \\
\hline & 325 & 760 & \\
\hline & 340 & 210 & 4 metal boxes \\
\hline \multirow{6}{*}{$\begin{array}{l}\text { Pacific Northwest Laboratory } \\
\text { (PNL) }\end{array}$} & 324 & 15 & \\
\hline & 325 & 330 & \\
\hline & $325 \mathrm{~A}$ & 5 & \\
\hline & 340 & 125 & \\
\hline & $209 E$ & 20 & \\
\hline & 2312 & 220 & \\
\hline \multirow{6}{*}{$\begin{array}{l}\text { Rockwell Hanford Operations } \\
\text { (RHO) }\end{array}$} & $202 \mathrm{~A}$ & 295 & \\
\hline & 202AL & 6 & \\
\hline & $222 S$ & 7 & \\
\hline & 2335 & 35 & \\
\hline & $234-5 z$ & 6575 & 57 L-10 containers \\
\hline & 2 WTF & 6 & \\
\hline \multicolumn{4}{|c|}{ OFFSITE GENERATORS } \\
\hline General Electric (GE) & Vallecitos Nuclear Center, CA & 53 & 1 FRP Plywood Box \\
\hline Westinghouse Electric Corporation & $\begin{array}{l}\text { Advanced Reactors (WARD) and } \\
\text { Nuclear Fuels Divisions (WNFD) } \\
\text { - Cheswick. PA }\end{array}$ & 349 & 27 \\
\hline Babcock and Wilcox (B \& W) & $\begin{array}{l}\text { Park Township, PA Plutonium } \\
\text { Facility }\end{array}$ & 685 & \\
\hline Battelle Memorial Institute (BMI) & Columbus, $\mathrm{OH}$ & 42 & \\
\hline Energy Systems Group (ESG) & Canoga Park, CA & 49 & \\
\hline EXXON Nuclear & Richland, WA & 1 & \\
\hline
\end{tabular}

Many of the drums containing waste from within a particular generator are likely to hold similar contents, since they were generated by the same processes. To achieve batches of similar types of waste is one of the first goals of batching. This is arguably the easiest and most consistent method of batching, since the generating facility is virtually always included on the solid waste burial records, and is usually marked on the drum itself. 
Table 5.1-2 shows the number of 208-L drums in each module of Trench $4 C-04$ sorted by generator.

Table 5.1-2. Trench 4C-04 Number of 208-L Drums in Modules Sorted by Generator.

\begin{tabular}{|c|c|c|c|c|c|c|c|c|c|c|c|c|c|c|c|c|c|c|c|}
\hline & 1 & 2 & 3 & 4 & 5 & 6 & 7 & 8 & 9 & 10 & 11 & 12 & 13 & 141 & 15 & 16 & 17 & 18 & 19 \\
\hline & & & & & & & & & & & & & & & & & & & \\
\hline \multicolumn{20}{|l|}{ JA Jones } \\
\hline & & & & & & & & & & & & & & & & & & & \\
\hline WHC-324 & & & & & & & & & & & & & & & 19 & 16 & 20 & 27 & 1 \\
\hline \multicolumn{20}{|l|}{ WHC 308} \\
\hline WHC-325 & 77 & 294 & 49 & 100 & 87 & 104 & 27 & 53 & & & & & & & & & & & \\
\hline \multirow[t]{2}{*}{ WHC.340 } & & & & 24 & & & & 24 & 24 & 22 & 34 & 17 & 33 & 11 & 15 & & & & \\
\hline & & & & & & & & & & & & & & & & & & & \\
\hline PNL-324 & & & & & & & & & & & & & & & & 1 & 3 & 111 & \\
\hline PNL-325 & 16 & 27 & 39 & & 119 & 86 & 17 & & & & & & & & & & & 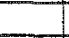 & \\
\hline PNL-325A & & 5 & & & & & & & & & & & & & & & & & \\
\hline PNL-340 & & & & & & & & 15 & 61 & & 23 & 8 & 10 & 18 & 8 & & & & \\
\hline PNL-209E & & & & & & & & 9 & & & 13 & & & & & & 10 & & \\
\hline \multirow[t]{2}{*}{ PNL-2312 } & 48 & 24 & 14 & 95 & & 14. & 8 & & 9 & 1 & 2 & & 11 & & & 4] & & & \\
\hline & & & & & & & & & & & & & & & & & & & \\
\hline RHO-202A & & 10 & & 66 & & & & & & & & & 944 & 57 & 2 & & 12 & 9 & \\
\hline \multicolumn{2}{|l|}{$\mathrm{RHO}-202 \mathrm{AL}$} & & & 6 & & & & & & & & & & & & & & & \\
\hline $8 H 0-222 \mathrm{~S}$ & 4 & 3 & & & & & & & & & & & & & & & & & \\
\hline AHO. 2335 & & & & & 11 & 7 & & 27 & & & & & & & & & & & \\
\hline RHO-234-5Z & 573 & 394 & 464 & 311 & 356 & 308 & 518 & 457 & 398 & 262 & 171 & 137 & 185 & 303 & 244 & 245 & 477 & 522 & 285 \\
\hline \multirow[t]{3}{*}{ RHO-2WTF } & & & & & & & 6 & & & & & & & & & & & & \\
\hline & & & & & & & & & & & & & & & & & & & \\
\hline & & & & & & & & & & & & & & & & & & & \\
\hline GE-VAL & & & & & & & & & & 69 & & 32 & 35 & & & & & & \\
\hline WARD WNFD & & & & & & & & & 52 & 48 & 26 & & 107 & 32. & 68 & 70 & 50 & & \\
\hline $\mathrm{B} \& W$ & & & & & & & & & & 142 & 256 & 61 & 8 & 84 & 29 & & & & \\
\hline BMI & & 42 & & & & & & & & & & & & & & & & & \\
\hline ESG & & & & & & & & & 40 & & & & & & & & & 6 & 3 \\
\hline EXXON & & & & & & & & & 1 & & & & & & & & & & \\
\hline & & & & & & & & & & & & & 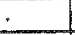 & & & & & & \\
\hline & & & & & & & & & & & & & & & & & & & \\
\hline Total & 798 & 719 & 566 & 602 & 573 & 519 & 576 & 585 & 577 & 544 & 525 & 255 & 533 & 499 & 385 & 336 & 572 & 575 & 289 \\
\hline
\end{tabular}


WHC-SD-WO26-TI-009, ReV.0

Table $5.1-3$ provides the relative percentage of drums in each module that were contributed by a given generator.

Table 5.1-3. Trench 4C-04 Relative Percentage of 208-L Drums in Modules by Generator.

\begin{tabular}{|c|c|c|c|c|c|c|c|c|c|c|c|c|c|c|c|c|c|c|c|}
\hline Generator & 1 & 2 & 3 & 4 & 51 & 6 & 7 & 8 & 91 & 101 & 911 & 121 & 93 & 141 & 951 & 161 & 17 & 181 & 19 \\
\hline & & & & & & & & & & & & & & & & & & & \\
\hline \multicolumn{20}{|l|}{ JA Jones } \\
\hline & & & & & & & & & & & & & & & & & & & \\
\hline WHC-308 & & & & & & & & & & & & & & & $5 \%$ & $5 \%$ & $3 \%$ & $5 \%$ & $0 \%$ \\
\hline \multicolumn{20}{|l|}{ WHC.324 } \\
\hline WHC-325 & $19 \%$ & $30 \%$ & $9 \%$ & $17 \%$ & $15 \%$ & $20 \%$ & $5 \%$ & $9 \%$ & & & & & & & & & & & \\
\hline \multirow[t]{2}{*}{ WHC-340 } & & & & $4 \%$ & & & & $4 \%$ & $4 \%$ & $4 \%$ & $6 \%$ & $7 \%$ & $6 \%$ & $2 \%$ & $4 \%$ & & & & \\
\hline & & & & & & & & & & & & & & & & & & & \\
\hline PNL-324 & & & & & & & & & & & & & & & & $0 \%$ & $1 \%$ & $2 \%$ & \\
\hline PNL-325 & $2 \%$ & $4 \%$ & $7 \%$ & & $29 \%$ & $17 \%$ & $3 \%$ & & & & & & & & & & & $m$ & \\
\hline \multirow[t]{2}{*}{ PNL-325A } & & $1 \%$ & & & & & & & & & & & & & & & & & \\
\hline & & & & & & & & $3 \%$ & ११\% & & $4 \%$ & $3 \%$ & $2 \%$ & $4 \%$ & $2 \%$ & & & & \\
\hline PNL-209E & & & & & & & & $2 \%$ & & & $2 \%$ & & & & & & $2 \%$ & & \\
\hline \multirow[t]{2}{*}{ PNL-2312 } & $7 \%$ & $3 \%$ & $2 \%$ & $16 \%$ & & $3 \%$ & $1 \%$ & & $0 \%$ & $0 \%$ & $0 \%$ & & $2 \%$ & & & $1 \%$ & & & \\
\hline & & & & & & & & & & & & & & & & & & & \\
\hline AHO-202A & & $1 \%$ & & $11 \%$ & & & & & & & & & $27 \%$ & $90 \%$ & $1 \%$ & & $2 \%$ & $2 \%$ & \\
\hline AHO-202AL & & & & $1 \%$ & & & & & & & & & & & & & & & \\
\hline AHO-222S & $1 \%$ & $0 \%$ & & & & & & & & & & & & & & & & & \\
\hline RHO.2335 & & & & & $2 \%$ & $1 \%$ & & $5 \%$ & & & & & & & & & & & \\
\hline AHO- $234-52$ & $80 \%$ & $55 \%$ & $82 \%$ & $52 \%$ & $62 \%$ & $59 \%$ & $90 \%$ & $78 \%$ & 699 & $48 \%$ & $33 \%$ & $54 \%$ & $35 \%$ & $61 \%$ & $63 \%$ & $73 \%$ & $83 \%$ & $99 \%$ & $99 \%$ \\
\hline \multirow[t]{2}{*}{ AHO-2WTH } & & & & & & & $1 \%$ & & & & & & & & & & & & \\
\hline & & & & & & & & & & & & & & & & & & & \\
\hline GE-VAL & & & & & & & & & & $13 \%$ & & $13 \%$ & $7 \%$ & & & & & & \\
\hline WARD/WNFD & & & & & & & & & $9 \%$ & $9 \%$ & $5 \%$ & & $20 \%$ & $6 \%$ & $18 \%$ & $29 \%$ & $9 \%$ & & \\
\hline$B \& W$ & & & & & & & & & & $26 \%$ & $49 \%$ & $24 \%$ & $2 \%$ & $17 \%$ & $8 \%$ & & & & \\
\hline EMI & & $6 \%$ & & & & & & & & & & & & & & & & & \\
\hline ESG & & & & & & & & & $7 \%$ & & & & & & & & & $8 \%$ & $9 \%$ \\
\hline EXXON & & & & & & & & & $0 \%$ & & & & & & & & & & \\
\hline & & & & & & & & & & & & & & & & & & & \\
\hline
\end{tabular}


The waste from Module 19, the first module that is to be retrieved, is $99 \%$ from building 234-5Z (the PFP), with the remaining 1\% from the ESG (only three drums from this facility) and WHC building 324 (only one drum). These proportions can be seen in Figure 5.1 . 1. Wastes from the PFP plant were generated primarily as a result of plutonium processing. maintenance, housekeeping, and waste processing. These wastes include such items as dissolver heels, graphite molds, ceramics, piping, tubing, bolts, screws, rags, paper cartons, and HEPA filters. For a more detailed description of these wastes, see "Characterization of Past and Present Waste Streams from the Plutonium Finishing Plant" (Duncan et al. 1993). Typical wastes from the ESG include paper, plastic, rubber, cement, lead, and metals; wastes from WHC building 324 include cement, concrete, glass, metal, paper, plastic, and rubber.

Figure 5.1-1. Relative Percentage of Drums in Module 19 by Generator.

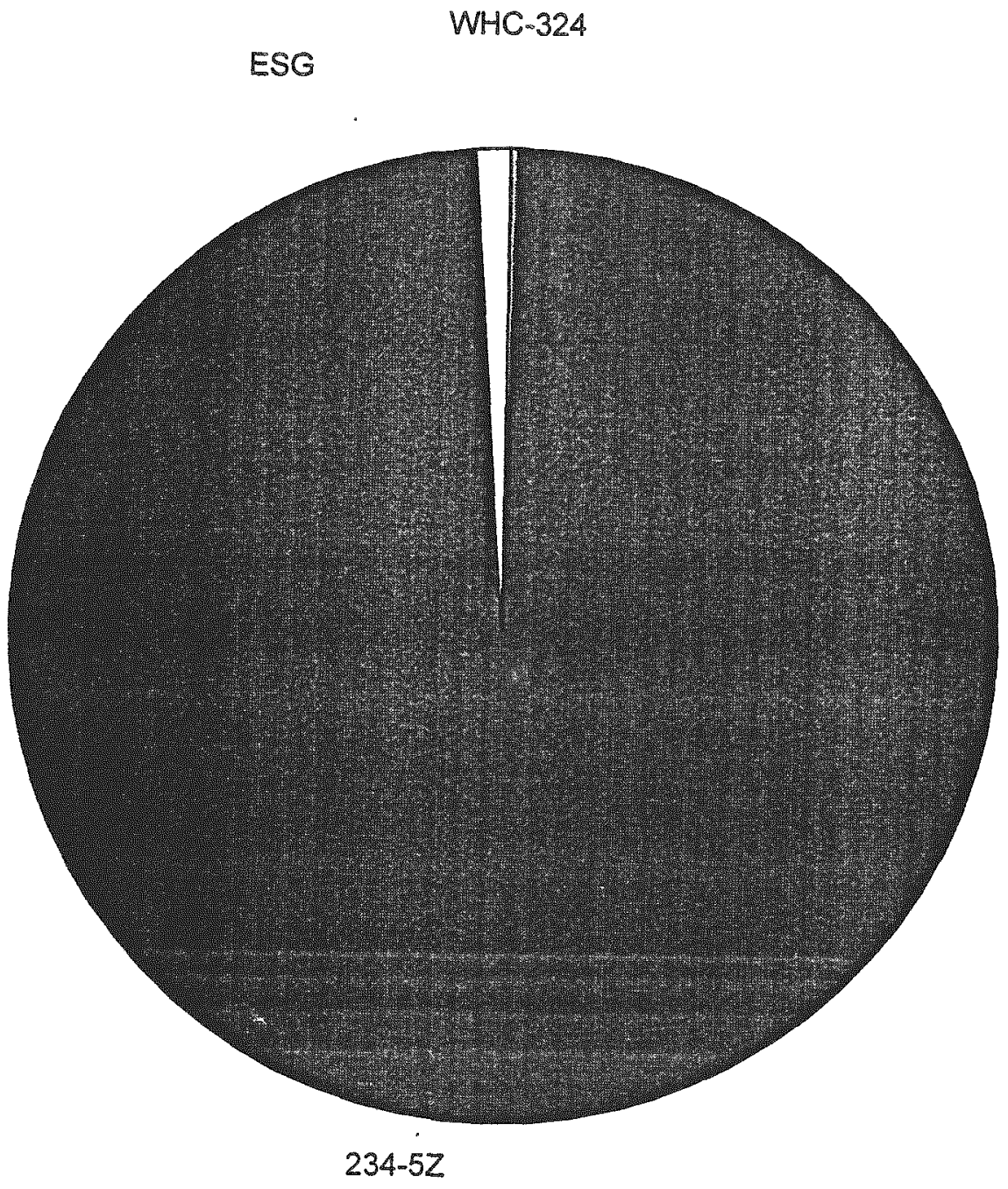


The next module to be retrieved is Module 18, which contains waste that is $91 \%$ from the PFP, $5 \%$ from WHC bulding 324, 2\% from PNL building 324, $1 \%$ from bullding $202 \mathrm{~A}$ (the PUREX Plant) and 1\% from the ESG. These proportions can be seen in Figure 5 1-2. Waste from the PFP and the ESG are described in the previous section. Waste from the PUREX process includes items such as spent and falled equipment and tools, housekeeping and glovebox maintenance items, ventilation HEPA filters, demolition and major equipment removal, and processing items. For a more detalled description of these wastes, see "Characterization of Past and Present Waste Streams from the Plutonium-Uranium Extraction Plant" (Pottmeyer et al. 1993a). Waste from PNL building 324 includes paper, plastic, metal, wood, and glass.

Figure 5.1-2. Relative Percentage of Drums in Module 18 by Generator.

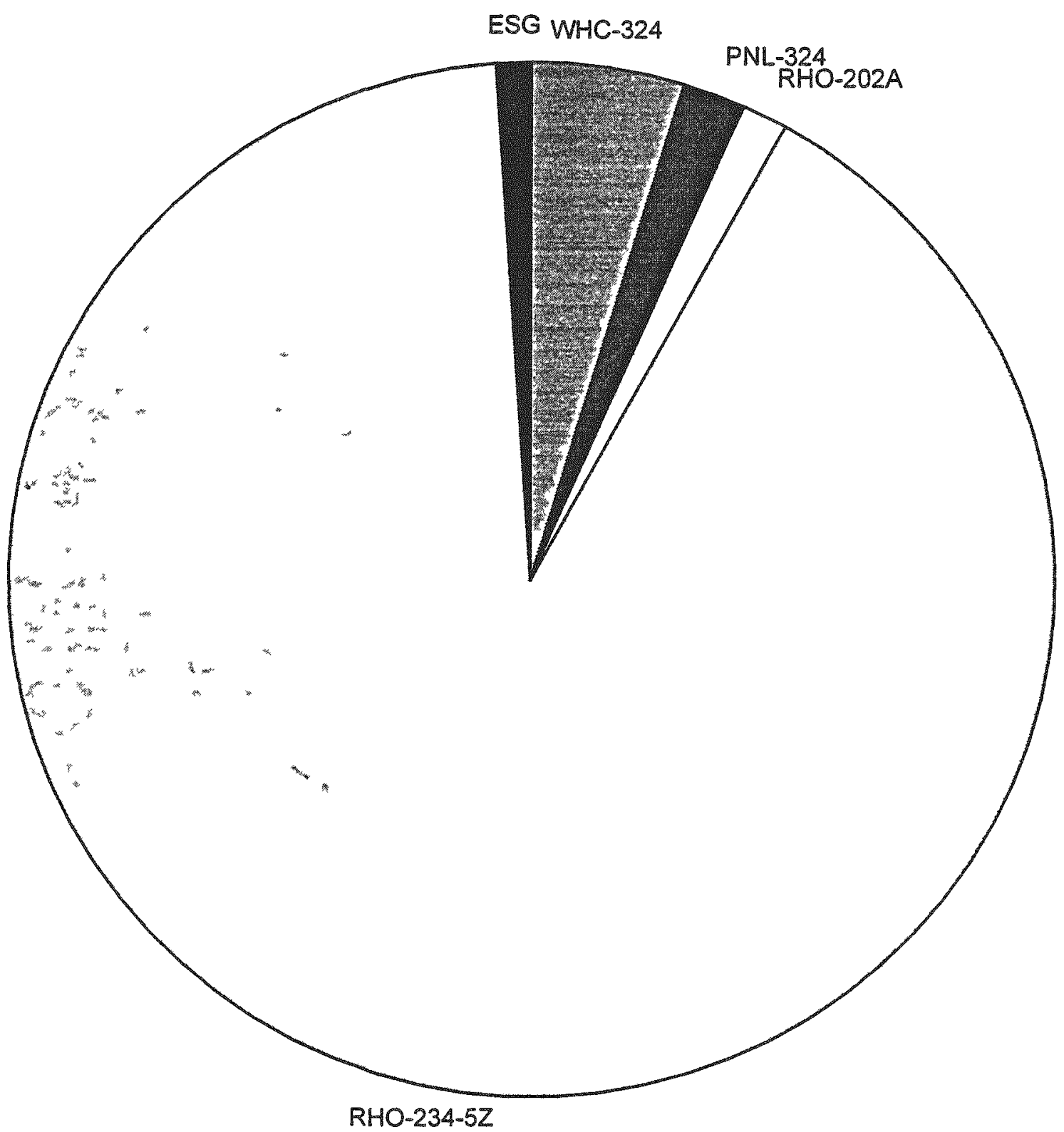


Module 17 contains waste that is $83 \%$ from the PFP, $9 \%$ from WARDMNFD, $3 \%$ from WHC building $324,2 \%$ from the PUREX Plant, $2 \%$ from building $209-E$, and $1 \%$ from building 324 (this is only three drums). These proportions can be seen in Figure 5.1-3. Wastes from the PFP, the PUREX Plant, and building 324 are described above. The wastes from WARDNNFD were generated primarily as a result of the decontamination and decommissioning (D\&D) of these facilities. The D\&D process required the removal of all process equipment, the associated glove-box type containment structures, the glovebox ventilation ductwork and filtration systems, and associated service items. For a more detailed description of the wastes, see "Radioactive Waste Shipments to Hanford Retrievable Storage from Westinghouse Advanced Reactors and Nuclear Fuels Divisions, Cheswick, Pennsylvania" (Duncan et al. 1994). Building 209-E drums contain combustible wastes including paper, rubber, plastic, and combustible glovebox wastes of stripcoat, rubber, and plastic.

Figure 5.1-3. Relative Percentage of Drums in Module 17 by Generator.

WHC-324

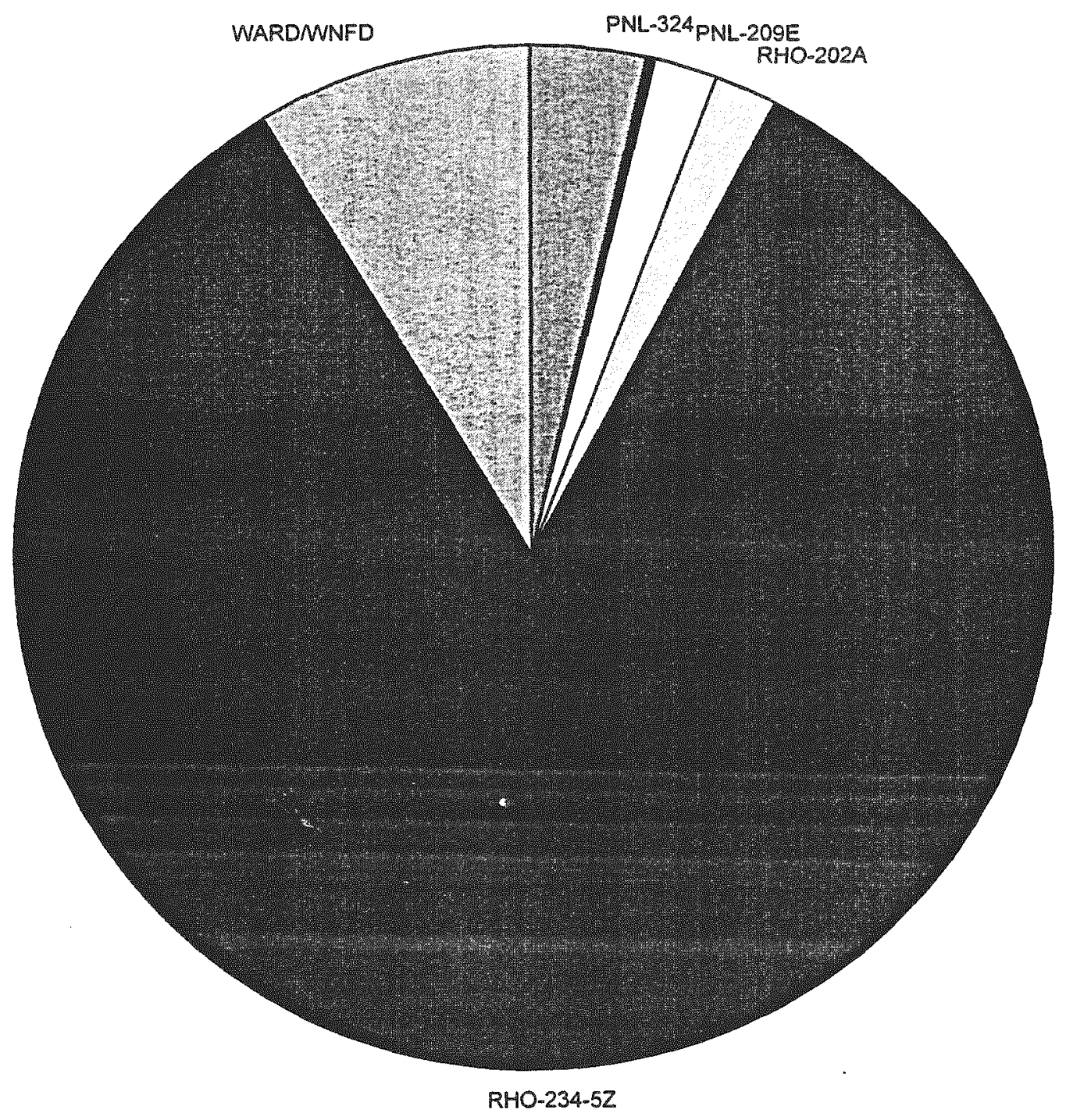


Module 16 contains waste that is $71 \%$ from the PFP. $23 \%$ from WARD/WNFD, $5 \%$ from WHC building $324,1 \%$ from bulding $231-Z$ (four drums), and less than $1 \%$ from PNL building 324 (one drum). These proportions can be seen in Figure 5.1-4. Wastes from the PFP, the PUREX Plant, building 324, and WARDMNFD are described above. The wastes generated from $231 \mathrm{Z}$ come from sources including general weapons development, process waste from gloveboxes, numerous classified research and development programs, advanced decontamination and decommissioning technologies, general laboratory procedures, foundry area, housekeeping activities, and four clean out campaigns. For a more detailed description of the wastes, see "Characterization of Past and Present Waste Streams from $231-Z$ " (Pottmeyer et al. 1993b).

Figure 5.1-4. Relative Percentage of Drums in Module 16 by Generator.

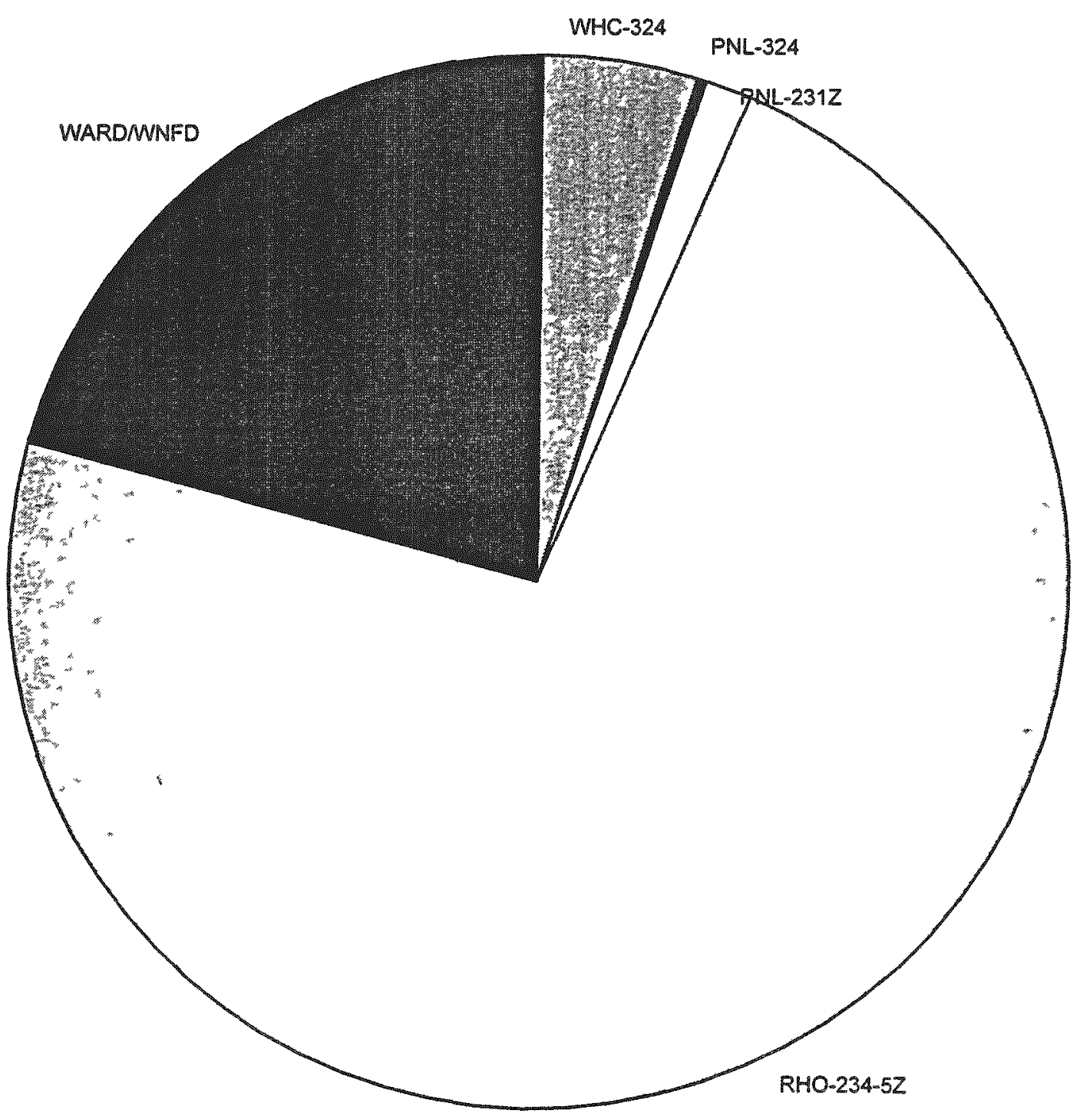


Module 15 contains waste that is $62 \%$ from the PFP, $20 \%$ from WARDNNFD, $7 \%$ from Babcock and Wilcox (B \& W), $6 \%$ from bulling $340,5 \%$ from WHC bulding 324, and less than $1 \%$ from the Purex Plant (this is only two drums). These proportions can be seen in Figure 5.1-5. Wastes from the PFP and WARDMNFD are described above. Wastes from $B$ \& W consist of line and laboratory wastes, non-line waste, primary HEPA filters, jet mill bags, liquid wastes, hot cell liquid wastes, and contamınated hydraulic and vacuum pump oil. For a more detalled description of the wastes, see "Radioactive Waste Shipments to Hanford Retrievable Storage from Babcock and Wilcox, Leechburg. PA" (Duncan 1994). Wastes from building 340 consist of paper, plastıc, metal, glass, and anımal waste.

Figure 5.1-5. Relative Percentage of Drums in Module 15 by Generator.

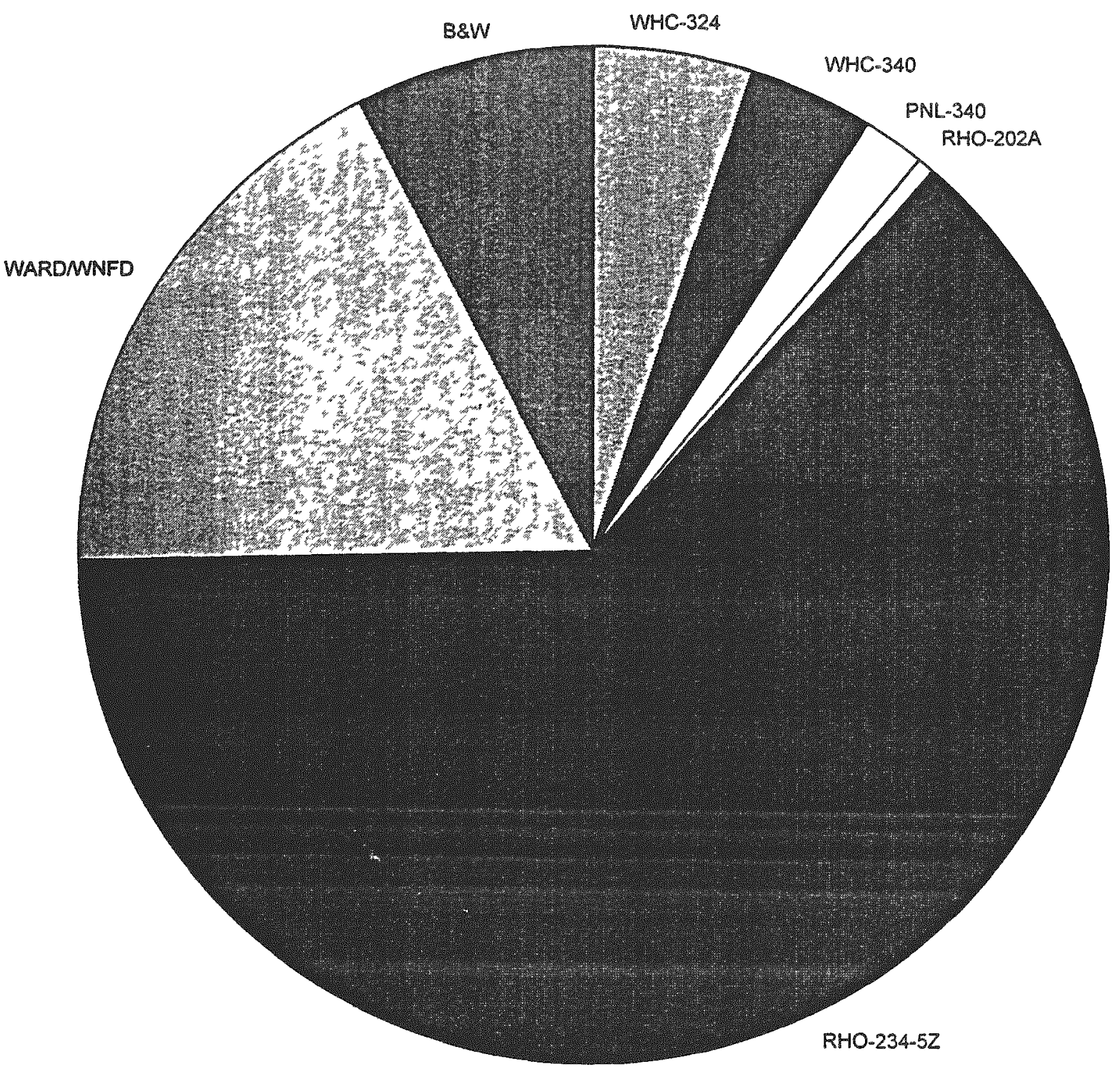


Module 14 contains waste that is $59 \%$ from the PFP. $17 \%$ from Babcock and Wilcox, $10 \%$ from the PUREX Plant, $8 \%$ from WARD NNFD, $6 \%$ from building 340 , and less than $1 \%$ from GE-Vallecitos (one box). These proportions can be seen in Figure 5.1-6. Wastes from the PFP, Babcock and Wilcox, the PUREX Plant, and building 340 are described above. Waste from GE-Vallecitos was generated primarily as the result of D\&D activities, and includes process and fabrication equipment, gloveboxes, glovebox supporting apparatus, ventilation ducting, and other miscellaneous service items contaminated with plutonium. For a more detailed description of these wastes, see "Radioactive Waste Shipments to Hanford Retrievable Storage from the General Electric Vallecitos Nuclear Center, Pleasanton, California" (Vejvoda et al. 1993).

Figure 5.1-6. Relative Percentage of Drums in Module 14 by Generator.

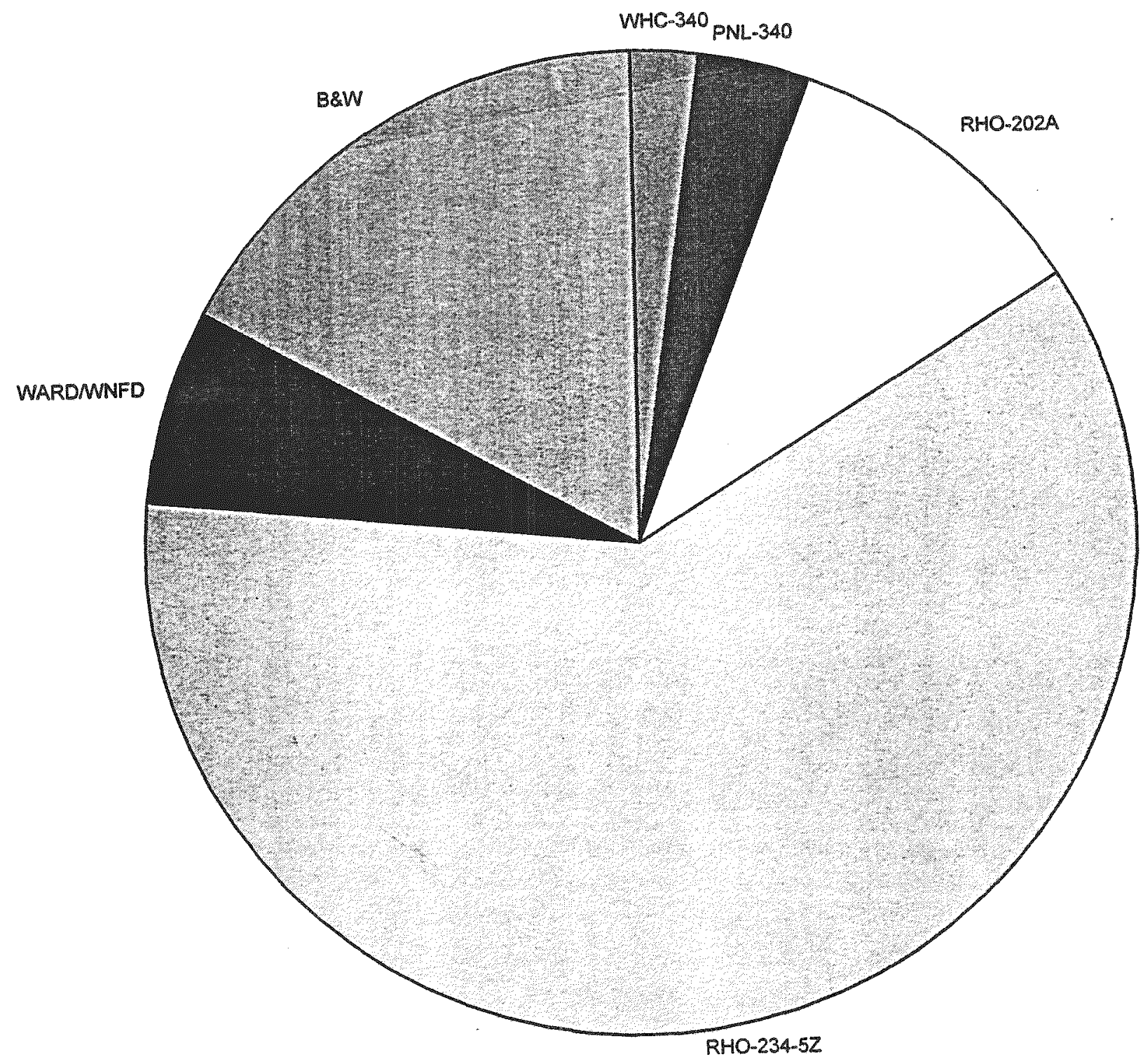


Module 13 contains waste that is $35 \%$ from the PFP, $27 \%$ from the PUREX Plant, $20 \%$ from WARDNNFD, $8 \%$ from building $340,7 \%$ from GE-Vallecitos, $2 \%$ from building 2312 , and $1 \%$ from Babcock and Wilcox. These proportions can be seen in Figure 5.1-7. All generators of waste stored in Module 13 have been described above.

Figure 5.7.7. Relative Percentage of Drums in Module 13 by Generator.

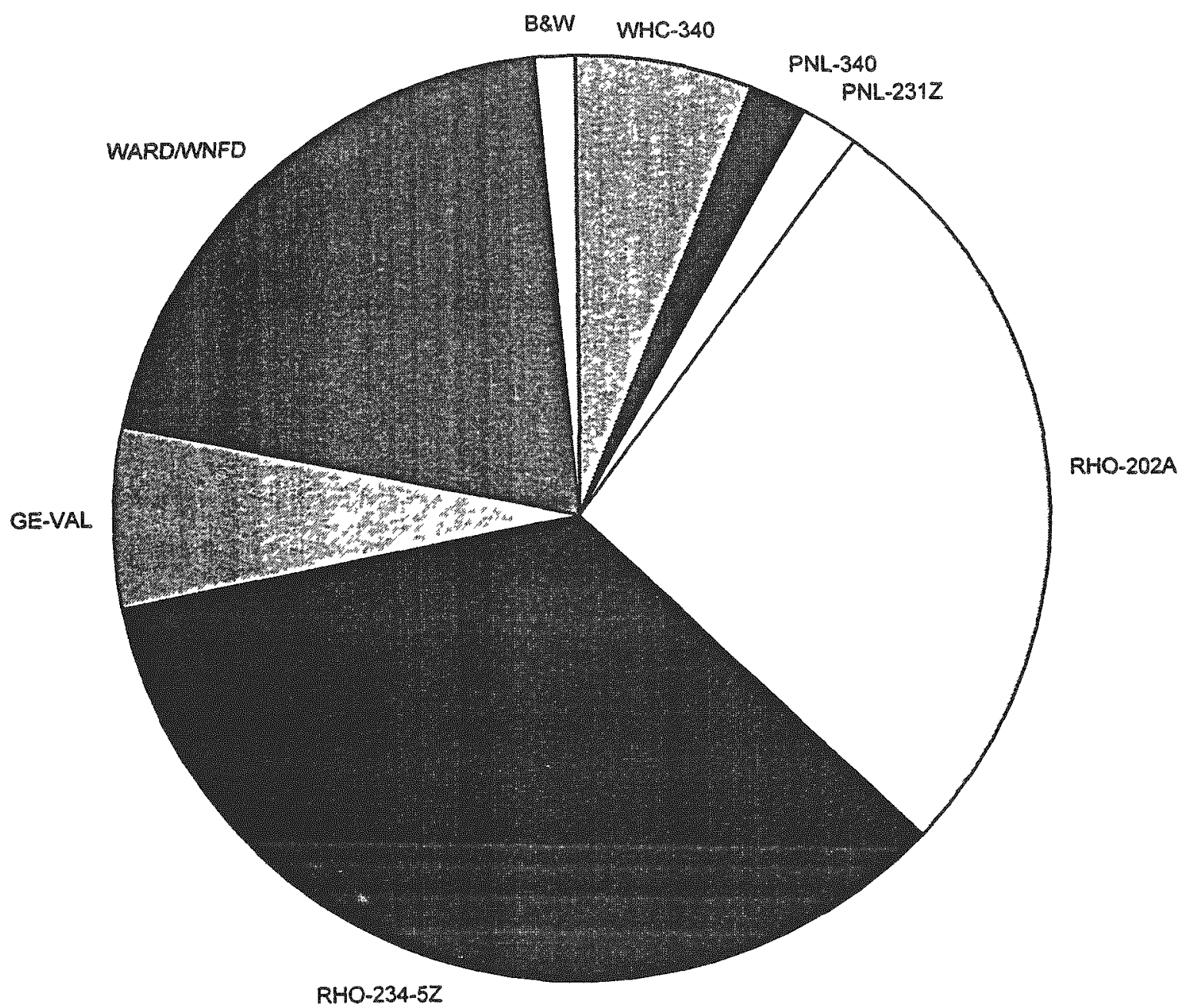


Module 12 contains waste that is $52 \%$ from the PFP. $23 \%$ from Babcock and Wilcox. $12 \%$ from GE-Vallecitos, $10 \%$ from building 340 , and $3 \%$ (five boxes) from J.A. Jones. These proportions can be seen in Figure 5.1-8. J.A. Jones is the only generator not previously discussed; it's waste consists of ductwork, plastic, rags, filter boxes, and barrels.

Figure 5.1-8. Relative Percentage of Drums in Module 12 by Generator.

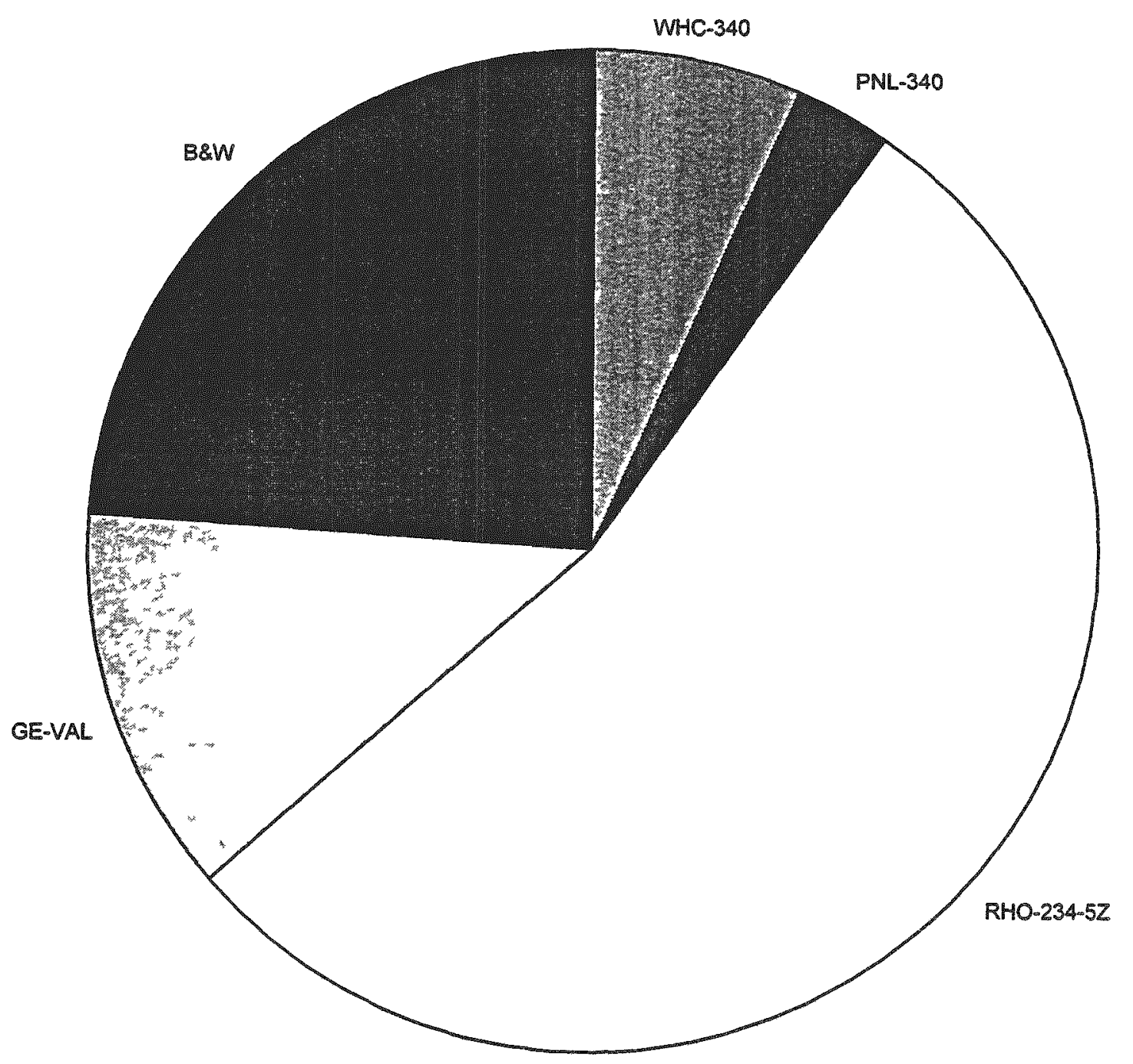


Module 11 contains waste that is $49 \%$ from Babcock and Wilcox, $33 \%$ from the PFP, $11 \%$ from building $340,5 \%$ from WARD/WNFD, and $2 \%$ from bulding $209-E$. These proportions can be seen in Figure 5.1-9. All generators of waste stored in Module 11 have been described above.

Figure 5.1-9. Relative Percentage of Drums in Module 11 by Generator.

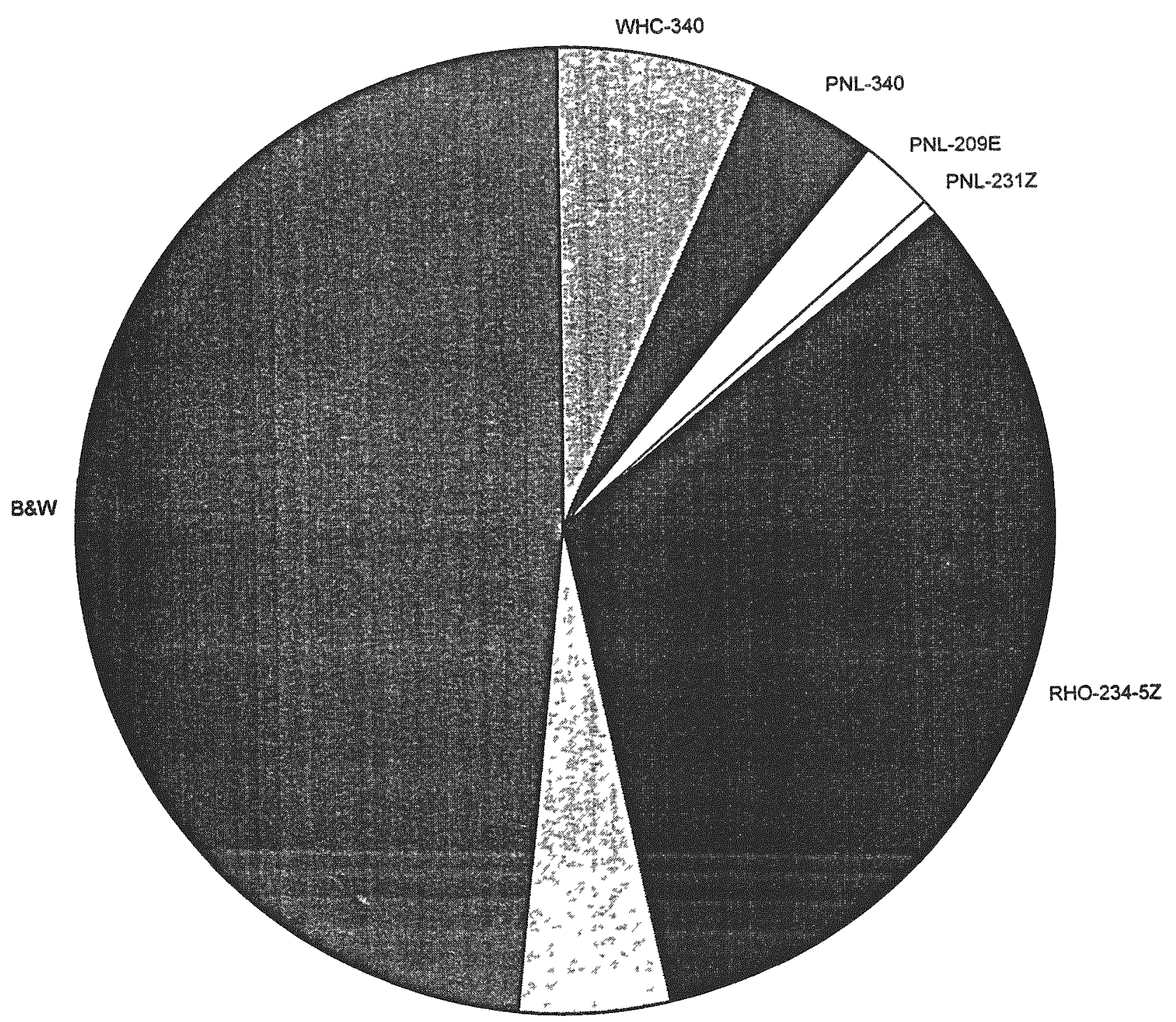


Module 10 contans waste that is $48 \%$ from the PFP, $26 \%$ from Babcock and Wilcox, $13 \%$ from GE-Vallecitos, $9 \%$ from WARDNWND. $4 \%$ from bulding 340 , and less than $1 \%$ from buildings WHC 324 and $231-2$ combined. These proportions can be seen in Figure 5.1 10. All generators of waste stored in Module 10 have been described above.

Figure 5.1.10. Relative Percentage of Drums in Module 10 by Generator.

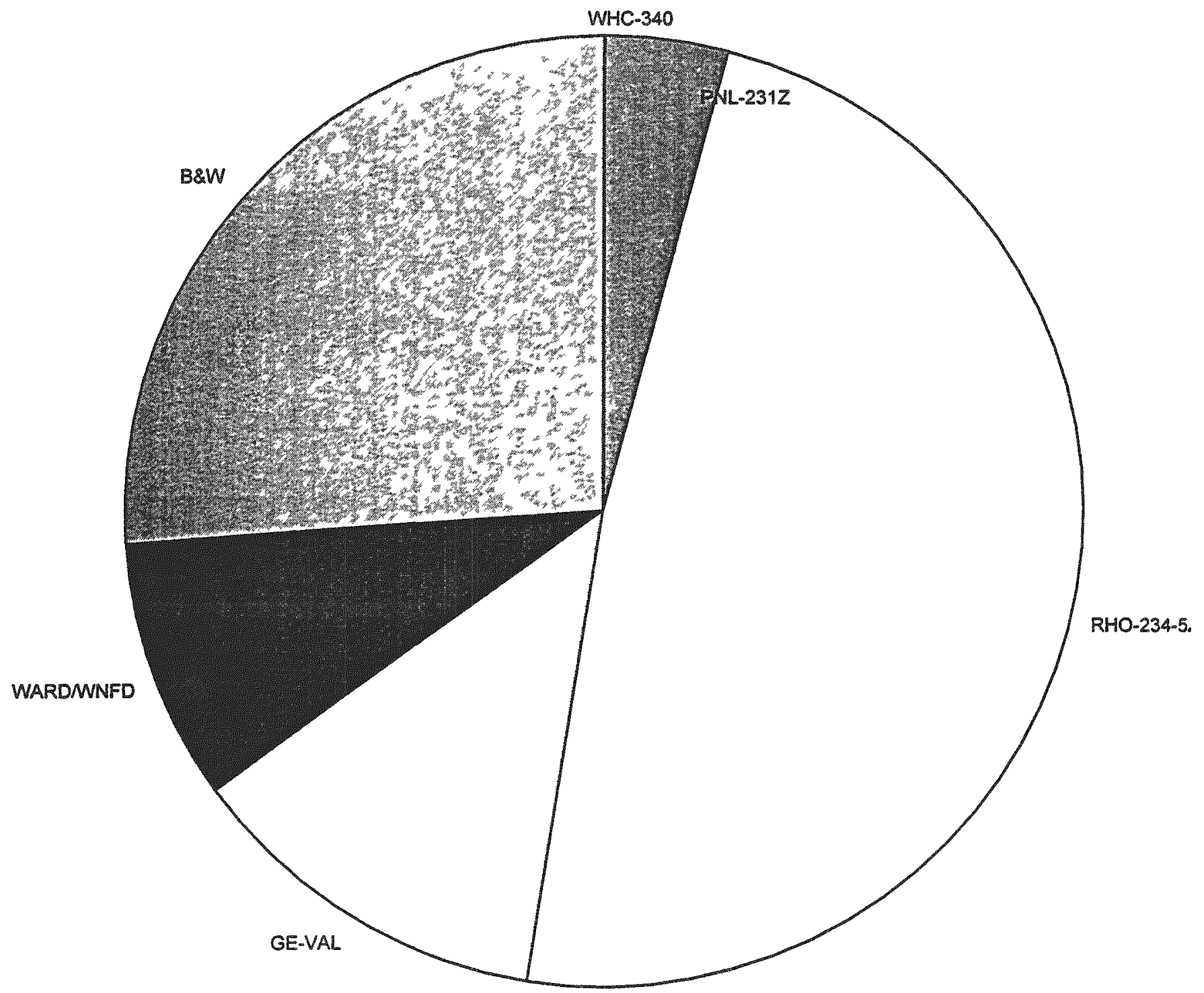


Module 9 contains waste that is $69 \%$ from the PFP. $15 \%$ from building $340,9 \%$ WARDMNFD, $7 \%$ from the ESG, and less than $1 \%$ from Exxon and building $231-Z$. These proportions can be seen in Figure 5.1-11. Exxon is the only generator not previously discussed; however, this facility contributes a very small portion of the total waste, and no detailed information on that waste is available.

Figure 5.1-11. Relative Percentage of Drums in Module 9 by Generator.

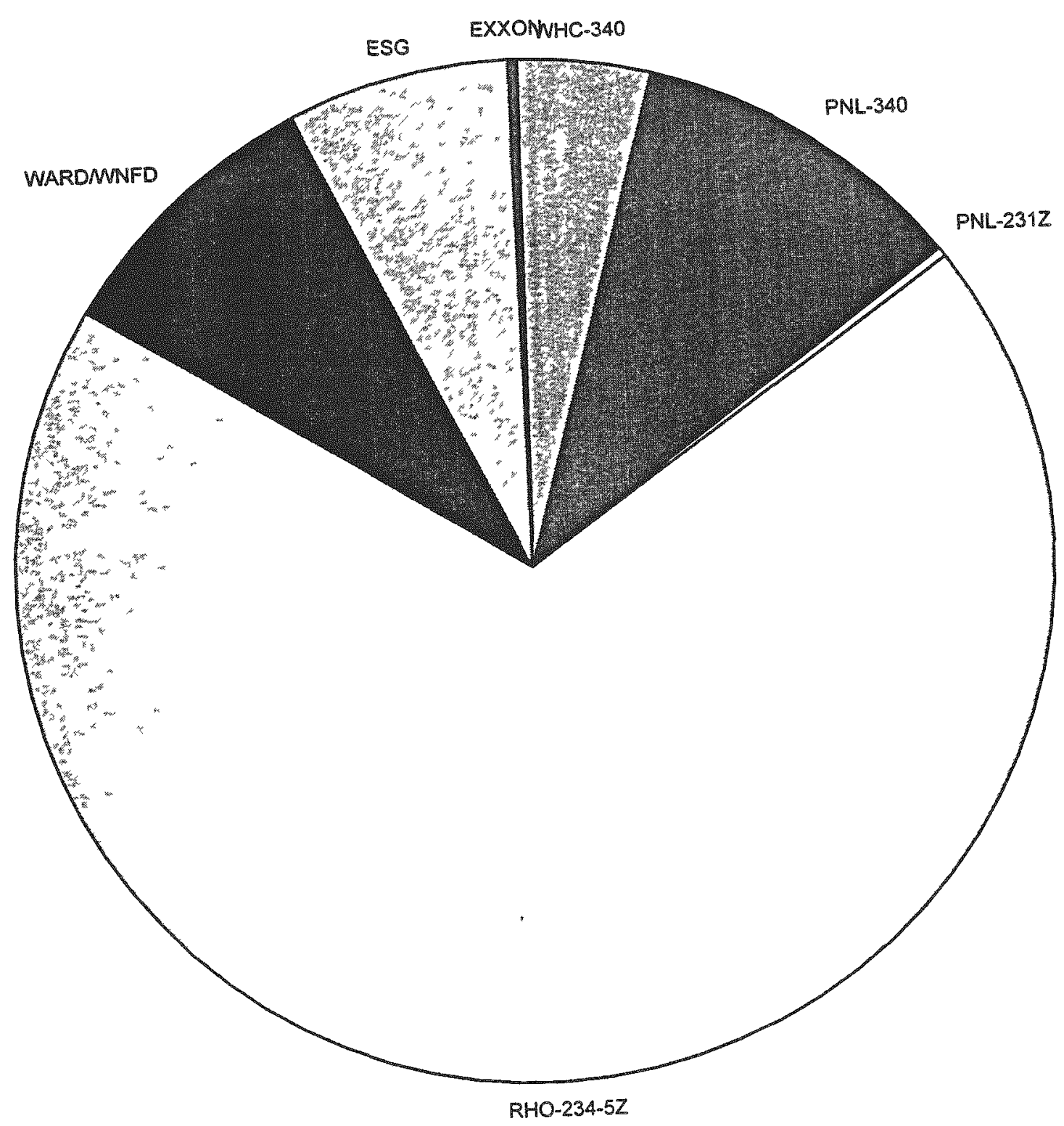


Module 8 contains waste that is $78 \%$ from the PFP, $9 \%$ from building $325,7 \%$ from building $340,5 \%$ from building $233-S$, and $1 \%$ from building $209-E$. These proportions can be seen in Figure 5.1-12. There are two generators of waste in Module 8 that have not been previously discussed: building 325 , and building 233-S. Wastes from building $233-S$ consists mainly of cleaning rags, plastic, paper, cloth, decontamination waste, and metal from load out hood. Waste from building 325, a research facility, typically consists of plastic vials and bottles, broken glass, electrodes, paper towels, neoprene gloves, and old laboratory equipment. For more detailed information on these wastes, see "Characterization of Past and Present Waste Streams from the 325 Radiochemistry Building" (Pottmeyer et al.1993).

Figure 5.1-12. Relative Percentage of Drums in Module 8 by Generator.

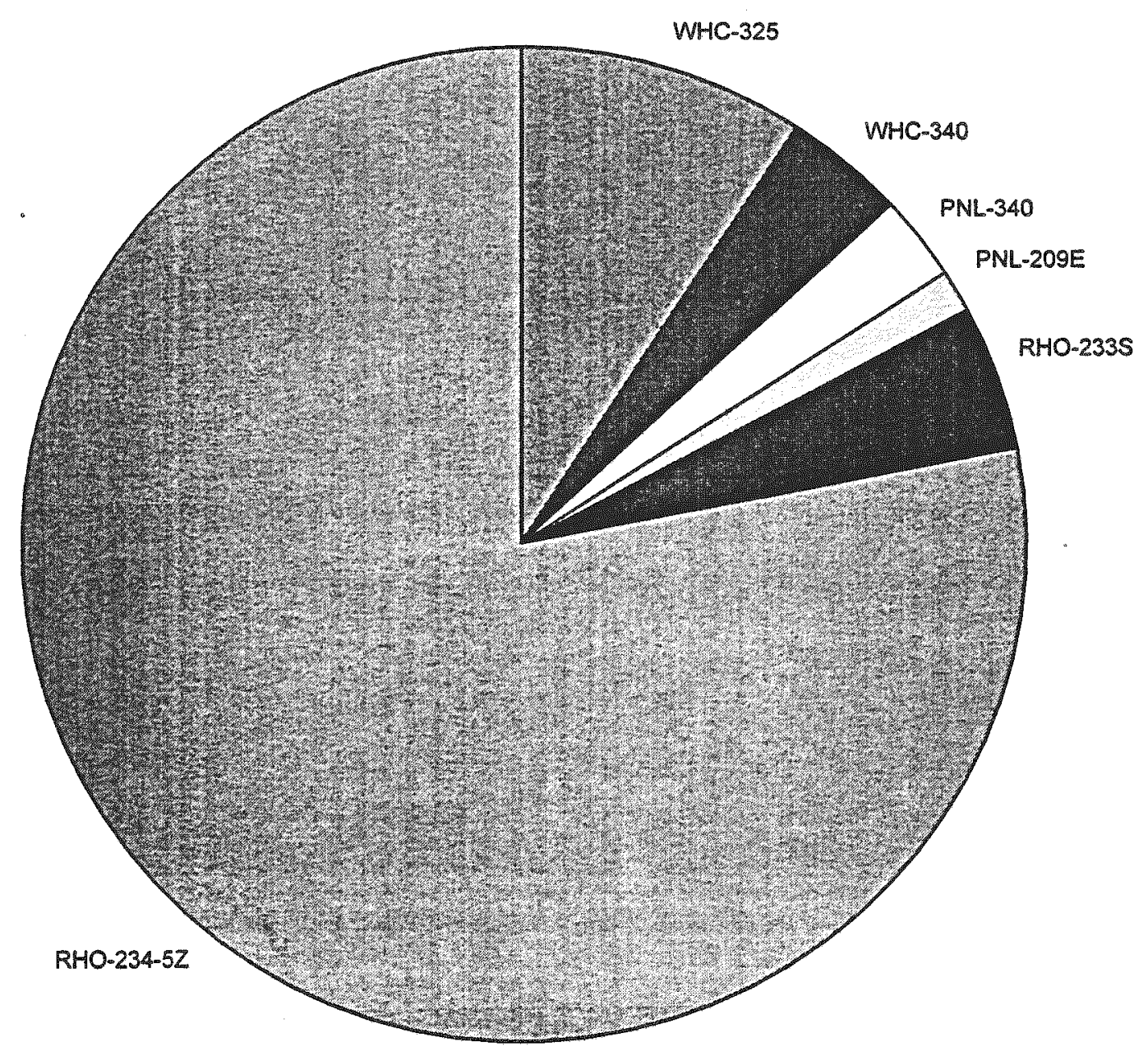


Module 7 contains waste that is $90 \%$ from the PFP, $8 \%$ from building $325,1 \%$ from building $231-Z$, and $1 \%$ from the 2 WTF tank farm. These proportions can be seen in Figure 5.1-13. 2WTF waste consists of contaminated soil in plastic bags.

Figure 5.1-13. Relative Percentage of Drums in Module 7 by Generator.

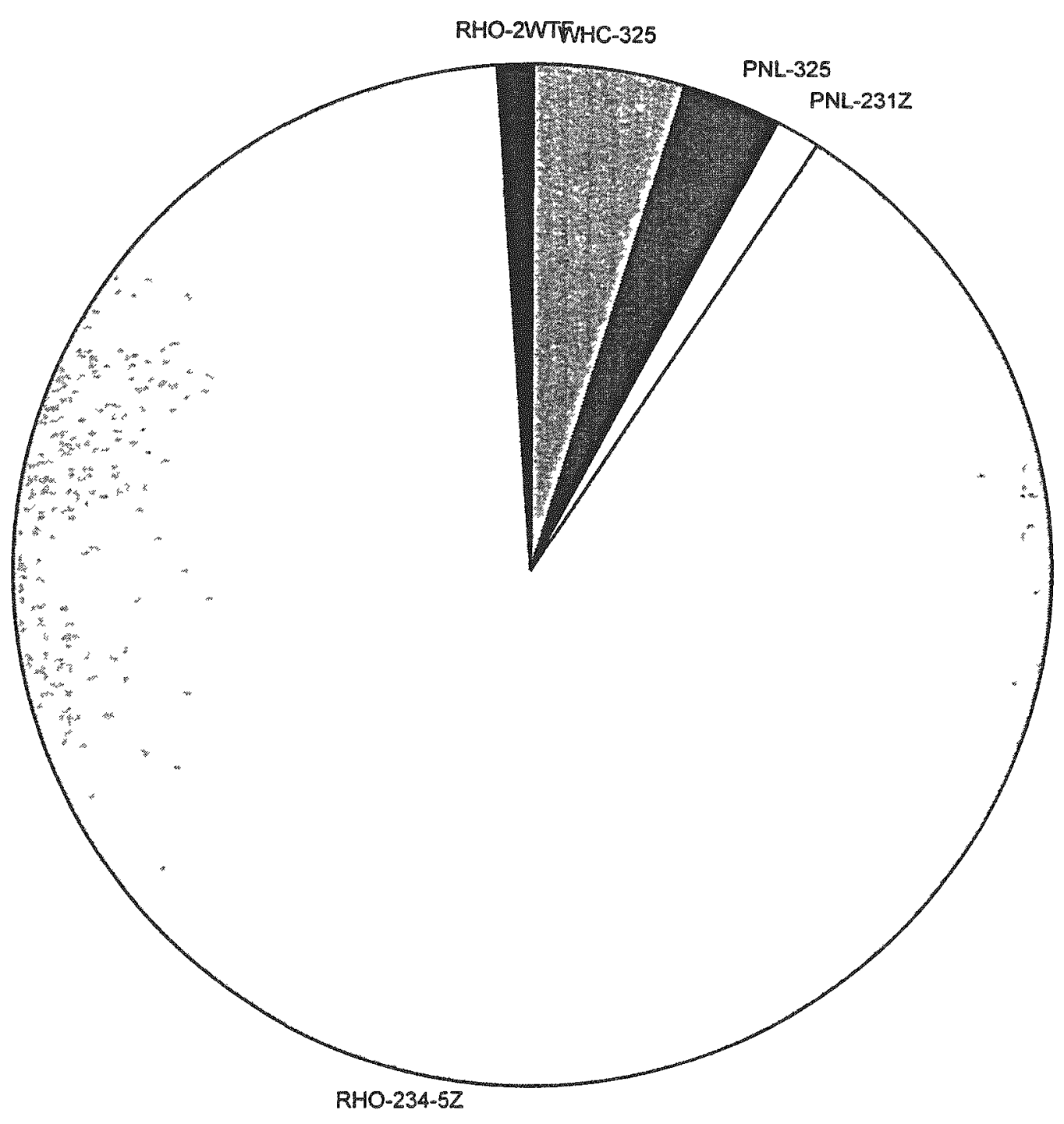


Module 6 contains waste that is $59 \%$ from the PFP. $37 \%$ from building $325,3 \%$ from $231 Z$, and $1 \%$ from building 233-S. These proportions can be seen in Figure 5.1-14. All generators of waste stored in Module 6 have already been described above.

Figure 5.1-14. Relative Percentage of Drums in Module 6 by Generator.

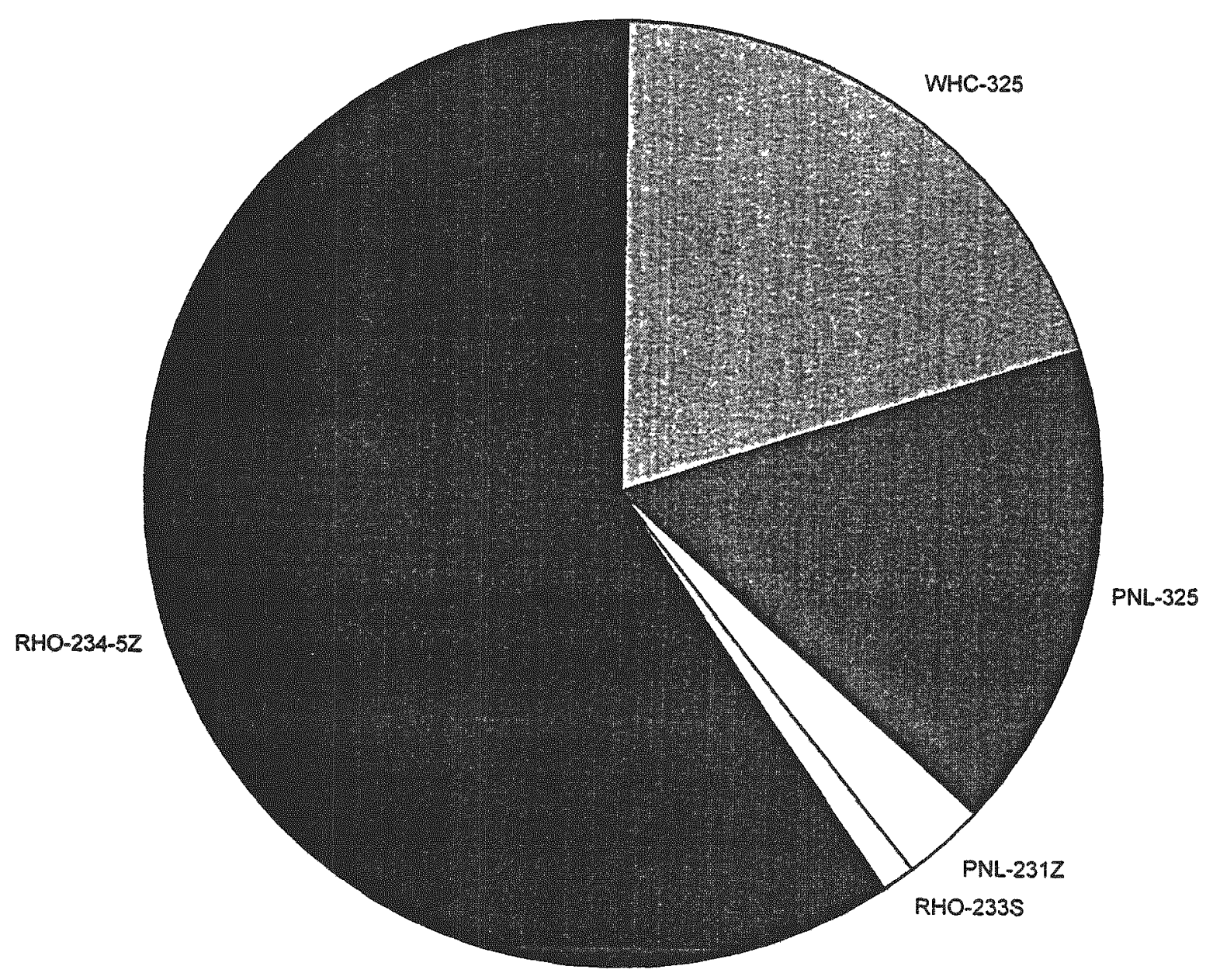


Module 5 contans waste that is $62 \%$ from the PFP, $36 \%$ from building 325 , and $2 \%$ from building 233-S. These proportions can be seen in Figure 5.1-15. All generators of waste stored in Module 5 have already been described above

Figure 5.1-15. Relative Percentage of Drums in Module 5 by Generator.

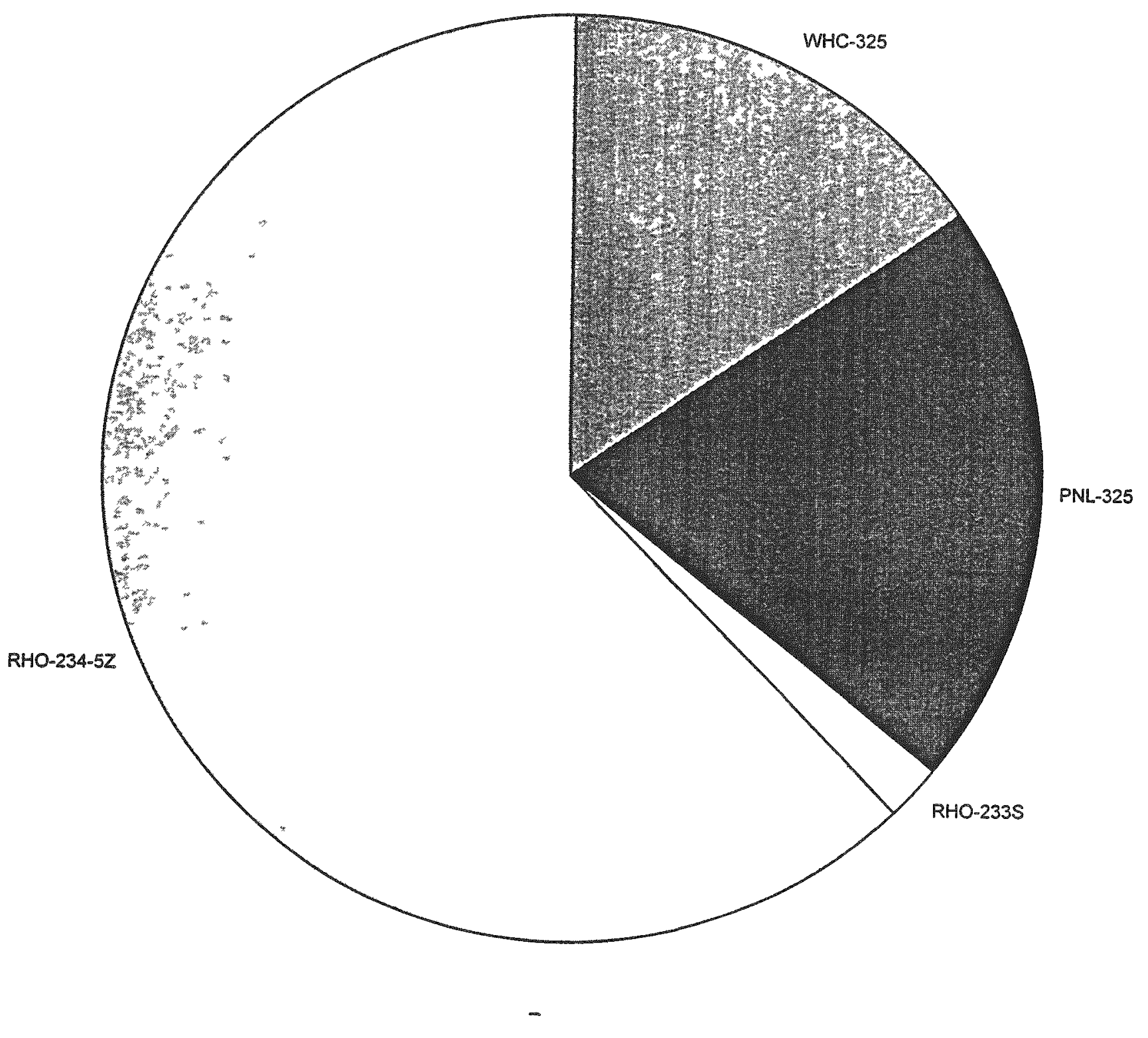


Module 4 contains waste that is $52 \%$ from the PFP. $17 \%$ from building $325,16 \%$ from building $231-Z, 12 \%$ from the PUREX Plant, and $3 \%$ from building 340 . These proportions can be seen in Figure 5.1-16. All generators of waste stored in Module 4 have already been described above.

Figure 5.1-16. Relative Percentage of Drums in Module 4 by Generator.

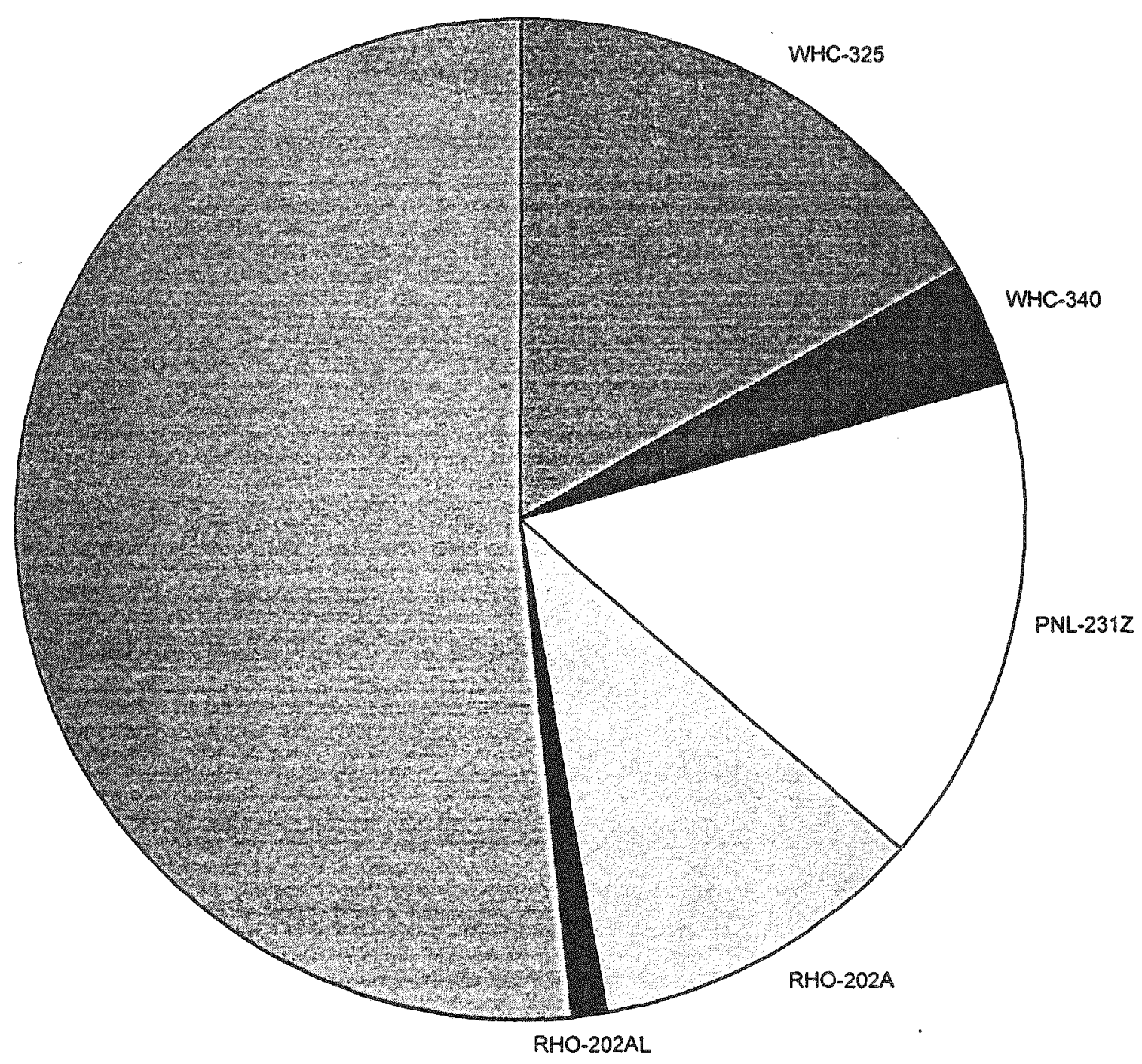


WHC-SD-W026-T1-009, Rev. O

Module 3 contains waste that is $82 \%$ from the PFP. $16 \%$ from bulding 325 , and $2 \%$ from 231-Z. These proportions can be seen in Figure 5.1-17. All generators of waste stored in Module 3 have already been described above.

Figure 5.1-17. Relative Percentage of Drums in Module 3 by Generator.

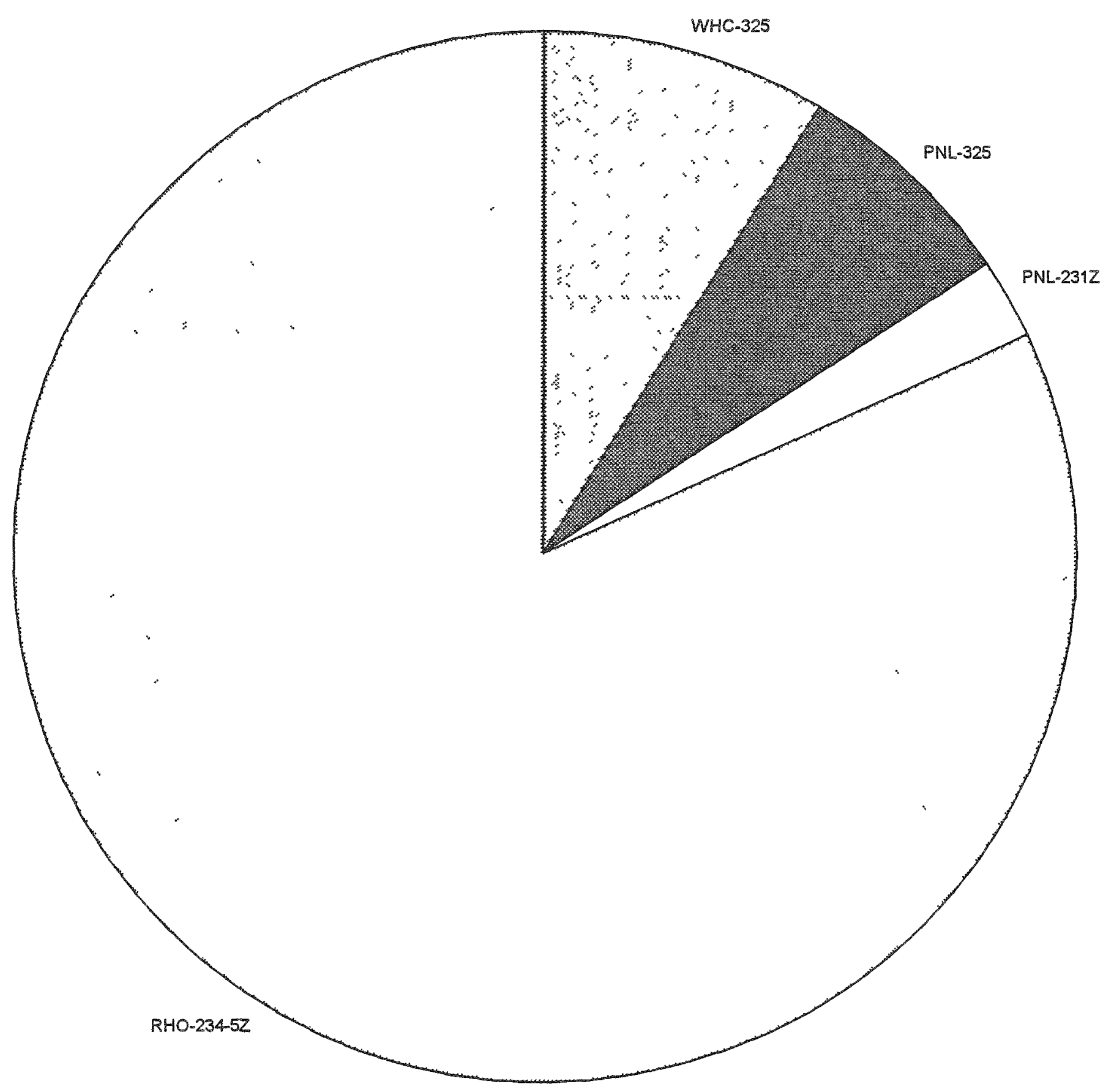


Module 2 contains waste that is $55 \%$ from the PFP, $35 \%$ from building $325,6 \%$ from the Battelle Memorial Institute (BMI), 3\% from the PUREX Plant, and $1 \%$ from building 222-S. These proportions can be seen in Figure 5.1-18. There are two generators not previously discussed: building 222-S and BMI. BMI waste drums contain R \& D Laboratory waste generated during the performance of DOE Contract programs. This waste consisted of glovebox wipes, small contaminated equipment and tools, box gloves, and other miscellaneous contaminated items normally associated with $R$ \& $D$ operations. Drums from building $222-S$ contain miscellaneous dry waste.

Figure 5.1-18. Relative Percentage of Drums in Module 2 by Generator.

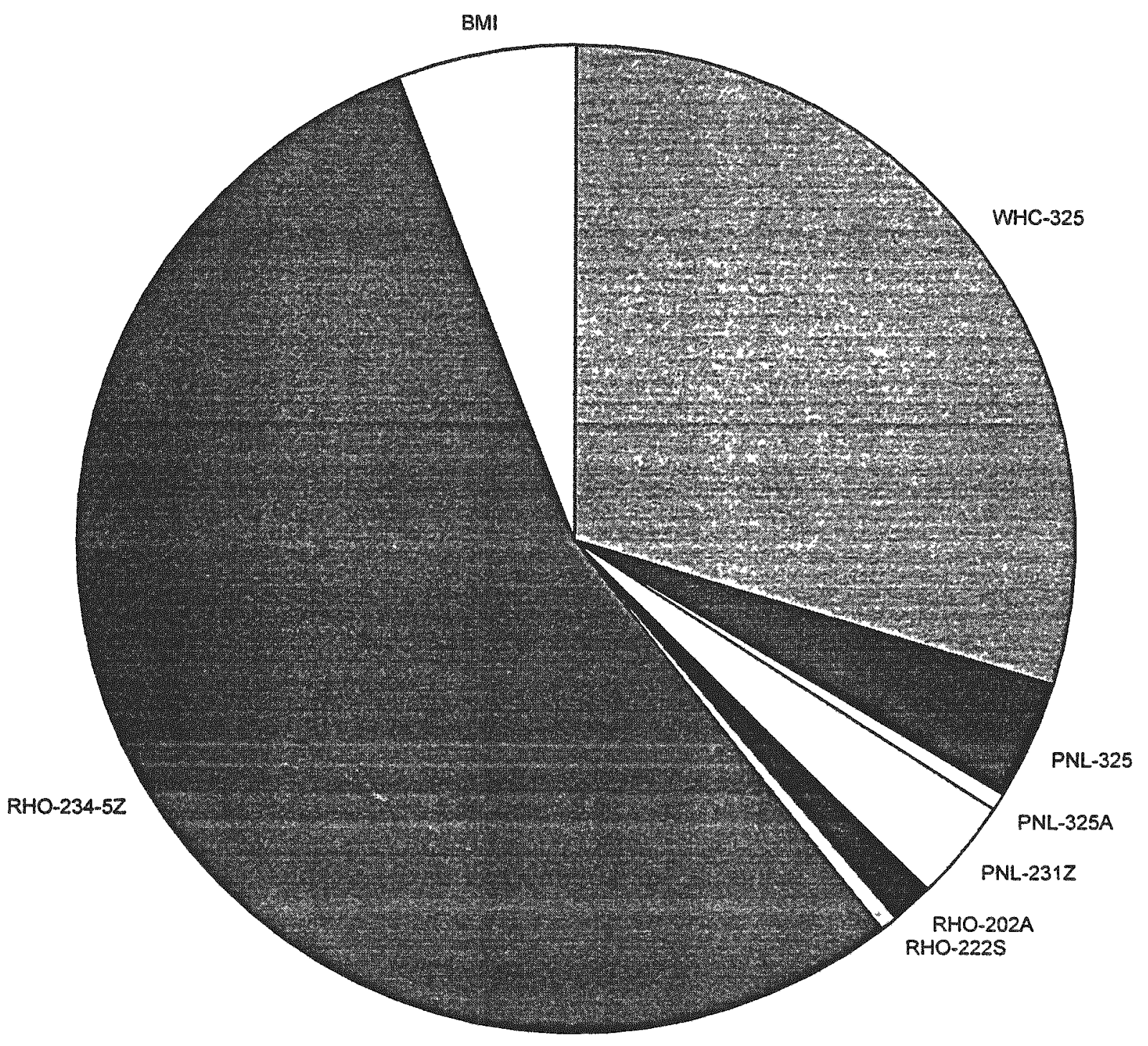


Module 1 contains waste that is $80 \%$ from the PFP. $13 \%$ from building $325,7 \%$ from 2312 , and less than $1 \%$ from building $222-S$. These proportions can be seen in Figure 5.1 19. All generators of waste stored in Module 1 have already been described above.

Figure 5.1-19. Relative Percentage of Drums in Module 1 by Generator.

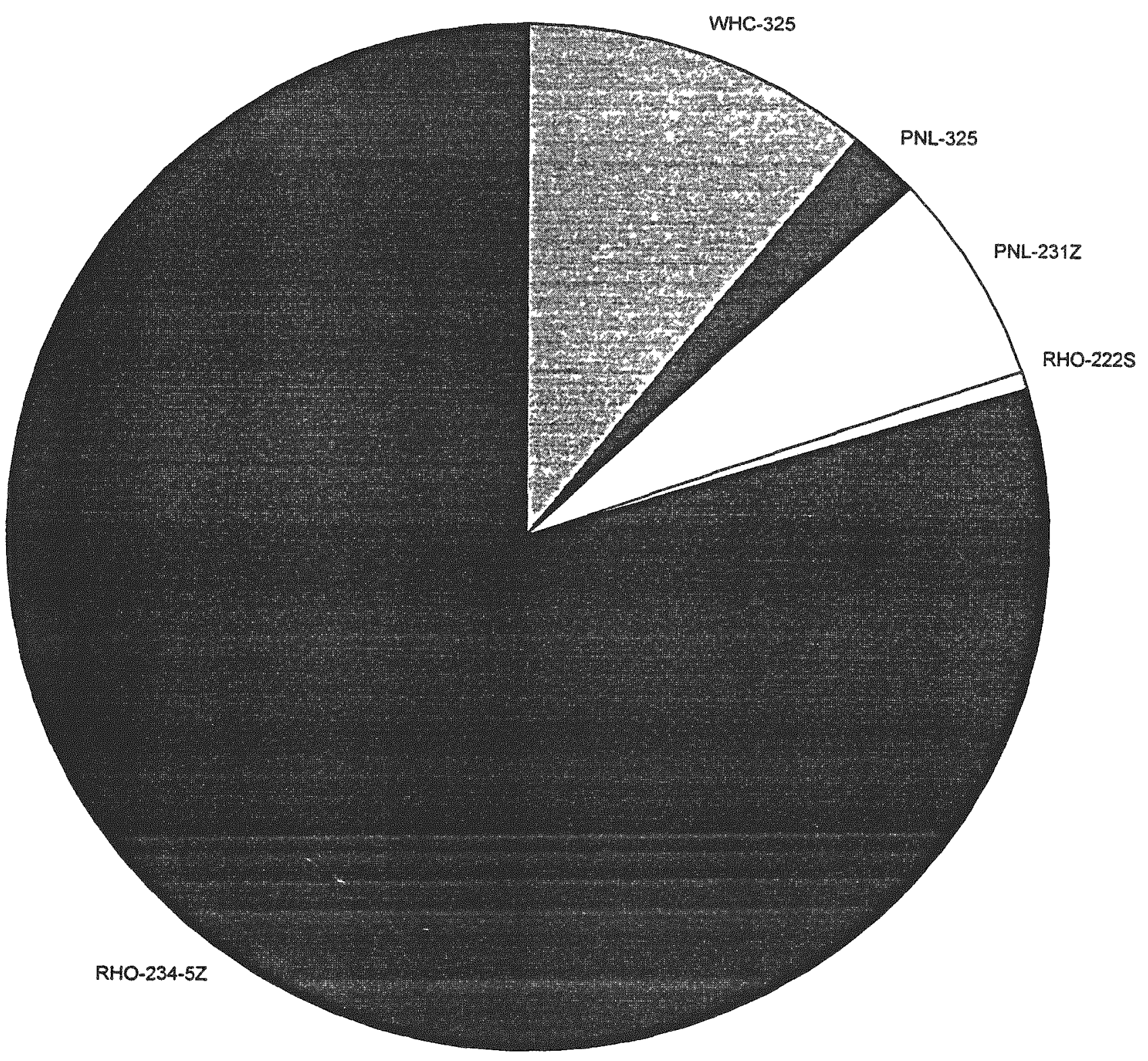




\subsection{TYPE OF PROCESS USED TO GENERATE OR PACKAGE THE WASTE}

As illustrated in the previous section, batching the waste drums in Trench 4 C- 04 by generator leads to some relatively small groups of drums to be processed in WRAP Module 1. Because the wastes procedure by some generators are the result of very similar operations or are packaged in a similar manner, it may be advantageous to create batches of drums generated by more than one facility. For trench $4 \mathrm{C}-04$ the following batches my be used:

- 300 Area Wastes - This batch includes wastes generated by both WHC and PNL in the 308, 324, 325, 325-A and 340 buildings. During the period from 1978 to 1984 , when these wastes were generated, the primary missions for these buildings centered around the research and development of reactor designs and fuels for nuclear poor generation, primarily the Fast Breeder Reactor Program.

In addition to the wastes being generated by similar processes, the wastes from the 300 Area were often packaged and shipped from a Central location. It is know, for example, that wastes originating in 325 were sometimes designated as 308,324 or 340 waste because they were shipped from one of those buildings.

- Laboratory Facilities - Laboratory facilities may be logically grouped in a batch because of the higher change of the presence of regulated hazardous chemicals, which were often packed in labpacks, in these drums. The reagents used in performing standard laboratory protocols are not always the same chemicals seen used in the chemical reprocessing plants on-site, even when the laboratory's primary mission was process control.

In this section, the 222-S laboratory and the PUREX analytical laboratory (202AL) were batched. The PFP also operated an analytical laboratory; however. the drums were not designated differently form process waste drums. It may be that NDE at the trench will provide sufficient information to distinguish these drums, which could then be batched with 222-S and 202-AL.

- Plutonium Processing - The 233-S facility waste found in this trench was from D \& D operations in 1979 and is probably contaminated with weapons grade (nominally $6 \%{ }^{240} \mathrm{Pu}$ ) plutonium. The $231-\mathrm{Z}$ facility normal $\mathrm{Pu}$, which consisted of $6.3 \%{ }^{240} \mathrm{Pu}$ and $0.6 \%{ }^{241} \mathrm{Pu}$, is similar.

Waste from 234-5Z (PFP) was also placed in this category and is probably a $50: 50 \mathrm{mix}$ of $6 \%$ and $12 \%{ }^{240} \mathrm{Pu}$. It is known that $231-\mathrm{Z}$ wastes were often shipped and designated as $234-5 \mathrm{Z}$ wastes.

- PUREX - The wastes produced by PUREX process were not judged to be sufficiently similar to allow batching with waste from any other generator in this trench.

- Offsite D \& D Waste - Most of the waste in Trench 4C-04 that was generated offsite is related to Breeder Reactor Program fuel production, testing, etc. and is contaminated with nominally $12 \%{ }^{240} \mathrm{Pu}$. The wastes from B \& $W$. WARDMNFD, and GE Vallectios come from the D \& D of glovebox lines used 
to produce fuels for the FFTF or for the research and development of FFTF and similar fuels.

At least some of the wastes from all three of these off-site generators was packaged with high density foam ("Instapak") to stabilize package contents during shipment to Hanford. This foam is described in WHC-EP-0672, Appendix G (VejVoda et al. 1993). Drums foamed in this manner may present some unique challenges during processing in WRAP Module 1.

- Other - This batch includes generators with only a nominal number of waste drums stored in this trench.

The wastes from these generators are not sufficiently characterized to allow them to be included in the pervious batches. This batch includes drums from BMI, ESG, Exxon Nuclear, the 200 West Tank Farms (2WTF) and PNL's 209-E facility

Table 5.2-1 provides a summary of trench 4C-04 modules sorted into the batches described above. Figures 5.2-1 through 5.2-19 show the relative numbers of drums in each batch for modules 19 through 1 , respectively. 
Table 5.2-1. Number of Drums in Batches Based on Waste Generator Process and/or Packaging Similarities.

\begin{tabular}{|c|c|c|c|c|c|c|c|c|c|c|c|c|c|c|c|c|c|c|c|}
\hline Module & 7 & 2 & 3 & 4 & 5 & 6 & 7 & 8 & 9 & 10 & 11 & 12 & 13 & 14 & 15 & 16 & 17 & 18 & 19 \\
\hline The 300 Area & 93 & 246 & 88 & 124 & 206 & 190 & 74 & 92 & 85 & 22 & 57 & 25 & 73 & 29 & 42 & 77 & 23 & 38 & 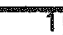 \\
\hline The PUREX Pfant & 0 & 10 & 0 & 66 & 0 & 0 & 0 & 0 & 0 & 0 & 0 & 0 & 144 & 51 & 2 & 0 & 12 & 9 & 0 \\
\hline Laboratories & 4 & 3 & 0 & 6 & 0 & 0 & 0 & 0 & 0 & 0 & 0 & 0 & 0 & 0 & 0 & 0 & 0 & 0 & 0 \\
\hline Plutonium Processing & 621 & 418 & 478 & 406 & 356 & 322 & 526 & 457 & 399 & 263 & 173 & 137 & 196 & 303 & 244 & 249 & 477 & 522 & 285 \\
\hline Off-Site D\&D Waste & o & 0 & 0 & 0 & 0 & 0 & 0 & o & 52 & 259 & 282 & 93 & 150 & 116 & 97 & 70 & 50 & 0 & 0 \\
\hline Other generators & 0 & 42 & 0 & 0 & 0 & o. & 6 & 9 & 41 & 0 & 13 & 0 & 0 & 0 & 0 & 0 & 10 & 6 & 3 \\
\hline & & & & & & & & & & & & & & & & & & & \\
\hline \multicolumn{20}{|l|}{ All Generators } \\
\hline TOTAL & 718 & 719 & 566 & 602 & 573 & 519 & 576 & 585 & 577 & 544 & 525 & 255 & 533 & 499 & 385 & 336 & 572 & 575 & 289 \\
\hline
\end{tabular}


Figure 5.2-1. Number of Drums in Waste

Generator Batches for Module 19.

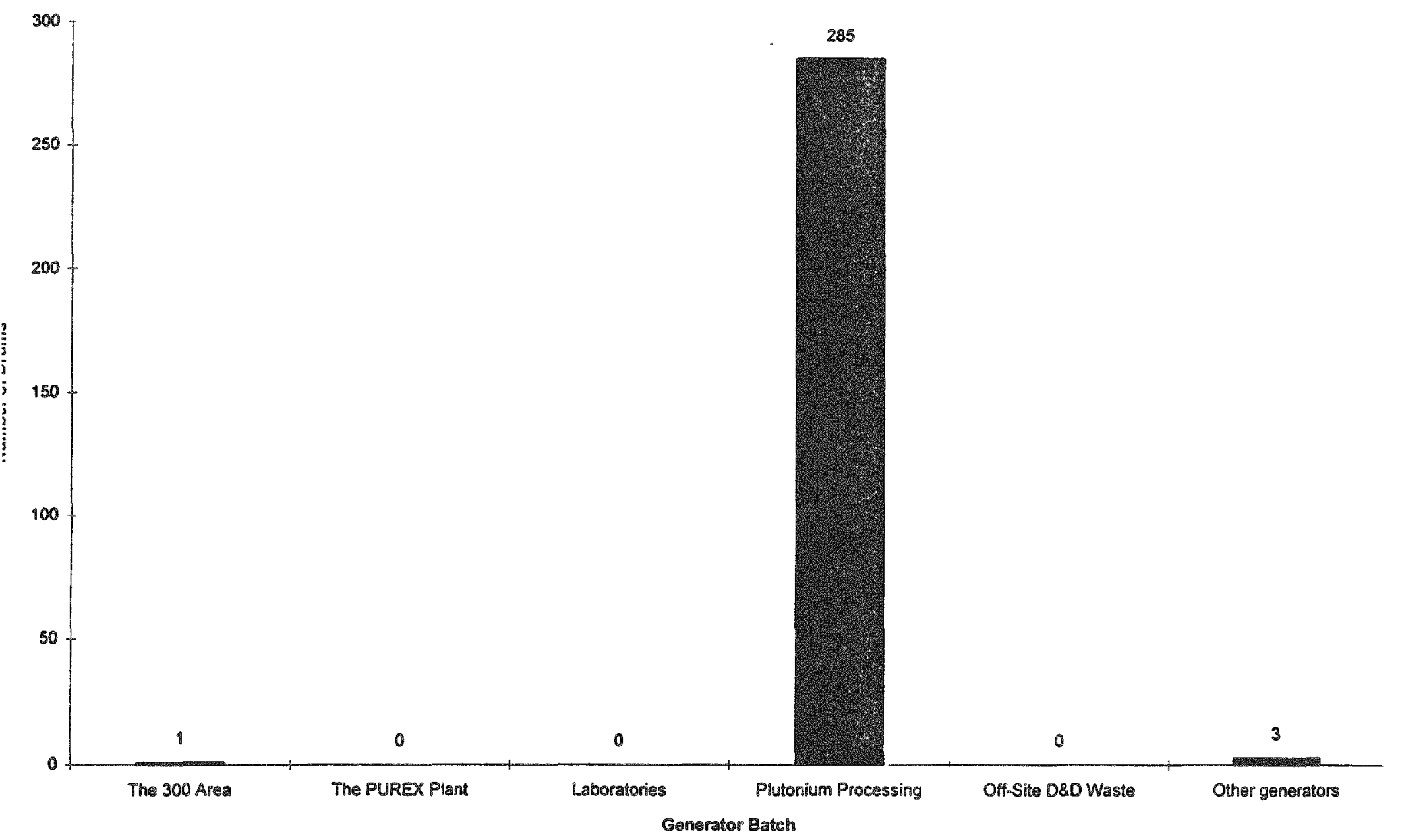


Figure 5.2-3. Number of Drums in Waste

Generator Batches for Module 17.

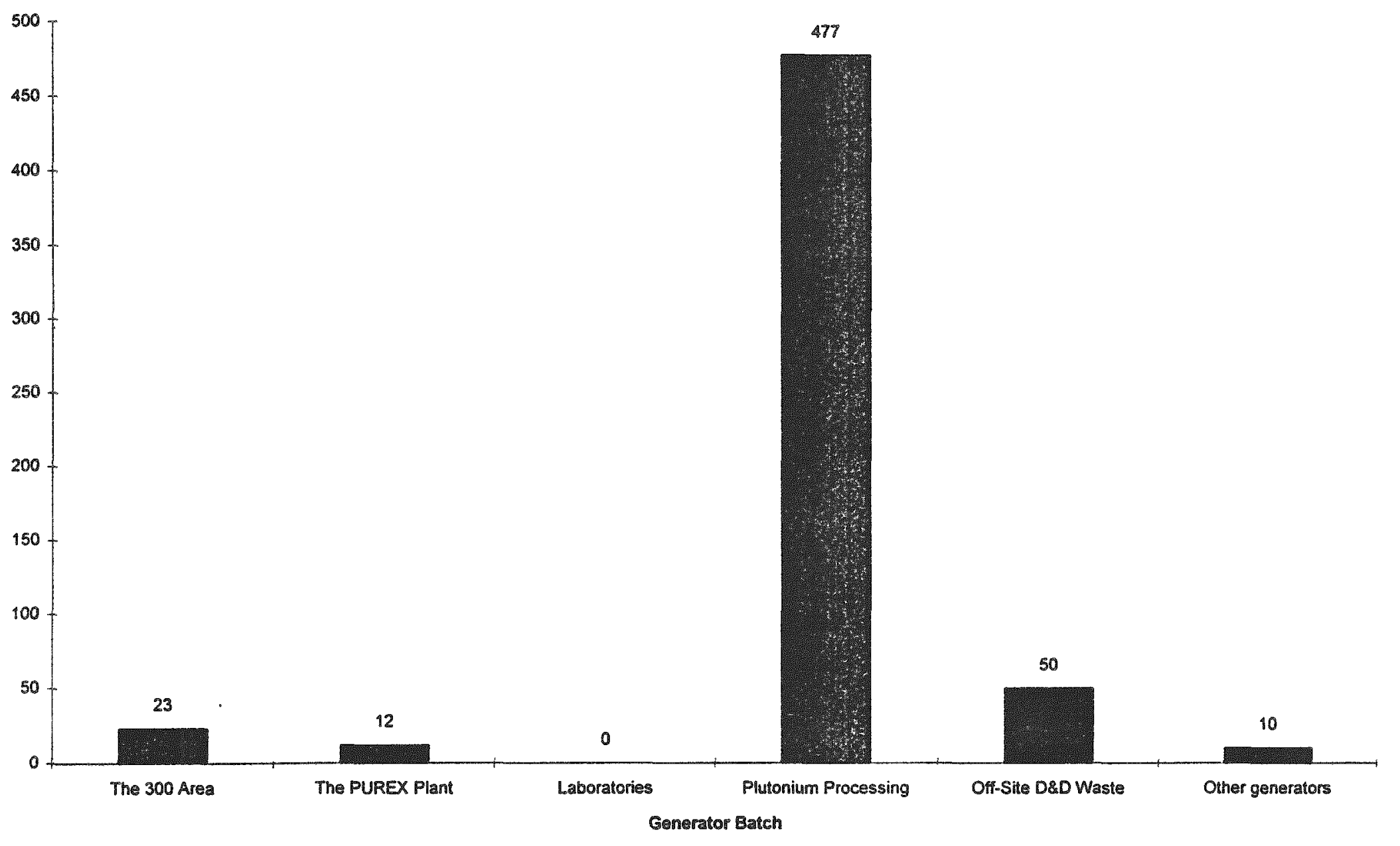


WHC-SD-W026-TI-009, Rev.O

Figure 5.2-4. Number of Drums in Waste

Generator Batches for Module 16.

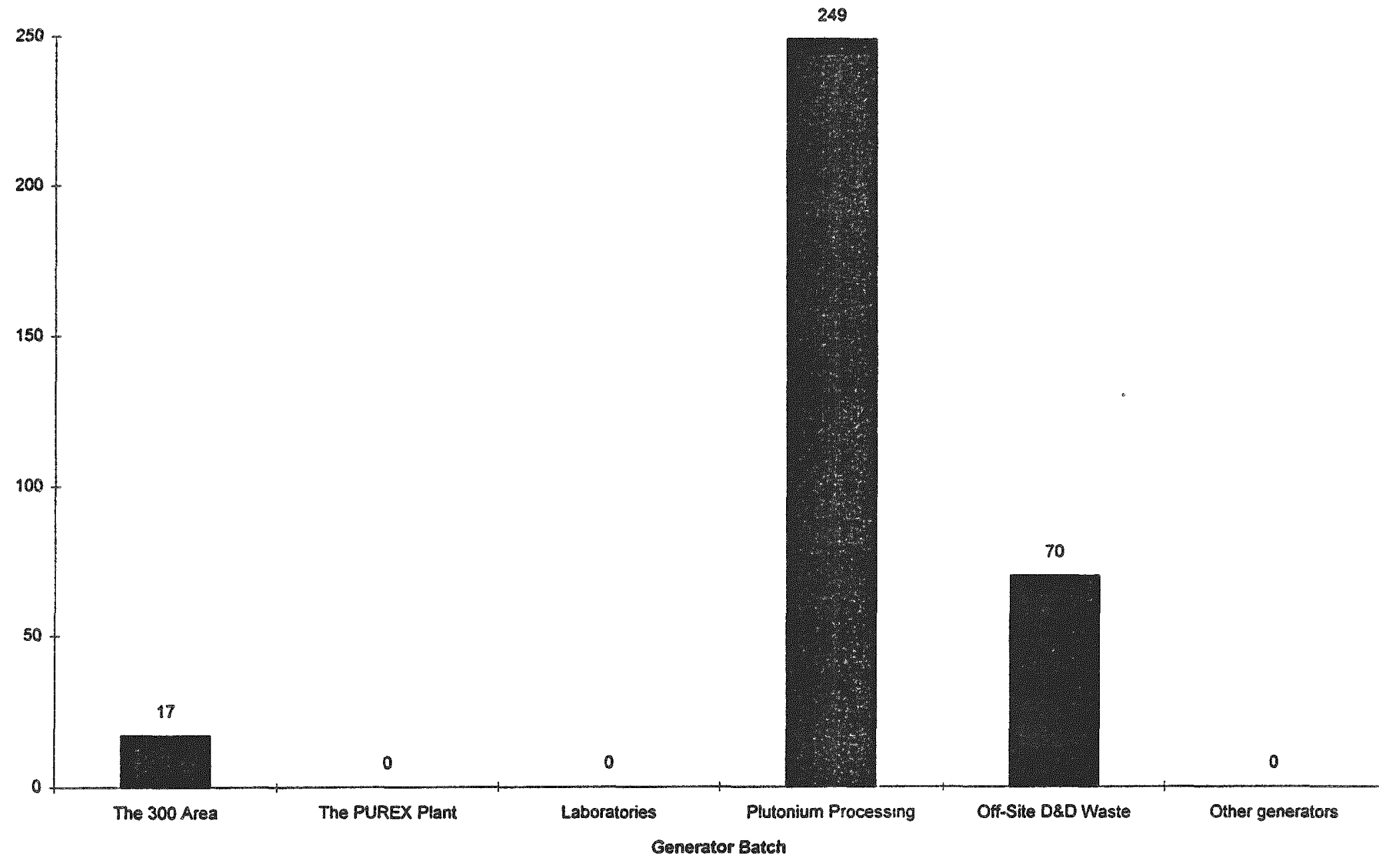


Figure 5.2-5. Number of Drums in Waste

Generator Batches for Module 15.

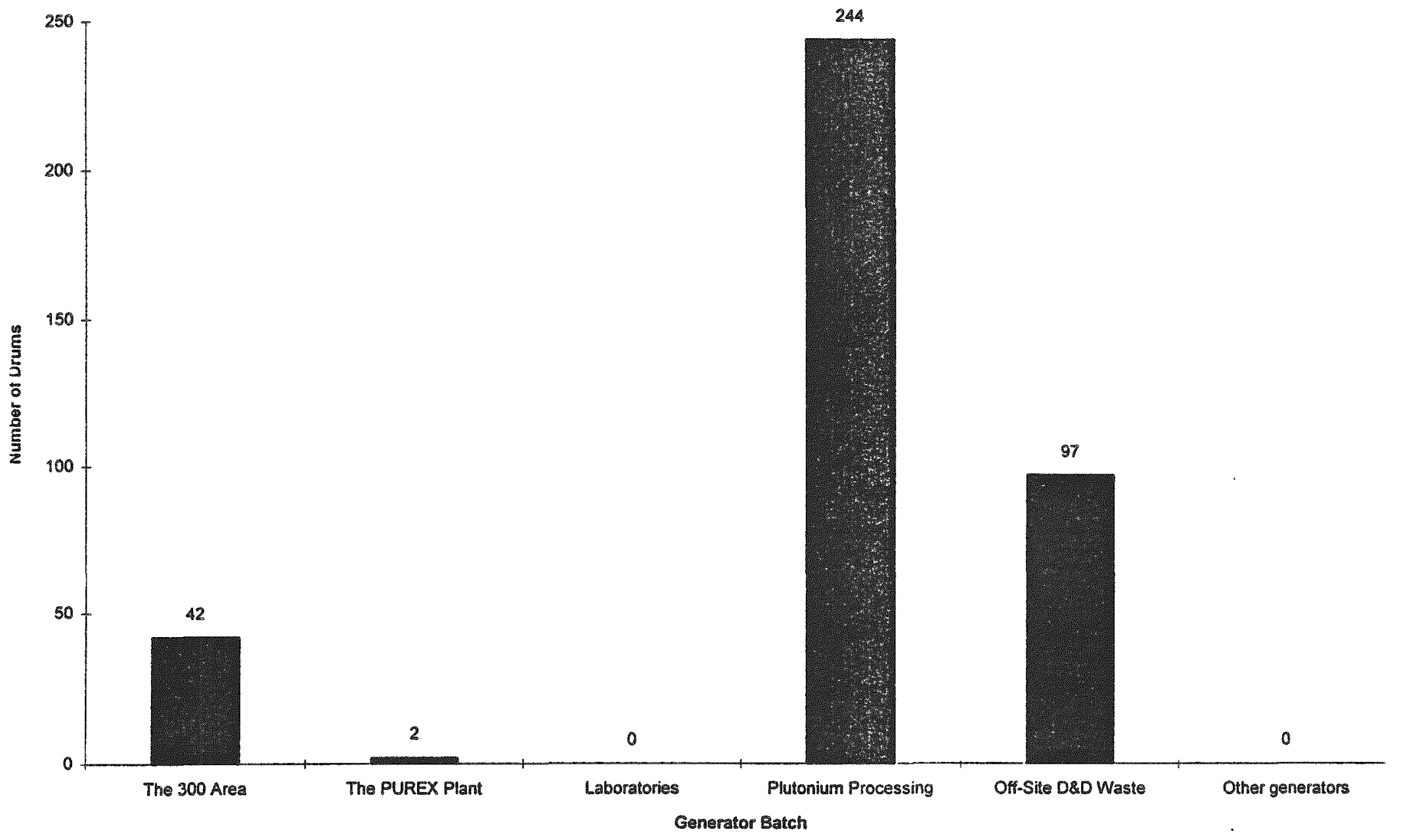


Figure 5.2-6. Number of Drums in Waste

Generator Batches for Module 14.

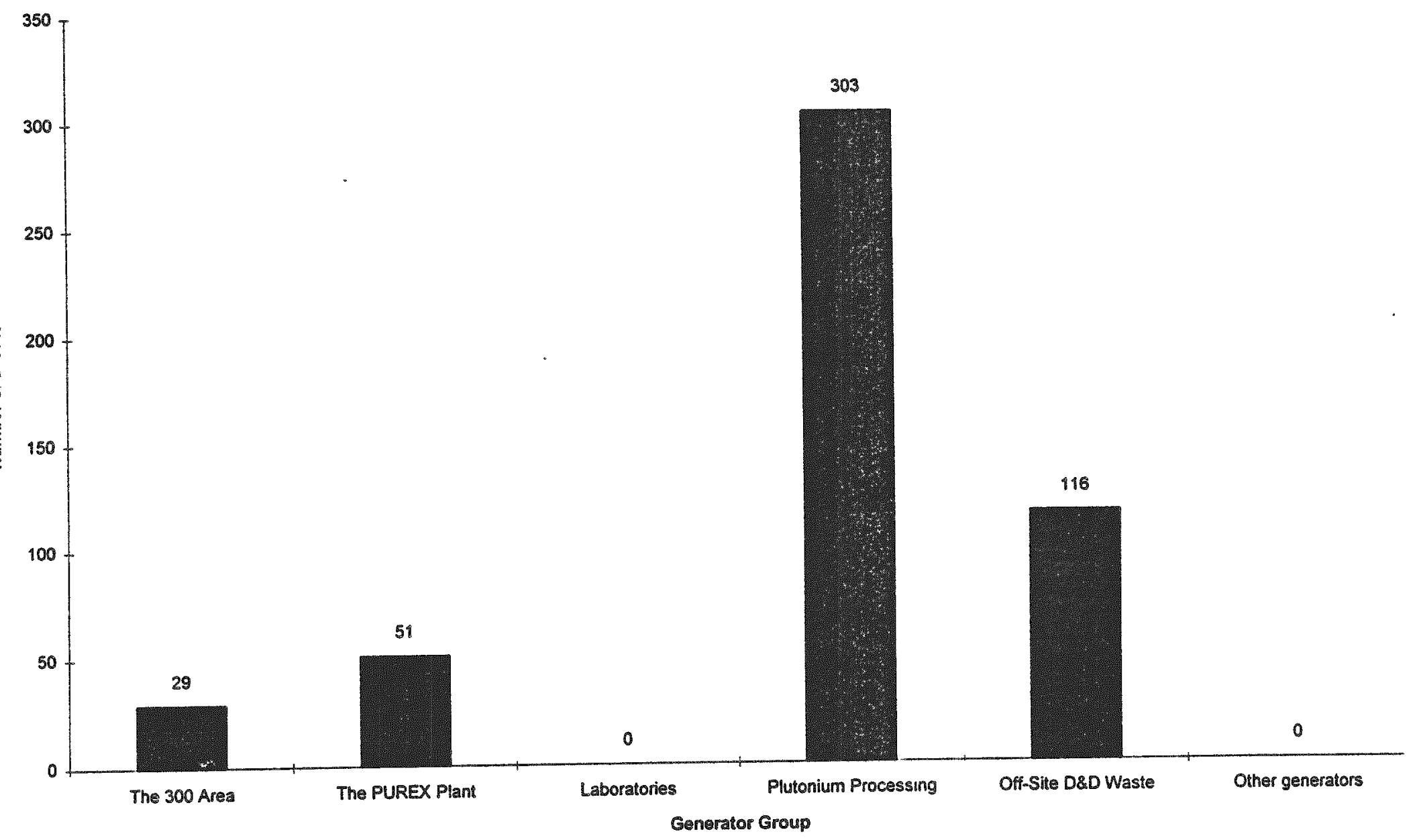


WHC-SD-W026-TI-009,Rev.0

Figure 5.2-7. Number of Drums in Waste

Generator Batches for Module 13.

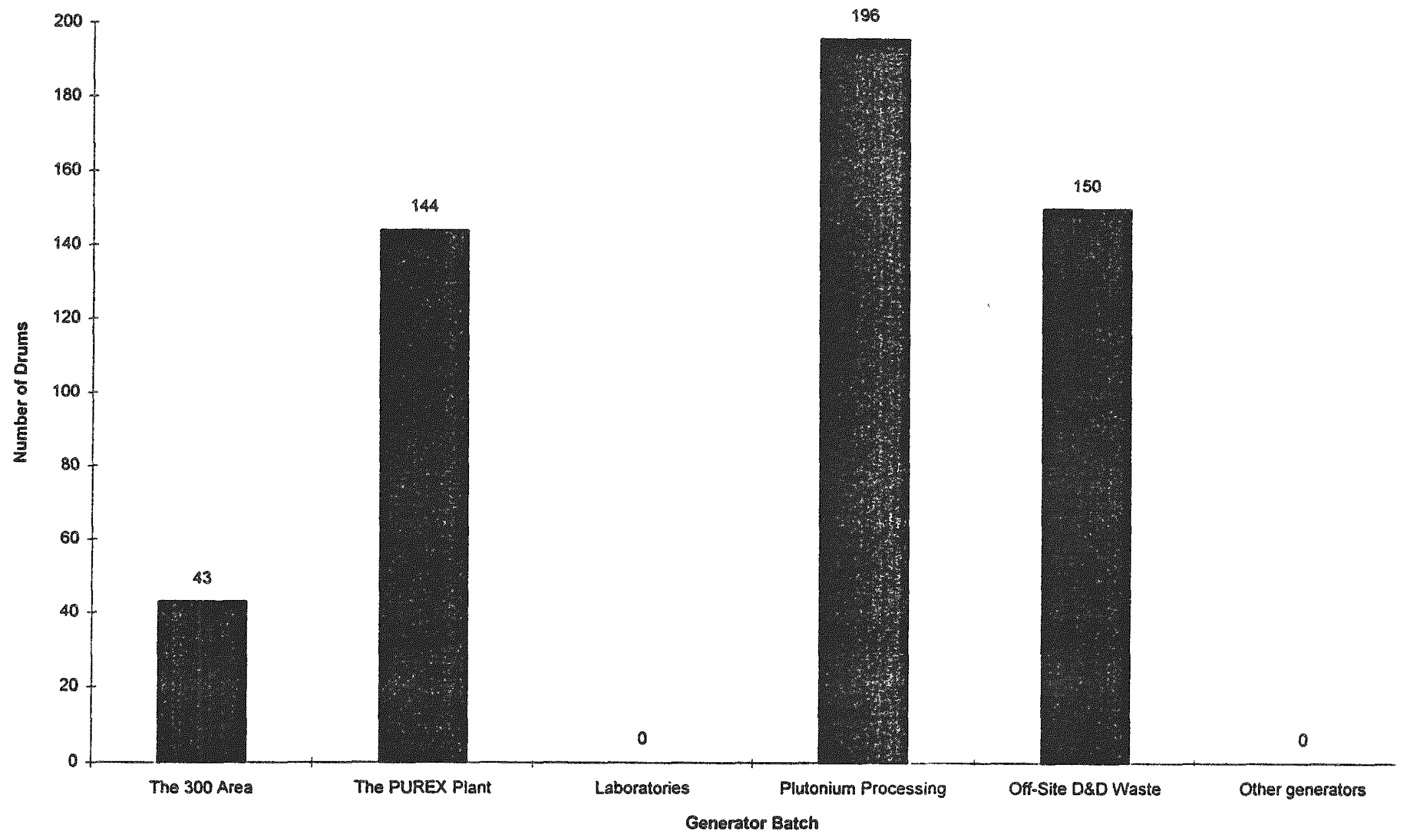


WHC-SD-W026-Tl-009, Rev. O

Figure 5.2-8. Number of Drums in Waste

Generator Batches for Module 12.

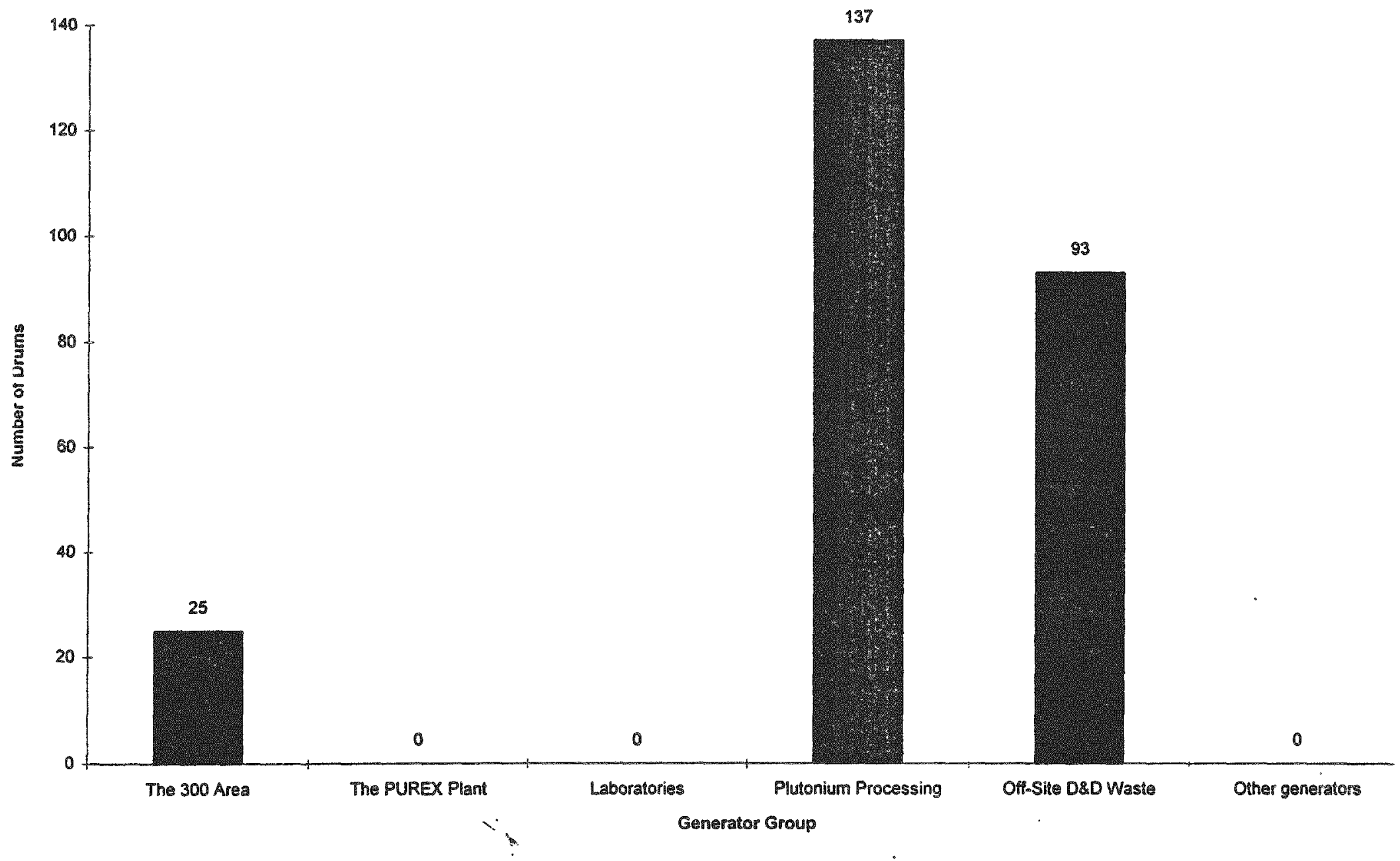


Figure 5.2-9. Number of Drums in Waste

Generator Batches for Module 11.

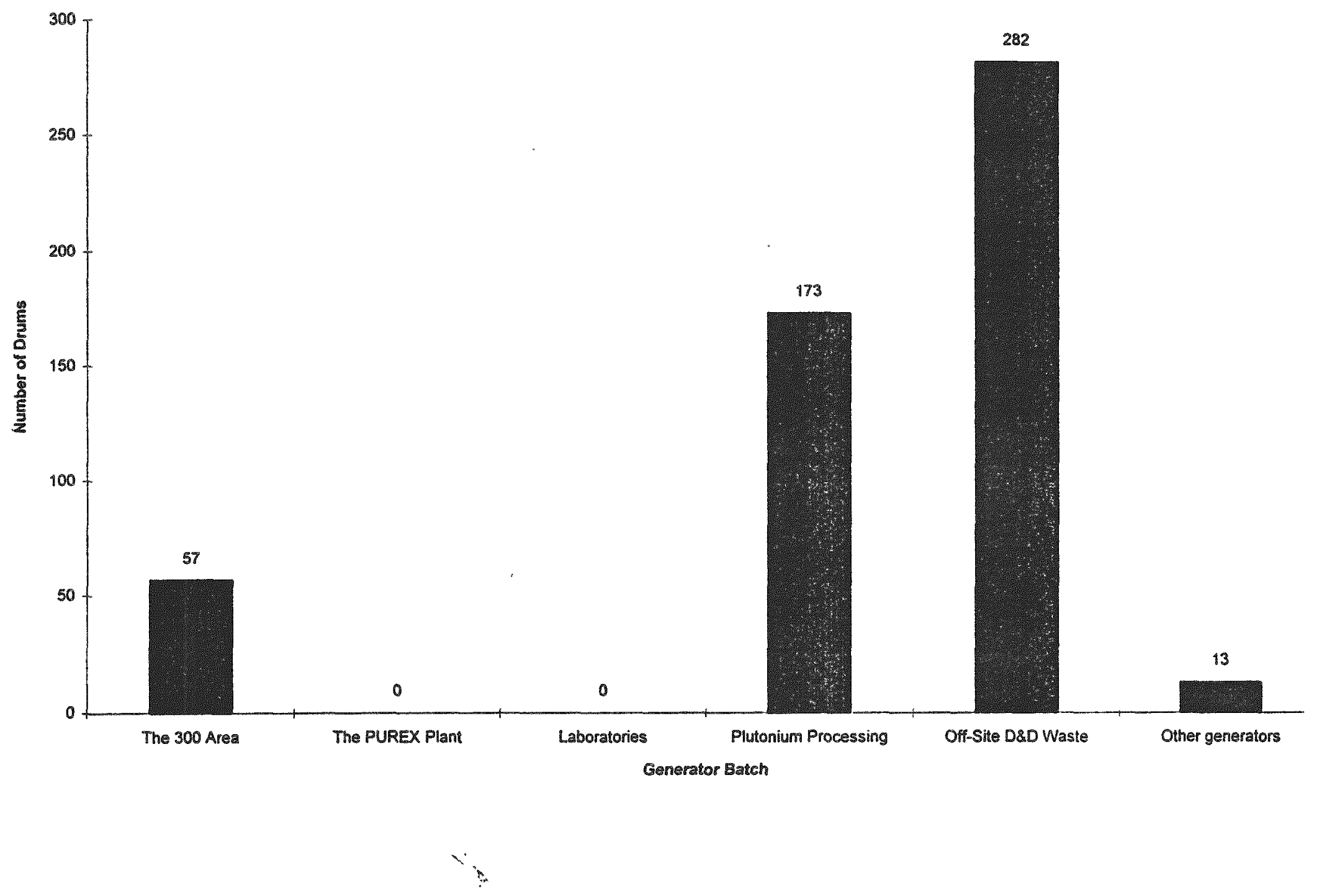


WHC-SD-W026-TI-009, Rev. O

Figure 5.2-10. Number of Drums in Waste

Generator Batches for Module 10.

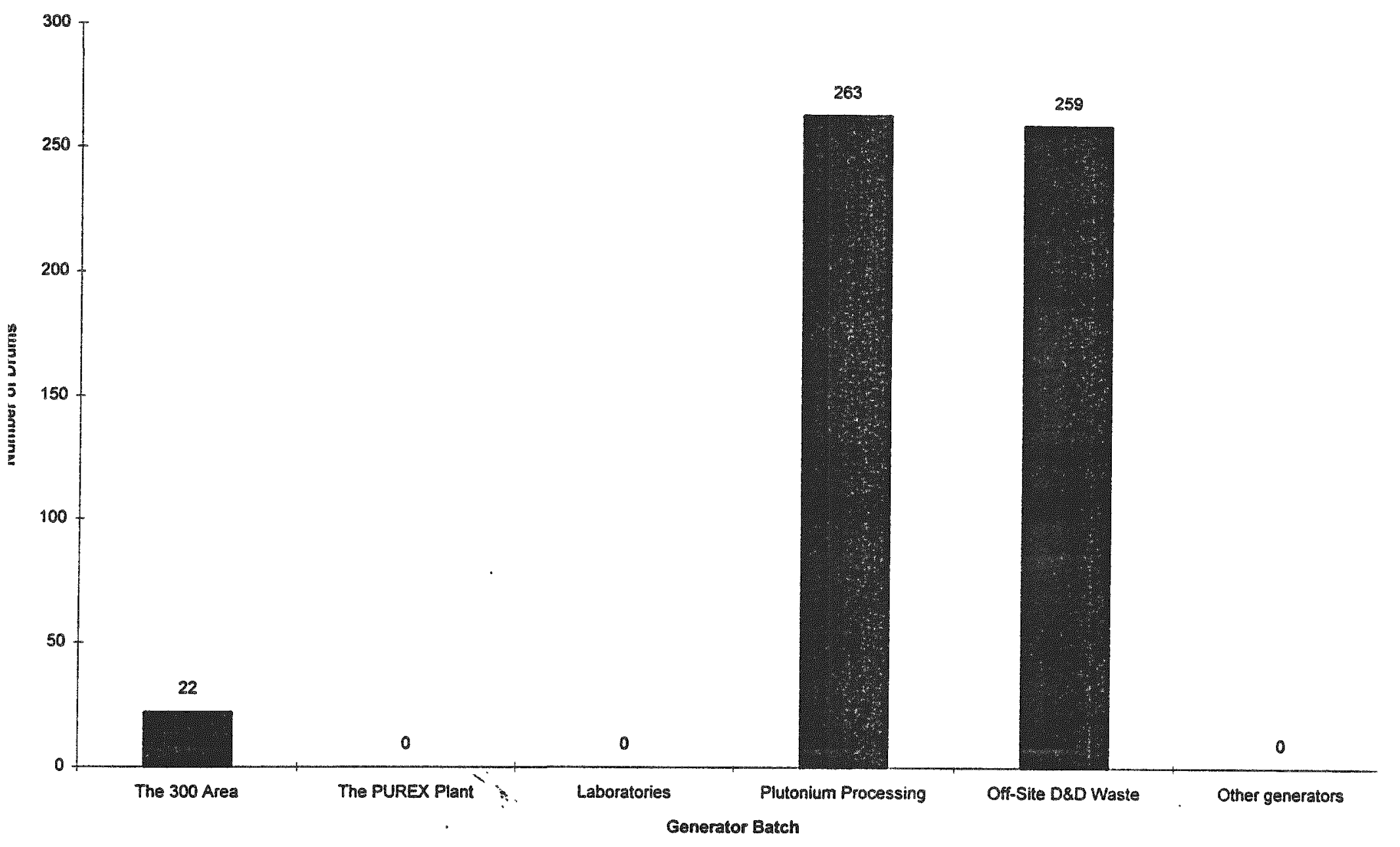


WHC-SD-W026-TI-009, Rev. O

Figure 5.2-11. Number of Drums in Waste

Generator Batches for Module 9.

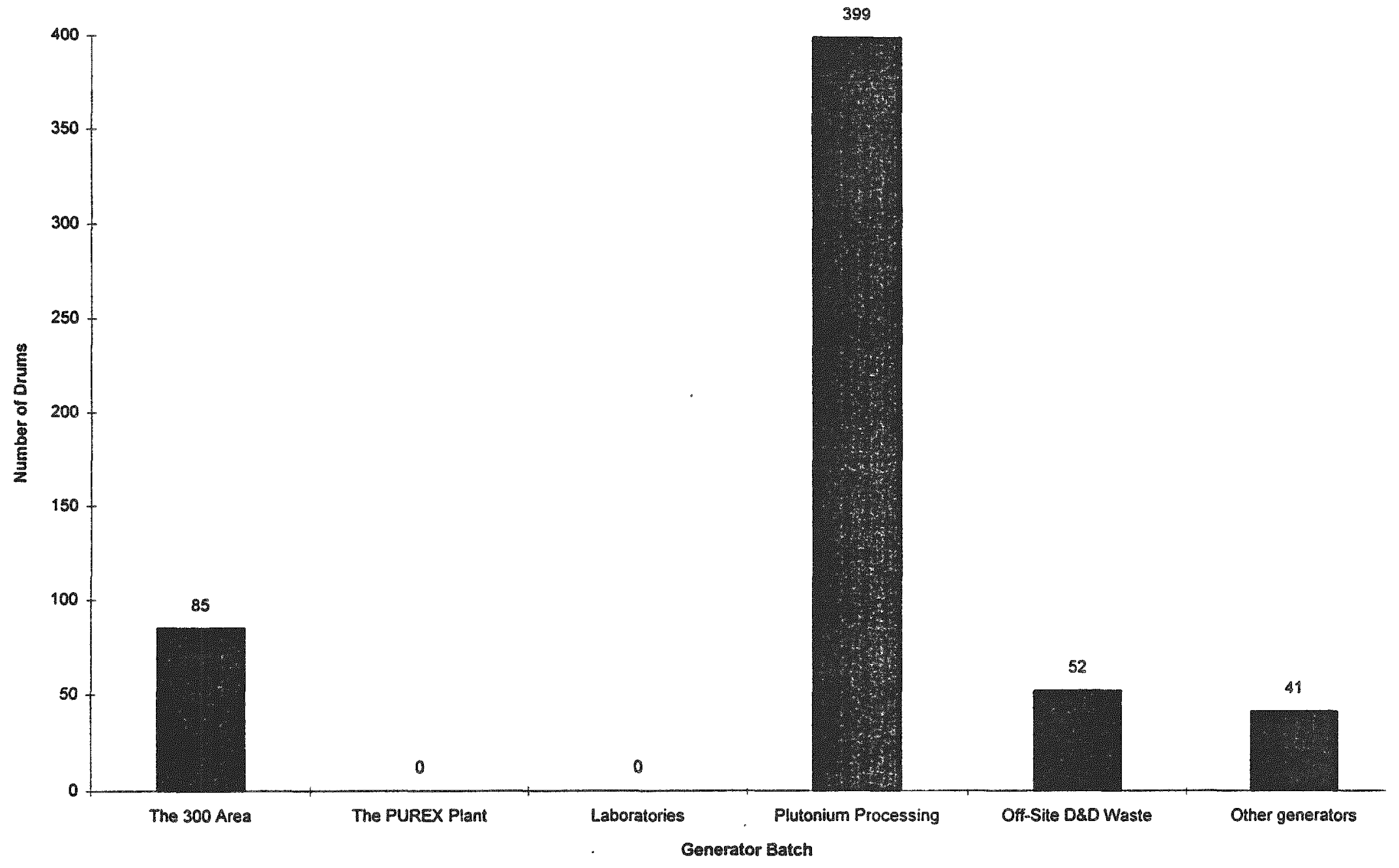


WHC-SD-W026-TI-009, Rev。O

Figure 5.2-12. Number of Drums in Waste

Generator Batches for Module 8.

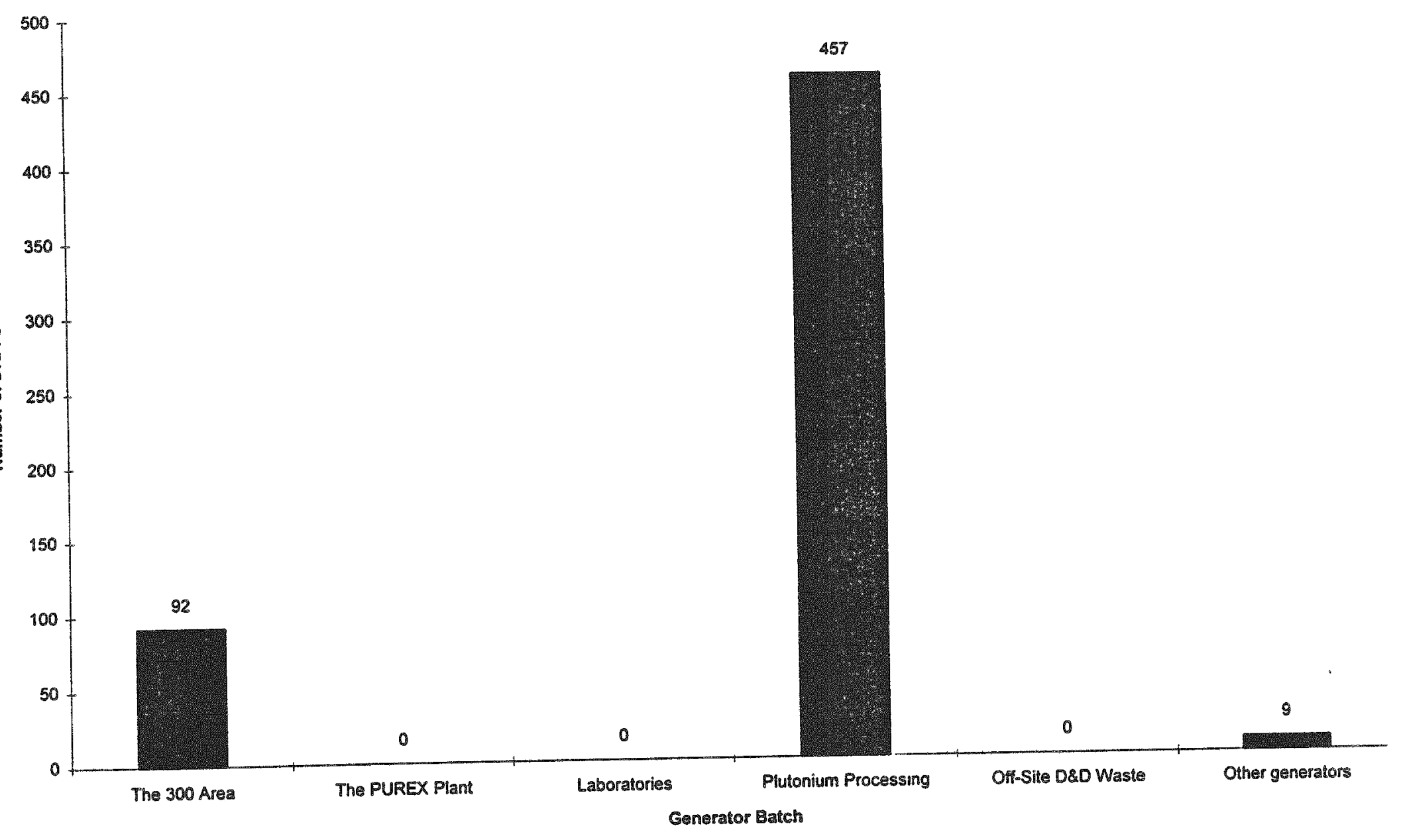


Figure 5.2-14. Number of Drums in Waste Generator Batches for Module 6.

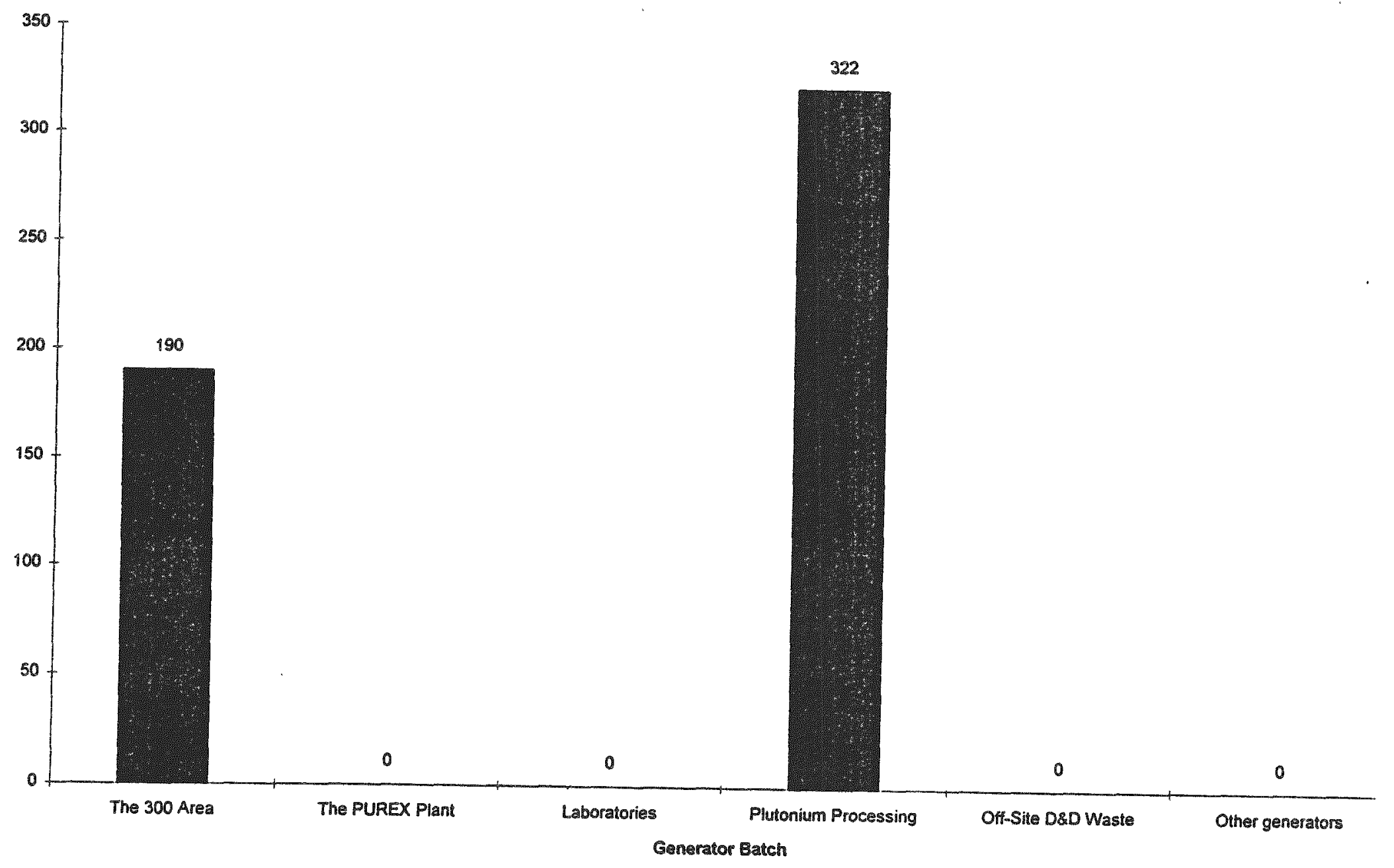


Figure 5.2-15. Number of Drums in Waste Generator Batches for Module 5.

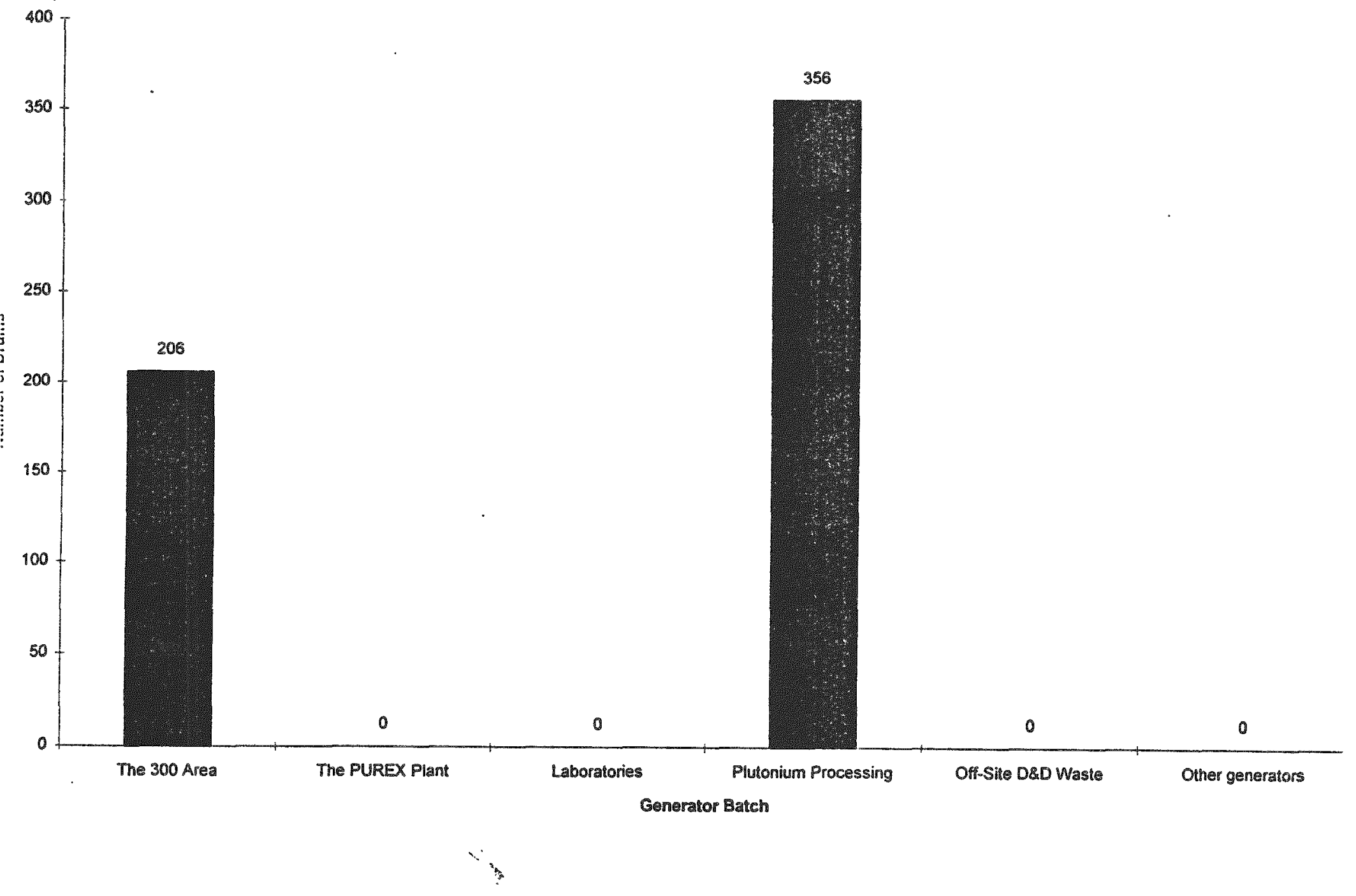


WHC-SD-W026-TI-009, Rev. O

Figure 5.2-16. Number of Drums in Waste

Generator Batches for Module 4.

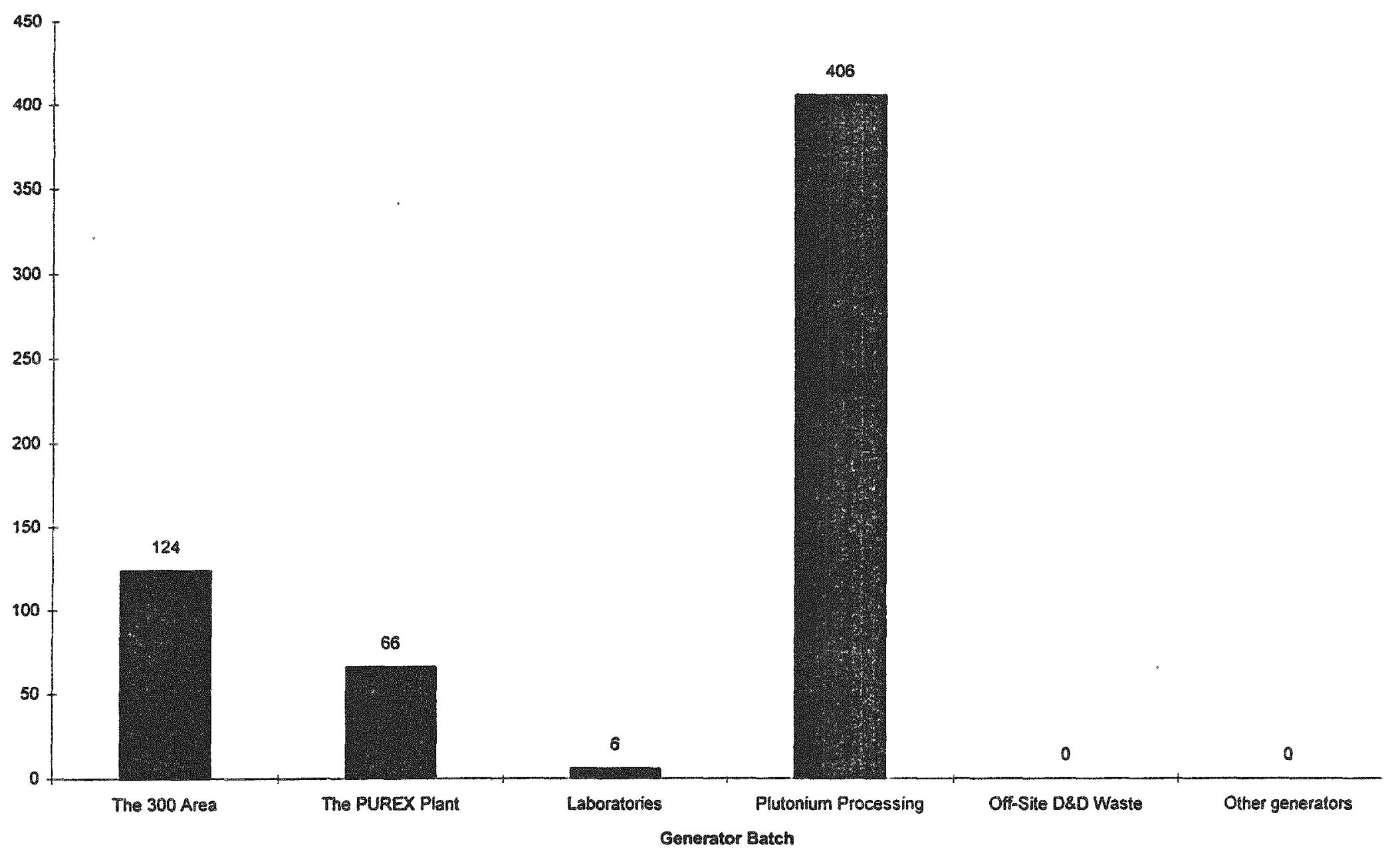


WHC-SD-W026-Tl-009,Rev.0

Figure 5.2-18. Number of Drums in Waste

Generator Batches for Module 2.

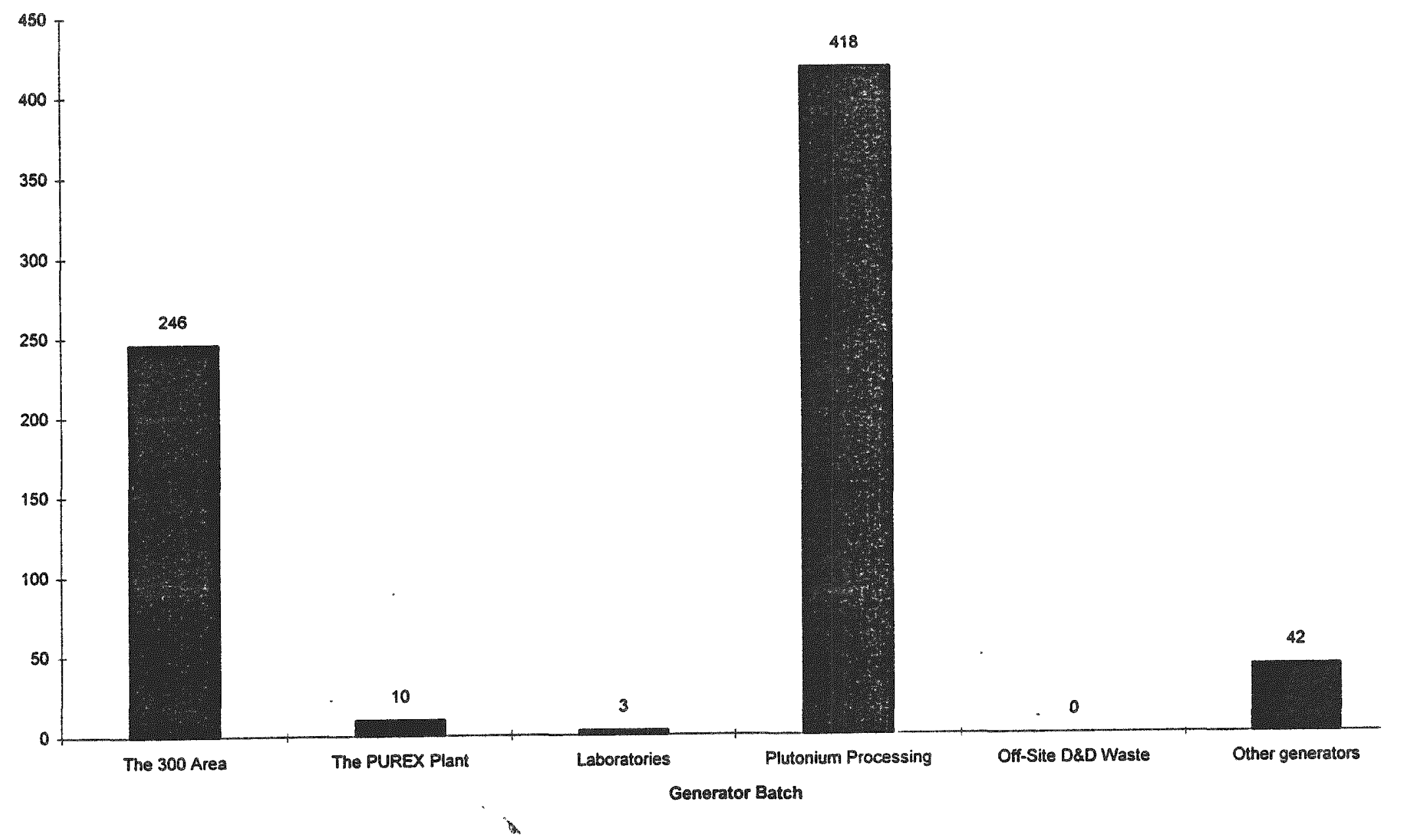




\subsection{PHYSICAL WASTE FORM}

The goal of batching by physical waste form is to increase WRAP Module 1 processing efficiency by dealing with batches that consist of similar physical types of waste materials, and to consolidate drums containing compactable contents. The information used for batching the trench by physical waste form is from the SWITS database. Waste form data were not entered into the database until 1978. After this date, the information available includes the waste contents description as well as special SWIMS codes that were applied to the wastes.

A comparison of the data for each module shows that, although there is some variation, the overall physical contents and their proportions are fairly consistent from module to module. Thus, an examination of the combined data from all modules will serve as the summary for many of the individual modules; minor differences for individual modules will be discussed separately.

The physical waste forms listed for 208-L drums in trench 4C-04 are shown in Table 5.3-1. sorted by generator. Figure 5.3-1 shows the percentage of the total number of drums that contains each physical type of waste. Note that the sum of these percentages will not be 100 , since most drums contain more than one type of waste and, therefore, are included in this figure in more than one column.

The first item of note is that the four physical waste forms that are located in the largest percentages of drums are all soft and compatible as well as combustible. Plastic and polyurethane are located in $61 \%$ of the drums and, of those drums, comprise an average approximately 40 volume $\%$ of their total contents (3\% min.; $90 \%$ max.). Most plastic and polyurethane was generated at the PFP, although almost all generators contributed to the total.

Paper and cardboard account for approximately $59 \%$ of the total number of drums. In these drums, paper and cardboard make up about $35 \%$ of the drum volume $12 \% \mathrm{~min} . ; 90 \%$ max). Most of this waste stream was generated in the PFP

Rubber is expected in $44 \%$ of the drums, which averages approximately $15 \%$ of the total content of each drum $(1 \% \mathrm{~min} . ; 50 \% \max )$. This waste was mostly generated at the PFP.

Cloth, rags, and nylon are found in $26 \%$ of the drums, and comprise about $35 \%$ of their total contents $(1 \% \mathrm{~min} .: 85 \% \max$.$) . Most of these materials were generated at the$ PFP.

In addition to these four waste forms, there are also much smaller percentages of other compatible, combustible items, including absorbent, kitty litter, and vermiculite (found in $3 \%$ of the drums): cotton and kotex (2\%); foam and styrofoam (less than $1 \%$ ): non-asbestos insulation (less than 1\%); and leather (less than 1\%). These constituents comprise an average of $5-15 \%$ of the total volume of the drums that they are contained in $(1 \% \min . ; 55 \% \max$.$) .$ Unlike the plastic, paper, rubber, and cloth, these rarer items are not found in all of the modules (in some cases, they are found in only one module) and are not mainly generated in any one location.

The second largest group of physical waste forms is much smaller than the first, and 
consists of wastes that are not compressible or combustible. The most significant group contains metal, iron, galvanized metal, and sheet metal and accounts for $15 \%$ of the total drums. These metals average about $25 \%$ of the volume of the drums they are located in $12 \%$ min.: $100 \%$ max. 1 . About one third of this waste was generated by the PFP. There are many other types of non-combustible, non-compactable waste forms also located in this trench, including aluminum (found in less than $1 \%$ of the total drums), cement ( $2 \%$ of the drums). ceramics (less than $1 \%)$, concrete $(2 \%)$, fiberglass $(2 \%)$, glass $(7 \%)$, marble (much less than $1 \%)$ rocks and gravel (less than $1 \%$, and stainless steel (less than 1\%). These materials have an average volume ranging from $5-15 \%$ of the total volume for the drums they are found in $(1 \% \min : 45 \% \max$.$) . Unlike the larger group of metals, these more rare constituents are$ not present in many of the modules; in fact, some of them are located in only one module.

There are also some items that are combustible but not highly compressible, although each is found in a very small percentage of the total number of drums. These physical waste forms include floor tile (found in less than $1 \%$ of the total drums), paints and Lucite $(2 \%)$, solvent and thinner (less than 1\%), wax (much less than 1\%), and wood, lumber, and plywood $(11 \%)$. These constituents are found in only a few of the modules, and comprise approximately $10 \%$ of the volume of the drums that contain them ( $1 \% \min . ; 67 \% \max$.$) .$

Miscellaneous, unknown, or "other" waste is listed for approximately $3 \%$ of the drums. Most of these drums are located in the earliest modules (1 through 5), since physical content records were not required to be kept when these wastes were emplaced. Many of the drums emplaced during this time frame simply do not have anything listed in the physical content category, including a miscellaneous or unknown designation.

Although not all of the modules contain exactly this mix of physical waste types and each type of waste is not found in every module, the majority of modules are similar to this overall description. Variances from the overall description above are discussed for each module in the following paragraphs. Wastes stored in trench $4 \mathrm{C}-04$ with unknown module locations are discussed last. 
WHC-SD-W026-TI-009, Rev. 0

Table 5.3-1. Number of Drums Listing Specific by Generator.

\begin{tabular}{|c|c|c|c|c|c|c|c|c|c|c|c|c|c|c|c|c|c|c|c|c|c|}
\hline & $\mathbb{8}$ & $\begin{array}{l}8 \\
8 \\
\mathbb{8}\end{array}$ & 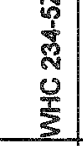 & $\begin{array}{l}\mathbb{v} \\
\vdots \\
\vdots \\
\end{array}$ & $\begin{array}{l}0 \\
0 \\
3 \\
\end{array}$ & $\begin{array}{l}0 \\
3 \\
0 \\
5 \\
\end{array}$ & 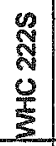 & $\begin{array}{l}0 \\
3 \\
5 \\
5 \\
5 \\
\end{array}$ & $\begin{array}{l}E \\
\sum \\
0 \\
0 \\
3 \\
3\end{array}$ & 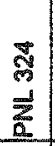 & $\begin{array}{l}\text { ని } \\
\text { है } \\
\frac{1}{\alpha}\end{array}$ & $\begin{array}{l}\mathbb{8} \\
8 \\
8 \\
2 \\
0\end{array}$ & $\begin{array}{l}0 \\
\frac{2}{3} \\
2 \\
2 \\
\end{array}$ & $\begin{array}{l}N \\
\frac{1}{2} \\
\sqrt[3]{2} \\
\frac{3}{2}\end{array}$ & 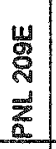 & $\begin{array}{l}3 \\
3 \\
8 \\
3\end{array}$ & $\begin{array}{l}0 \\
\mathscr{8} \\
4 \\
\end{array}$ & $\begin{array}{l}3 \\
\infty \\
\infty\end{array}$ & $\begin{array}{l}\overrightarrow{1} \\
\mathbb{2} \\
\mathbb{Q}\end{array}$ & 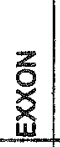 & $\sum_{\infty}^{\infty}$ \\
\hline $\begin{array}{l}\text { absorbant/kity litter/ } \\
\text { vermiculise }\end{array}$ & & & & 27 & 20 & 81 & & & & 4 & & & 14 & & & 194 & & & & & \\
\hline animal waste & & & & & & & & & & & 8 & & & & & & & & & & \\
\hline aluminum & & & & & & & & & & & & & & & & & & & 21 & & \\
\hline antifreezo & & & & & & & & & & & & & & & & & & & 24 & & \\
\hline boron & & & & & & & & & & & & & 7 & & & & & & & & \\
\hline carborundum & & & & & & & & & & & & & & & & & & & 21 & & \\
\hline cement & & & & 43 & & 93 & & & & & & & 9 & & & 29 & & & & & \\
\hline Ceramics & & & & & & & & & & & & & & & & 49 & & & & & \\
\hline cloth/ rags/ nylon & 204 & & 1875 & & 88 & 31 & & 32 & 6 & & 23 & & 9 & 3 & 10 & 256 & & 15 & & & \\
\hline concrete & & & & 43 & 55 & 64 & & & & 11 & & & 8 & & & & 9 & & & & \\
\hline copper metal & & & & & & & & & & & & & & & & & & & 21 & & \\
\hline cotton/ kotex & & & & & 53 & 39 & & & & & 6 & & & & & & & & 106 & & \\
\hline $\begin{array}{l}\text { dirt soil/ diatomaceous } \\
\text { earth }\end{array}$ & & & 9 & & & & & & & & 6 & & & & & 2 & & & 22 & & \\
\hline fiberglass & & & & & & & & & & & & & & & & 92 & & 85 & & & \\
\hline filters & & & 5 & & 82 & & & & & & & & & & & & & 363 & & & \\
\hline floor tile & 11 & & & & & & & & & & & & & & & & & & & & \\
\hline foam/styrofoam & & & & & & & & & & & & & & & & 14 & & & & & \\
\hline glass & & & 160 & 721 & 35 & 171 & & & & 14 & 54 & & 113 & & & 122 & & & 22 & & \\
\hline insulation (non asbestos) & & & & & & & & & & & & & & & & 23 & & & 22 & & \\
\hline lead & & & & & & & & & & & & & & & & & 9 & & & & \\
\hline leather & & & & & & & & & & & & & & & & 21 & & & & & \\
\hline marble & & & & & & & & & & & 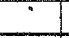 & & & & & & & & 11 & & \\
\hline $\begin{array}{l}\text { metal/ iron/galvanized } \\
\text { sheet }\end{array}$ & 24 & & 573 & 55 & 89 & 182 & & 26 & & 15 & 176 & & 106 & 17 & & 185 & 9 & & 54 & 1. & \\
\hline $\begin{array}{l}\text { miscellaneous/ unknown' } \\
\text { other }\end{array}$ & 17 & & 57 & & 26 & & & 7 & & & 2 & 4 & & & & 51 & & 61 & 35 & & 1 \\
\hline molybdenum & & & & & & & & & & & & & & & & & & & 22 & & \\
\hline oils & & & & & & & & & & & & & & & & 47 & & & 73 & & " \\
\hline organics & & & 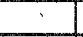 & & & & & & & & & & & & & 57 & & & & & \\
\hline paints/ lucite & & & 1 & & & & & & & & & & & & & 209 & & & 24 & & \\
\hline paperl cardboard & 196 & & 3771 & 63 & 152 & 206 & & 33 & 61 & 15 & 177 & & 112 & 20 & 32 & 422 & 28 & 510 & 1071 & & \\
\hline plastic polyurathane & 217 & & 3953 & 82 & 150 & 196 & & 33 & 6 & 16 & 176 & 1 & 112 & 20 & 32 & 422 & 28 & 510 & 107 & 11 & \\
\hline rock gravel & & & & & & & & & & & & & & & & 29 & & & & & \\
\hline rubber & 23 & & 3456 & 16 & 8 & 21 & & & 6 & & 154 & 1 & 19 & 16 & 22 & 412 & 19 & 495 & 41 & 11 & \\
\hline sludges & & & & & & 6 & & & & & & & & & & & & & & & \\
\hline solvents/ thinner & & & & & & & & & & & & & & & 13 & & & & & & \\
\hline stainless steel & & & & & & & & & & & & & & & & & & & 211 & & \\
\hline wax & & & & & & & & & & & & & 7 & & & & & & 1 & & \\
\hline wood/ lumber/ plywood & & & & 23 & 77 & 79 & & & & 12 & 5 & & 9 & 15 & & 250 & & 485 & 107 & & \\
\hline Total Number of Drums & 294 & 6 & 6610 & 82 & 711 & 204 & 71 & 45 & 61 & 16 & 288 & 21 & 143 & 222 & 32 & 453 & 491 & 572 & 136 & 11 & 42 \\
\hline
\end{tabular}


Percentage of Drums in Trench 4C-04 Listing Various Physical Contents

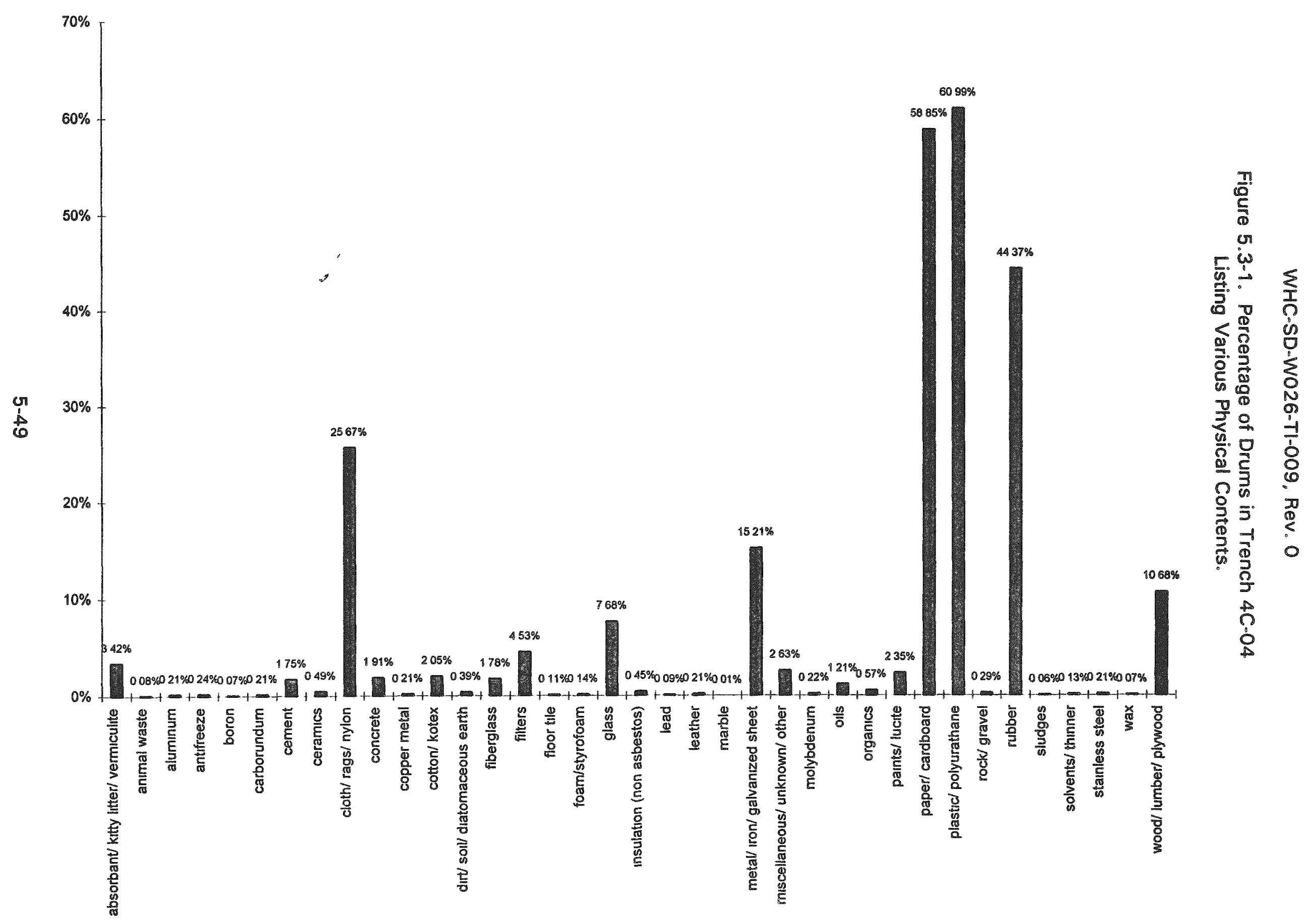


Figure 5.3-2 shows the number and percentage of physical contents listed for 208-L drums stored Module 19. Three drums ( $1 \%$ of the total number) contain a $9 \%$ volume of lead $19 \% \min . ; 9 \%$ max.) from the ESG. Lead is classified as a hazardous constituent.

Figure 5.3-2. Number and Percentage of Physical Contents Listed for 208-L Drums Stored.

\begin{tabular}{|c|c|c|c|c|c|}
\hline & 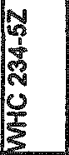 & 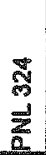 & $\begin{array}{l}\mathscr{9} \\
\stackrel{8}{4} \\
\text { I }\end{array}$ & TOTAL & Percentage \\
\hline cloth/ rags/ nylon & 199 & & & 199 & $68.86 \%$ \\
\hline concrete & & & 3 & 3 & $1.04 \%$ \\
\hline glass & 178 & & & 178 & $61.59 \%$ \\
\hline lead & & & 3 & 3 & $1.04 \%$ \\
\hline $\begin{array}{l}\text { metal/ iron/galvanized/ } \\
\text { sheet }\end{array}$ & 205 & & 3 & 208 & $71.97 \%$ \\
\hline paper/ cardboard & 273 & 9 & 3 & 277 & $95.85 \%$ \\
\hline plastic/ polyurathane & 274 & $\overline{1}$ & 3 & 278 & $96.19 \%$ \\
\hline rubber & 274 & & & $\overline{274}$ & $94.81 \%$ \\
\hline wood/lumber plywood & 2 & 4 & & 3 & $1.04 \%$ \\
\hline Total Number of Drums & 285 & 1 & 3 & 289 & $100.00 \%$ \\
\hline
\end{tabular}

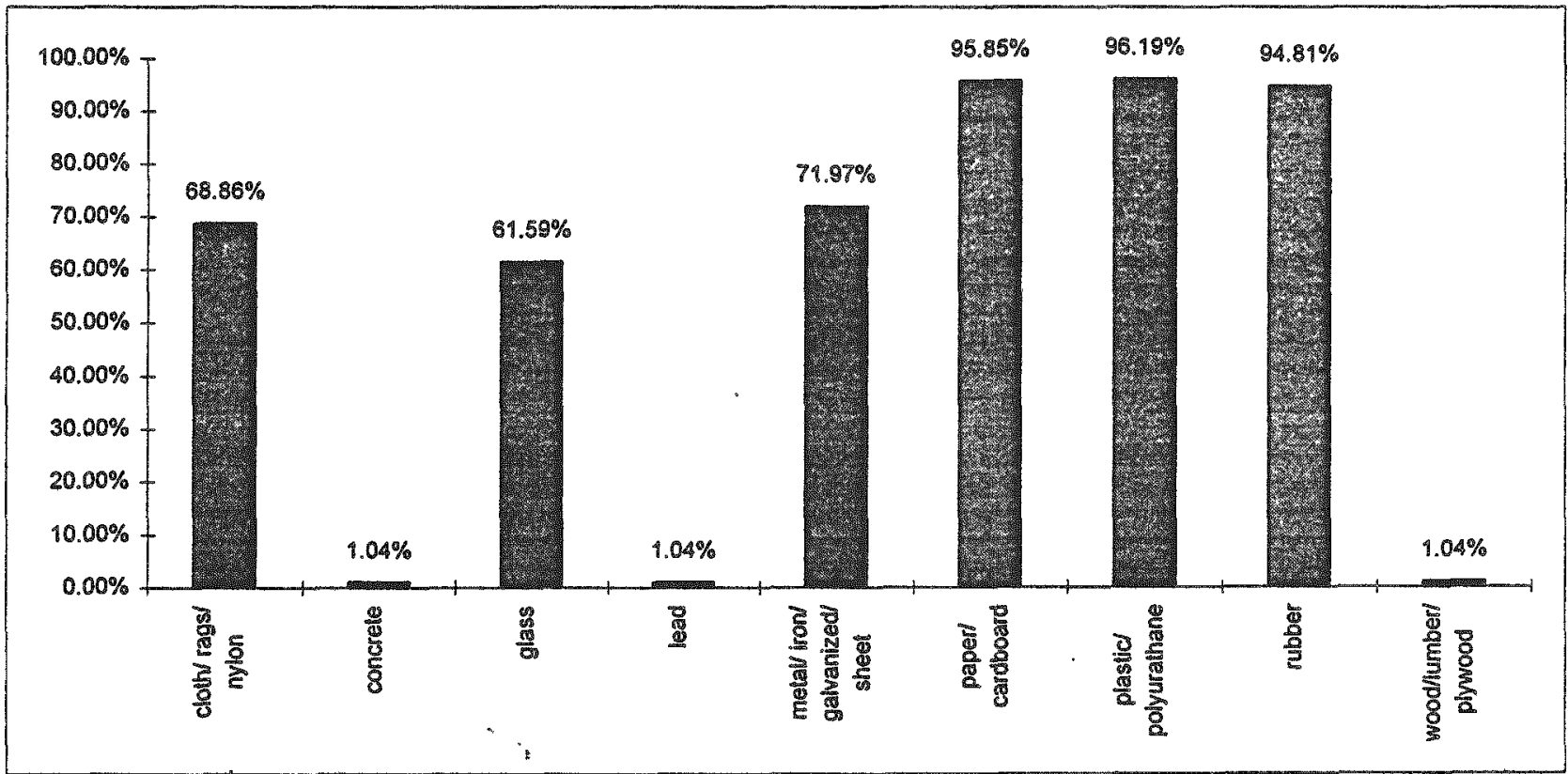


Figure 5.3-3 shows the number and percentage of physical contents listed for 208-L drums stored Module 18. In Module 18,6 drums $11 \%$ of the total number) contain $9 \%$ volume of lead from the ESG.

Figure 5.3-3. Number and Percentage of Physical Contents in Listed for 208.L. Drums Stored in Module 18.

\begin{tabular}{|c|c|c|c|c|c|c|c|}
\hline & $\begin{array}{l}\mathbb{d} \\
\text { d } \\
\text { U } \\
\frac{U}{3} \\
\frac{T}{3}\end{array}$ & 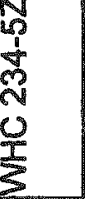 & $\begin{array}{l}\mathbb{Z} \\
\text { กै } \\
\text { บ } \\
\end{array}$ & $\begin{array}{l}\text { तै } \\
\text { ले } \\
\text { z }\end{array}$ & $\begin{array}{l}0 \\
\mathbb{W} \\
జ\end{array}$ & TOTAL & PERCENTAGE \\
\hline cement & & & 23 & & & 23 & $4.00 \%$ \\
\hline cloth/ rags/ nylon & 9 & 305 & & & & 314 & $54.61 \%$ \\
\hline concrete & & & 4 & 11 & 6 & 21 & $3.65 \%$ \\
\hline glass & & 108 & 27 & 11 & & 146 & $25.39 \%$ \\
\hline lead & & & & & 6 & 6 & $1.04 \%$ \\
\hline $\begin{array}{l}\text { metal/ iron/ } \\
\text { galvanized/ sheet }\end{array}$ & & 108 & 27 & 11 & 6 & 152 & $26.43 \%$ \\
\hline paper/ cardboard & & 502 & 27 & 11 & 6 & 546 & $94.96 \%$ \\
\hline plastic/ polyurathane & 9 & 514 & 27 & 11 & 6 & 567 & $98.61 \%$ \\
\hline rubber & 9 & 386 & & & & 395 & $68.70 \%$ \\
\hline $\begin{array}{l}\text { wood/lumber/ } \\
\text { plywood }\end{array}$ & & & & 11 & & 11 & $1.91 \%$ \\
\hline $\begin{array}{l}\text { Total Number of } \\
\text { Drums }\end{array}$ & 9 & 522 & 27 & 11 & 6 & 575 & $100.00 \%$ \\
\hline
\end{tabular}

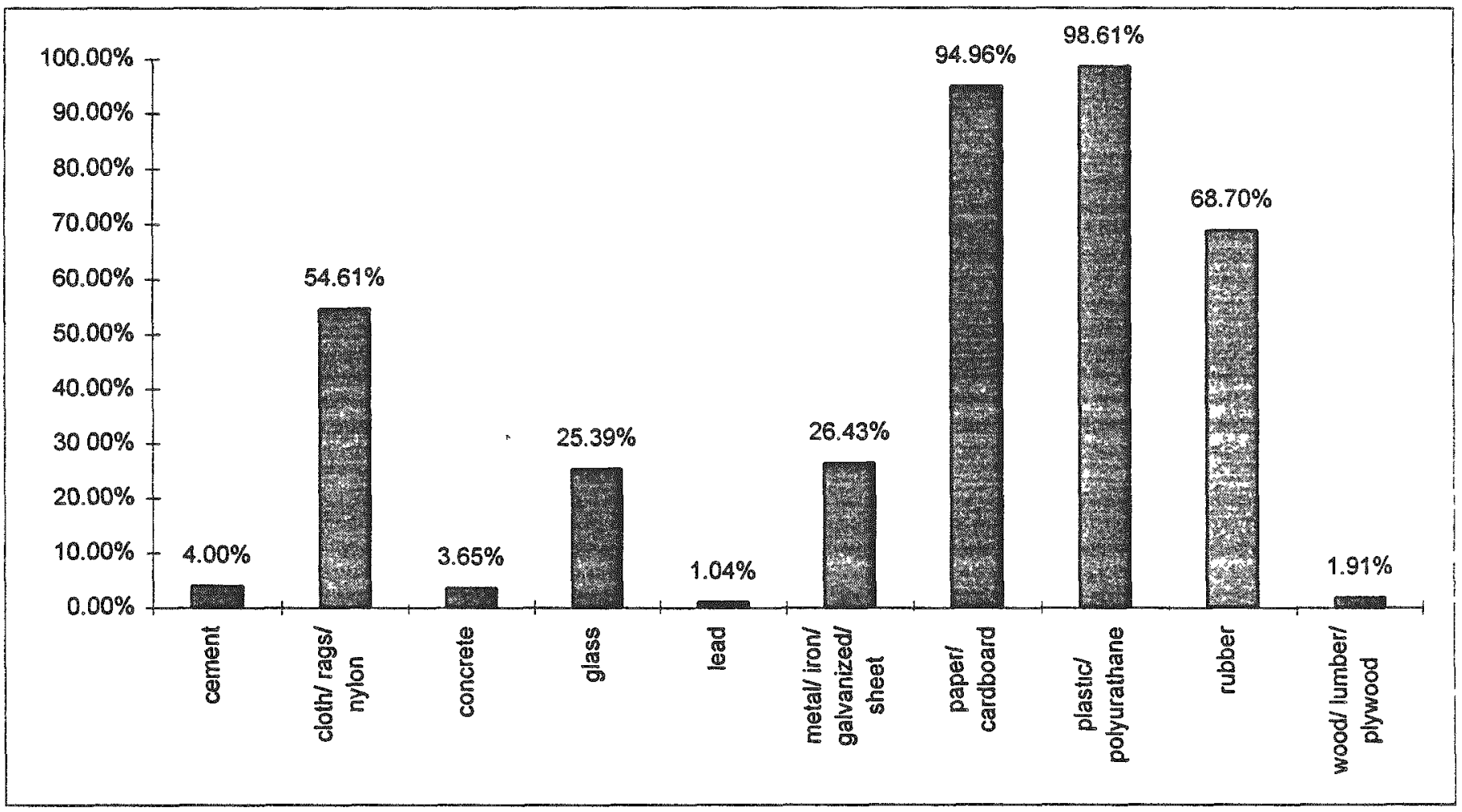


Figure 5.3-4 number and percentage of physical contents listed for 208- $\mathrm{L}$ drum stored in Module 17. In Module 17.2 drums $10.35 \%$ of the total number) contain dirt, soil, or diatomaceous earth, which is restricted from WRAP Module 1 . These constituents make up only $1 \%$ of the total volume of these drums.

Figure 5.3-4. Number and Percentage of Physical Contents Listed for 208-L Drums Stored in Module 17.

\begin{tabular}{|c|c|c|c|c|c|c|c|c|}
\hline & $\begin{array}{l}\mathbb{8} \\
\delta \\
\mathcal{U} \\
\frac{T}{3}\end{array}$ & 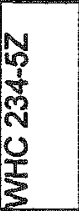 & $\begin{array}{l}\text { \&ี } \\
\text { ชิ } \\
\frac{1}{3}\end{array}$ & 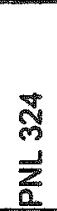 & 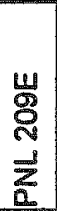 & 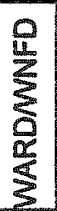 & TOTAL & PERCENTAGE \\
\hline $\begin{array}{l}\text { absorbant/ kitty } \\
\text { litter/ vermiculite }\end{array}$ & & & 20 & 3 & & & 23 & $4.02 \%$ \\
\hline cement & & & 20 & & & 11 & 31 & $5.42 \%$ \\
\hline cloth/ rags/ nylon & 12 & 72 & & & 10 & 23 & 117 & $20.45 \%$ \\
\hline concrete & & & 20 & & & & 20 & $3.50 \%$ \\
\hline $\begin{array}{l}\text { dirt soil/ } \\
\text { diatomaceous } \\
\text { earth }\end{array}$ & & & & & & 2 & 2 & $0.35 \%$ \\
\hline glass & & & 20 & 3 & & & 23 & $4.02 \%$ \\
\hline leather & & & & & & 8 & 8 & $1.40 \%$ \\
\hline $\begin{array}{l}\text { metal/ iron/ } \\
\text { galvanized/sheet }\end{array}$ & & & 20 & 3 & & 34 & 57 & $9.97 \%$ \\
\hline pain's/ lucite & & & & & & 38 & 38 & $6.64 \%$ \\
\hline paper/ cardboard & & 475 & 20 & 3 & 10 & 50 & 558 & $97.55 \%$ \\
\hline $\begin{array}{l}\text { plasticl } \\
\text { polyurathane }\end{array}$ & 12 & 471 & 20 & 3 & 10 & 50 & 566 & $98.95 \%$ \\
\hline rubber & 12 & 474 & & & & 39 & 525 & $91.78 \%$ \\
\hline $\begin{array}{l}\text { wood/lumber/ } \\
\text { plywood }\end{array}$ & & & & & & 23 & 23 & $4.02 \%$ \\
\hline $\begin{array}{l}\text { Total Number of } \\
\text { Drums }\end{array}$ & 12 & 477 & 20 & 3 & 10 & 50 & 572 & $100.00 \%$ \\
\hline
\end{tabular}

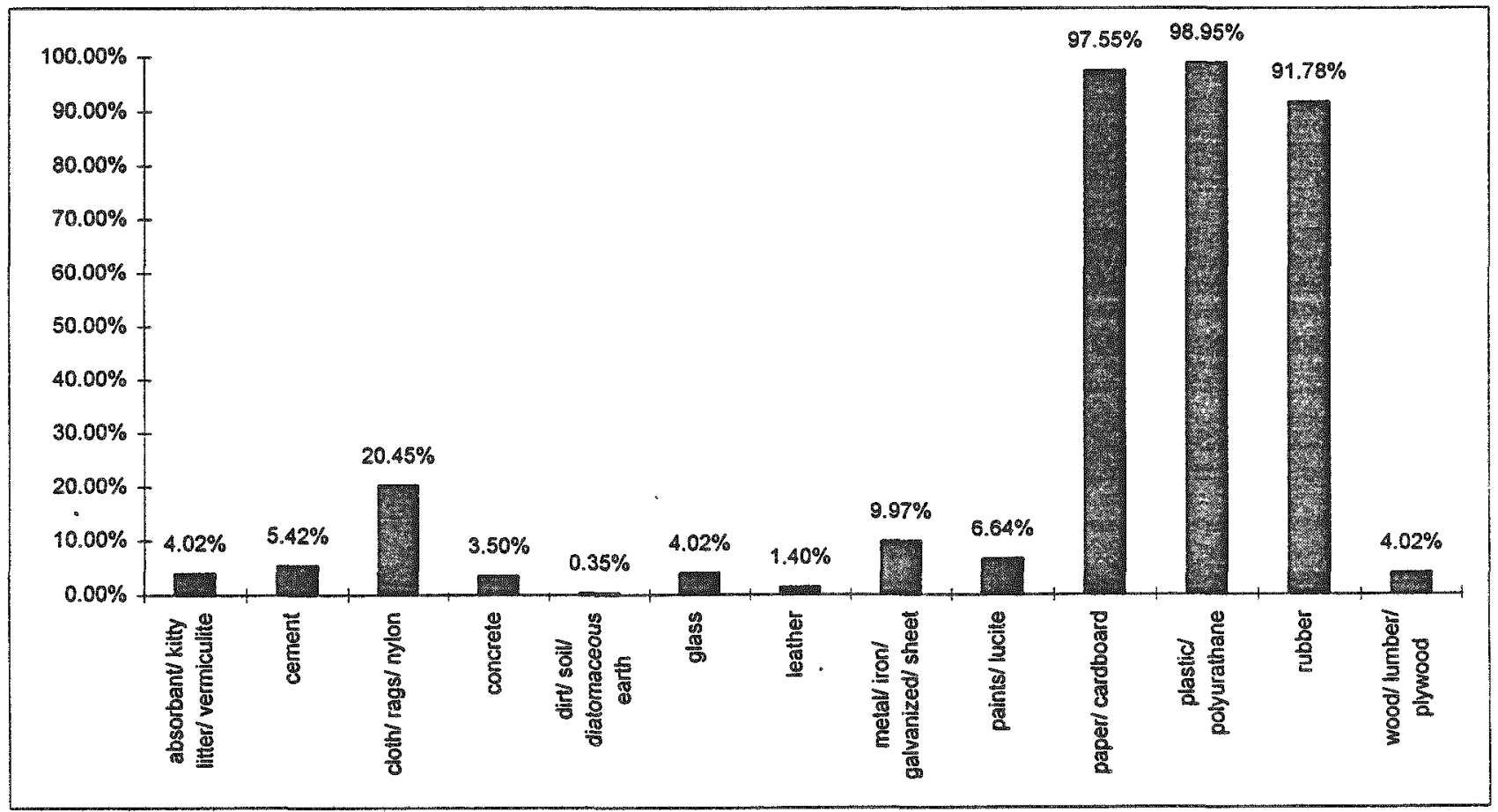


Figure 5.3-5. Shows the number and percentage of physical contents listed for $208-L$ drums stored in Module 16. Module 16 differs from the overall trench in that it has a larger percentage of drums containing combustible, compressible wastes (paper, cardboard, plastic, non-combustible items (metals and glass).

Figure 5.3-5 Number and Percentage of Physical Contents Listed for 208-L. Drums Stored in Module 16.

\begin{tabular}{|c|c|c|c|c|c|c|c|}
\hline - & $\mid \begin{array}{l}N \\
\frac{1}{2} \\
\frac{2}{5} \\
N \\
0 \\
\frac{1}{3} \\
\end{array}$ & 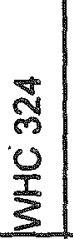 & $\begin{array}{l}\text { Nै } \\
\text { लै } \\
\ddot{z} \\
0\end{array}$ & 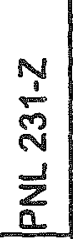 & $\begin{array}{l}\frac{0}{1} \\
\frac{1}{2} \\
\frac{1}{2} \\
\frac{1}{x} \\
\frac{1}{3}\end{array}$ & TOTAL & PERCENTAGE \\
\hline $\begin{array}{l}\text { absorbant/ kitty } \\
\text { litter/ vermiculite }\end{array}$ & & & 1) & & & 1 & $0.30 \%$ \\
\hline glass & & 16 & & & & 16 & $4.76 \%$ \\
\hline $\begin{array}{l}\text { metal/iron/ } \\
\text { galvanized/ sheet }\end{array}$ & & 16 & 1 & & 34. & 51) & $15.18 \%$ \\
\hline paints/ /ucite & & & & & 55 & 55] & $16.37 \%$ \\
\hline paper/ cardboard & 241 & 16 & & 4 & 70 & 331 & $98.51 \%$ \\
\hline $\begin{array}{l}\text { plasticl } \\
\text { polyurathane }\end{array}$ & 241 & 16 & 1. & 4 & 70 & 332 & $98.81 \%$ \\
\hline rubber & 241 & 16 & & 4 & 70 & 331 & $98.51 \%$ \\
\hline $\begin{array}{l}\text { wood/lumberl } \\
\text { plywood }\end{array}$ & & 16 & & 4 & 23 & 43 & $12.80 \%$ \\
\hline $\begin{array}{l}\text { Total Number of } \\
\text { Drums }\end{array}$ & 245 & 16 & 1 & 4 & 70 & 336 & $100.00 \%$ \\
\hline
\end{tabular}

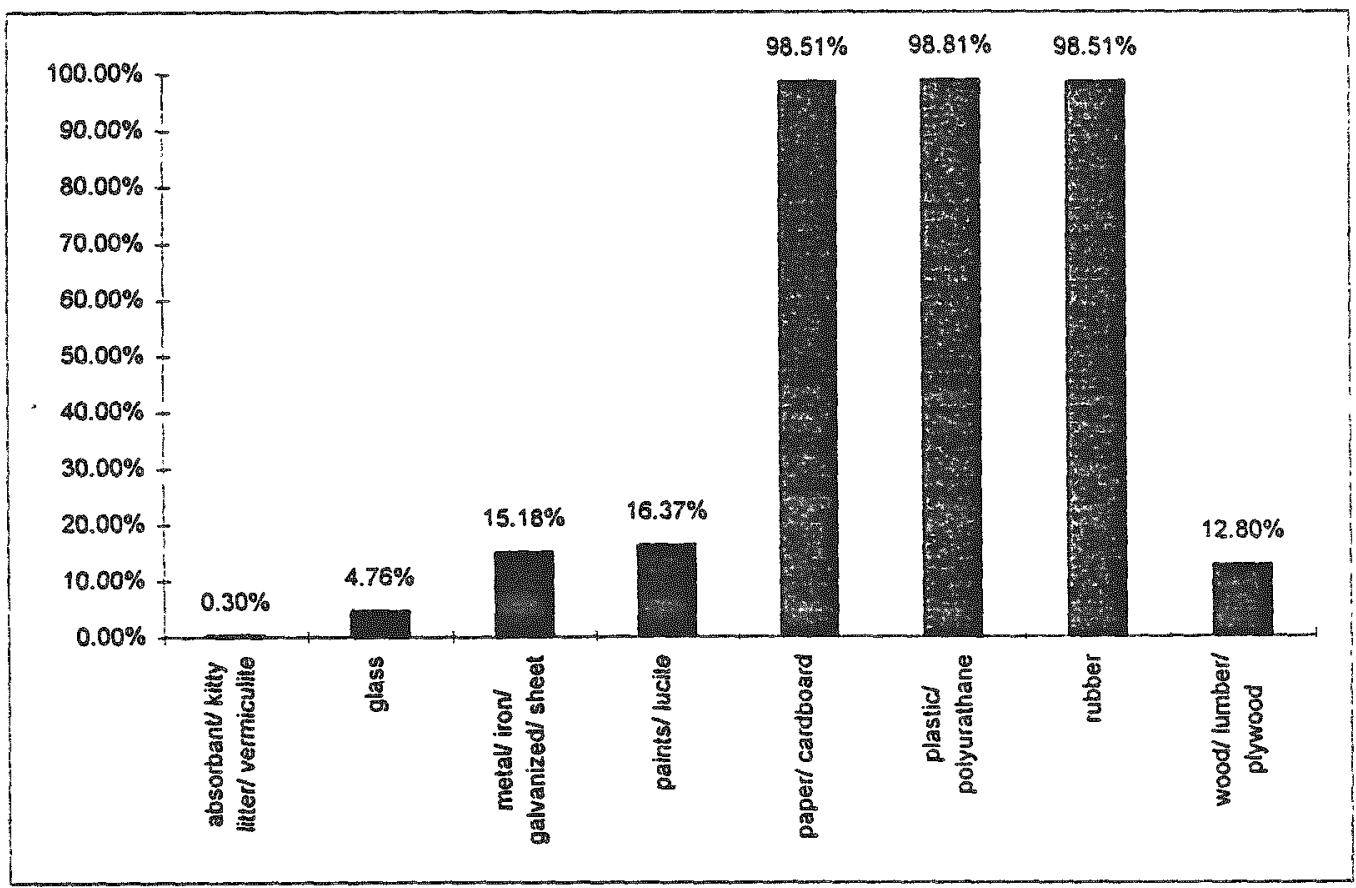


Figure 5.3-6 shows the number and percentage of physical contents listed for 208-L drums stored Module 15. Module 15 contains 28 drums $17 \%$ of the total drums in this module) that have filters in them. These filters are found in waste from $B$ \& $W$ and comprise $25 \%$ of the volume of the drums they are located in. Since WIPP will not accept filters, these will have to be removed.

Figure 5.3-6. Number and Percentage of Physical Contents Listed for 208-L Drums Stored in Module 15.

\begin{tabular}{|c|c|c|c|c|c|c|c|c|c|}
\hline & $\frac{8}{8}$ & 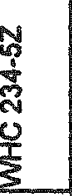 & $\frac{1}{3}$ & $\begin{array}{l}0 \\
\frac{9}{3} \\
\frac{9}{3}\end{array}$ & 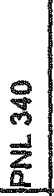 & $\begin{array}{l}\frac{0}{4} \\
\frac{1}{2} \\
\frac{2}{2} \\
\frac{2}{3} \\
3\end{array}$ & 3 & TOTAL & PERCENTAGE \\
\hline $\begin{array}{l}\text { absorbant kitty } \\
\text { litter/ vermiculite }\end{array}$ & & & 7 & & & 59 & & 66 & $17.14 \%$ \\
\hline cloth/ rags/ nyion & 2 & 15 & & & & 68 & & 85 & $22.08 \%$ \\
\hline concrete & & & 19 & 8 & 8 & & & 35 & $9.09 \%$ \\
\hline fiters & & & & & & & 28 & 28 & $7.27 \%$ \\
\hline glass & & & 9 & 14 & 8 & 20 & & 51 & $13.25 \%$ \\
\hline $\begin{array}{l}\text { metal/iron/ } \\
\text { galvanized/ sheet }\end{array}$ & & & 49 & 15 & 8 & 20 & & 62 & $16.10 \%$ \\
\hline paints/lucite & & & & & & 59 & & 59 & $15.32 \%$ \\
\hline paper/ cardboard & 2 & 226 & 19 & 15 & 8 & 68 & 28 & 366 & $95.06 \%$ \\
\hline $\begin{array}{l}\text { plastic } \\
\text { polyurathane }\end{array}$ & 2 & 242 & 19 & 15 & 8 & 68 & 28 & 382 & $99.22 \%$ \\
\hline rubber & & 225 & & & & 68 & 28 & 321 & $83.38 \%$ \\
\hline $\begin{array}{l}\text { wood/lumberl } \\
\text { plywood }\end{array}$ & & & 7 & 14 & & 68 & 28 & 117 & $30.39 \%$ \\
\hline $\begin{array}{l}\text { Total Number of } \\
\text { Drums }\end{array}$ & 2 & 244 & 19 & 15 & 8 & 68 & 29 & 385 & $100.00 \%$ \\
\hline
\end{tabular}

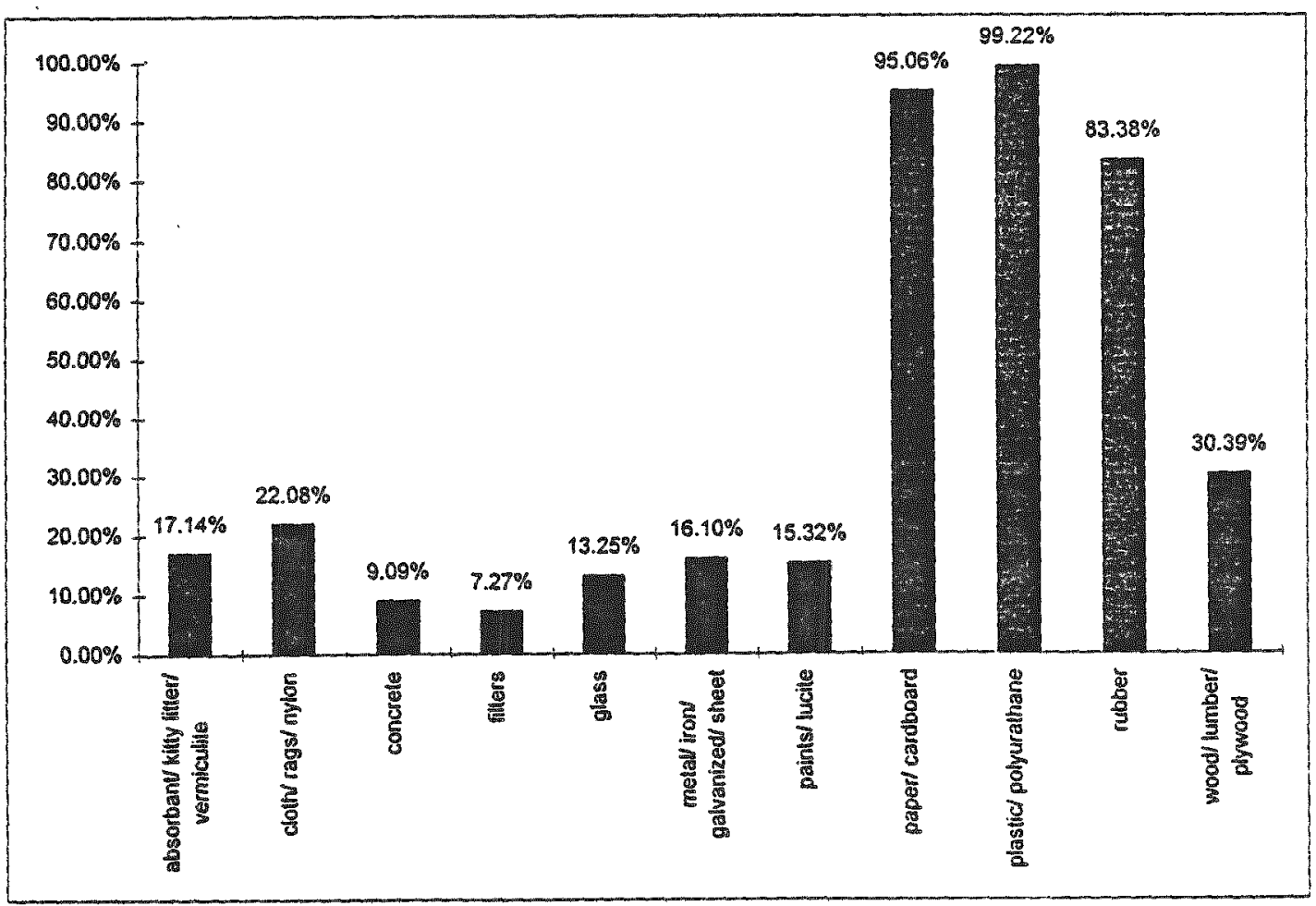


Figure 5.3-7 shows the number and percentage of physical contents listed for $208-L$ drums stored in Module 14 . Module 14 contains filters from B \& W, in 85 drums, or $17 \%$ of the total number of drums. They make up $25 \%$ of the volume of the drums they are located in. Boron from PNL building 340 is found in 6 drums (or $1 \%$ of the total number) and comprises $1 \%$ of the drum volume. Sludges from WHC building 340 comprise $12 \%$ of the volume of the 4 drums $1.4 \%$ of the total) that they are found in. Organics from WARDNNFD are found in one drum and comprise $5 \%$ of the drum volume.

Figure 5.3-7. Number and Percentage of Physical Contents Listed for 208-L Drums Stored in Module 14.

\begin{tabular}{|c|c|c|c|c|c|c|c|c|}
\hline & శ్ & 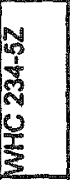 & $\begin{array}{l}9 \\
3 \\
\frac{1}{3} \\
3\end{array}$ & $\begin{array}{l}\text { 昌 } \\
\text { 龸 } \\
\underline{2}\end{array}$ & $\begin{array}{l}0 \\
\frac{4}{2} \\
\frac{3}{8} \\
\frac{1}{3}\end{array}$ & $\begin{array}{l}3 \\
\text { 离 } \\
0\end{array}$ & TOTAL & PERCENTAGE \\
\hline $\begin{array}{l}\text { absorbant/ kutty } \\
\text { Inter/ vermiculife }\end{array}$ & & & & 6 & 16 & & 22 & $444 \%$ \\
\hline boron & & & & 6 & & & 6 & $120 \%$ \\
\hline cloth/ rags/ nyion & 51 & 58 & 1 & & 31 & 15 & 156 & $3126 \%$ \\
\hline concrete & & & 11 & & & & 111 & $220 \%$ \\
\hline cotron/ kotex & & & 10 & & & & 10 & $200 \%$ \\
\hline fiberglass & & & & & 1 & 85 & 86 & $1723 \%$ \\
\hline filters & & & & & & 85 & 85 & $1703 \%$ \\
\hline floor tile & 11 & & & & & & 911 & $220 \%$ \\
\hline foam/ styrofoam & & & & & 14 & & 141 & $281 \%$ \\
\hline giass & & & 9 & 18 & & & 27 & $541 \%$ \\
\hline $\begin{array}{l}\text { metal/ Iron/ } \\
\text { galvanized/ sheet }\end{array}$ & & 30 & 11 & 18 & & & 59 & $1182 \%$ \\
\hline organics & & & & & 1 & & 1 & $020 \%$ \\
\hline paints lucte & & & & & 1 & & 1 & $020 \%$ \\
\hline paperl cardboard & 51 & 285 & 11 & 98 & 31 & 85 & 481 & $9639 \%$ \\
\hline $\begin{array}{l}\text { plastid } \\
\text { polyurathane }\end{array}$ & 51 & 278 & 11 & 18 & 31 & 85 & 474 & $9499 \%$ \\
\hline rubber & & 274 & & 6 & 31 & 70 & 381 & $7635 \%$ \\
\hline sludges & & & 2 & & & & 2 & $040 \%$ \\
\hline wax & & & & (6) & & & (6) & $120 \%$ \\
\hline $\begin{array}{l}\text { wood/lumber/ } \\
\text { lywwood }\end{array}$ & & & & & 1 & 85 & 86 & $1723 \%$ \\
\hline $\begin{array}{l}\text { Total Number of } \\
\text { Drums }\end{array}$ & 51 & 303 & 11 & 18) & 32 & 84 & 499 & $10000 \%$ \\
\hline
\end{tabular}

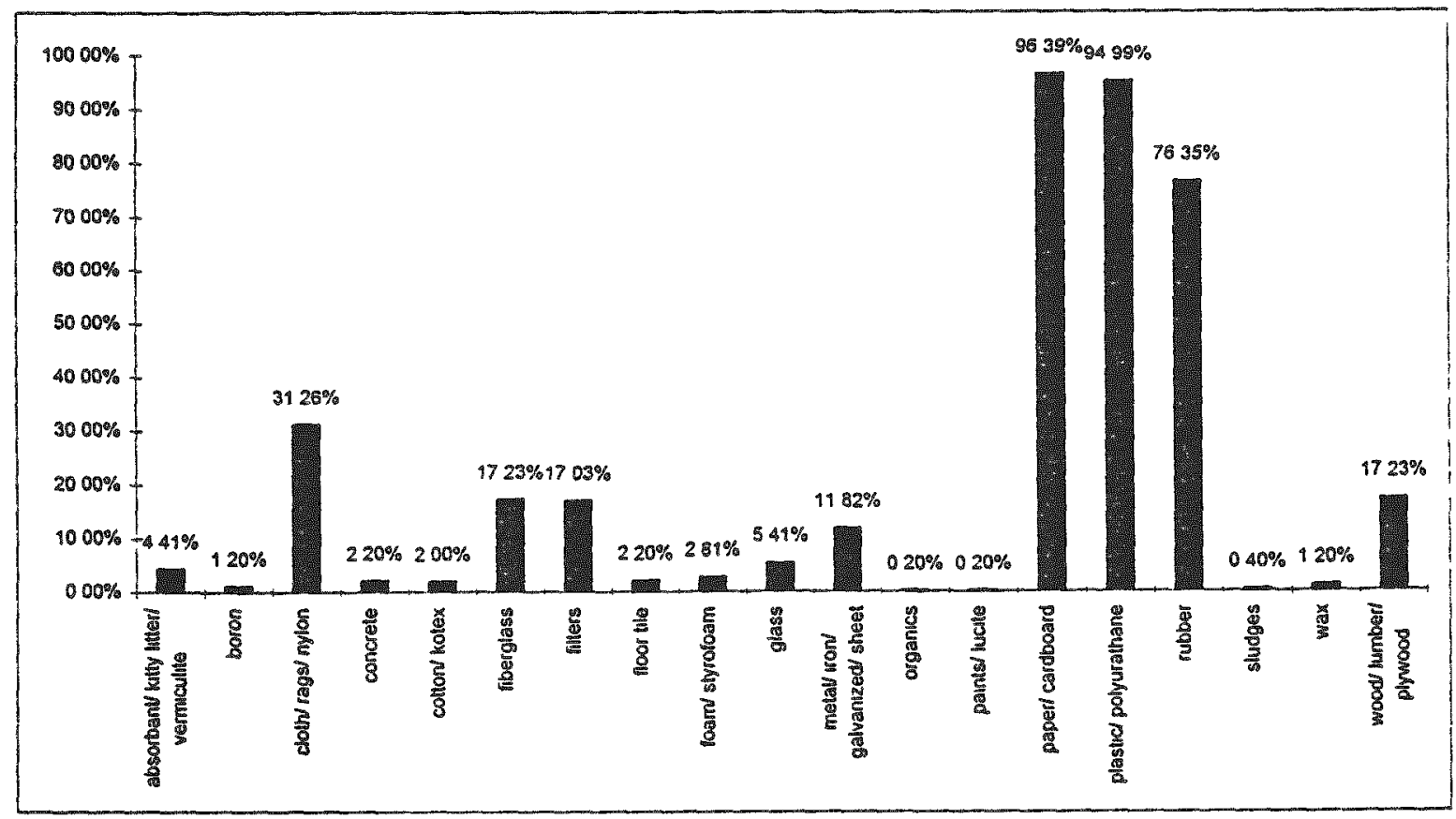


Figure 5.3-8 shows the number and percentage of physical contents listed for 208-L drums stored Module 13. Module 13 contains 1 drum from PNL 340 with a $1 \%$ volume of boron in it. It also contains 4 drums $1.75 \%$ of the total number) with $12 \%$ volumes of sludges from WHC building 340. In addition, 58 drums $(11 \%$ of the total number) contain organics and oils from WARDNNFD and GE-Vallecitos, compromising an average of $5 \%$ of their volumes $\left(1 \% \min _{\mathrm{s}} ; 5 \% \max .\right)$.

Figure 5.3-8. Number and Percentage of Physical Contents Listed for 208-L Drums Stored in Module 13.

\begin{tabular}{|c|c|c|c|c|c|c|c|c|c|}
\hline & $\begin{array}{l}\mathbb{8} \\
\mathbb{8} \\
0\end{array}$ & 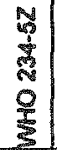 & $\begin{array}{l}9 \\
8 \\
\frac{2}{2} \\
\frac{7}{3}\end{array}$ & $\begin{array}{l}\frac{9}{7} \\
\frac{1}{2}\end{array}$ & 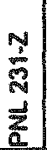 & $\frac{3}{3}$ & $\begin{array}{l}\frac{0}{4} \\
\frac{3}{3} \\
\frac{8}{8} \\
\frac{8}{3}\end{array}$ & TOTAL & PERCENTAGE \\
\hline $\begin{array}{l}\text { absorbanU kitty } \\
\text { gitter vermiculite }\end{array}$ & & &. & 8 & & & 49 & 57 & $10.69 \%$ \\
\hline boron & & & & 1 & & & & 91 & $0.19 \%$ \\
\hline cement & & & 301 & 9 & & & & 39 & $7.32 \%$ \\
\hline ceramies & & & & & & & 49 & 49 & $9.19 \%$ \\
\hline cloth/ rags/ nylon & 128 & 24 & 17 & 9 & & & 105 & 283 & $53.10 \%$ \\
\hline concrete & & & 4 & & & & & 4 & $0.75 \%$ \\
\hline cotton/ kotex & & & 21 & & & 34 & & 55 & $10.32 \%$ \\
\hline Thberglass & & & & & & & 91 & 911 & $17.07 \%$ \\
\hline glass & & & 30 & 8 & & & 49 & 371 & $16.32 \%$ \\
\hline leather & & & & & & & 13 & 43 & $2.44 \%$ \\
\hline $\begin{array}{l}\text { metalliron/ } \\
\text { galvanized/ sheet }\end{array}$ & 24 & 10 & 34 & 10 & 11 & 32 & 49 & 170 & $31.89 \%$ \\
\hline oits & & & & & & 2 & & 2 & $0.38 \%$ \\
\hline organics & & & & & & & 56 & 561 & $10.51 \%$ \\
\hline Daints/ fucite & & & & & & 2 & 561 & 581 & $10.88 \%$ \\
\hline paperf cardboard & 141 & 185 & 34 & 10 & 11 & 35 & 105 & 529 & $99.25 \%$ \\
\hline $\begin{array}{l}\text { plasticl } \\
\text { polyurathane }\end{array}$ & 141 & 1851 & 34 & 10 & 11 & 35 & 105 & 529 & $99.25 \%$ \\
\hline rubber & & 158 & 17 & 1 & 11 & 3 & 105 & 303 & $56.85 \%$ \\
\hline sludges & & & 4 & & & & & 4 & $0.75 \%$ \\
\hline wax & & & & 11 & & & & 11 & $0.19 \%$ \\
\hline $\begin{array}{l}\text { wood/lumberf } \\
\text { olywood }\end{array}$ & & & & 2 & 11 & 35 & 105 & 151 & $30.21 \%$ \\
\hline $\begin{array}{l}\text { Total Number of } \\
\text { Drums }\end{array}$ & 144 & 185 & 33 & 10 & 911 & 35 & 107 & 533 & $100.00 \%$ \\
\hline
\end{tabular}

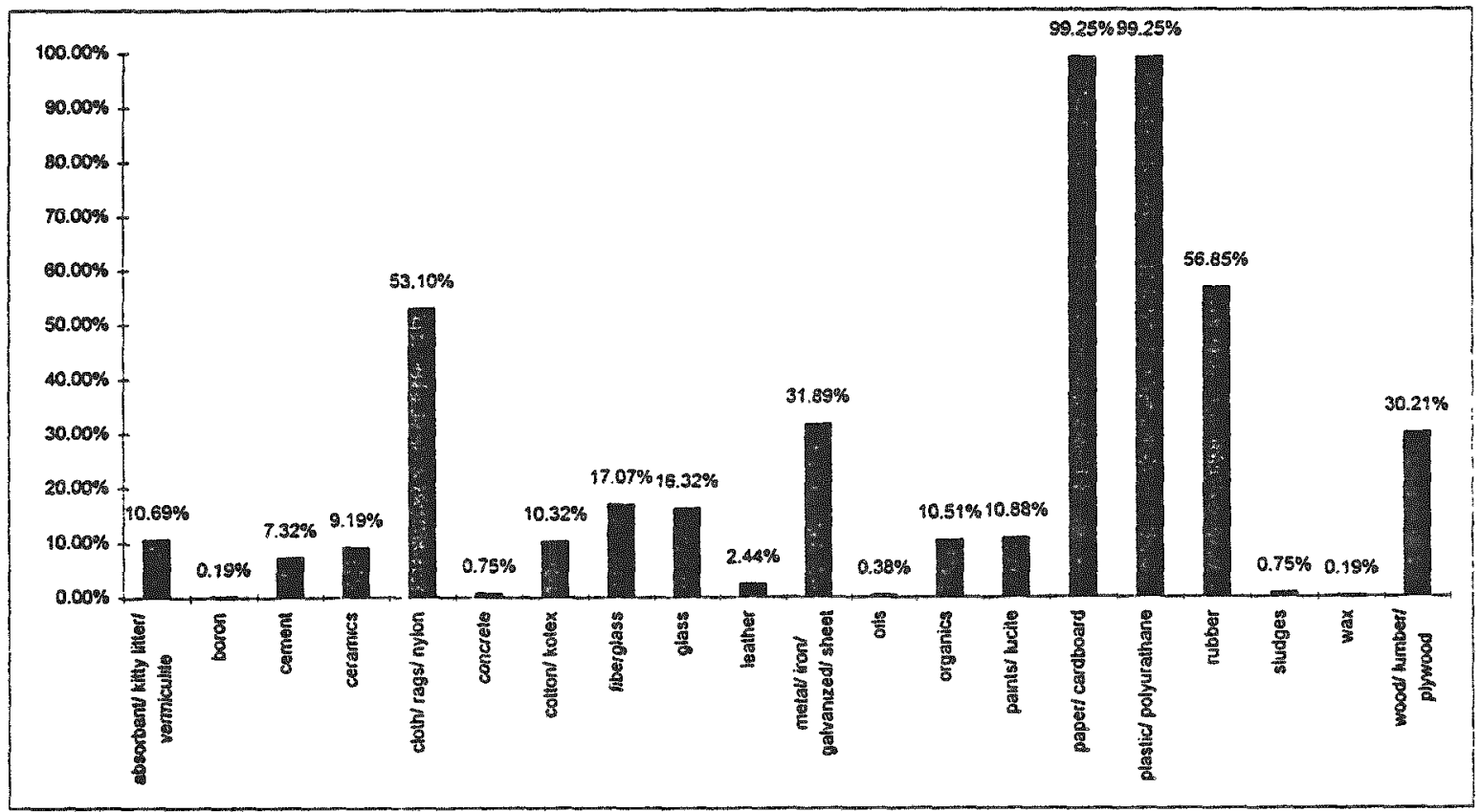


Figure 5.3-9 shows the number and percentage of physical contents listed for 208-L drums stored Module 12 . Module 12 contains 4 drums $(2 \%$ of the total number) that have filters in them. The filters are from the PFP, and the drums that contain them contain only filters. There are 31 drums $(12 \%$ of the total number) that contain a $1 \%$ volume of oil $11 \%$ min.: $1 \%$ max.) from GE-Vallecitos. This module also contains 10 drums (4\% of the total) which contain miscellaneous, unknown, or other materials.

Figure 5.3-9. Number and Percentage of Physical Contents Listed for 208-L in Module 12.

\begin{tabular}{|c|c|c|c|c|c|c|c|}
\hline & 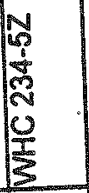 & $\begin{array}{l}\frac{9}{7} \\
\frac{O}{3} \\
\frac{1}{3}\end{array}$ & $\begin{array}{l}\text { 음 } \\
\stackrel{\vec{z}}{\mathrm{z}}\end{array}$ & $\frac{j}{j}$ & 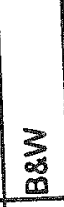 & TOTAL & PERCENTAGE \\
\hline $\begin{array}{l}\text { absorbant/ kitty } \\
\text { litter/ vermiculite }\end{array}$ & & 13 & & & & 13 & $5.10 \%$ \\
\hline cement & & 1 & & & & 1 & $0.39 \%$ \\
\hline cloth/ rags/ nylon & 6 & 13 & & & & 19 & $7.45 \%$ \\
\hline Cotton/ kotex & & & & 32 & & 32 & $12.55 \%$ \\
\hline filters & 4 & & & & & 4 & $1.57 \%$ \\
\hline glass & & 14 & 8 & & & 22 & $8.63 \%$ \\
\hline $\begin{array}{l}\text { metal/ iron/ } \\
\text { gaivanized/ sheet }\end{array}$ & 17 & 14 & 8 & & & 39 & $15.29 \%$ \\
\hline $\begin{array}{l}\text { miscellaneous/ } \\
\text { unknown/ other }\end{array}$ & & & & 10 & & 10 & $3.92 \%$ \\
\hline \begin{tabular}{|l|} 
oiis \\
\end{tabular} & & & & 31 & & 31 & $12.16 \%$ \\
\hline paints/ lucite & & & & 22 & & 22 & $8.63 \%$ \\
\hline paper/ cardboard & 148 & 14 & 8 & 32 & 61 & 233 & $91.37 \%$ \\
\hline plasticl & & & & & & & \\
\hline polyurathane & 121 & 14 & 8 & 32 & 61 & 236 & $92.55 \%$ \\
\hline rubber & 133 & & & 22 & 61 & 216 & $84.71 \%$ \\
\hline $\begin{array}{l}\text { wood/lumberl } \\
\text { plywood }\end{array}$ & & 13 & & 32 & 61 & 106 & $41.57 \%$ \\
\hline Total Number of & 137 & 17 & 8 & 32 & 61 & 255 & $100.00 \%$ \\
\hline
\end{tabular}

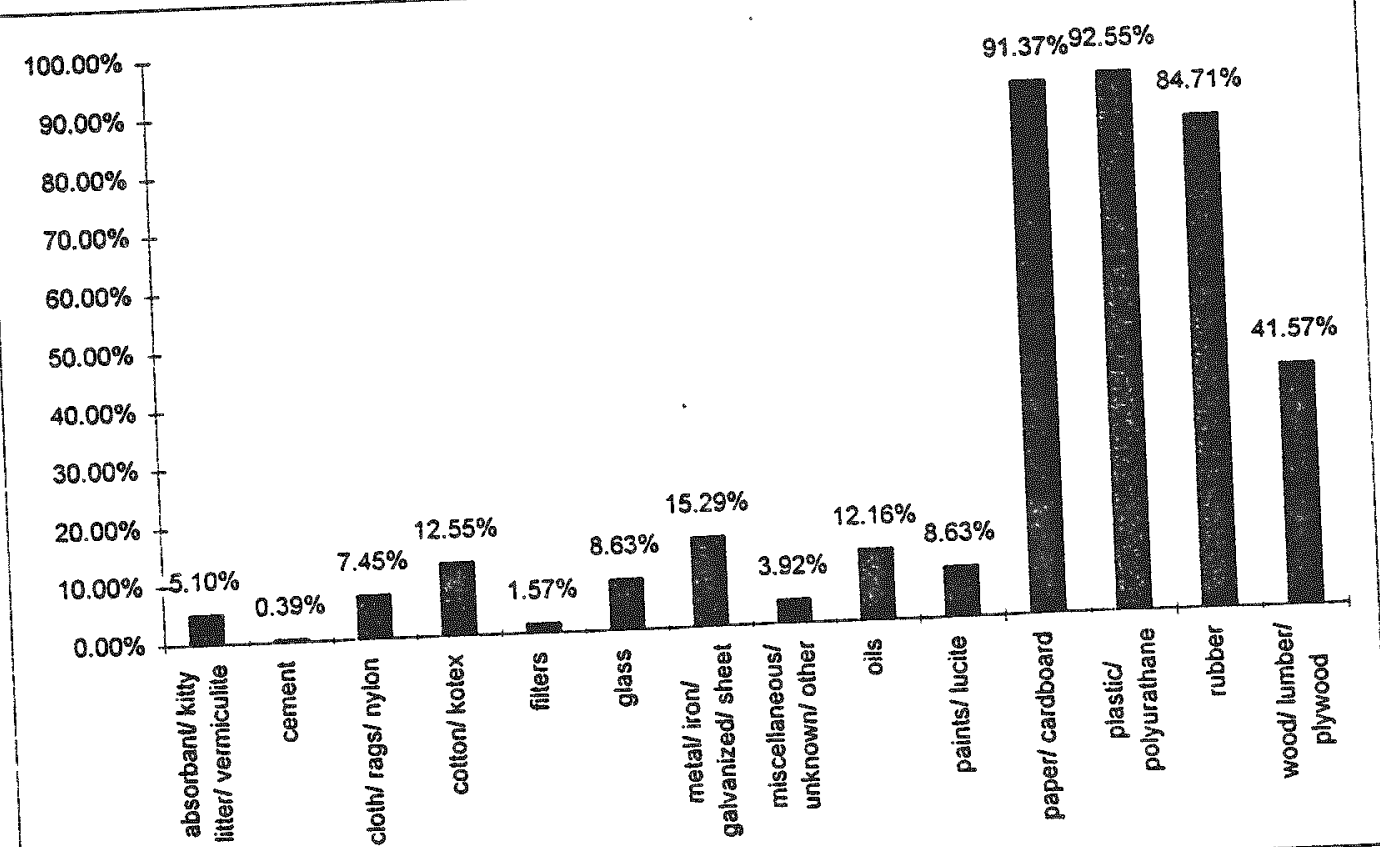


Figure 5.3-10 shows the number and percentage of physical contents listed for 208- $L$ drums stored Module 11. Approximately $33 \%$ of the drums (175 drums) in Module 11 contain filters from Babcock and Wilcox. These drums contain an average volume of $12 \%$ filters (5\% min.: $17 \%$ max.).

Figure 5.3-10. Number and Percentage of Physical Contents Listed for 208-L. Drums Stored in Module 11.

\begin{tabular}{|c|c|c|c|c|c|c|c|c|c|}
\hline- & 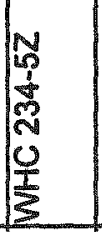 & $\begin{array}{l}\text { 애 } \\
0 \\
\frac{1}{1}\end{array}$ & $\begin{array}{l}\text { 앰 } \\
\text { Z } \\
\text { Z }\end{array}$ & $\begin{array}{l}\frac{N}{\frac{1}{3}} \\
\frac{1}{2} \\
\frac{1}{\alpha}\end{array}$ & $\begin{array}{l}\text { 岁 } \\
\text { N } \\
\frac{\vec{z}}{2} \\
\end{array}$ & 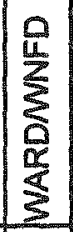 & $\begin{array}{l}3 \\
08 \\
0\end{array}$ & TOTAL & PERCENTAGE \\
\hline $\begin{array}{l}\text { absorbant/ kitty } \\
\text { litter/ vermiculite }\end{array}$ & & 23 & & & & & & 23 & $4.38 \%$ \\
\hline cement & & 23 & & & & 26 & & 49 & $9.33 \%$ \\
\hline cloth/rags/ nylon & 22 & & & & & 19 & & 41 & $7.81 \%$ \\
\hline fillers & & & & & & & 175 & 175 & $33.33 \%$ \\
\hline glass & 21 & 33 & 23 & & & 7 & & 84 & $16.00 \%$ \\
\hline $\begin{array}{l}\text { metal/ iron/ } \\
\text { galvanized/ sheet }\end{array}$ & 58 & 33 & 23 & & & 26 & & 140 & $26.67 \%$ \\
\hline paper/ cardboard & 113 & 33 & 23 & & 13 & 26 & 256 & 464 & $88.38 \%$ \\
\hline $\begin{array}{l}\text { plasticl } \\
\text { polyurathane }\end{array}$ & 120 & 33 & 23 & & 13 & 26 & 256 & 471 & $89.71 \%$ \\
\hline rubber & 99 & & & & 13 & 26 & 256 & 394 & $75.05 \%$ \\
\hline solvents/ thinners & & & & & 13 & & & 13 & $2.48 \%$ \\
\hline $\begin{array}{l}\text { wood/lumberl } \\
\text { plywood }\end{array}$ & & 22 & & & & 7 & 256 & 285 & $54.29 \%$ \\
\hline $\begin{array}{l}\text { Total Number of } \\
\text { Drums }\end{array}$ & 171 & 34 & 23 & 2 & 13 & 26 & 256 & 525 & $100.00 \%$ \\
\hline
\end{tabular}

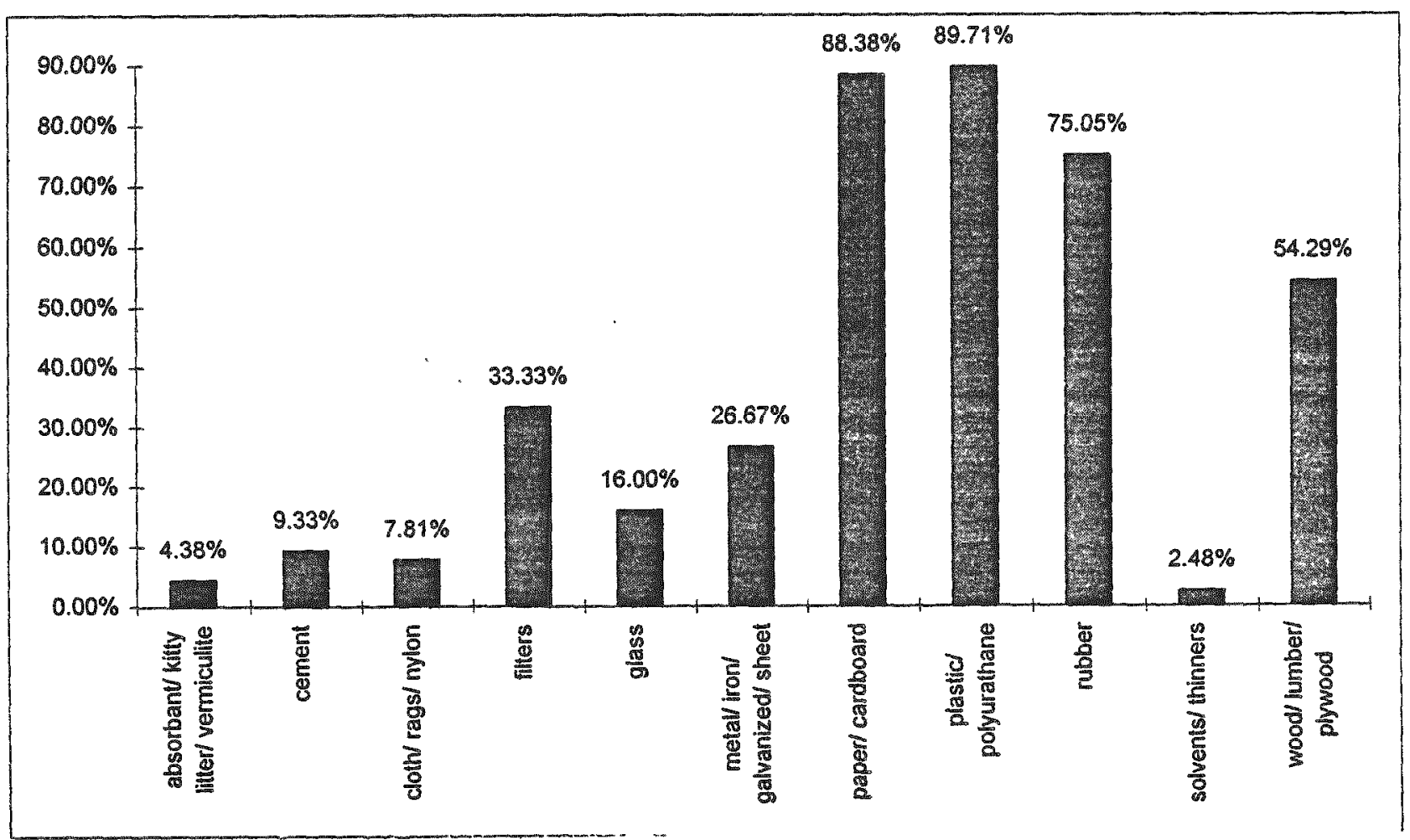


Figure 5.3-11 shows the number and percentage of physical contents listed for 208 $\mathrm{L}$ drums stored Module 10. Module 10 contains 87 drums (16\% of the total number) that are miscellaneous, unknown, or other wastes. These wastes were generated by WARDMNFD, GE-Vallecitos, and B \& W. Filters are contained in 80 drums $(15 \%$ of the total number $)$ from $\mathrm{B} \& \mathrm{~W}$ and average $16 \%$ of the volume of these drums $(12 \%$ min.: $35 \%$ max. $)$. GE-Vallecitos generated 22 drums ( $4 \%$ of the total number) that contain dirt, soil, or diatomaceous earth. which averages $7 \%$ of the volume of these drums. Carborundum from GE-Vallecitos comprises $1 \%$ of the volume of 21 drums $14 \%$ of the total number). Molybdenum from GEVallecitos comprises $1 \%$ of the volume of 22 drums ( $4 \%$ of the total number). Oils from GEVallecitos and WARDMNFD comprise an average $8 \%$ of the volume $(1 \% \min . ; 20 \% \max$. of 87 drums $(16 \%$ of the total number), and 21 drums (4\% of the total number) from GEVallecitos contain a $10 \%$ volume of copper metal. Finally. 24 drums ( $4 \%$ of the total number) from GE-Vallecitos contain antifreeze, another hazardous constituent. Antifreeze makes up $4 \%$ of the volume of the drums it is in.

Figure 5.3-11. Number and Percentage of Physical Contents Listed for 208-L Drums Stored in Module 10.

\begin{tabular}{|c|c|c|c|c|c|c|c|c|}
\hline & 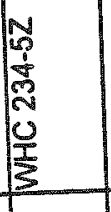 & 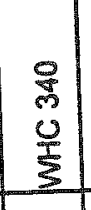 & $\begin{array}{l}\frac{N}{6} \\
\frac{6}{3} \\
\frac{1}{2} \\
\end{array}$ & $\begin{array}{l}j \\
\mathbb{1} \\
0 \\
0\end{array}$ & $\begin{array}{l}0 \\
\frac{1}{1} \\
3 \\
3 \\
0 \\
3 \\
3 \\
3\end{array}$ & $\begin{array}{c}3 \\
8 \\
0 \\
0\end{array}$ & TOTAL & PERCENTAGE \\
\hline $\begin{array}{l}\text { absorbant/kitty } \\
\text { litter/vermiculite }\end{array}$ & & & & & 48 & & 48 & $\frac{8.82 \%}{2060 \%}$ \\
\hline aluminum & & & & 21 & & & 21 & $3.86 \%$ \\
\hline antifreeze & & & & 24 & & & 24 & $4.41 \%$ \\
\hline carborundum & & & & 21 & & & 21 & $3.86 \%$ \\
\hline cement & & 22 & & & 18 & & 40 & $7.35 \%$ \\
\hline copper metal & & & & 21 & & & 21 & $\frac{3.86 \%}{735 \%}$ \\
\hline cotton/kotex & & & & 40 & & & 40 & $7.35 \%$ \\
\hline $\begin{array}{l}\text { dirtsoil/ diatomaceous } \\
\text { earth }\end{array}$ & & & & 22 & & & 22 & $4.04 \%$ \\
\hline filters & & & & & & 80 & 80 & $14.71 \%$ \\
\hline glass : & & 22 & & 22 & 30 & & 74 & $13.60 \%$ \\
\hline $\begin{array}{l}\text { insulation (non- } \\
\text { asbestos) }\end{array}$ & & & & 22 & 1 & & 23 & $4.23 \%$ \\
\hline marbie & & & & 1 & & & 1 & $0.18 \%$ \\
\hline $\begin{array}{l}\text { metal/ iron/ } \\
\text { galvanized/sheet }\end{array}$ & 77 & 22 & 1 & 22 & 47 & & 169 & $39.07 \%$ \\
\hline $\begin{array}{l}\text { miscellaneous/ } \\
\text { unknown/ other }\end{array}$ & & & & 25 & 1 & 61 & 87 & $15.99 \%$ \\
\hline molybdenum & & & & 22 & & & 22 & $4.04 \%$ \\
\hline oils & & & & 40 & 47 & & 87 & $15.99 \%$ \\
\hline paints/ lucite & 11 & & & & & & 1 & $0.18 \%$ \\
\hline paper/ cardboard & 172 & 22 & 1) & 40 & 47 & 80 & 362 & $66.54 \%$ \\
\hline plasticl polyurathane & 238 & 22 & 1 & 40 & 48 & 80 & 429 & $78.86 \%$ \\
\hline rock gravel & & & & & 29 & & 29 & $5.33 \%$ \\
\hline rubber & & & & 16 & 48 & 80 & 144 & $26.47 \%$ \\
\hline stainless steel & & & & 21 & & & 21 & $3.86 \%$ \\
\hline $\begin{array}{l}\text { wood/lumberl } \\
\text { plywood }\end{array}$ & & 22 & & 40 & 30 & 55 & 147 & $27.02 \%$ \\
\hline $\begin{array}{l}\text { Total Number of } \\
\text { Drums }\end{array}$ & 262 & 22 & 1 & 69 & 48 & 142 & 544 & $100.00 \%$ \\
\hline
\end{tabular}




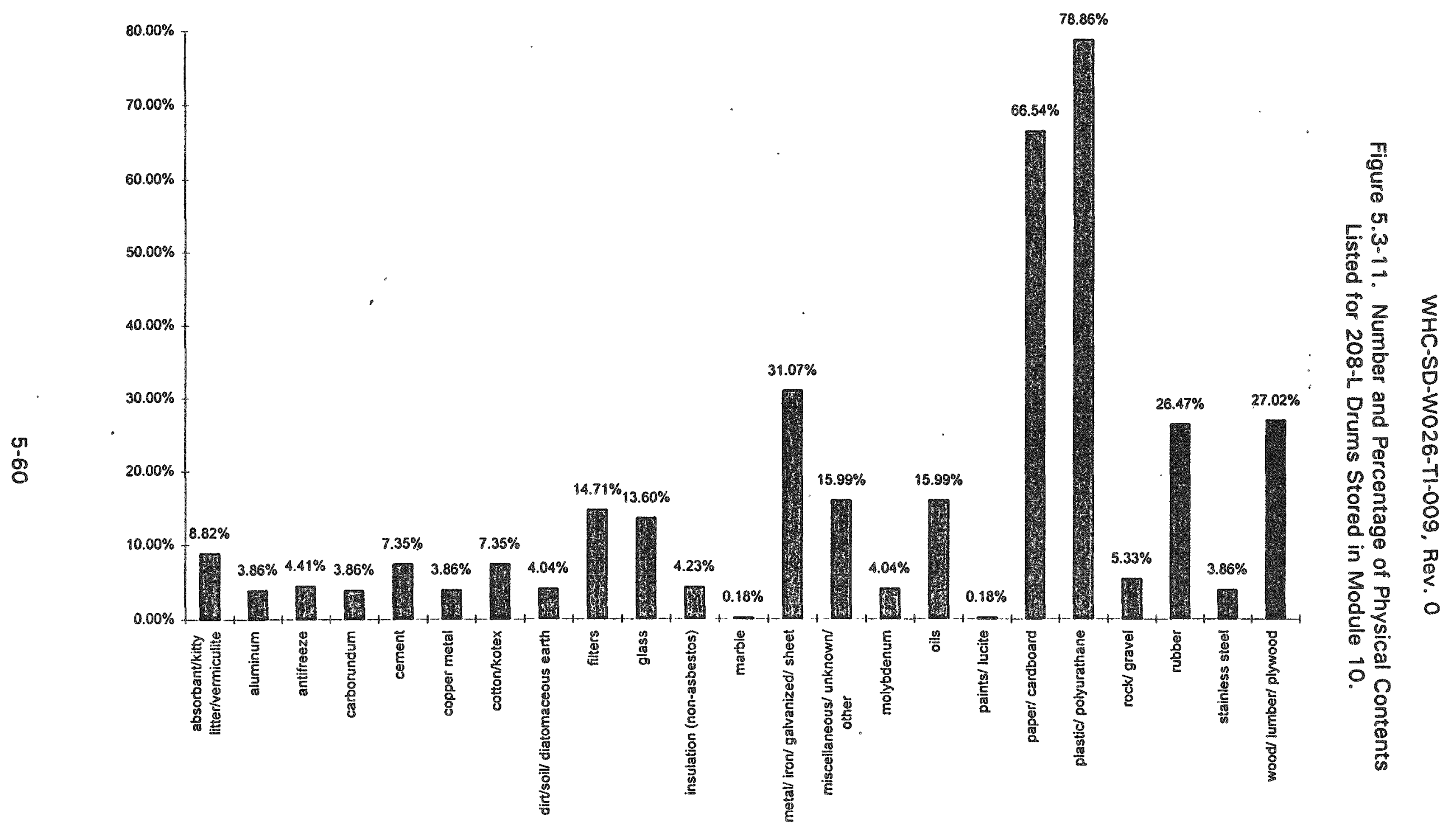


Figure 5.3-12 shows the number and percentage of physical contents listed for 208-L stored Module 9. Module 9 contains 50 drums $19 \%$ of the total) from WARDMNFD designated as miscellaneous, unknown, or other. Also, $2 \%$ of the drums ( 9 drums) contain $40 \%$ dirt, soll, or diatomaceous earth by volume from PFP.

Figure 5.3-12. Number and Percentage of Physical Contents Listed for 208-L Drums Stored in Module 9.

\begin{tabular}{|c|c|c|c|c|c|c|c|c|c|c|}
\hline & $\begin{array}{l}1 \\
\frac{1}{1} \\
\text { N } \\
0 \\
\frac{1}{3} \\
3\end{array}$ & $\begin{array}{l}\text { O } \\
\frac{1}{3} \\
\frac{1}{3}\end{array}$ & $\begin{array}{l}\frac{2}{2} \\
\frac{2}{3} \\
\frac{y}{3}\end{array}$ & $\begin{array}{l}\text { 유 } \\
\text { 3. } \\
\text { 굴 } \\
\text { L }\end{array}$ & $\begin{array}{l}\frac{N}{1} \\
\frac{1}{3} \\
\frac{1}{2} \\
\frac{2}{2}\end{array}$ & $\begin{array}{l}\frac{0}{\frac{1}{2}} \\
\frac{3}{2} \\
\frac{1}{3} \\
3\end{array}$ & $\begin{array}{l}8 \\
\stackrel{5}{4} \\
\end{array}$ & $\begin{array}{l}z \\
\frac{z}{8} \\
\stackrel{x}{4} \\
\end{array}$ & TOTAL & PERCENTAGE \\
\hline $\begin{array}{l}\text { absorbant/ kitty } \\
\text { inter/ vermiculite }\end{array}$ & & 25 & & & & 22 & & & 47 & $8.15 \%$ \\
\hline cement & & 17 & & & & & & & 17 & $2.95 \%$ \\
\hline cloth/ rags/ rylon & 282 & & 1 & & & 29 & & & 312 & $54.07 \%$ \\
\hline concrele & & 25 & & & & & & & 25 & $4.33 \%$ \\
\hline cotton/ kotex & & 4 & & & & & & & 4 & $0.69 \%$ \\
\hline $\begin{array}{l}\text { dirt soill } \\
\text { diatomaceous } \\
\text { earth }\end{array}$ & 9 & & & & & & & & 9 & $1.56 \%$ \\
\hline glass & & 49 & & 32 & & 23 & & & 104 & $18.02 \%$ \\
\hline $\begin{array}{l}\text { insulation (non- } \\
\text { asbestos) }\end{array}$ & & & & & & 22 & & & 22 & $3.81 \%$ \\
\hline $\begin{array}{l}\text { metal/iron/ } \\
\text { galvanized/sheet }\end{array}$ & 7 & 53 & 1 & 32 & & 1 & & 1 & 95 & $16.46 \%$ \\
\hline $\begin{array}{l}\text { miscellaneous/ } \\
\text { unknown/other }\end{array}$ & & & & & & 50 & & & 50 & $8.67 \%$ \\
\hline paperl cardboard & 214 & 53 & 1 & 32 & 1 & 51 & 19 & & 371 & $64.30 \%$ \\
\hline $\begin{array}{l}\text { plastic } \\
\text { polyurathane }\end{array}$ & 359 & 53 & 1 & 32 & 1 & 51 & 19 & 1 & 517 & $89.60 \%$ \\
\hline rubber & 31 & 4 & & 12 & 1 & 51 & 19 & 1 & 119 & $20.62 \%$ \\
\hline $\begin{array}{l}\text { Total Number of } \\
\text { Drums }\end{array}$ & 398 & 24 & 0 & 61 & 4 & 52 & 40 & 1 & 577 & $100.00 \%$ \\
\hline
\end{tabular}

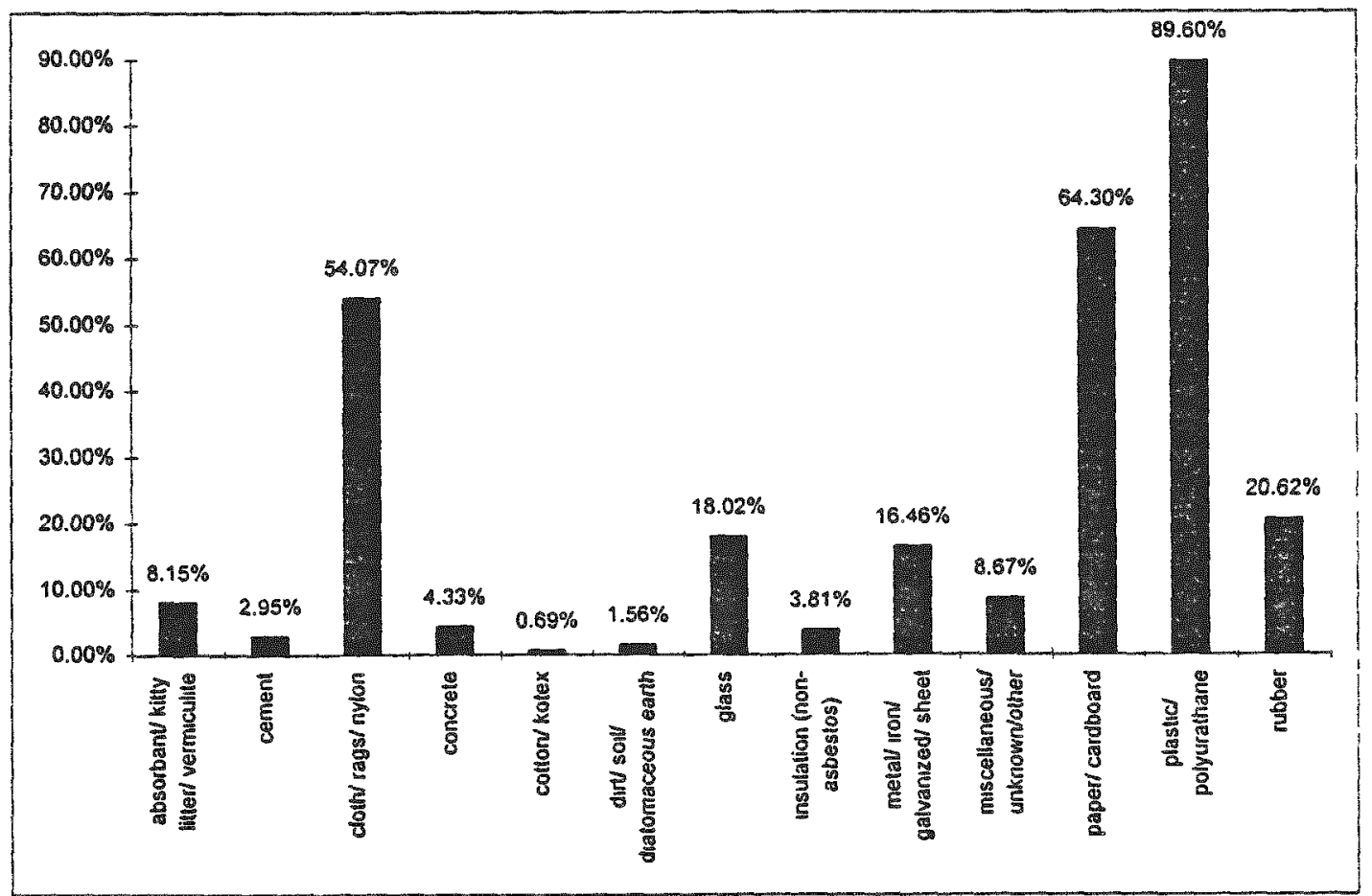


Figure 5.3-13 shows the number and percentage of physical contents listed for 208-L drums stored Module 8 . In Module 8 , there are 8 drums $(1 \%$ of the total number) from PNL building 340 that contain $15 \%$ animal waste, which is prohibited from WRAP Module 1 processing. Also, there is 1 drum $1.17 \%$ of the total number) from the PFP that contains only filters.

Figure 5.3-13. Number and Percentage of Physical Contents Listed for 208-L. Drums stored in Module 8.

\begin{tabular}{|c|c|c|c|c|c|c|c|c|}
\hline & 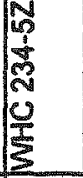 & $\begin{array}{l}\text { Sิ } \\
\frac{0}{3} \\
\frac{1}{3}\end{array}$ & $\begin{array}{l}0 \\
\text { D } \\
0 \\
3 \\
3\end{array}$ & $\begin{array}{l}\mathscr{2} \\
\text { N̂ } \\
\frac{U}{1} \\
\frac{1}{3}\end{array}$ & $\frac{0}{\frac{0}{2}}$ & $\begin{array}{l}\frac{1}{8} \\
\frac{8}{8} \\
\frac{1}{2} \\
0\end{array}$ & TOTAL & PERCENTAGE \\
\hline $\begin{array}{l}\text { absorbant/ kitty } \\
\text { litter/ vermiculite }\end{array}$ & & & 20 & & & & 20 & $3.42 \%$ \\
\hline animal waste & & & & & 8 & & 8 & $1.37 \%$ \\
\hline cloth/ rags/ nyion & 392 & 23 & & 18 & & & 433 & $74.02 \%$ \\
\hline concrete & & & 16 & & & & 16 & $2.74 \%$ \\
\hline cotton/ kotex & & 53 & 4 & & & & 57 & $9.74 \%$ \\
\hline filters & 1 & & & & & & 1 & $0.17 \%$ \\
\hline glass & 31 & & & & 15 & & 46 & $7.86 \%$ \\
\hline $\begin{array}{l}\text { metal/iron/ } \\
\text { galvanized/sheet }\end{array}$ & 57 & 53 & 24 & 18 & 15 & & 167 & $28.55 \%$ \\
\hline paper/ cardboard & 440 & 53 & 24 & 18 & 15 & 9 & 559 & $95.56 \%$ \\
\hline $\begin{array}{l}\text { plastic } \\
\text { polyurathane }\end{array}$ & 384 & 53 & 24 & 18 & 15 & 9 & 503 & $85.98 \%$ \\
\hline rubber & 388 & & & & & 9 & 397 & $67.86 \%$ \\
\hline $\begin{array}{l}\text { wood/ lumber/ } \\
\text { plywood }\end{array}$ & & & 8 & & 7 & & 15 & $2.56 \%$ \\
\hline $\begin{array}{l}\text { Total Number of } \\
\text { Drums }\end{array}$ & 457 & 53 & 24 & 27 & 15 & 9) & 585 & $100.00 \%$ \\
\hline
\end{tabular}

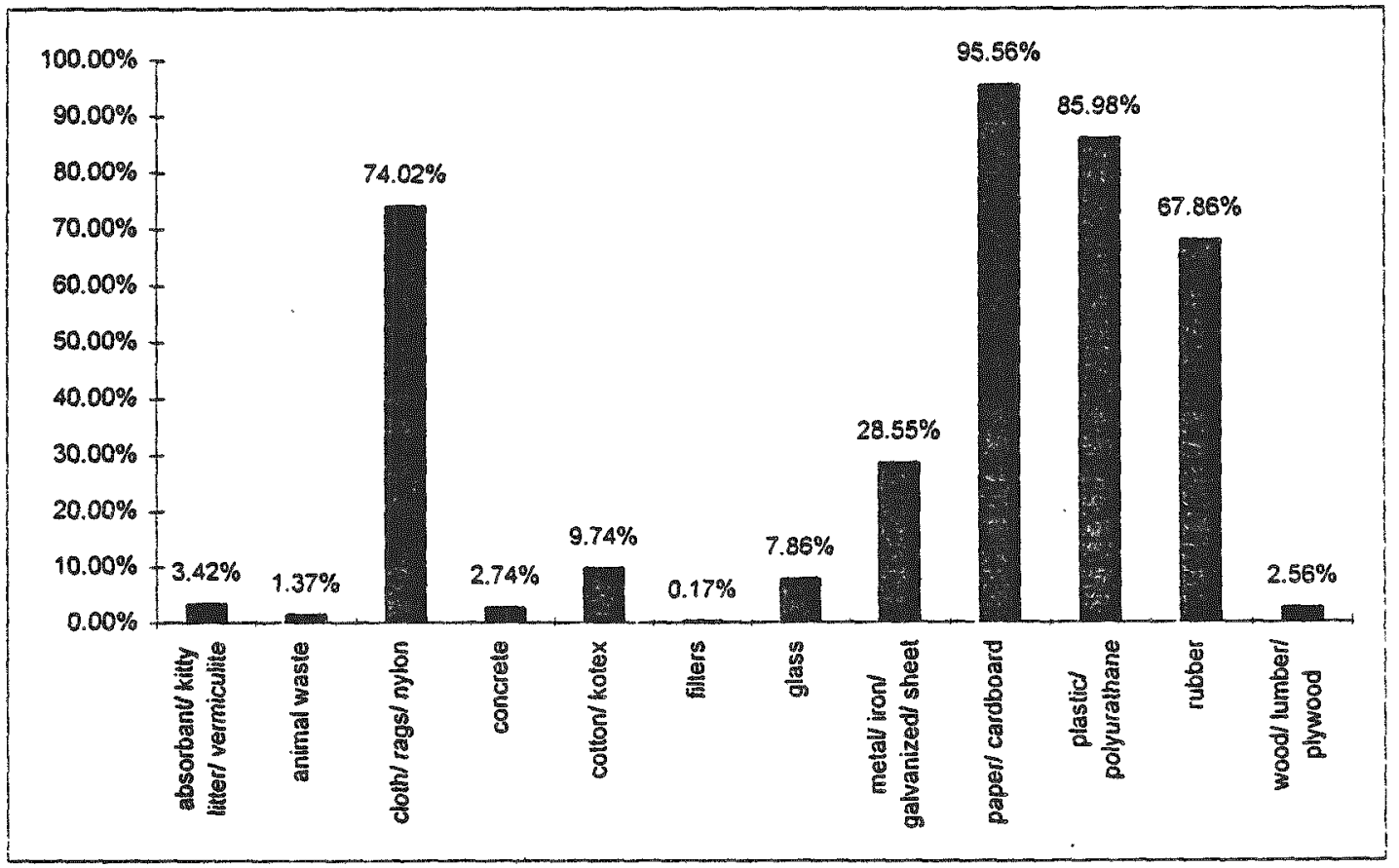


Figure 5.3-14 shows the number and percentage of physical contents listed for 208-L drums stored Module 7. In Module 7, there are 8 drums (1\% of the total number) from PNL building 325 that contain $15 \%$ volume animal waste. Also, there are 8 drums from the PFP that contain miscellaneous, unknown, or other wastes.

Figure 5.3-14. Number and Percentage of Physical Contents Listed for 208-L Drums Stored in Module 7.

\begin{tabular}{|c|c|c|c|c|c|c|c|}
\hline & 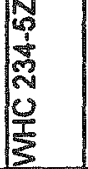 & $\begin{array}{l}\text { 跑 } \\
\text { 勺े } \\
\frac{1}{3}\end{array}$ & $\begin{array}{l}\frac{4}{5} \\
\frac{5}{2} \\
\frac{T}{3} \\
\frac{T}{3}\end{array}$ & $\begin{array}{l}\text { लू } \\
\text { के } \\
\frac{1}{a}\end{array}$ & $\begin{array}{l}\frac{y}{2} \\
\frac{1}{2} \\
\frac{1}{2}\end{array}$ & TOTAL & PERCENTAGE \\
\hline $\begin{array}{l}\text { absorbant/ kitty } \\
\text { litterf vermiculite }\end{array}$ & & 11 & & & & 11 & $1.91 \%$ \\
\hline animal waste & & & & 8 & & 8 & $1.39 \%$ \\
\hline cloth/ rags/ nylon & 472 & & 6 & & 3 & 481 & $83.51 \%$ \\
\hline concrete & & 27 & & & & 27 & $4.69 \%$ \\
\hline glass & & 16 & & 17 & & 33 & $5.73 \%$ \\
\hline $\begin{array}{l}\text { metal/ iron/ } \\
\text { galvanized/ sheet }\end{array}$ & & 27 & & 17 & 5 & 49 & $8.51 \%$ \\
\hline $\begin{array}{l}\text { miscellaneous/ } \\
\text { unknown/ other }\end{array}$ & 8 & & & & & 8 & $1.39 \%$ \\
\hline paper/ cardboard & 499 & 27 & 6 & 17 & 3 & 552 & $95.83 \%$ \\
\hline $\begin{array}{l}\text { plasticl } \\
\text { polyurathane }\end{array}$ & 498 & 27 & 6 & 17 & 3 & 554 & $95.66 \%$ \\
\hline rubber & 445 & & 6 & & & 451 & $78.30 \%$ \\
\hline $\begin{array}{l}\text { wood/ lumberl } \\
\text { plywood }\end{array}$ & & 16 & & & 3 & 19 & $3.30 \%$ \\
\hline $\begin{array}{l}\text { Total Number of } \\
\text { Drums }\end{array}$ & 518 & 27 & 6 & 17 & 8 & 576 & $100.00 \%$ \\
\hline
\end{tabular}

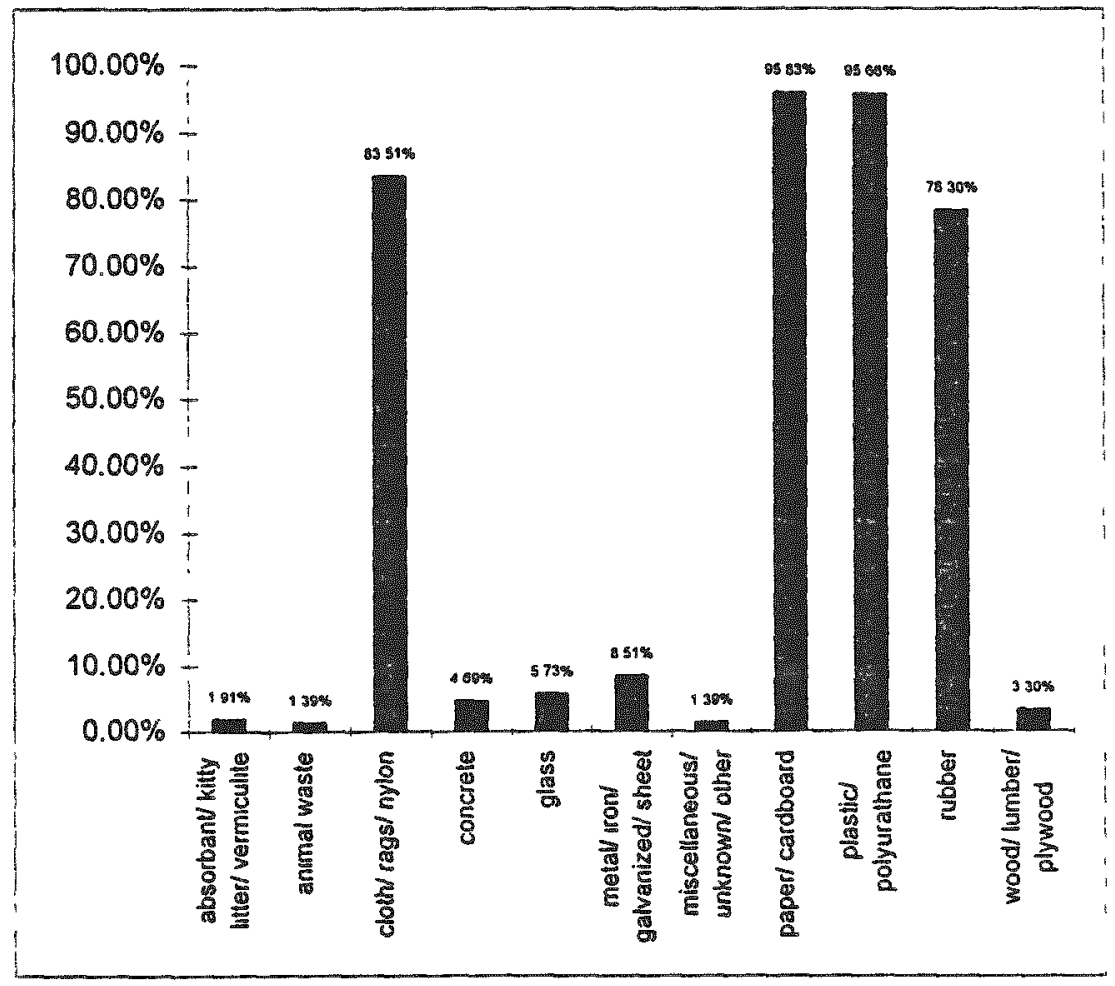


Figure 5.3-15 shows the number and percentage of physical contents listed for 208-L drums stored Module 6. In Module 6. there are 82 drums $116 \%$ of the total number) from WHC building 325 that contain $50 \%$ volume filters. Also, there are 16 drums $13 \%$ of the total number) from the PFP. WHC building 233-S, WHC building 325, and PNL building 325 that contain miscellaneous, unknown, or other wastes.

Figure 5.3-15. Number and Percentage of Physical Contents Listed for 208-L Drums Stored in Module 6.

\begin{tabular}{|c|c|c|c|c|c|c|c|}
\hline & 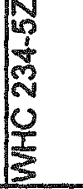 & 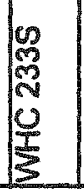 & $\begin{array}{l}0 \\
\frac{1}{3} \\
\frac{1}{3}\end{array}$ & $\begin{array}{l}\text { กิ } \\
\text { के } \\
\frac{1}{2}\end{array}$ & $\begin{array}{l}\frac{N}{2} \\
\stackrel{2}{2} \\
\frac{1}{2}\end{array}$ & TOTAL & PERCENTAGE \\
\hline $\begin{array}{l}\text { absorbant kitty } \\
\text { litter/ vermiculite }\end{array}$ & & & 7 & & & 7 & $4.35 \%$ \\
\hline cloth/ rags/ nylon & 24 & 5 & 53 & & & 82 & $15.80 \%$ \\
\hline concrete & & & 18 & & & 18 & $3.47 \%$ \\
\hline filters & & & 82 & & & 82 & $15.80 \%$ \\
\hline glass & & & 11) & 14 & & 25 & $4.82 \%$ \\
\hline $\begin{array}{l}\text { metal/iron/ } \\
\text { galvanized/ sheer }\end{array}$ & & 6 & 7 & 83 & & 96 & $18.50 \%$ \\
\hline $\begin{array}{l}\text { miscellaneous/ } \\
\text { unknown/ other }\end{array}$ & 7 & 7 & 1 & 1 & & 16 & $3.08 \%$ \\
\hline paper/ cardboard & 24 & 6 & 60 & 83 & & 173 & $33.33 \%$ \\
\hline $\begin{array}{l}\text { plasticl } \\
\text { polyurathane }\end{array}$ & 24 & 6 & 58 & 83 & & 171 & $32.95 \%$ \\
\hline rubber & 24 & & 7 & 83 & & 114 & $21.97 \%$ \\
\hline $\begin{array}{l}\text { wood/lumber/ } \\
\text { plywood }\end{array}$ & & & 53 & & & 53 & $10.21 \%$ \\
\hline $\begin{array}{l}\text { Total Number of } \\
\text { Drums }\end{array}$ & 308 & 7 & 104 & 86 & 14 & 519 & $100.00 \%$ \\
\hline
\end{tabular}

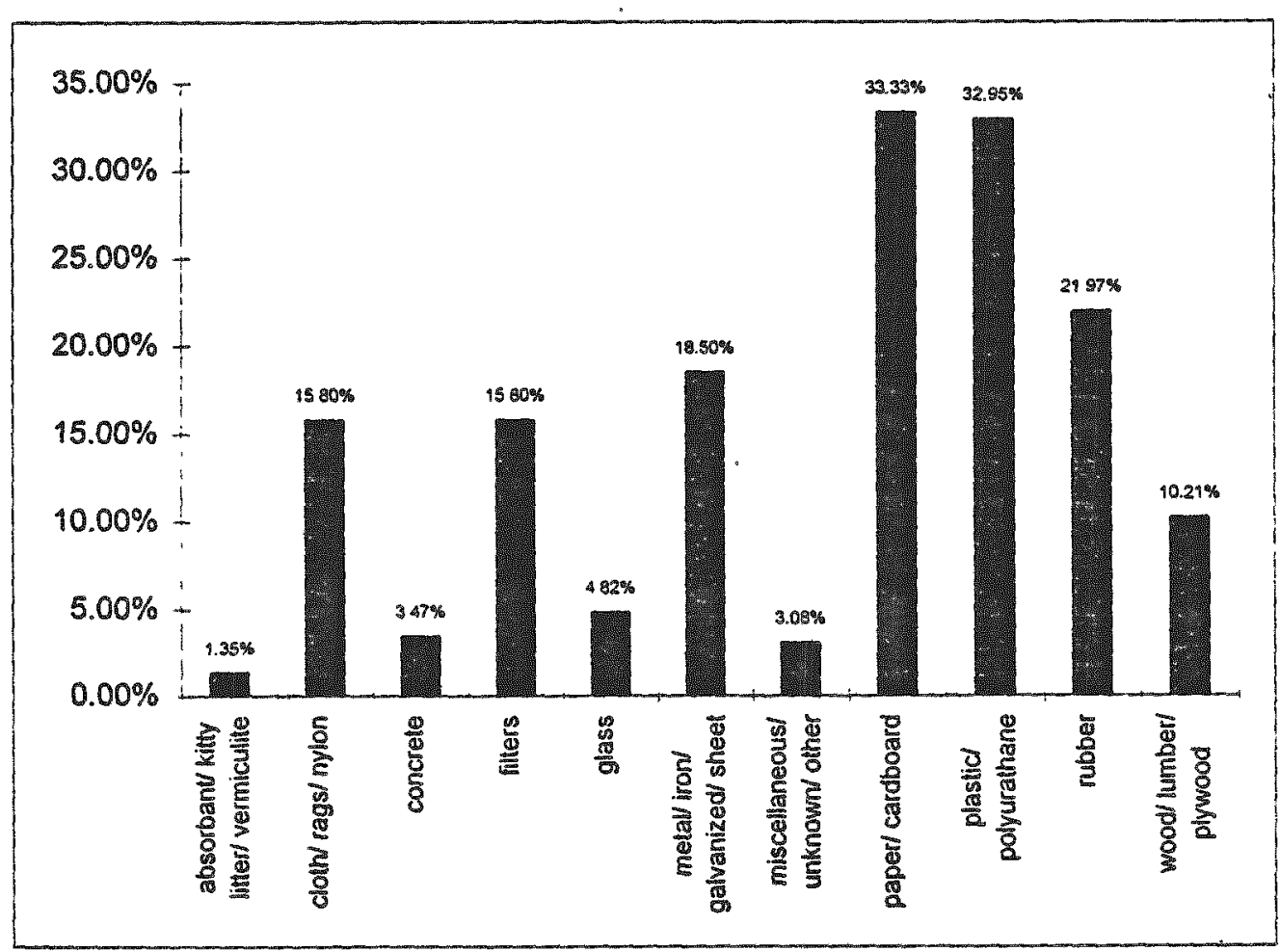


Figure 5.3-16 shows the number and percentage of physical contents listed for 208-L drums stored Module 5. In Module 5, there are 6 drums $11 \%$ of the total number) from PNL building 325 that contain $10 \%$ volume of dirt, soil, or diatomaceous earth. Also, there are 20 drums ( $3 \%$ of the total number) from the PFP. WHC building 325, and PNL building 325 that contain miscellaneous, unknown, or other wastes.

Figure 5.3-16. Number and Percentage of Physical Contents Listed for 208-L Drums Stored in Module 5.

\begin{tabular}{|c|c|c|c|c|c|c|}
\hline & 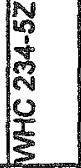 & 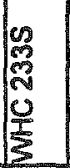 & $\begin{array}{l}\text { \%ึ } \\
\frac{1}{3} \\
\frac{1}{3}\end{array}$ & 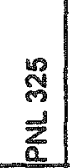 & TOTAL & PERCENTAGE \\
\hline $\begin{array}{l}\text { absorbant/ kitty } \\
\text { litter/ vermiculite }\end{array}$ & & & 2 & & 2 & $0.35 \%$ \\
\hline cloth rags/ nylon & & 8 & 11 & 22 & 41 & $7.16 \%$ \\
\hline concrete & & & 10 & & 10 & $1.75 \%$ \\
\hline cotton/ kotex & & & & 6 & 6 & $1.05 \%$ \\
\hline $\begin{array}{l}\text { dirt/ soil/ } \\
\text { diatomaceous } \\
\text { earth }\end{array}$ & & & & 6 & 6 & $1.05 \%$ \\
\hline glass & & & 8 & 24 & 32 & $5.58 \%$ \\
\hline $\begin{array}{l}\text { metal/iron/ } \\
\text { galvanized/sheet }\end{array}$ & & & 2 & 76 & 78 & $43.61 \%$ \\
\hline $\begin{array}{l}\text { miscellaneous/ } \\
\text { unknown other }\end{array}$ & 9 & & 10 & 1 & 20 & $3.49 \%$ \\
\hline paper/ cardboard & & 8 & 11 & 76 & 95 & $16.58 \%$ \\
\hline $\begin{array}{l}\text { plasticl } \\
\text { polyurathane }\end{array}$ & & 8 & 11 & 76 & 95 & $16.58 \%$ \\
\hline rubber & & & & 71 & 71 & $12.39 \%$ \\
\hline $\begin{array}{l}\text { wood/lumberl } \\
\text { plywood }\end{array}$ & & & 8 & 5 & 13 & $2.27 \%$ \\
\hline $\begin{array}{l}\text { Total Number of } \\
\text { Drums }\end{array}$ & 356 & 14 & 87 & 119 & 573 & $100.00 \%$ \\
\hline
\end{tabular}

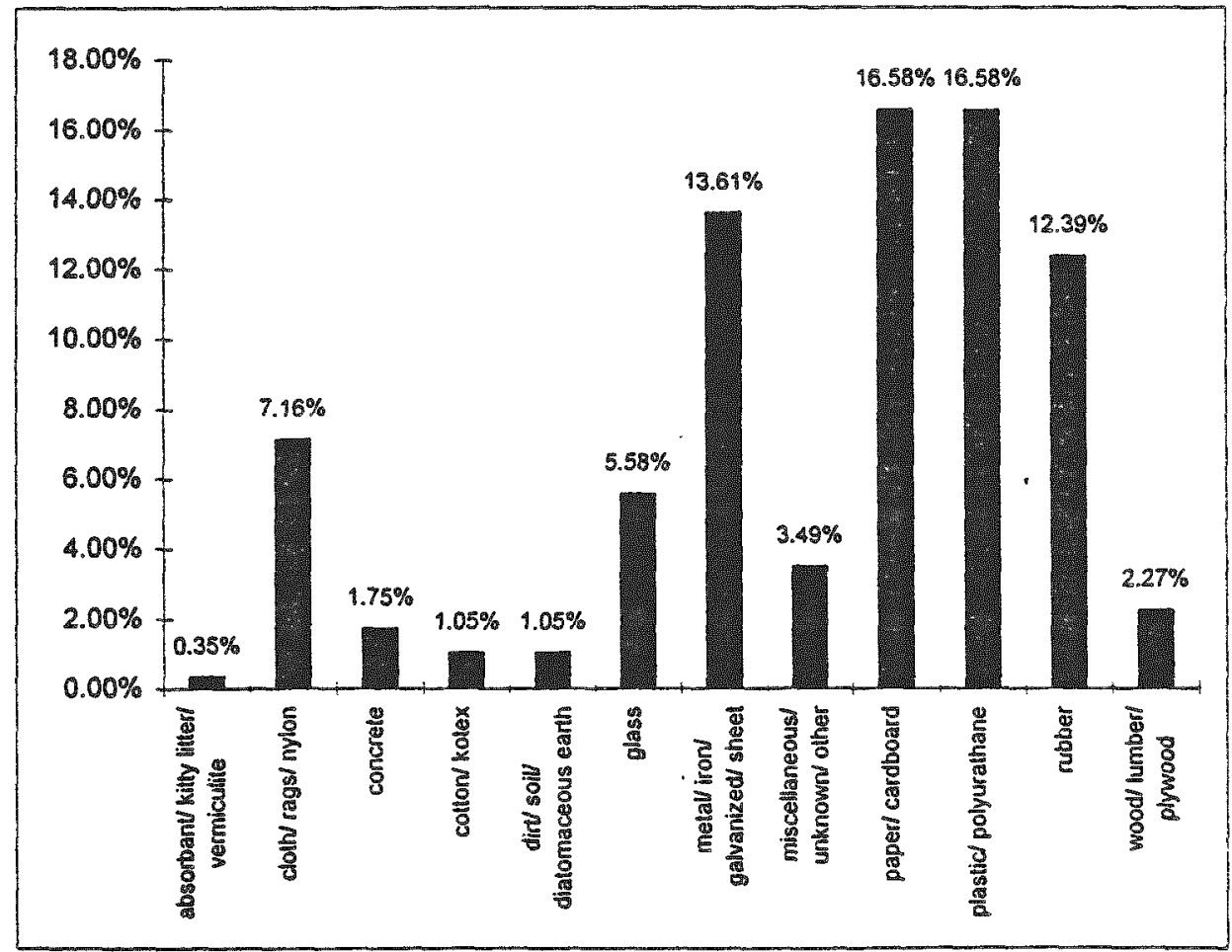


Figure 5.3-17 shows the number and percentage of physical contents listed for 208-L drums stored Module 4. In Module 4, contents are listed for only 27 of 602 drums, or $4.4 \%$ of the total number of drums. Of those listed, 23 drums (3.8\% of the total number) are listed as miscellaneous, unknown, or other. The other $0.6 \%$ is listed as metal, iron, galvanized, or sheet metal (100\% of the volume).

Figure 5.3-17. Number and Percentage of Physical Contents Listed for 208-L. Drums stored in Module 4.

\begin{tabular}{|c|c|c|c|c|c|c|c|c|}
\hline & $\frac{\mathbb{\alpha}}{\delta}$ & $\frac{\kappa}{\delta}$ & $\begin{array}{l}N \\
0 \\
1 \\
1 \\
2 \\
2 \\
0 \\
1 \\
3 \\
3\end{array}$ & $\begin{array}{l}\text { Nิ } \\
\text { กิ } \\
\frac{1}{1} \\
\end{array}$ & $\begin{array}{l}\text { \& } \\
\text { J } \\
\frac{1}{3}\end{array}$ & $\frac{N}{2}$ & TOTAL & PERCENTAGE \\
\hline $\begin{array}{l}\text { metal/iron/ } \\
\text { galvanized/ sheet }\end{array}$ & & & 4 & & & & 4 & $0.66 \%$ \\
\hline $\begin{array}{l}\text { miscellaneous/ } \\
\text { unknown/ other }\end{array}$ & & 17 & 2 & 4 & & & 23 & $3.82 \%$ \\
\hline $\begin{array}{l}\text { Total Number of } \\
\text { Drums }\end{array}$ & 6 & 66 & 311 & 100 & 24 & 95 & 602 & $100.00 \%$ \\
\hline
\end{tabular}

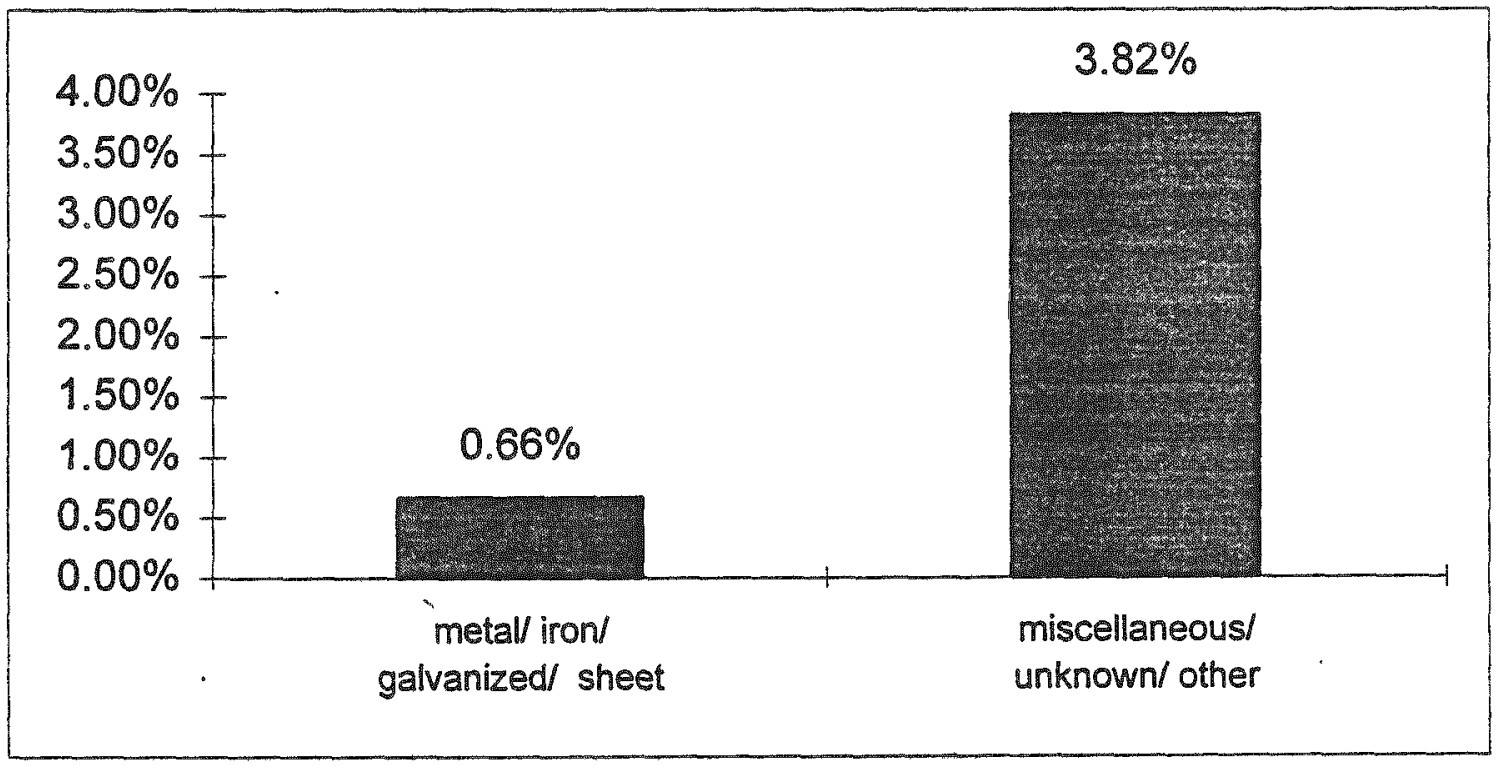


Figure 5.3-18 shows the number and percentage of physical contents listed for 208-L drums stored Module 3. In Module 3, contents are listed for only 12 of 566 drums, or $2 \%$. Of those listed, 8 drums (1.5\% of the total number) are listed as miscellaneous, unknown, or other. The other $0.5 \%$ is listed as various combustible, compatible waste types $125 \%$ volume).

Figure 5.3-18. Number and Percentage of Physical Contents Listed for 208-L Drums Stored in Module 3.

\begin{tabular}{|c|c|c|c|c|c|c|}
\hline MODULE 3 & 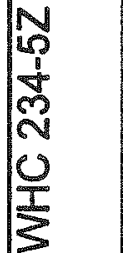 & $\begin{array}{l}\text { స్ } \\
\text { लొ } \\
\frac{U}{3} \\
\frac{1}{3}\end{array}$ & $\begin{array}{l}\text { مै } \\
\text { กै } \\
\frac{1}{2}\end{array}$ & $\begin{array}{l}\frac{N}{\frac{1}{N}} \\
\text { N } \\
\frac{1}{2} \\
\end{array}$ & TOTAL & PERCENTAGE \\
\hline cloth/ rags/ nylon & 1 & & & & \begin{tabular}{r|}
1 \\
\end{tabular} & $0.18 \%$ \\
\hline $\begin{array}{l}\text { miscellaneous/ } \\
\text { unknown/ other }\end{array}$ & 4 & 4 & & & 8 & $1.41 \%$ \\
\hline paper/ cardboard & 1 & & & & 1 & $0.18 \%$ \\
\hline $\begin{array}{l}\text { plasticl } \\
\text { polyurathane }\end{array}$ & 1 & & & & 1 & $0.18 \%$ \\
\hline rubber & 1 & & & & 1 & $0.18 \%$ \\
\hline $\begin{array}{l}\text { Total Number of } \\
\text { Drums }\end{array}$ & 464 & 49 & 39 & 14 & 566 & $100.00 \%$ \\
\hline
\end{tabular}

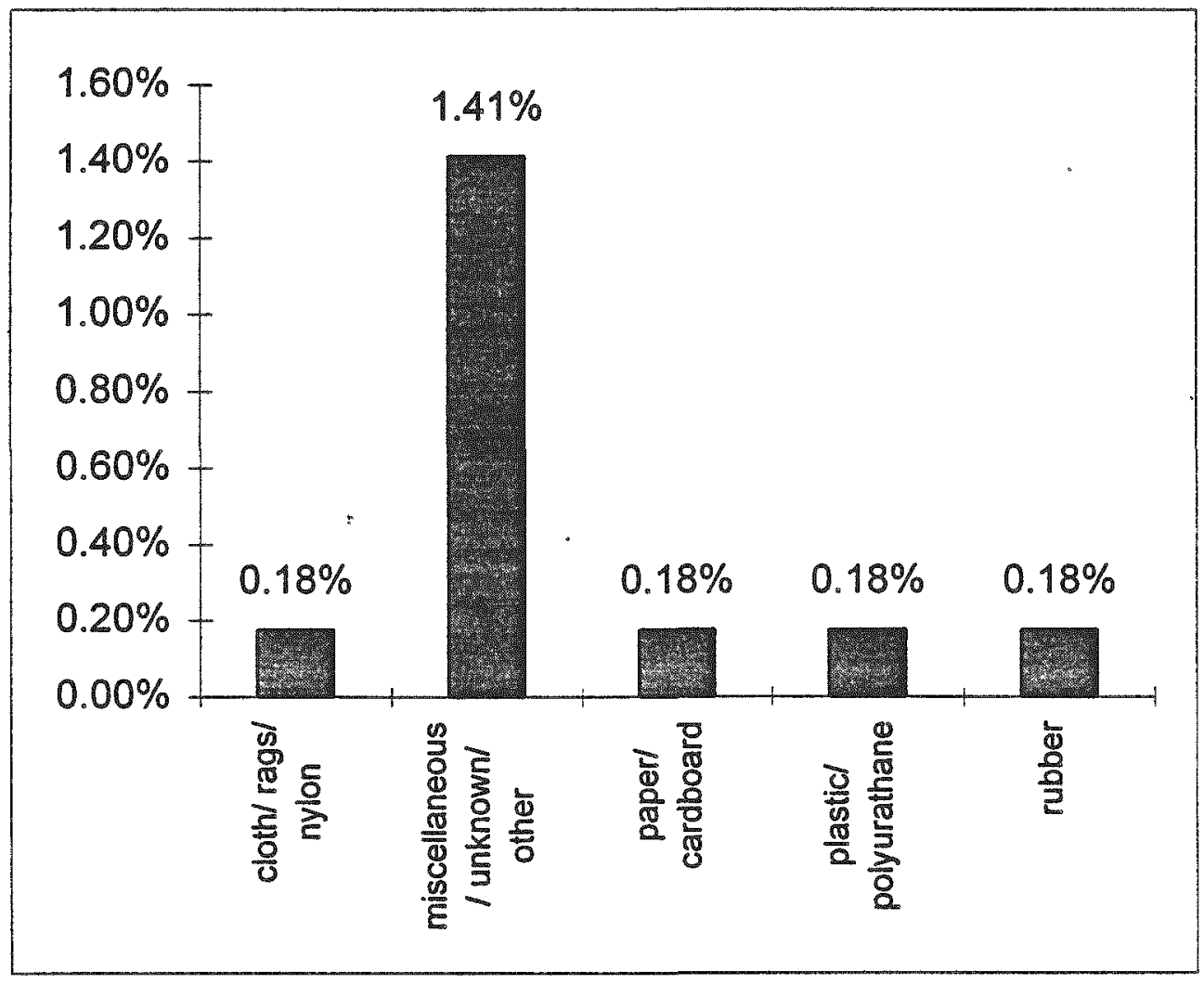


Figure 5.3-19 shows the number and percentage of physical contents listed for 208-L drums stored Module 2. In Module 2, contents are listed for only 39 of 719 drums, or $5.5 \%$. Of those listed 11 drums $11.5 \%$ of the total number) are listed as miscellaneous, unknown, or other. The other $4 \%$ is listed as various combustible, compatible waste types $125 \%$ volumes).

Figure 5.3-19. Number and Percentage of Physical Contents Listed for 208-L Drums Stored in Module 2.

\begin{tabular}{|c|c|c|c|c|c|c|c|c|c|c|}
\hline & న్ & $\begin{array}{l}\mathscr{N} \\
\text { Nิ } \\
\frac{U}{3}\end{array}$ & 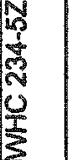 & $\begin{array}{l}\text { స్ } \\
\text { ญै } \\
\frac{1}{3}\end{array}$ & 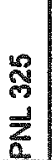 & $\begin{array}{l}\frac{5}{2} \\
\text { బิ } \\
\frac{1}{2}\end{array}$ & $\begin{array}{l}\frac{y}{2} \\
\frac{1}{2} \\
\frac{2}{2}\end{array}$ & $\sum_{\mathbb{\infty}}$ & TOTAL & PERCENTAGE \\
\hline cloth/rags/nylon & 2 & & 3 & 1 & 1 & & & & 7 & $0.97 \%$ \\
\hline $\begin{array}{l}\text { miscellaneous/ } \\
\text { unknown/other }\end{array}$ & & & 1 & 5 & & 4 & & 4 & 11 & $1.53 \%$ \\
\hline paper/ cardboard & 2 & & 3 & 1 & 1 & & & & 7 & $0.97 \%$ \\
\hline $\begin{array}{l}\text { plasticl } \\
\text { polyurathane }\end{array}$ & 2 & & 3 & 1 & & 1 & & & 7 & $0.97 \%$ \\
\hline rubber & 2 & & 3 & 1 & & 11 & & & 7 & $0.97 \%$ \\
\hline $\begin{array}{l}\text { Total Number of } \\
\text { Drums }\end{array}$ & 10 & 3 & 394 & 214 & 27 & 5 & 24 & 42 & 719 & $100.00 \%$ \\
\hline
\end{tabular}

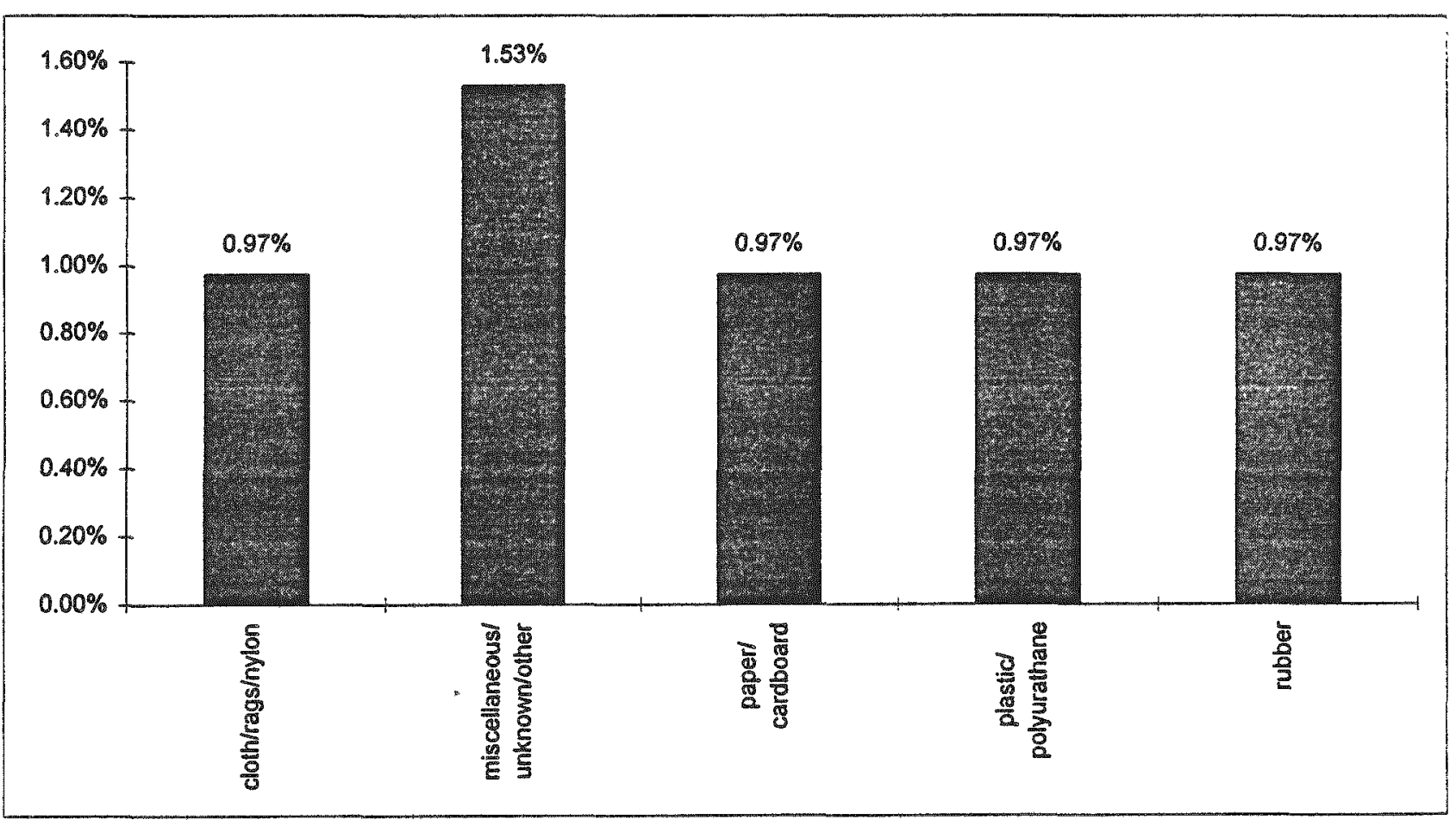


Figure 5.3-20 shows the number and percentage of physical contents listed for 208-L drums stored in Module 1. Module 1 lists the contents of only 28 of 718 drums, or $4 \%$. All of those drums are listed as miscellaneous, unknown, or other.

Figure 5.3-20. Number and Percentage of Physical Contents Listed for 208-L Drums Stored in Module 1.

\begin{tabular}{|c|c|c|c|c|c|c|c|}
\hline & 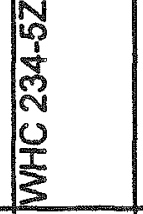 & $\begin{array}{l}\text { N } \\
\text { } \\
0 \\
\frac{0}{1} \\
3\end{array}$ & $\begin{array}{l}\mathbb{5} \\
\text { हn } \\
\text { है } \\
\frac{3}{2} \\
\text { Z }\end{array}$ & $\begin{array}{l}\frac{N}{2} \\
\text { D } \\
\frac{Z}{Z} \\
\end{array}$ & $\begin{array}{l}\text { N } \\
\text { N } \\
0 \\
\frac{1}{\alpha} \\
\end{array}$ & TOTAL & PERCENTAGE \\
\hline $\begin{array}{l}\text { miscellaneous/ } \\
\text { unknown/ other }\end{array}$ & 26 & 2 & & & & 28 & $3.90 \%$ \\
\hline Total Number of Drums & 573 & 77 & 16 & 48 & 4 & 718 & $100.00 \%$ \\
\hline
\end{tabular}

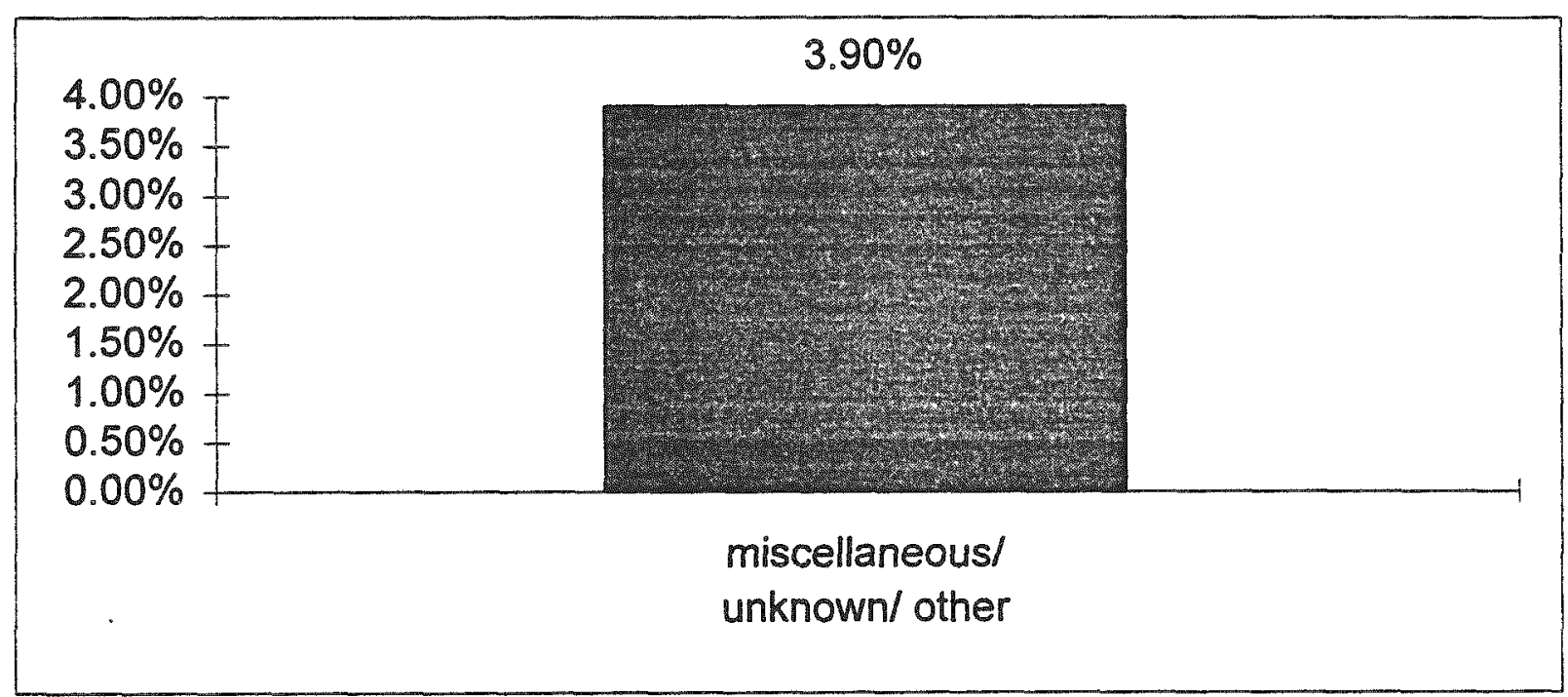


Figure 5.3-21 shows the numbers and percentage of physical contents for which no module is given. Of the 295 drums whose contents are listed, but for which no module is given. 199 contain combustible, compatible materials such as paper, plastic, and cloth $11 \%$ volume $\min _{0}: 85 \%$ volume max.). Another 22 drums contain non-combustible, noncompatible waste types such as metals and concrete ( $1 \%$ min.: $55 \%$ max.) and 25 contain combustible, non-compatible materials such as wood, lumber, paint, and Lucite $11 \%$ min.; $19 \%$ max.). The contents of 27 drums are miscellaneous, unknown, or other wastes while 4 contain filters $(13 \%$ volume min.; $40 \%$ volume max.). The drums listed that contain hazardous constituents include: 7 with antifreeze (4\% volume), 8 with oils $(1 \%$ volume min.; $20 \%$ volume max.), 2 with organics (5\% volume), and 1 with solvents ( $35 \%$ volume).

Figure 5.3-21. Number and Percentage of Physical Contents Listed for 208-L Drums for which Module is Unknown.
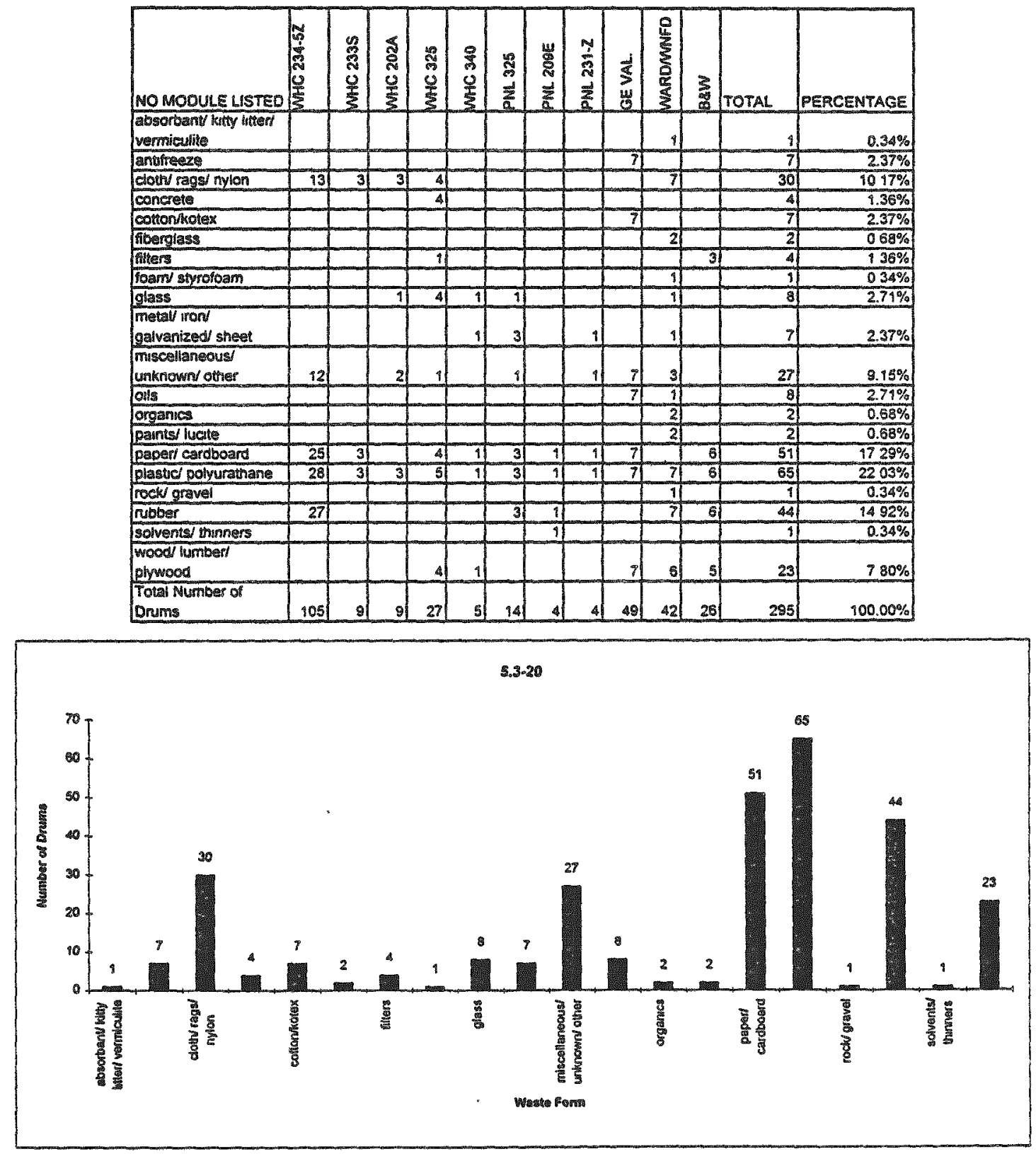


\subsection{HAZARDOUS/DANGEROUS CHEMICALS}

The information about hazardous chemicals presented in this section comes from many sources, but due to the fact that hazardous constituents were not required to be listed on the solid waste burial records until 1986, it is not always complete. Characterization reports have been completed for the largest generators of historical waste: the PFP (Duncan et al. 1993), the PUREX Plant (Pottmeyer et al. 1993a), building 213-Z (Pottmeyer et al. 1993b), the 325 Laboratory (shared by WHC and PNL) (Pottmeyer et al. 1993c), GE's Vallecitos Nuclear Center (Vejvoda et al. 1993), B \& W Leechburg, PA facility (Duncan 1994a), and WARDMNFD (Duncan 1994b). These reports were compiled using historical documents, the SWITS database, and interviews with knowledgeable individuals. These major generators produced approximately $86 \%$ of the retrievably stored waste that will be batched. Similar reports are not available for the $14 \%$ of the waste produced by other generators.

There are very few drums for which hazardous constituents are listed in the SWITS database. Table 5.4-1 provides a list of these chemicals and substances, sorted by module number (if known) and generator. Unfortunately, many of the constituents listed are generic categories such as organic, oil, or solvent.

Because records of hazardous chemicals are not complete, testing will be required to determine which chemicals are present in each drum. The WRAP Module 1 Sampling Study and Waste Characterization Alternatives Study (Bergeson et al. 1994) identifies hazardous or dangerous chemicals suspected to be present in the mixed wastes that will be retrieved and processed in WRAP Module 1. This document reviewed the analytes expected from the largest seven generators along with possible methods for their detection including visual inspection, NDE, NDA, Field Screening, Head Gas Sampling and laboratory analysis. Table 5.4-2 summarizes the analytes expected from the major historical waste generators and the probable method for detection associated with each chemical.

Batching according to the hazardous chemicals that may be present will potentially reduce the number of tests necessary to determine the chemical content of each drum. Drums with records showing similar lists of chemicals potentially present can be batched together, since the same or similar tests can be applied. Also, drums with small numbers of chemicals potentially present chemicals will not be batched with drums that have a greater number of chemicals potentially present since these drums require more testing.

Since retrieval will begin with the most recently emplaced modules and proceed to the oldest modules, Module 19 will be discussed first and Module 1 last.

Module 19 contains waste that is $99 \%$ from the PFP, $1 \%$ from ESG, and less that $1 \%$ from building 308. Since ESG and building 308 are relatively minor generators, they are not covered by Table 5.4-2. Table 5.2-2 does show a list of all chemicals that will have to be tested for in the PFP batch and the recommended method of testing for each chemical. There are several hazardous chemicals that are known to be present in this module. SWITS records show that there are 3 drums containing lead from the ESG. 
WHC-SD-W026-T1-009, Rev. 0

Table 5.4.1. Hazardous Chemicals Listed in the SWITS Database

\begin{tabular}{|c|c|c|}
\hline $\begin{array}{l}\text { Module } \\
\text { Number }\end{array}$ & Generator & $\begin{array}{l}\text { Hazardous Constituents Listed } \\
\text { with Drum Count }\end{array}$ \\
\hline \multirow[t]{2}{*}{10} & GE VAL & $\begin{array}{l}\text { 23- Antifreeze } \\
4 \text { - Copper } \\
40 \text { - Oil }\end{array}$ \\
\hline & WARDNWFD & $\begin{array}{l}38 \text { - Oil } \\
9 \text { - Organic }\end{array}$ \\
\hline 11 & PNL 209E & 13 - Solvents \\
\hline 12 & GE VAL & 31 - Oil \\
\hline \multirow[t]{2}{*}{13} & GE VAL & 2- Oil \\
\hline & WARDMNFD & 56-Organic \\
\hline 14 & WARD WNFD & 1-Organic \\
\hline 16 & PNL 324 & 1 - Beryllium \\
\hline 17 & RHO 234-5Z & 3-Asbestos \\
\hline \multirow[t]{2}{*}{18} & RHO 234-5Z & 1 - Asbestos \\
\hline & RKD ESG & 6-Lead \\
\hline 19 & RKD ESG & 3-Lead \\
\hline \multirow[t]{3}{*}{ Unknown } & GE VAL & $\begin{array}{l}\text { 7- Antifreeze } \\
\text { 7- Oil }\end{array}$ \\
\hline & WARDMNFD & $\begin{array}{l}1 \text { - Oil } \\
2 \text { - Organic }\end{array}$ \\
\hline & PNL 209E & 1 -Solvents \\
\hline
\end{tabular}

Module 18 contains waste that is $7 \%$ from ESG, building 308 , and building 324 , which have not been characterized for hazardous chemicals. Of the remaining drums, $2 \%$ of the waste originated at the PUREX Plant and $91 \%$ at the PFP. These wastes will comprise two separate batches, since a majority of the tests required for these two generators are different. Table 5.2-2 shows a list of the chemicals that must be tested for in the PFP and the PUREX plant wastes, and the recommended method of testing for each chemical. The SWITS database lists 6 drums from the ESG that contain lead and 1 drum from the PFP that contains asbestos. 
Module 17 contains waste that is $6 \%$ from building 308 , building $209-E_{\text {, and building }}$ 324, which will be batched together since there are no records for these buildings. $2 \%$ of the waste originated at the PUREX Plant, and $83 \%$ at the PFP, and $9 \%$ from WARDNNFD. This will comprise three separate batches, since the tests required for the PUREX Plant and the PFP are, for the most part, different, and there are only a few tests required for WARDMNFD. This can be seen in Table 5.2-2. The SWITS database lists 3 drums from the PFP that contain asbestos.

Module 16 contains $5 \%$ of the drums from buildings 308 and 324 , which have both had the potential hazardous chemicals identified. Of the remaining $71 \%$ is from the PFP, $23 \%$ from WARDNNFD, and $1 \%$ is from building $231-Z$. These wastes could potentially form two batches: one with the waste from the PFP and one with the waste from building $231-Z$ and WARDNNFD, since these two generators require only a few tests and many of them are the same. (See Table 5.2-2). The SWITS database lists 1 drum from PNL building 324 that contains beryllium.

Module 15 contains waste that is $10 \%$ from buildings 340 and 308 , which have not been characterized for potential hazardous chemicals. Approximately $62 \%$ of the waste is from the PFP, 20\% from WARDNNFD, $7 \%$ from Babcock and Wincox, and less than $1 \%$ from the PUREX plant. These wastes will require 3 batches: one for PFP, one for the PUREX Plant, and one for $B \& W$ and WARDMNFD combined as each generator requires only a few tests and many of them are similar). (See Table 5.2-2.)

Module 14 contains waste that is $5 \%$ from building $340,59 \%$ from the PFP, $17 \%$ from B \& W, $10 \%$ from the PUREX Plant, $8 \%$ from WARDNNFD, and less than $1 \%$ from GEVallecitos. This waste can be broken up into three batches: one for waste from the PFP, one for the waste from the PUREX Plant, and one for the combined wastes of $B$ \& $W$, WARDWNFD, and GE-Vallecitos, since they share many of the same tests.

(See Table 5.2-2.) The SWITS database lists one drum from WARDNNFD containing organic materials.

Module 13 contains waste that is $8 \%$ from building $340,35 \%$ from the PFP, $27 \%$ from the PUREX Plant, $20 \%$ from WARD WNFD, $7 \%$ from GE-Vallecitos, $2 \%$ from building $231-Z$, and $1 \%$ from $B$ \& $W$. This will make four batches: one for the PFP, one for the PUREX Plant, one for B \& W, and one for the combined wastes of 231-Z, WARD/WNFD, and GE-Vallecitos. (See Table 5.2-2.) The SWITS database lists 56 drums from WARDMNFD containing organic materials and 2 drums from GE-Vallecitos containing oil.

Module 12 contains waste that is $13 \%$ from building 340 and J.A. Jones, which have not had potential hazardous chemicals characterized. Of the remaining buildings, $52 \%$ are from the PFP, $23 \%$ from $B$ \& W, and $12 \%$ from GE-Vallecitos. This will require two batches: one for the waste from the PFP, and one for the wastes from B \& W and GE-Vallecitos. (See Table 5.2-2.) The SWITS database lists 31 drums from GE-Vallecitos containing oil.

Module 11 contains waste that is $13 \%$ from buildings 340 and $209-E$, which have not been characterized. Of the remaining waste, $49 \%$ of the waste is from $B \& W, 33 \%$ from the PFP, and $5 \%$ from WARDNNFD. This will require two batches: one from the PFP, and one from $B$ \& W and WARDNNFD. (See Table 5.2-2.) The SWITS database lists 13 drums from PNL building 209-E that contain solvents. 
Module 10 contains waste that is $4 \%$ from buildings 340 and 308 , which are not characterized. Of the remaining waste, $48 \%$ of the waste is from the PFP, $26 \%$ from $B$ \& W. $13 \%$ from GE-Vallecitos, $9 \%$ from WARD WNFD, and less than $1 \%$ from building $231-2$. This will take three batches: one for the PFP waste, one for the B \& W waste, and one for the WARDNNFD, 231-Z, and GE-Vallecitos waste. (See Table 5.2-2.) The SWITS database lists 23 drums from GE-Vallecitos that contain antifreeze, 4 drums from GE-Vallecitos that contain copper, 40 drums from GE-Vallecitos that contain oil, 38 drums from WARDMNFD that contain oil, and 9 drums from WARDNNFD that contain organic material.

In Module $9,22 \%$ of the waste was generated by building $340, E S G$, and Exxon. The hazardous chemicals from these facilities have not been characterized. The remaining waste includes $69 \%$ from the PFP, $9 \%$ from WARDNNFD, and less than $1 \%$ from building $231-Z$. These wastes could comprise two batches: one with the waste from the PFP and one with the waste from building $231-Z$ and WARDMNFD. (See Table 5.2-2.)

Module 8 contains $13 \%$ of waste from buildings $340,233-S$, and $209-E$ which are incompletely characterized. An additional $78 \%$ of the waste is from the PFP, and $9 \%$ is from WHC building 325. These could comprise two separate batches. (See Table 5.2-2.)

Module 7 contains waste that is $1 \%$ from building 2WTF, which will be batched by itself since the hazardous chemicals from this building have not been characterized: $90 \%$ from the PFP: $5 \%$ from WHC building $325 ; 3 \%$ from PNL building 325 ; and $1 \%$ from building 231-Z. These wastes might comprise three batches: one from the PFP, one from WHC and PNL building 325, and one from building 231-Z. (See Table 5.2-2.)

Module 6 contains waste that is $59 \%$ from the PFP, $20 \%$ from WHC building 325. $17 \%$ from PNL building $325,3 \%$ from $231-Z$, and $1 \%$ from building $233-S$. These wastes could comprise three batches: one from the PFP, one from WHC and PNL building 325 , and one from building 231-Z. (See Table 5.2-2.)

Module 5 contains waste that is $62 \%$ from the PFP, $21 \%$ from PNL building 325 , and $15 \%$ from WHC building $325,2 \%$ from building $233-5$. These wastes might comprise two batches: one for the waste from the PFP, and one for the waste from the WHC and PNL building 325 . (See Table 5.2-2.)

Module 4 contains waste that is $3 \%$ from building 340 , which might be batched by itself since characterization for this building has not been done, and $52 \%$ from the PFP, $17 \%$ from WHC building 325, $16 \%$ from building $231-Z, 11 \%$ from the PUREX Plant, and $1 \%$ from the PUREX Analytical Lab (AL). This module may require three batches: one from the PFP, one from the PUREX plant and $A L$, and one from WHC building 325 . (See Table 5.2-2.)

Module 3 contains waste that is $81 \%$ from the PFP, $9 \%$ from WHC building $325,8 \%$ from PNL building 325 , and $2 \%$ from $231-Z$. These wastes could comprise three batches: one from the PFP, one from WHC and PNL building 325, and one from building 231-Z.

(See Table 5.2-2.) 
Module 2 contains waste that is $8 \%$ from $\mathrm{BMI}$ and building $222-5$, neither of which have been characterized fully. Of the remaining waste, $55 \%$ is from the PFP, $30 \%$ from WHC building $325,4 \%$ from PNL building 325 , and $3 \%$ from the PUREX Plant. Waste in this module might be placed in three batches: one for the PFP, one for the PUREX Plant, and one from the WHC and PNL building 325. (See Table 5.2-.2)

Module 1 contains waste that is $80 \%$ from the PFP. $11 \%$ from WHC in building 325. $7 \%$ from building $231-2,2 \%$ from PNL building 325 , and less than $1 \%$ from building $222-S$. The potential hazardous chemicals in waste from 225 have not been characterized at present. The other wastes could comprise three batches: one from the PFP, one from WHC and PNL building 325, and one from building 231-Z. (See Table 5.2-2.) 
Table 5.4-2. Characterization Methods to be Used for Analytes Suspected in Retrievably Stored Waste. (5 sheets)

\begin{tabular}{|c|c|c|c|c|c|c|c|c|c|}
\hline \multicolumn{10}{|c|}{ BATCH DEFINITION BY GENERATOR $===>$} \\
\hline $\begin{array}{c}\text { CHARACTERIZATION } \\
\text { ELEMENTS }\end{array}$ & $\begin{array}{c}\text { PFP } \\
\text { Procl } \\
\text { Lab } \\
\end{array}$ & $\begin{array}{c}\text { PUREX } \\
\text { Plant } \\
\end{array}$ & $\begin{array}{c}\begin{array}{c}\text { PUREX } \\
\text { Lab }\end{array} \\
\end{array}$ & $\begin{array}{l}\text { WHC } \\
325 \\
\text { Bldg } \\
\end{array}$ & $\begin{array}{l}\text { PNL } \\
325 \\
\text { Bidg } \\
\end{array}$ & $B \& W$ & $\begin{array}{c}231-z \\
\text { Bldg } \\
\end{array}$ & $\begin{array}{c}\text { WARD } \\
\text { and } \\
\text { WNFD } \\
\end{array}$ & VNC \\
\hline Number of Drums $====>$ & 21196 & 2506 & 1506 & 2414 & 1717 & 1451 & 1360 & 910 & 150 \\
\hline \multicolumn{10}{|c|}{ CHEMICAL Found in TRU waste but not in the 8 generators listed. } \\
\hline Acetic Acid [64-19-7] & $\mathbf{s}$ & $s$ & - & $s$ & - & - & - & - & - \\
\hline Acetone [67-64-1] & $S / H$ & - & $S / H$ & $\mathrm{~S} / \mathrm{H}$ & $\mathrm{S} / \mathrm{H}$ & $\cdot$ & $S / H$ & - & - \\
\hline Aluminum (metal) [7429-90-5] & v & v & $\cdot$ & v & - & - & $\cdot$ & - & v \\
\hline Aluminum Nitrate [13473-90-0] & s & $s$ & $\cdot$ & - & - & - & - & - & - \\
\hline Aluminum Sulfate [10043-01-3] & $s$ & - & $\cdot$ & - & - & $\cdot$ & - & $\cdot$ & - \\
\hline Ammonia (Anhydrous) [7664-41.7] & - & - & $\cdot$ & $s$ & $s$ & - & . & - & - \\
\hline Ammonium Ceric Nitrate [16774.21-3] & S & $\infty$ & - & $\therefore$ & - & 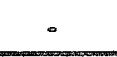 & . & - & $\cdot$ \\
\hline Ammonium Chloride[12125.02-9] & $s$ & - & $\therefore$ & 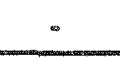 & - & - & - & - & - \\
\hline Ammonium Fluoride[12125-01-8] & - & $\mathrm{s}$ & - & - & - & - & $=$ & - & $=$ \\
\hline Ammonium Hydroxide[1336-21-6] & $s$ & - & - & $\mathrm{s}$ & $S$ & - & $\cdot$ & - & $=$ \\
\hline Ammonium Nitrate [6484-52-2] & - & 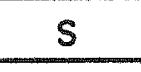 & - & - & - & $\cdot$ & $\therefore$ & $\sim$ & - \\
\hline Ammonium Sulfate [10043-0 1-3] & $\mathrm{s}$ & - & - & - & 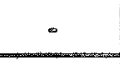 & - & - & $\cdot$ & - \\
\hline Arsenic (metal) [7440-38-2] & $s$ & $\therefore$ & - & 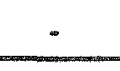 & - & - &. & $\cdot$ & 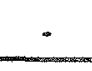 \\
\hline Asbestos [1332-21-4] & EN & EN & EN & EN & 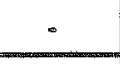 & - & EN & EN & EN \\
\hline Barium (metal) [7440-39-3] & - & $s$ & $s$ & - & - & $\cdot$ & - & - & 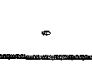 \\
\hline Barium Nitrate [10022-31-8] & - & - & - & $s$ & $\cdot$ & - & - & - & $=$ \\
\hline Benzene [71-43-2] & $S / H$ & - & 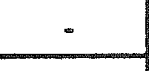 & - & - & - & $S / H$ & - & $\therefore$ \\
\hline Beryilium [74.40-41.7] & $S$ & $s$ & - & $S$ & - & $S$ & $S$ & - & $\therefore$ \\
\hline Boric Acid [10043-35-3] & $S$ & - & $\cdot$ & $S$ & - & - & - & - & 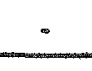 \\
\hline Butanol [79-36-3] & - & - & $\cdot$ & - & $S / H$ & - & - & - & $=$ \\
\hline Cadmium (dust) [7440-43-9] & - & $s$ & $s$ & - & - & - & $s$ & $\therefore$ & - \\
\hline Cadmium Nitrate [10325-94-7] & - & $\mathrm{s}$ & $s$ & - & - & - & - & - & - \\
\hline Calcium Chloride [10043-52-4] & - & - & - & $s$ & $s$ & - & - & - & - \\
\hline Calcium Nitrate [10124-37-5] & - & - & - & $s$ & - & - & - & - & - \\
\hline Carbon Tetrachloride[56-23-5] & $\mathrm{S} / \mathrm{H}$ & $S / H$ & $\mathrm{~S} / \mathrm{H}$ & $S / H$ & $S / H$ & - & $S / H$ & $\therefore$ & - \\
\hline Ceric Sulfate [13590-82-4] & - & - & $s$ & s & s & - & - & - & - \\
\hline Cerous Nitrate [10108-73-3] & - & - & - & $s$ & 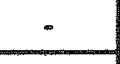 & - & $\cdot$ & $\cdot$ & - \\
\hline Chloroform $[67-66-3]$ & - & $S / H$ & $S / H$ & $\cdot$ & - & - & - & - & $=$ \\
\hline Chlorosulfonic Acid [7790-94-5] & $\mathrm{s}$ & $\cdot$ & - & - & - & - & - & - & - \\
\hline
\end{tabular}

$S=$ Sample Analysis, $B S=$ Basis Sampling, $V=$ Visual Inspection, $H=$ Head-Gas Sampling, $E=N D E, A=N D A$ 5-76 
Table 5.4-2. Characterization Methods to be Used for Analytes Suspected in Retrievably Stored Waste. (5 sheets)

\begin{tabular}{|c|c|c|c|c|c|c|c|c|c|}
\hline \multicolumn{10}{|c|}{ BATCH DEFINITION BY GENERATOR $===>$} \\
\hline $\begin{array}{c}\text { CHARACTERIZATION } \\
\text { ELEMENTS }\end{array}$ & $\begin{array}{c}\text { PFP } \\
\text { Proc/ } \\
\text { Lab } \\
\end{array}$ & $\begin{array}{c}\text { PUREX } \\
\text { Plant } \\
\end{array}$ & $\begin{array}{l}\text { PUREX } \\
\text { Lab }\end{array}$ & $\begin{array}{l}\text { WHC } \\
325 \\
\text { BIdg }\end{array}$ & $\begin{array}{l}\text { PNL } \\
325 \\
\text { BIdg }\end{array}$ & $B \& W$ & $\begin{array}{c}231 \cdot z \\
\text { Bldg }\end{array}$ & $\begin{array}{l}\text { WARD } \\
\text { and } \\
\text { WNFD }\end{array}$ & VNC \\
\hline Chromic Acid [7738-94-5] & - & - & $\therefore$ & $\mathrm{s}$ & 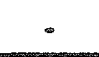 & - & - & - & - \\
\hline * Chromium (metal)[7440-47-3] & - & - & - & . & $\infty$ & - & - & - & - \\
\hline Citric Acid [77-92.9] & - & - &. & $s$ & . &. & . & - & - \\
\hline Copper $[7440-50-8]$ & - & EN & EN & - & - & - & - & - & EN \\
\hline - Cresylic Acid [1319-77-3] & - & $=$ & - & - & - & - & - & - & - \\
\hline Cyclohexane [110-82-7] & - & $S / H$ & $S / H$ & . & - & - & $=$ & . & - \\
\hline Decane $[124-18-5]$ & - & $s$ & - & - & - & - & . & - & - \\
\hline * Diesel [68476-34-6/68334-30-5] & . & - & - & . & - & . & $=$ & - & - \\
\hline * Dioctyl Phthalate (DOP) [1 17-84-0] & - & - & - & - & - & . & . & - & - \\
\hline Ethanol $[64-17-5]$ & - & - & - & $s$ & $S$ & - & - & - & - \\
\hline Ethylbenzene [100-41-4] & - & - & . & $=$ & . & - & - & - & - \\
\hline Ethylene Glycol [107-21-1] & - & - & - & - & - & - & - & . & s \\
\hline Ferric Nitrate [10421-48-4] & s & $s$ & - & $s$ & - & - & - & - & - \\
\hline Ferric Sulfate [10028-22-5] & - & - & - & s & - & - & - & - & - \\
\hline Ferrous Sulfate [7720-78-7] & $\circ$ & - & $S$ & - & $s$ & - & 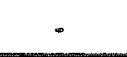 & - & - \\
\hline Formaldehyde $[50-00-0]$ & - & $s$ & - & - & - & - & - & - & - \\
\hline Freon-113 [76-13-1] & - & - & - & - & - & - & $s$ & - & - \\
\hline Hexachlorobenzene[118-74-1] & - & - & - & - & - & - & . & - & $=$ \\
\hline Hexone [108-10.1] & - & $S$ & $s$ & $s$ & $s$ & . & - & - & - \\
\hline Hydraulic Fluid with PCBs & - & - & - & . & - & - & $s$ & $s$ & s \\
\hline Hydrazine [302-01-2] & $s$ & $s$ & - & s & $s$ & - & . & - & - \\
\hline Hydriodic Acid [10034-85-2] & s & - & - & $s$ & $s$ & . & - & . & - \\
\hline Hydrobromic Acid [10035-10-6] & $s$ & - & s & . & - & - & - & - & - \\
\hline Hydrochloric Acid [7647-01-0] & $s$ & - & S & $s$ & $s$ & . & s & - & - \\
\hline Hydrofluoric Acid [7664-39-3] & $s$ & - & - & $s$ & $s$ & $s$ & - & - & - \\
\hline Hydrogen Peroxide [7722.84-1] & $\mathrm{S}$ & $\mathrm{s}$ & $s$ & $s$ & $s$ & - & $s$ & - & - \\
\hline * Isobutanol [78-83-1] & - & - & - & - & - & - & - & - & - \\
\hline Isopropyl Ethanol [67-63-0] & - & - & s & $s$ & $s$ & - & - & - & - \\
\hline Kerosene [8008-20-6] & - & $s$ & $s$ & S & $s$ & - & - & - & - \\
\hline Lead [7439-92-1] & - & $E$ & $E$ & E & - & - & E & E & E \\
\hline Lead Chromate [7758-97-6] & $S$ & - & - & - & - & - & - & - & - \\
\hline Magnesium [7439-95-4] & - & - & V & - & - & - & - & . & - \\
\hline
\end{tabular}

$S=$ Sample Analysis, $B S=$ Basis Sampling, $V=$ Visual Inspection, $H=$ Head-Gas Sampling, $E=N D E, A=N D A$ 
Table 5.4-2. Characterization Methods to be Used for Analytes Suspected in Retrievably Stored Waste. (5 sheets)

\begin{tabular}{|c|c|c|c|c|c|c|c|c|c|}
\hline $\begin{array}{c}\text { CHARACTERIZATION } \\
\text { ELEMENTS }\end{array}$ & $\begin{array}{c}\text { PFP } \\
\text { Procl } \\
\text { Lab } \\
\end{array}$ & $\begin{array}{c}\text { PUREX } \\
\text { Plant }\end{array}$ & $\begin{array}{c}\text { PUREX } \\
\text { Lab } \\
\end{array}$ & $\begin{array}{c}\text { WHC } \\
325 \\
\text { Bldg } \\
\end{array}$ & $\begin{array}{l}\text { PNL } \\
325 \\
\text { Bldg } \\
\end{array}$ & B\&W & $\begin{array}{c}231-Z \\
\text { Bidg } \\
\end{array}$ & $\begin{array}{c}\text { WARD } \\
\text { and } \\
\text { WNFD }\end{array}$ & VNC \\
\hline Mercuric Thiocyanate [592-85-8] & $s$ & - & $=$ & $\therefore$ & $\therefore$ & - & 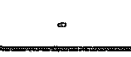 & - & - \\
\hline Mercury $[7439.97-6]$ & V & v & V & V & V & V & V & V & - \\
\hline Methanol [67-56-1] & $S / H$ & - & - & $S / H$ & $S / H$ & - & 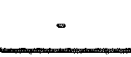 & - & - \\
\hline Methylene Chloride [75-09-2] & $\cdot$ & - & $\cdot$ & $\mathrm{S} / \mathrm{H}$ & $=$ & - & $\mathrm{S} / \mathrm{H}$ & - & - \\
\hline Methyl Ethyl Ketone [78-93-3] & - & - & $\therefore$ & $\mathbf{s}$ & $S$ & - & - & - & $=$ \\
\hline Methyl Lactic Acid [80-55-7] & - & - & - & $s$ & $s$ & $\cdot$ & - & $\cdot$ & - \\
\hline Naphthalene [91-20-3] & - & $s$ & - & - & - & $\therefore$ & - & - & $\therefore$ \\
\hline Napthylamine [134-32-7/91-59-8] & $S$ & - &. & - & - & - & - & - & - \\
\hline Nitric Acid [7697-37-2] & $s$ & $S$ & $S$ & $S$ & $s$ & $S$ & $S$ & $S$ & - \\
\hline Nitrilotriacetic Acid [139-13-9] & 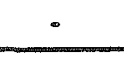 &. &. & - & $s$ & 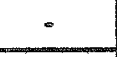 & $\therefore$ & - & - \\
\hline Oxalic Acid [144-62-7] & $s$ & $s$ & - & $S$ & $s$ & - & $=$ & $S$ & - \\
\hline Pentasodium DTPA [1 40-01-2] & - & - & - & - & $s$ & - & - & $\cdot$ & - \\
\hline Perchloric Acid [7601-90-3] & - & - & - & $S$ & $S$ & - & $\therefore$ & $\therefore$ & $\therefore$ \\
\hline Phosphoric Acid [7664-38-2] & $s$ & $s$ & $\therefore$ & $S$ & $s$ & $\mathbf{s}$ & $s$ & - & $\cdot$ \\
\hline Polychlorinated Bipheny! [1336-36-3] & $s$ & - & - & $=$ & - & $\therefore$ & $S$ & - & - \\
\hline Potassium Acetate [127-08-2] & $\mathrm{s}$ & - & - & - & - & - & - & - &. \\
\hline Potassium Carbonate[584-08-7] & s & - & - & $S$ & - & - & - & - & - \\
\hline Potassium Chromate[7789-00-6] & - & - & $\therefore$ & $S$ & - & - & 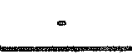 & - & $\cdot$ \\
\hline - Potassium Cyanide[15 1-50-8] &. & $\infty$ & $=$ & - & - & - & - & - & - \\
\hline Potassium Fluoride[7789-23-3] & - & $s$ & - & - & - & - & - & - & - \\
\hline Potassium Hydroxide [1310-58-3] & $\mathbf{s}$ & $s$ & $S$ & $\mathbf{S}$ & $s$ & - & $\cdot$ & - & - \\
\hline Propane [74-98-6] & V & - & $=$ & - & - & - & $\mathrm{V}$ & - & - \\
\hline - Pyridine [110.86-1] & - &. & - & $\cdot$ & - & - & - & - & - \\
\hline Silicon [7440-21-3] & - & $s$ & - & $=$ & - & - & - & - & - \\
\hline - Silver (metal) [7440-22-4] & - & - & $=$ & - & $=$ & - & - & - & - \\
\hline Silver Chloride [7783-90-6] & $s$ & - & $\cdot$ & - & - & $\therefore$ & - & - & - \\
\hline Silver Nitrate [7761.88-8] & $s$ & $s$ & $s$ & $s$ & $s$ & - & $\cdot$ & - & - \\
\hline Silver Oxide [20667-12-3] & $s$ & - & - & - & - & - & - & - & - \\
\hline Silver Sulfate [10294-26-5] & $s$ & - & - & - & - & - & - & - & - \\
\hline Sodium [7440-23-5] & - & - & $\cdot$ & s & $=$ & - & $\mathbf{S}$ & - & $\cdot$ \\
\hline Sodium Bicarbonate [144-55-8] & $\cdot$ & $\cdot$ & $\therefore$ & $s$ & $\cdot$ & - & - & - & - \\
\hline Sodium Bisufite [7639-90-5] & $S$ & - & s & $s$ & - & - & - & - & - \\
\hline
\end{tabular}

$S=$ Sample Analysis, $B S=$ Basis Sampling,$V=$ Visual Inspection, $H=$ Head-Gas Sampling, $E=N D E, A=N D A$ 
WHC-SD-W026-Tl-009, Rev. 0

Table 5.4-2. Characterization Methods to be Used for Analytes

Suspected in Retrievably Stored Waste. (5 sheets)

\begin{tabular}{|c|c|c|c|c|c|c|c|c|c|}
\hline $\begin{array}{c}\text { CHARACTERIZATION } \\
\text { ELEMENTS }\end{array}$ & $\begin{array}{l}\text { PFP } \\
\text { Procl } \\
\text { Lab }\end{array}$ & $\begin{array}{l}\text { PUREX } \\
\text { Plant }\end{array}$ & $\begin{array}{l}\text { PUREX } \\
\text { Lab }\end{array}$ & $\begin{array}{c}\text { WHC } \\
325 \\
\text { BIdg }\end{array}$ & $\begin{array}{l}\text { PNL } \\
325 \\
\text { Bldg } \\
\end{array}$ & B\&W & $\begin{array}{l}231-Z \\
\text { Bldg }\end{array}$ & $\begin{array}{l}\text { WARD } \\
\text { and } \\
\text { WNFD }\end{array}$ & VNC \\
\hline Sedium Bromate [7789-38-0] & - & - & $s$ & - & - & - & - & - & - \\
\hline Sodium Carbonate [197-19-8] & $S$ & $\mathbf{S}$ & $s$ & $s$ & $s$ & $\cdot$ & - & - & - \\
\hline - Sodium Chromate [7775-11-3] & - & . & - & - & - & . & - & - & . \\
\hline Sodium Dichromate[10588-01-9] & - & $=$ & - & $s$ & $s$ & - & - & - & - \\
\hline Sodium Fluoride [7681-49-4] & $s$ & $s$ & $s$ & - & $s$ & . & - & - & - \\
\hline Sadium Hydroxide [1310-73-2] & $\mathbf{S}$ & $s$ & $s$ & s & s & - & s & - & - \\
\hline Sadium Hypochlorite [7681-52-9] & - & - & - & $s$ & - & - & - & - & - \\
\hline Sodium Nitrate [7631-99-4] & $\mathbf{S}$ & $\mathbf{S}$ & $\mathbb{S}$ & $s$ & $s$ & - & - & - & - \\
\hline Sodium Nitrite [7632-00-0] & $s$ & $s$ & - & $s$ & - & $s$ & - & - & - \\
\hline Sodium Oxalate $[62-76-0]$ & $s$ & - & - & $\mathrm{s}$ & $\therefore$ & - &. & - & - \\
\hline Sodium Phosphate [76-54-9] & - & - & - & $\mathrm{s}$ & $s$ & $\cdot$ & $S$ & $\cdot$ & - \\
\hline Sodium Silicate [1344-09-8] & - & - & - & $s$ & $s$ & - & - & - & - \\
\hline Strontium Nitrate[10042-76-9] & $=$ & - & - & s & $s$ & - & - & - & - \\
\hline Sulfamic Acid [5329-14-6] & $s$ & $s$ & - &. & - & - & $s$ & - & - \\
\hline Sulfuric Acid [7664-93-9] & $s$ & $s$ & $\$$ & $S$ & S & $s$ & - & $=$ & - \\
\hline Tartaric Acid [87-69-4] & - & s & - & - & - & - & - & . & - \\
\hline Teflon [9002-84-0] & $=$ & - & - & - & - & - & V & - & $\therefore$ \\
\hline - Tetrachloroethylene [127-18-4] & - & - & - & - & - & - & - & $\cdot$ & - \\
\hline Tetrasodium EDTA [62-02-8] & - & - & - & $s$ & $s$ & - & . & - & - \\
\hline Taluene [108-88-3] & $\mathrm{S} / \mathrm{H}$ & - & - & $\mathrm{S} / \mathrm{H}$ & $S / H$ & - & - & - & - \\
\hline Tributyl Phosphate [126-73-8] & $s$ & $s$ & $s$ & $s$ & $s$ & - & - & $\cdot$ & - \\
\hline Trichloroethane $[79-00-5 / 71.55-6]$ & $\cdot$ & $\mathrm{S} / \mathrm{H}$ & - & $\mathrm{S} / \mathrm{H}$ & $S / H$ & - & $\mathrm{S} / \mathrm{H}$ & $\cdot$ & $\cdot$ \\
\hline Trichloroethylene [79-01-6] & - & - & - & - & - & $\cdot$ & $\mathbf{S}$ & - & $=$ \\
\hline Tungsten (powder) [7440-33-7] & $S$ & - & - & $\infty$ & - & - & $s$ & - & - \\
\hline Undecane [1120-21-4] & - & $S$ & - & $=$ & - & - & - & - & - \\
\hline $\begin{array}{l}\text { Uranyl Nitrate Hexahydrate } \\
{[13520-83-7]}\end{array}$ & - & - & - & - & - & - & $S$ & - & - \\
\hline Vanadium Pentoxide[1314-62-1] & - & - & - & $S$ & $S$ & - & - & - & - \\
\hline Xylene [1330-20-7] & $S / H$ & $\mathrm{~S} / \mathrm{H}$ & $S / H$ & $\mathrm{~S} / \mathrm{H}$ & $S / H$ & - & - & - & - \\
\hline Zirconium [7440-67-7] & - & V & - & V & $=$ & - & V & - & - \\
\hline
\end{tabular}

$S=$ Sample Analysis, $B S=$ Basis Sampling,$V=$ Visual Inspection, $H=$ Head-Gas Sampling, $E=N D E, A=N D A$ 5-79 


\subsection{RADIOCHEMICAL TYPE AND QUANTITY}

There are a number of data fields in the SWITS database that contain information concerning the radioactive constituents of each waste container. In the following sections consideration is given to batching drums by total dose rate, neutron dose, thermal power, and isotope identify and quantity.

\subsubsection{Total Dose Rate}

This data field gives the total surface dose rate at $1 \mathrm{~cm}$ from the container in mrem/hour. Both WRAP Module 1 and WIPP require that the surface dose rate be less than 200 mrems/hour for each container. Since the majority of drums in Trench 4C-04 were emplaced prior to 1982 , it is important to note that dose rates for pre-1982 waste was entered on a per shipment basis and only the measurement from the container with the highest radiation level was recorded.

No drums in Trench 4C-04 are recorded at a dose rate higher than the $200 \mathrm{mrem} / \mathrm{hour}$ limit. Histograms showing the number of drums in several dose rate categories by generator are found in Figures 5.5-1 through 5.5-19. These figures correspond to Module 19 through 1. respectively. Figure 5.5-20 provides the same information for drums in Trench 4C-04 with unknown module locations. 
Figure 5.5-1. Surface Dose Rates for Drums in Module 19 Sorted by Generator.

Maximum Total Dose Rate

at $1 \mathrm{~cm}$ in mrems/hour

\begin{tabular}{|c|r|r|r|r|r|r|}
\hline Generator & $<=1$ & $<=10$ & $<=50$ & $<=100$ & $<=150$ & $<=200$ \\
\hline 324 & & 1 & & & & \\
\hline $234-5 Z$ & 281 & 3 & & & & \\
\hline ESG & & & 3 & & & \\
\hline
\end{tabular}

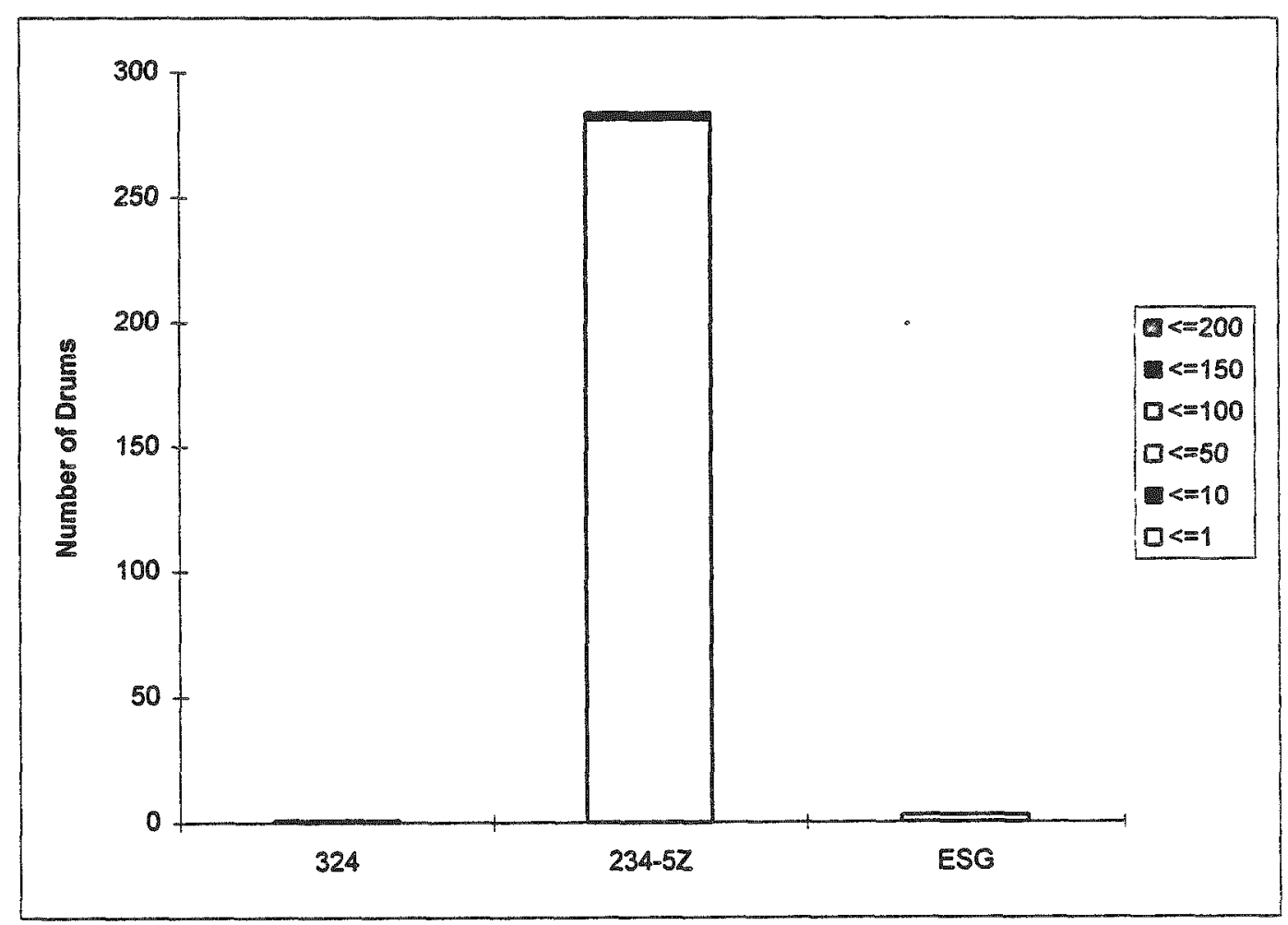

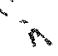


WHC-SD-W026-TI-009, Rev. 0

Figure 5.5-2. Surface Dose Rates for Drums in Module 18 Sorted by Generator.

Maximum Total Dose Rate

at $1 \mathrm{~cm}$ in mrems/hour

\begin{tabular}{|c|r|r|r|r|r|r|}
\hline Generator & $<=1$ & $<=10$ & $<=50$ & $<=100$ & $s=150$ & $\leqslant=200$ \\
\hline 324 & 6 & 28 & 4 & & & \\
\hline $202 \mathrm{~A}$ & 6 & 3 & & & & \\
\hline ESG & 465 & 46 & 4 & & & \\
\hline
\end{tabular}

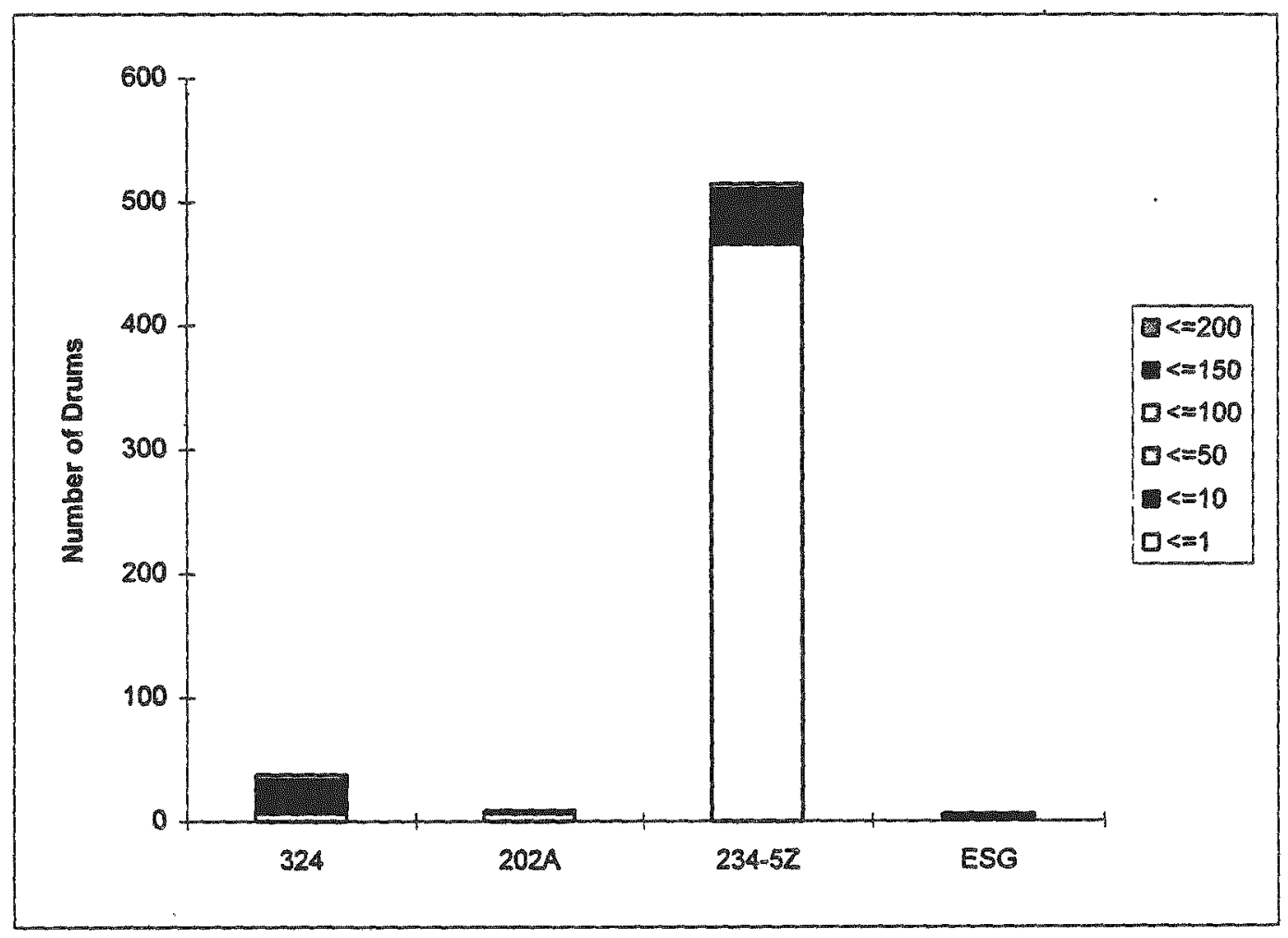


WHC-SD-W026-TI-009,Rev. 0

Figure 5.5-3. Surface Dose Rates for Drums in

Module 17 Sorted by Generator.

Maximum Total Dose Rate

at $1 \mathrm{~cm}$ in mrems/hour

\begin{tabular}{|c|r|r|r|r|r|r|r|}
\hline Generator & $<=1$ & $<=10$ & $<=50$ & $<=100$ & $<=150$ & $<=200$ & Unknown \\
\hline 324 & 13 & 9 & 1 & & & & \\
\hline PNL 209E & & 7 & 2 & 1 & & & \\
\hline $202 \mathrm{~A}$ & 12 & & & & & & \\
\hline $234-52$ & 387 & 80 & 7 & & & & \\
\hline WARDMNFD & 47 & & 2 & 1 & & & \\
\hline
\end{tabular}

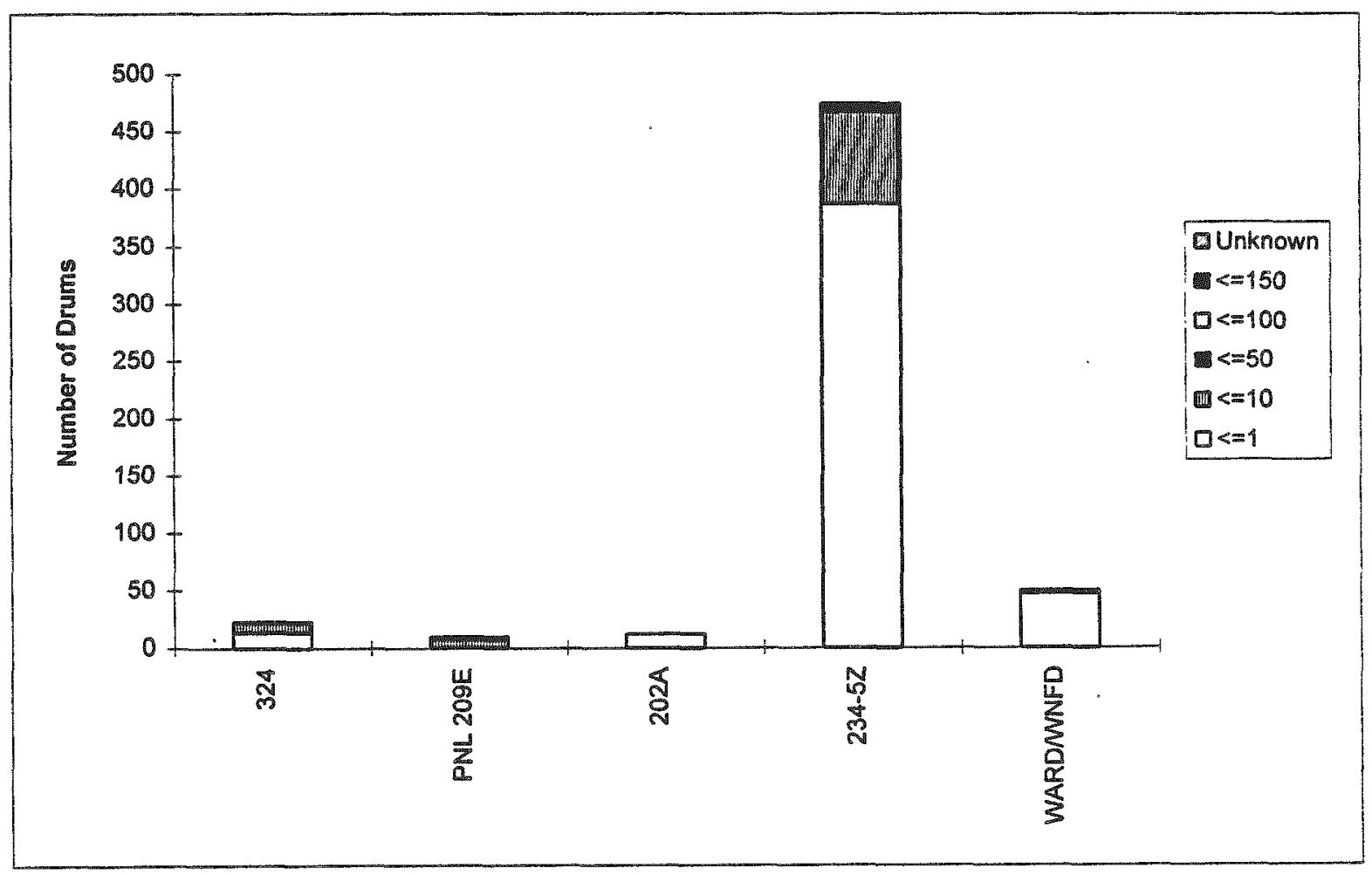


WHC-SD-W026-TI-009, Rev.0

Figure 5.5-4. Surface Dose Rates for Drums in Module 16 Sorted by Generator.

Maximum Total Dose Rate

at $1 \mathrm{~cm}$ in mrems/hour

\begin{tabular}{|c|c|c|c|c|c|c|}
\hline Generator & $\Leftrightarrow 1$ & $<=10$ & $<=50$ & $<=100$ & $<=150$ & $<=200$ \\
\hline \multicolumn{7}{|l|}{308} \\
\hline 324 & 13 & 4 & & & & \\
\hline \multicolumn{7}{|l|}{325} \\
\hline \multicolumn{7}{|l|}{$325 A$} \\
\hline \multicolumn{7}{|l|}{340} \\
\hline \multicolumn{7}{|l|}{ PNL 209E } \\
\hline PNL 231-Z & 4 & & & & & \\
\hline \multicolumn{7}{|l|}{$202 A$} \\
\hline \multicolumn{7}{|l|}{$202 \mathrm{AL}$} \\
\hline \multicolumn{7}{|l|}{$222 S$} \\
\hline \multicolumn{7}{|l|}{2335} \\
\hline $234-5 z$ & 229 & 9 & 4 & & & \\
\hline \multicolumn{7}{|l|}{ 2WTF } \\
\hline \multicolumn{7}{|l|}{ GE-VAL } \\
\hline WARDMNFD & 67 & 3 & & & & \\
\hline \multicolumn{7}{|l|}{$B \& W$} \\
\hline \multicolumn{7}{|l|}{ BMI } \\
\hline \multicolumn{7}{|l|}{ ESG } \\
\hline EXXON & & & & & & \\
\hline
\end{tabular}

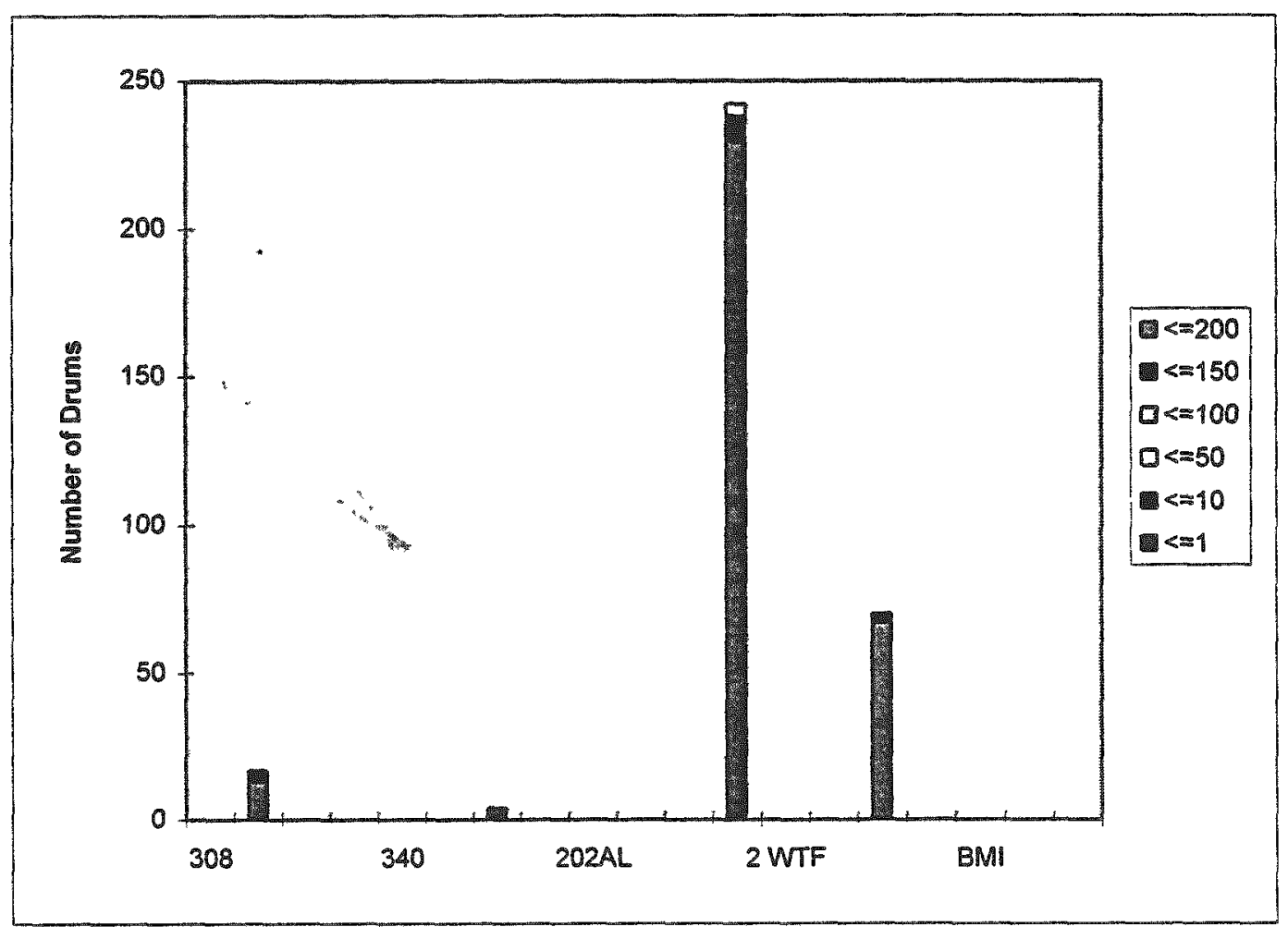


WHC-SD-W026-TI-009, Rev. 0

Figure 5.5-5. Surface Dose Rates for Drums in Module 15 Sorted by Generator.

Maximum Total Dose Rate

at $1 \mathrm{~cm}$ in mrems/hour

\begin{tabular}{|c|r|r|r|r|r|r|}
\hline Generator & $<=1$ & $<=10$ & $<=50$ & $<=100$ & $<=150$ & $<=200$ \\
\hline 324 & 10 & 7 & 2 & & & \\
\hline 340 & 11 & 8 & 3 & & & \\
\hline $202 \mathrm{~A}$ & & 2 & & & & \\
\hline $234-52$ & 230 & 12 & 2 & & & \\
\hline WARDMNFD & 56 & 2 & 3 & 2 & 3 & 2 \\
\hline B \& W & 25 & 1 & 2 & & & \\
\hline
\end{tabular}

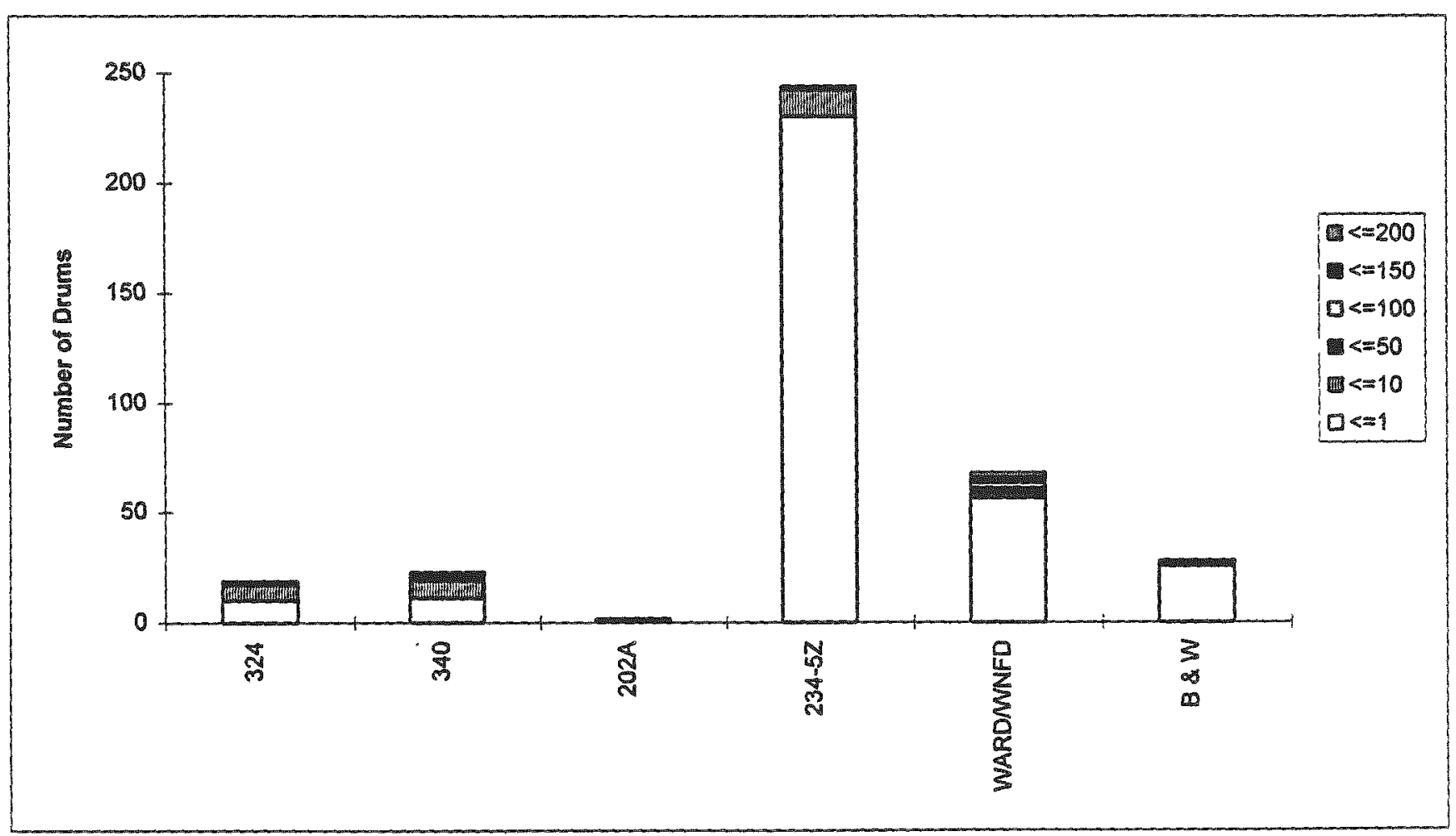


WHC-SD-W026-TI-009, ReV.O

Figure 5.5-6. Surface Dose Rates for Drums in Module 14 Sorted by Generator.

Maximum Total Dose Rate

at $1 \mathrm{~cm}$ in mrems/hour

\begin{tabular}{|c|r|r|r|r|r|r|}
\hline Generator & $<=1$ & $<=10$ & $<=50$ & $<=100$ & $<=150$ & $<=200$ \\
\hline 340 & 15 & 12 & 2 & & & \\
\hline $202 A$ & 41 & 10 & & & & \\
\hline $234-52$ & 290 & 11 & & & & \\
\hline WARDMNFD & & 31 & & & & \\
\hline B \& W & 57 & 20 & 7 & & & \\
\hline
\end{tabular}

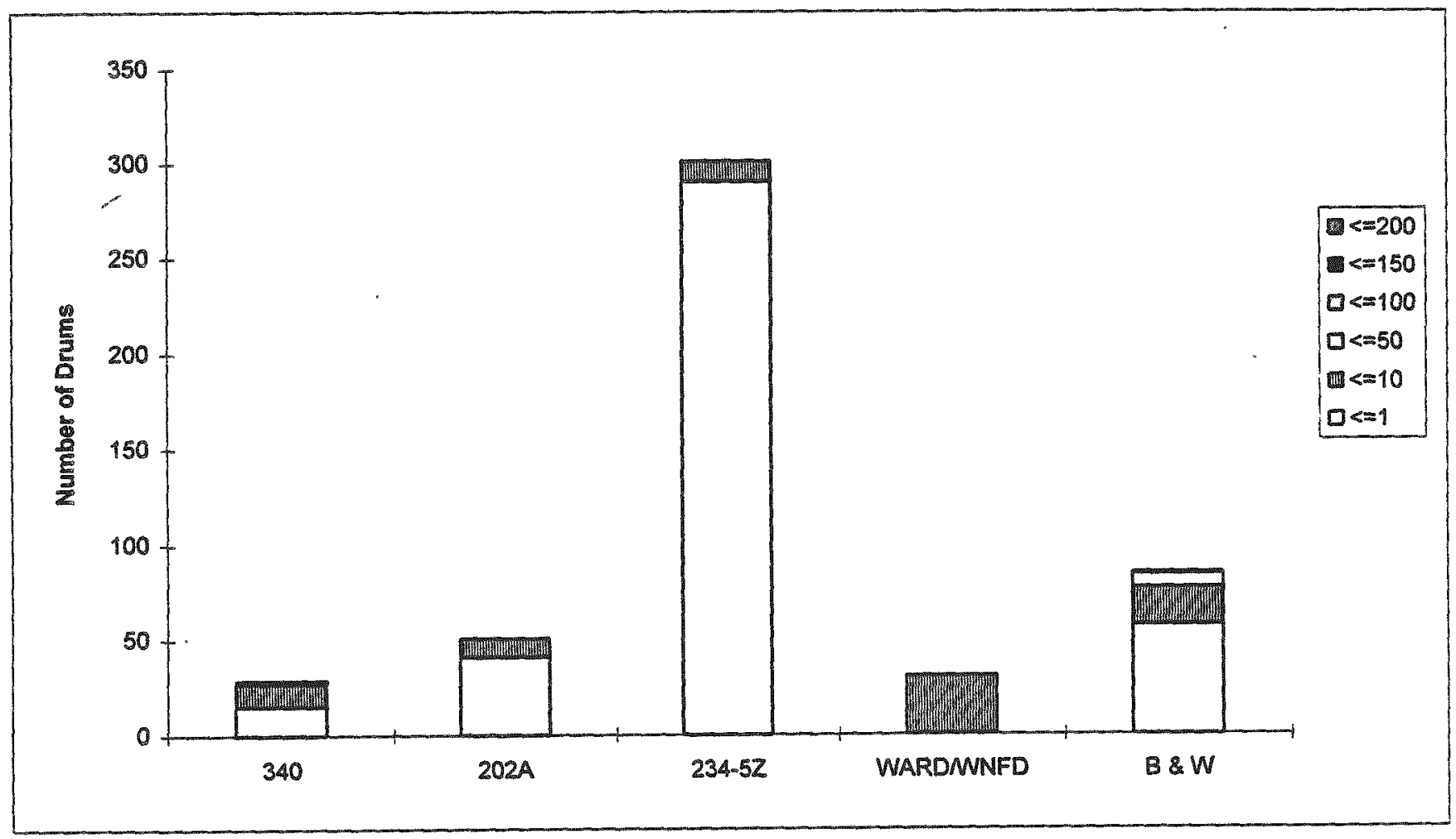


WHC-SD-W026-T1-009, Rev。0

Figure 5.5-7. Surface Dose Rates for Drums in Module 13 Sorted by Generator.

Maximum Total Dose Rate

at $1 \mathrm{~cm}$ in mrems/hour

\begin{tabular}{|c|r|r|r|r|r|r|}
\hline Generator & $<=1$ & $<=10$ & $<=50$ & $<=100$ & $<=150$ & $<=200$ \\
\hline 340 & 39 & 5 & & & & \\
\hline PNL 231-Z & 11 & & & & & \\
\hline $202 \mathrm{~A}$ & 122 & 19 & & & & \\
\hline $234-5 Z$ & 165 & 20 & & & & \\
\hline GE-VAL & 35 & & & & & \\
\hline WARDMNFD & 1 & 104 & & & & \\
\hline B \& W & & 8 & & & & \\
\hline
\end{tabular}

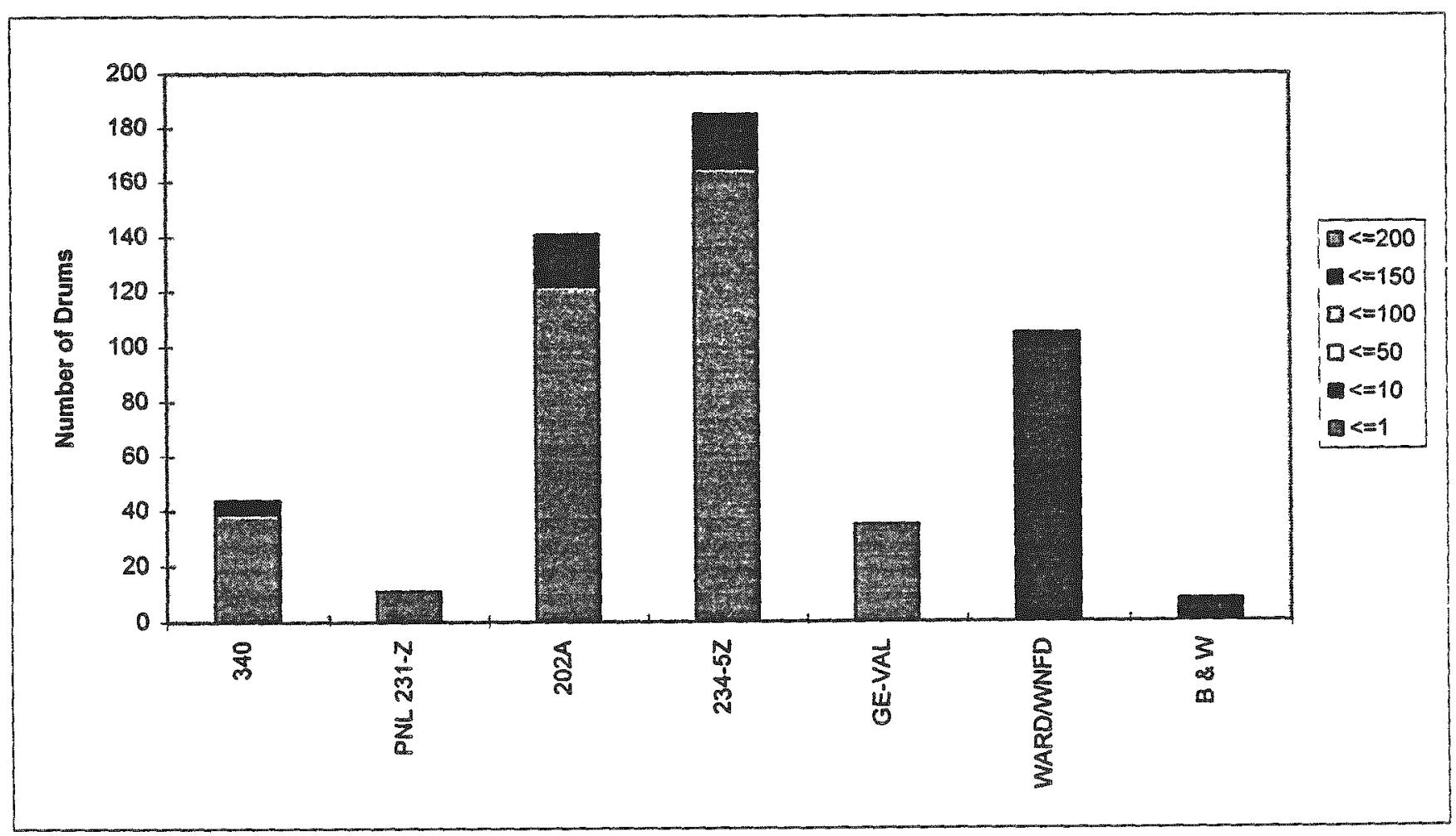


WHC-SD-W026-T1-009, Rev. O

Figure 5.5-8. Surface Dose Rates for Drums in Module 12 Sorted by Generator.

Maximum Total Dose Rate

at $1 \mathrm{~cm}$ in mrems/hour

\begin{tabular}{|c|r|r|r|r|r|r|}
\hline Generator & $<=1$ & $<=10$ & $<=50$ & $<=100$ & $<=150$ & $<=200$ \\
\hline 340 & 22 & & & & & \\
\hline $234-52$ & 102 & 35 & & & & \\
\hline GE-VAL & 32 & & & & & \\
\hline B \&W & 61 & & & & & \\
\hline
\end{tabular}

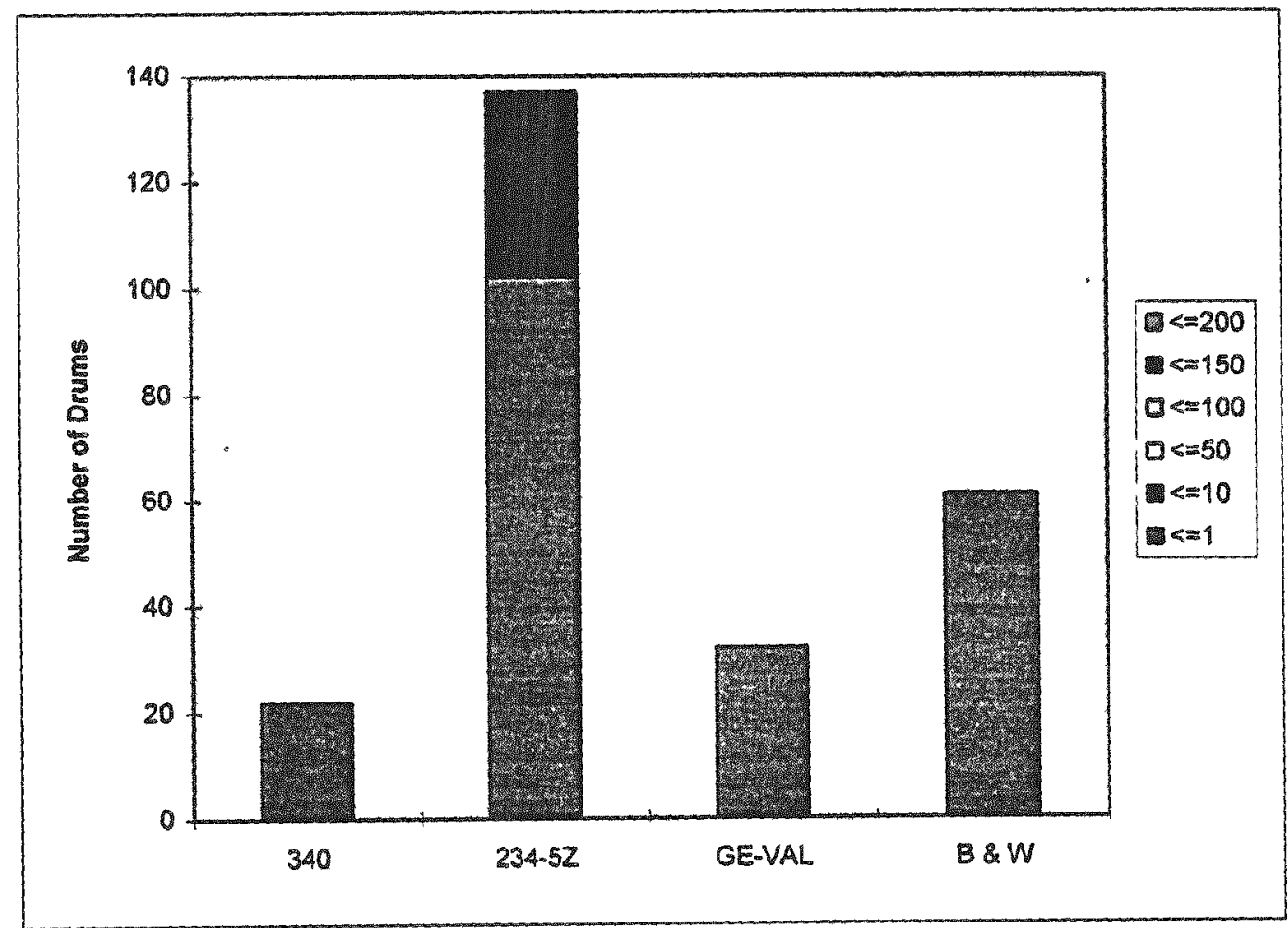


WHC-SD-W026-TI-009, Rev.0

Figure 5.5-9. Surface Dose Rates for Drums in Module 11 Sorted by Generator.

Maximum Total Dose Rate

at $1 \mathrm{~cm}$ in mrems/hour

\begin{tabular}{|c|r|r|r|r|r|r|}
\hline Generator & $<=1$ & $<=10$ & $<=50$ & $<=100$ & $<=150$ & $<=200$ \\
\hline 325 & 221 & 2 & & & & \\
\hline $325 \mathrm{~A}$ & 5 & & & & & \\
\hline PNL 231-Z & 23 & & & & & \\
\hline $202 \mathrm{~A}$ & 10 & & & & & \\
\hline $222 \mathrm{~S}$ & 3 & & & & & \\
\hline $234-5 \mathrm{Z}$ & 385 & & & & & \\
\hline BMI & 40 & & & & & \\
\hline
\end{tabular}

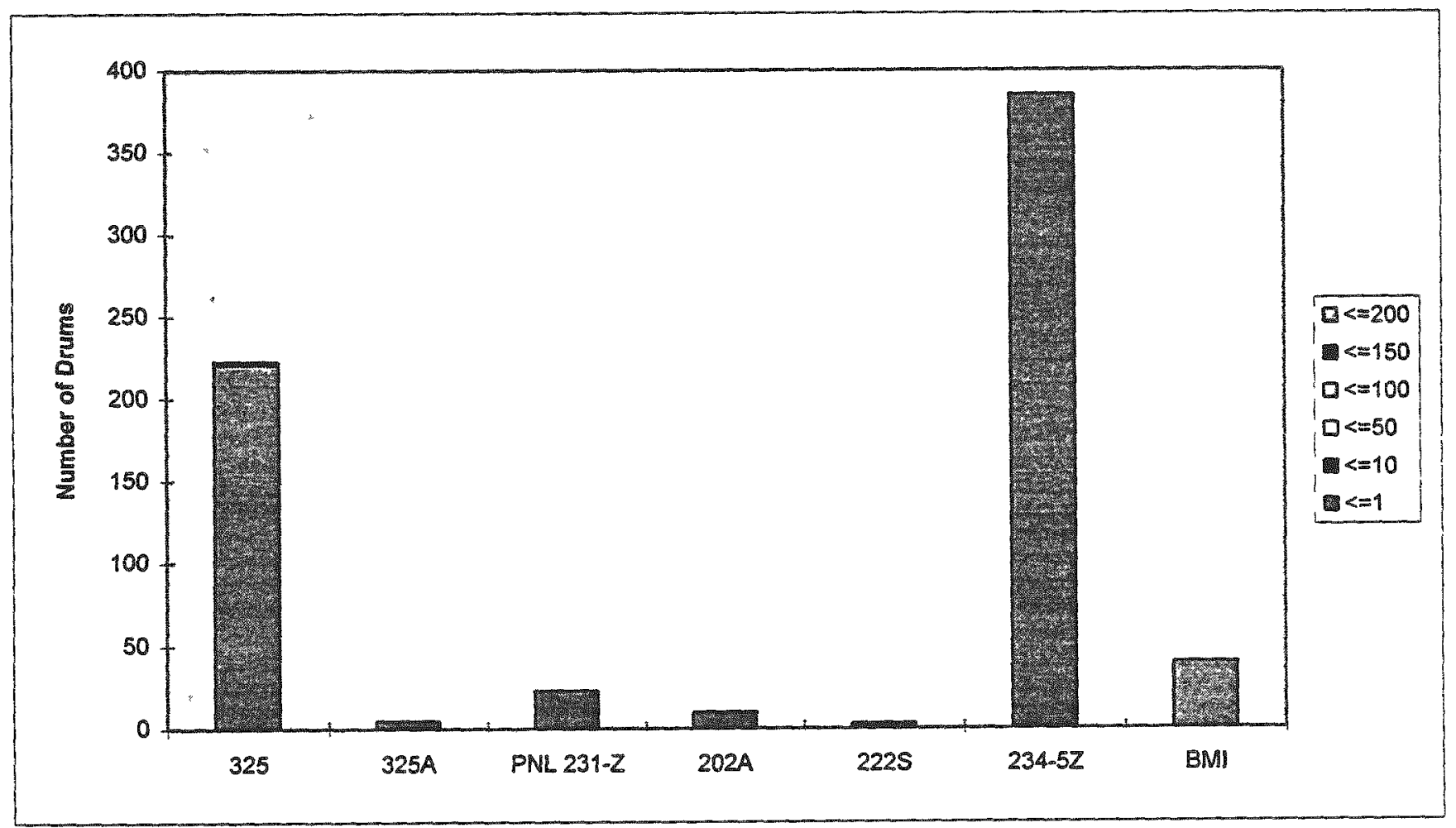


WHC-SD-W026-TI-009, Rev.O

Figure 5.5-10. Surface Dose Rates for Drums in Module 10 Sorted by Generator.

Maximum Total Dose Rate

at $1 \mathrm{~cm}$ in mrems/hour

\begin{tabular}{|c|r|r|r|r|r|r|}
\hline Generator & $<=1$ & $<=10$ & $<=50$ & $<=100$ & $<=150$ & $<=200$ \\
\hline 340 & 45 & 11 & & & & \\
\hline PNL 209E & 13 & & & & & \\
\hline $234-52$ & 96 & 24 & & & & \\
\hline WARDMNFD & 26 & & & & & \\
\hline B \& W & 256 & & & & & \\
\hline
\end{tabular}

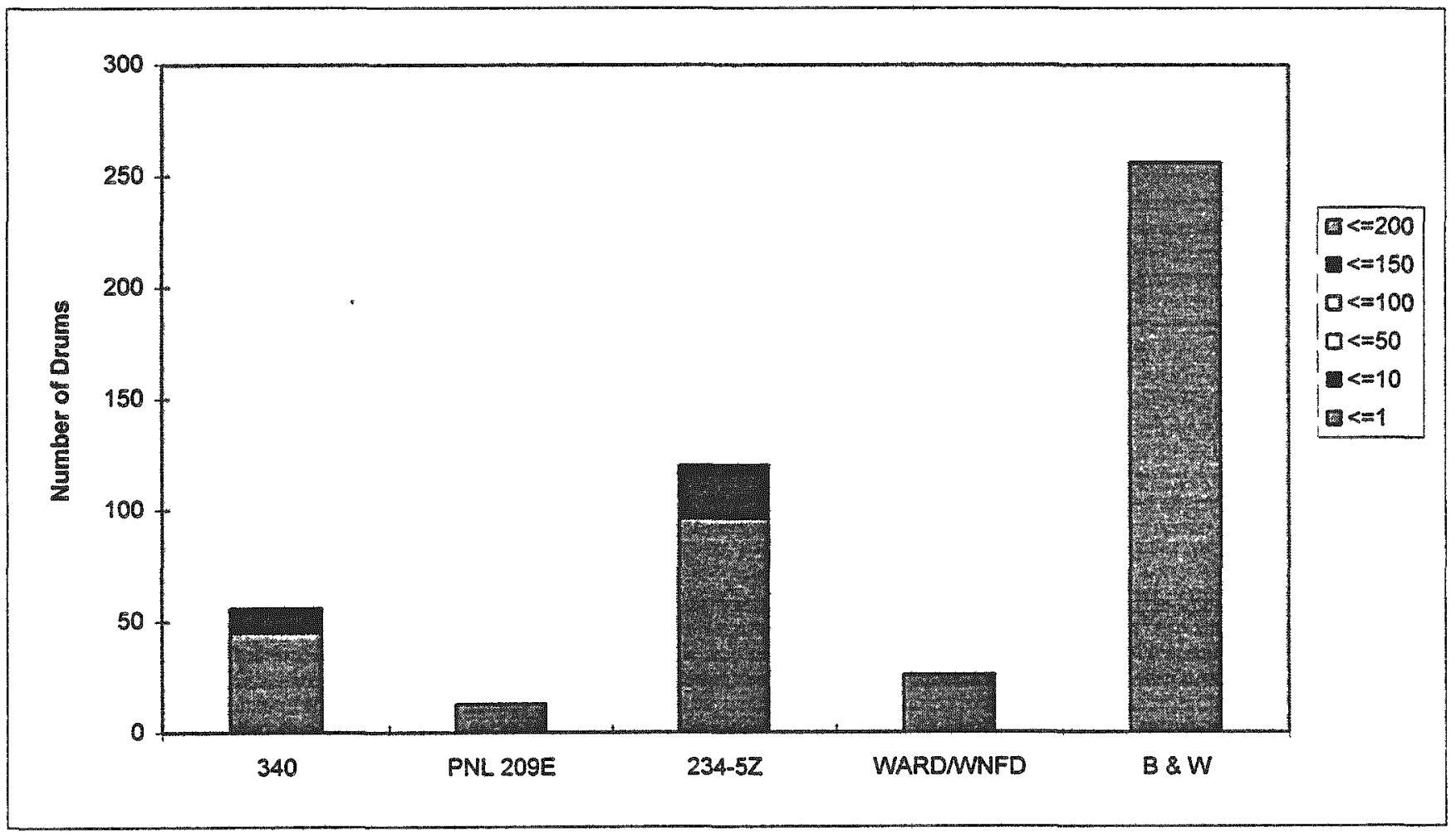


WHC-SD-W026-T1-009, Rev.O

Figure 5.5-11. Surface Dose Rates for Drums in Module 9 Sorted by Generator.

Maximum Total Dose Rate

at $1 \mathrm{~cm}$ in mrems/hour

\begin{tabular}{|c|r|r|r|r|r|r|r|}
\hline Generator & $<=1$ & $<=10$ & $<=50$ & $<=100$ & $<=150$ & $<=200$ & Unknown \\
\hline 340 & 22 & & & & & & \\
\hline PNL 231-Z & 1 & & & & & & \\
\hline $234-5 Z$ & 115 & 133 & 2 & & & & \\
\hline GE-VAL & 62 & & & & & & \\
\hline WARDWNFD & 48 & & & & & & \\
\hline B \&W & 141 & & & & & & \\
\hline
\end{tabular}

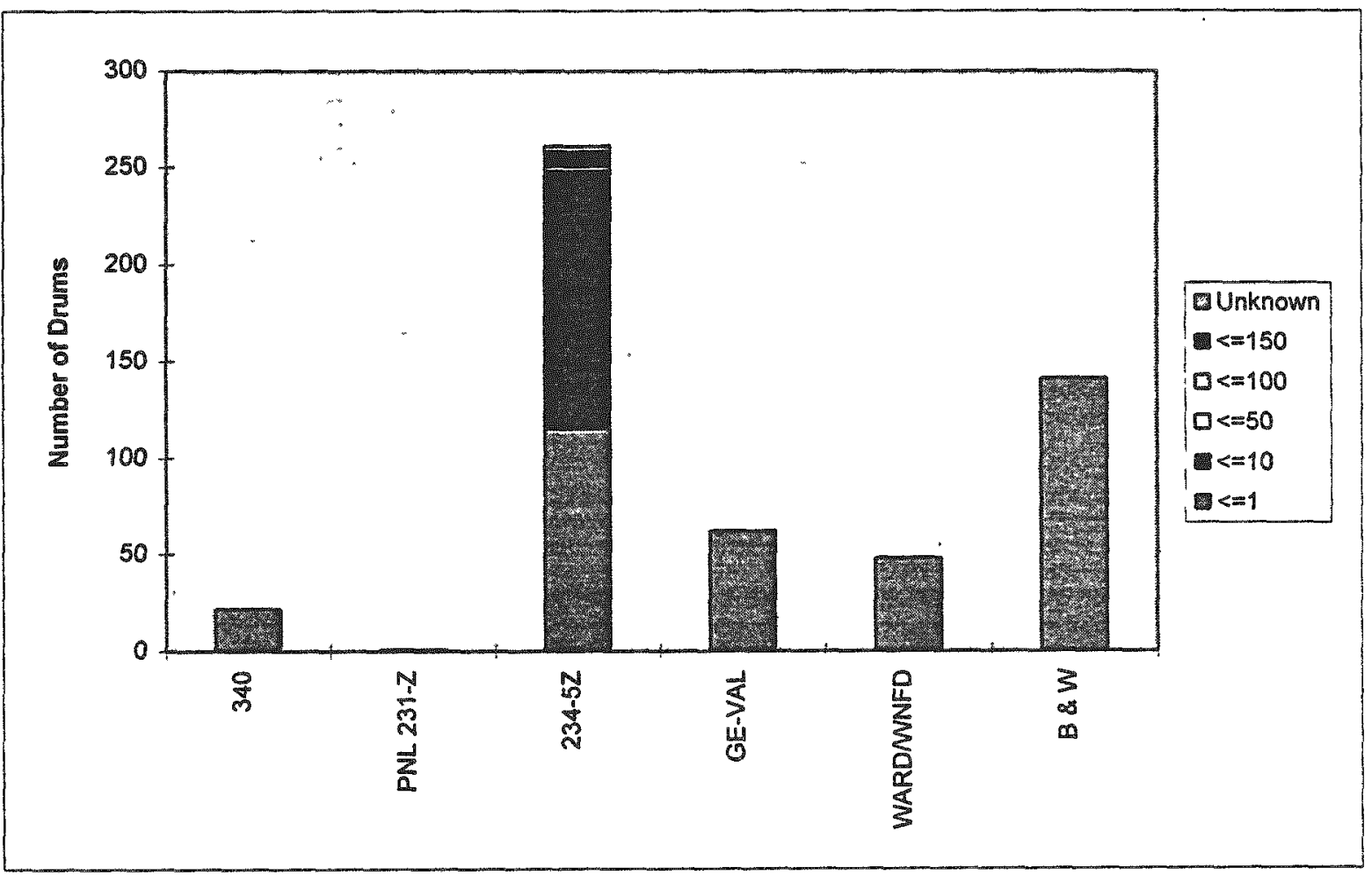


WHC-SD-W026-Tl-009, Rev.U

Figure 5.5-12. Surface Dose Rates for Drums in Module 8 Sorted by Generator.

Maximum Total Dose Rate

at $1 \mathrm{~cm}$ in mrems/hour

\begin{tabular}{|c|r|c|c|c|c|c|}
\hline Generator & $<=1$ & $<=10$ & $<=50$ & $s=100$ & $<=150$ & $<=200$ \\
\hline 340 & 410 & & & & & \\
\hline PNL 231-Z & 1 & & & & & \\
\hline 2335 & 1 & & & & & \\
\hline $234-52$ & 392 & & & & & \\
\hline WARDMNFD & 51 & & & & & \\
\hline ESG & 19 & & & & & \\
\hline
\end{tabular}

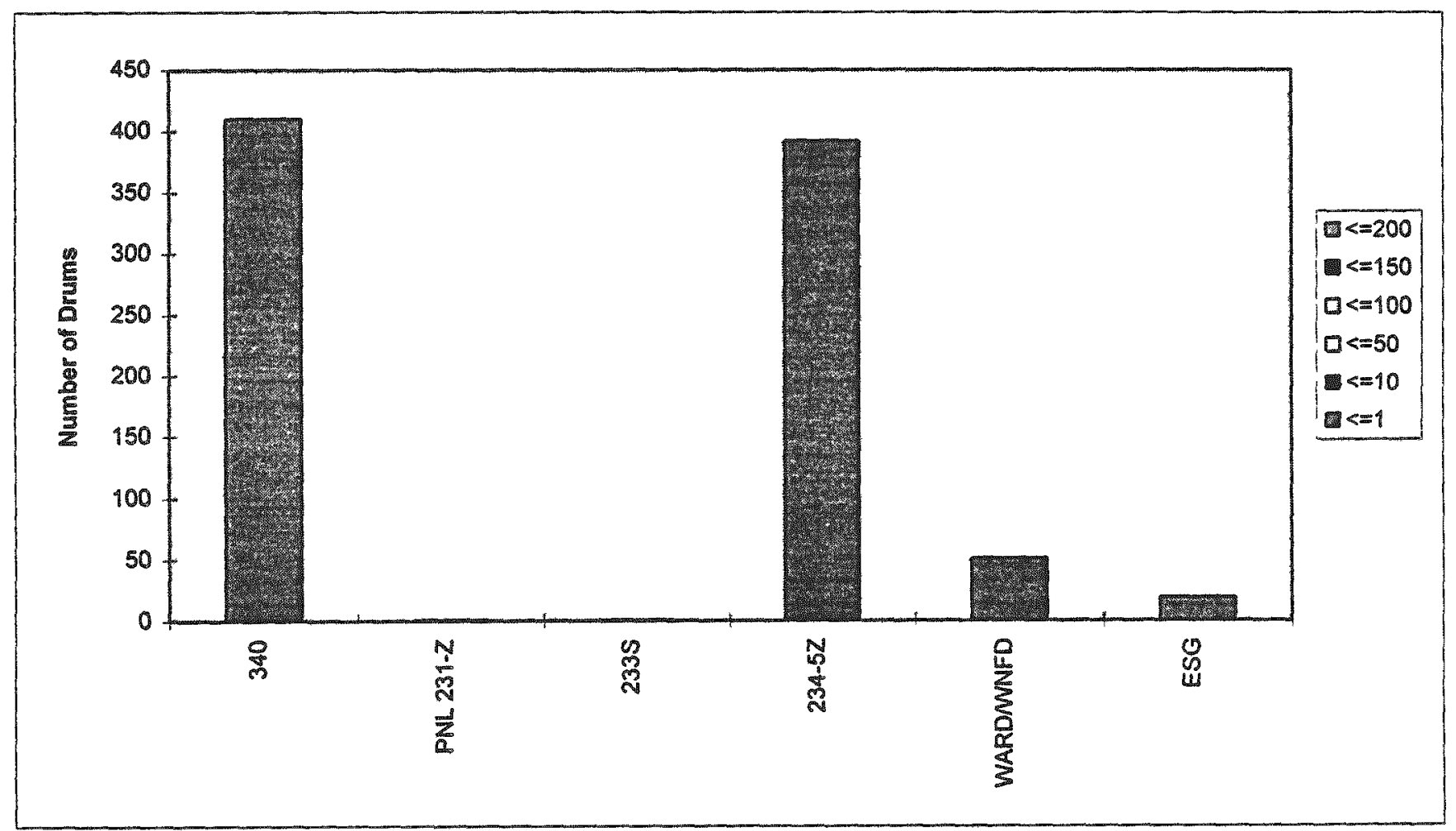


WHL-SU-VVU $\angle 0-11-U U Y$, nev.

Figure 5.5-13. Surface Dose Rates for Drums in Module 7 Sorted by Generator.

Maximum Total Dose Rate

at $4 \mathrm{~cm}$ in mrems/hour

\begin{tabular}{|c|r|r|r|r|r|l|}
\hline Generator & $<=1$ & $<=10$ & $<=50$ & $<=100$ & $<=150$ & $<=200$ \\
\hline 325 & & 53 & & & & \\
\hline 340 & 8 & 31 & & & & \\
\hline PNL 209E & 9 & & & & & \\
\hline 2335 & 18 & & & & & \\
\hline $234-52$ & 457 & & & & & \\
\hline
\end{tabular}

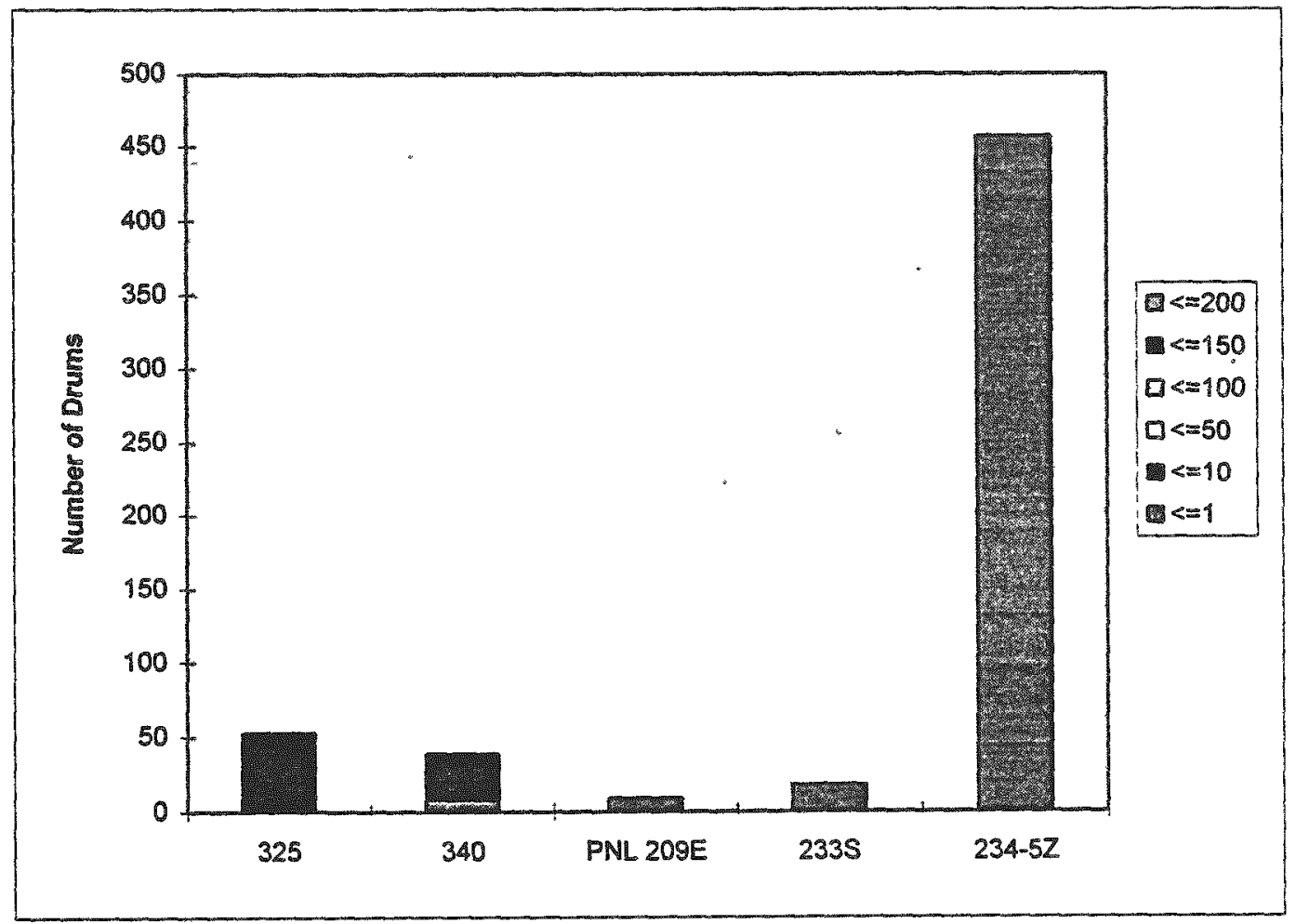


WHC-SD-W026-TI-009, Rev. O

Figure 5.5-14. Surface Dose Rates for Drums in Module 6 Sorted by Generator.

Maximum Total Dose Rate

at $1 \mathrm{~cm}$ in mrems/hour

\begin{tabular}{|c|r|r|r|r|r|r|}
\hline Generator & $<=1$ & $<=10$ & $<=50$ & $<=100$ & $<=150$ & $<=200$ \\
\hline 325 & & 44 & & & & \\
\hline PNL 231-Z & 8 & & & & & \\
\hline $234-5 Z$ & 517 & & & & & \\
\hline 2 WTF & & 6 & & & & \\
\hline
\end{tabular}

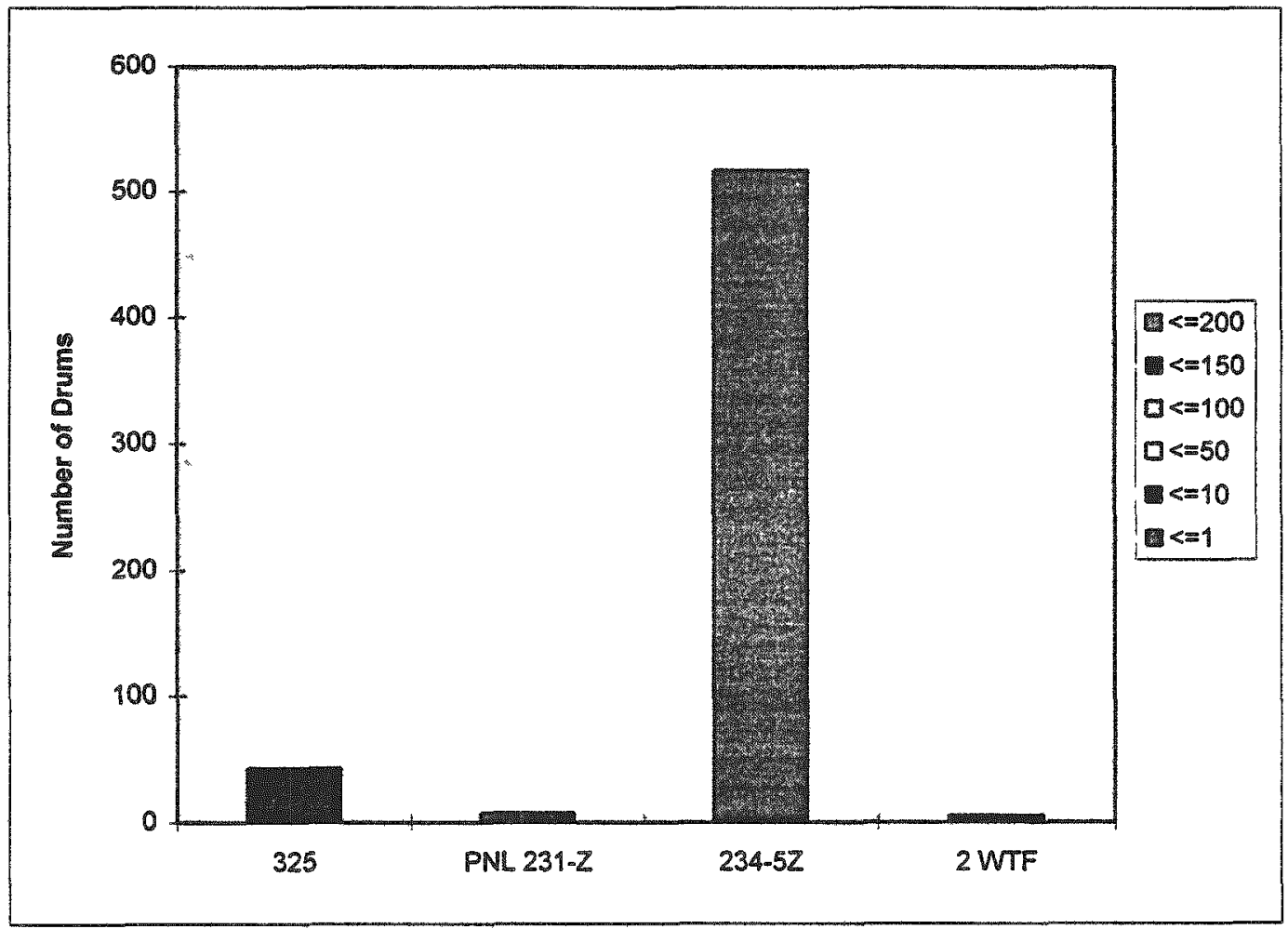


VบTIL-DU

Figure 5.5-15. Surface Dose Rates for Drums in Module 5 Sorted by Generator.

Maximum Total Dose Rate

at $1 \mathrm{~cm}$ in mrems/hour

\begin{tabular}{|c|r|r|r|r|r|r|}
\hline Generator & $<=1$ & $<=10$ & $<=50$ & $<=100$ & $<=150$ & $<=200$ \\
\hline 325 & 139 & 46 & & & & \\
\hline PNL 231-Z & 14 & & & & & \\
\hline 2335 & 7 & & & & & \\
\hline $234-52$ & 304 & & & & & \\
\hline
\end{tabular}

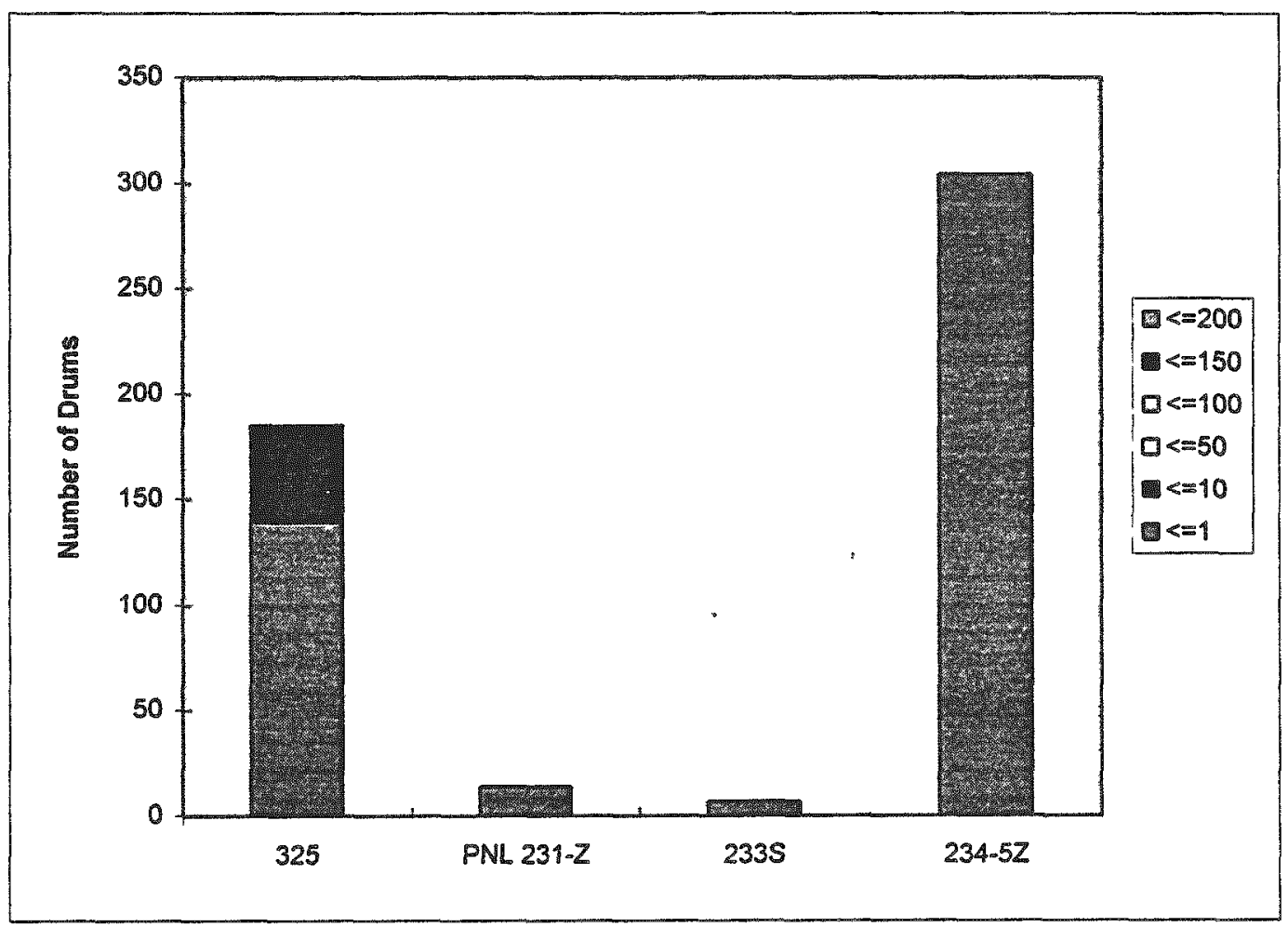


WHC-SD-W026-TI-009, Rev. O

Figure 5.5-16. Surface Dose Rates for Drums in Module 4 Sorted by Generator.

Maximum Total Dose Rate

at $1 \mathrm{~cm}$ in mrems/hour

\begin{tabular}{|c|r|r|r|r|r|r|}
\hline Generator & $s=1$ & $<=10$ & $<=50$ & $<=100$ & $<=150$ & $<=200$ \\
\hline 325 & 192 & 9 & & & & \\
\hline 2335 & 8 & & & & & \\
\hline $234-52$ & 337 & & & & & \\
\hline
\end{tabular}

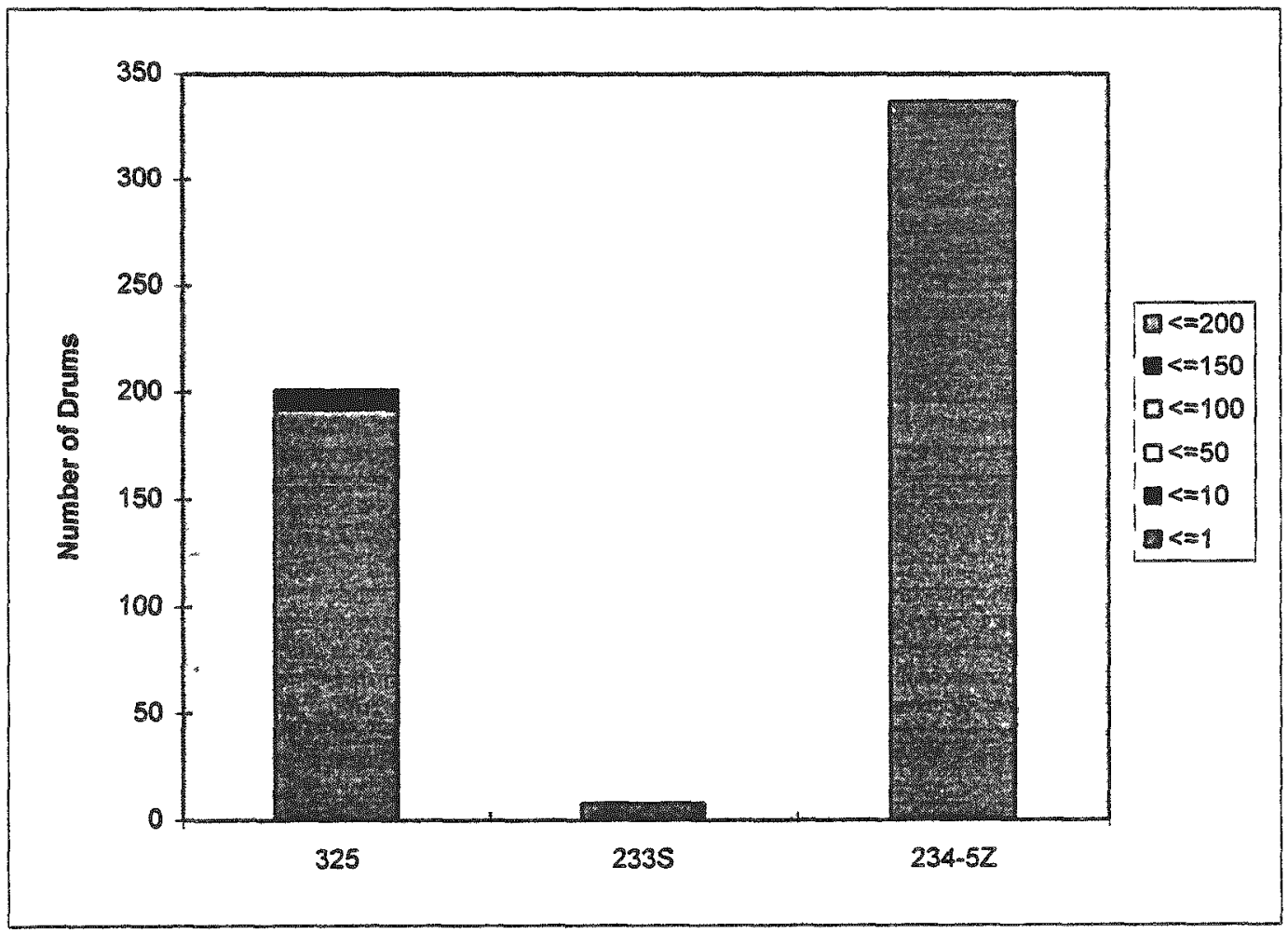




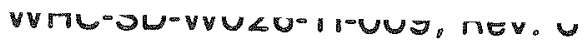

Figure 5.5-17. Surface Dose Rates for Drums in Module 3 Sorted by Generator.

Maximum Total Dose Rate

at $1 \mathrm{~cm}$ in mrems/hour

\begin{tabular}{|c|r|c|c|c|c|c|}
\hline Generator & $<=1$ & $<=10$ & $<=50$ & $<=100$ & $<=150$ & $<=200$ \\
\hline 325 & 74 & & & & & \\
\hline PNL 231-Z & 85 & & & & & \\
\hline $202 \mathrm{~A}$ & 64 & & & & & \\
\hline $202 \mathrm{AL}$ & 6 & & & & & \\
\hline $234.5 Z$ & 264 & & & & & \\
\hline
\end{tabular}

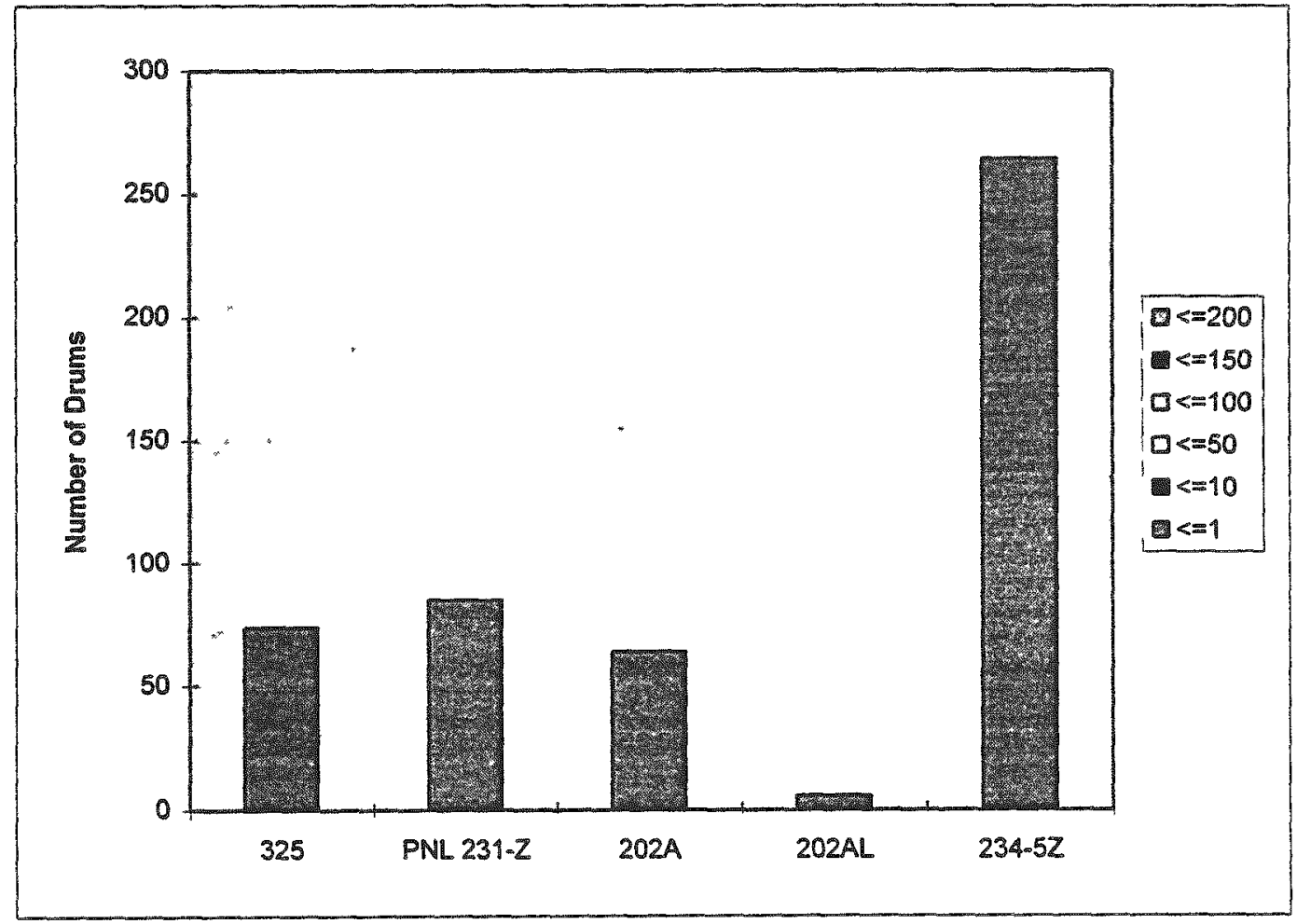


WHC-SD-W026-TI-009, Rev.O

Figure 5.5-18. Surface Dose Rates for Drums in Module 2 Sorted by Generator.

Maximum Total Dose Rate

at $1 \mathrm{~cm}$ in mrems/hour

\begin{tabular}{|c|r|c|c|c|c|c|}
\hline Generator & $<=1$ & $<=10$ & $<=50$ & $<=100$ & $<=150$ & $<=200$ \\
\hline 325 & 92 & & & & & \\
\hline PNL $231-Z$ & 14 & & & & & \\
\hline $234-52$ & 462 & & & & & \\
\hline
\end{tabular}

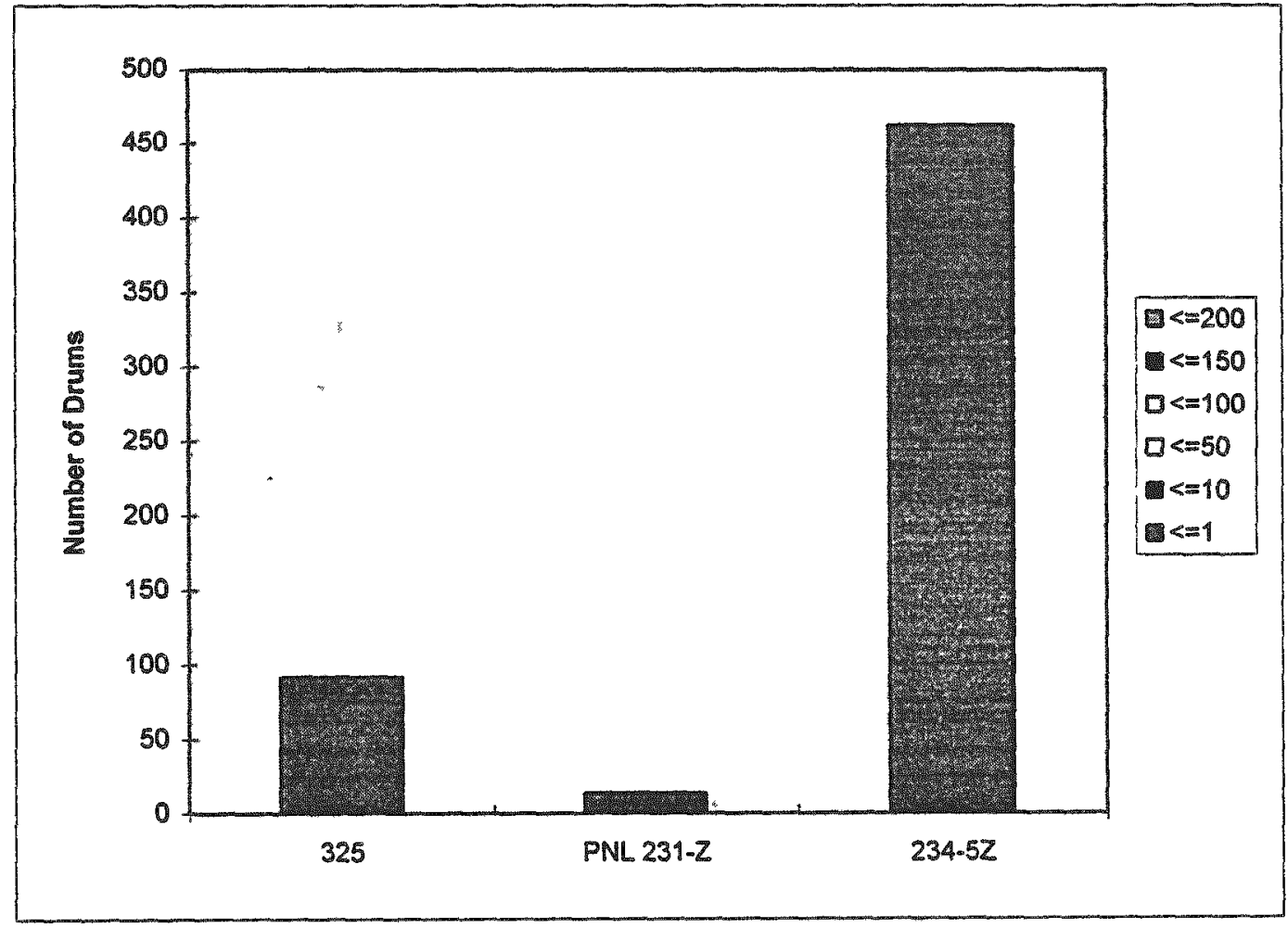


WHC-SD-W026-T1-009, Rev。O

Figure 5.5-19. Surface Dose Rates for Drums in Module 1 Sorted by Generator.

Maximum Total Dose Rate

at $1 \mathrm{~cm}$ in mrems/hour

\begin{tabular}{|c|c|c|c|c|c|c|}
\hline Generator & $s=1$ & $<=10$ & $<=50$ & $<=100$ & $<=150$ & $<=200$ \\
\hline 325 & 83 & 5 & 1 & & & \\
\hline PNL 231-Z & 42 & & & & & \\
\hline $222 \mathrm{~S}$ & 4 & & & & & \\
\hline $234-52$ & 564 & & & & & \\
\hline
\end{tabular}

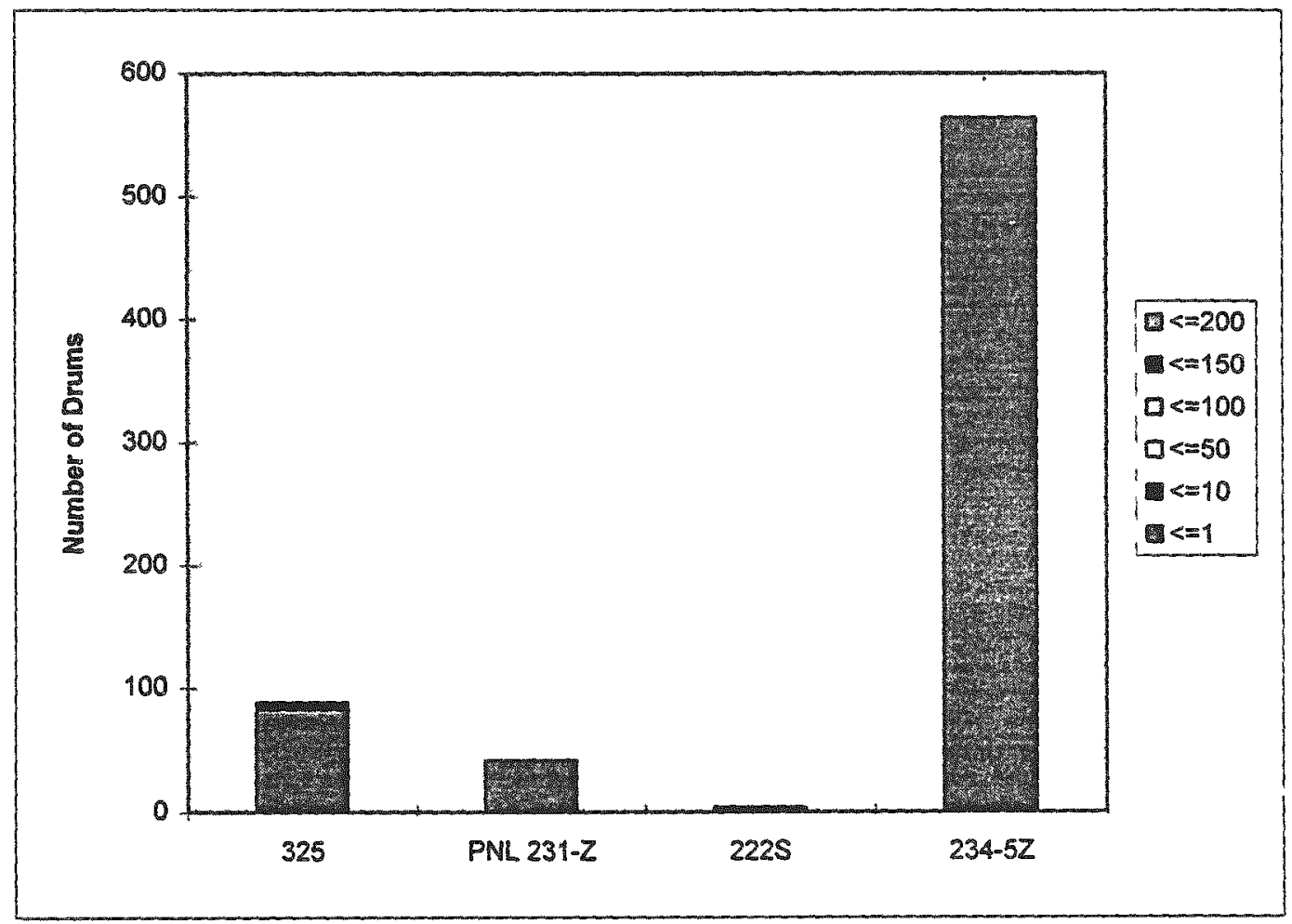


WHC-SD-W026-TI-009, Rev.O

Figure 5.5-20. Surface Dose Rates for Drums in Unknown Modules Sorted by Generator.

Maximum Total Dose Rate

at $1 \mathrm{~cm}$ in mrems/hour

\begin{tabular}{|c|r|r|r|r|r|r|}
\hline Generator & $<=1$ & $<=10$ & $<=50$ & $<=100$ & $<=150$ & $<=200$ \\
\hline 325 & 55 & 1 & & & & \\
\hline 340 & 1 & & & & & \\
\hline PNL 209E & 1 & & & & & \\
\hline PNL 231-Z & 16 & & & & & \\
\hline $202 \mathrm{~A}$ & 4 & 1 & & & & \\
\hline 2335 & 3 & & & & & \\
\hline GE-VAL & 129 & 1 & & & & \\
\hline WARDMNFD & 4 & & & & & \\
\hline B \&W & 6 & & & & & \\
\hline BMI & 1 & & & & & \\
\hline
\end{tabular}

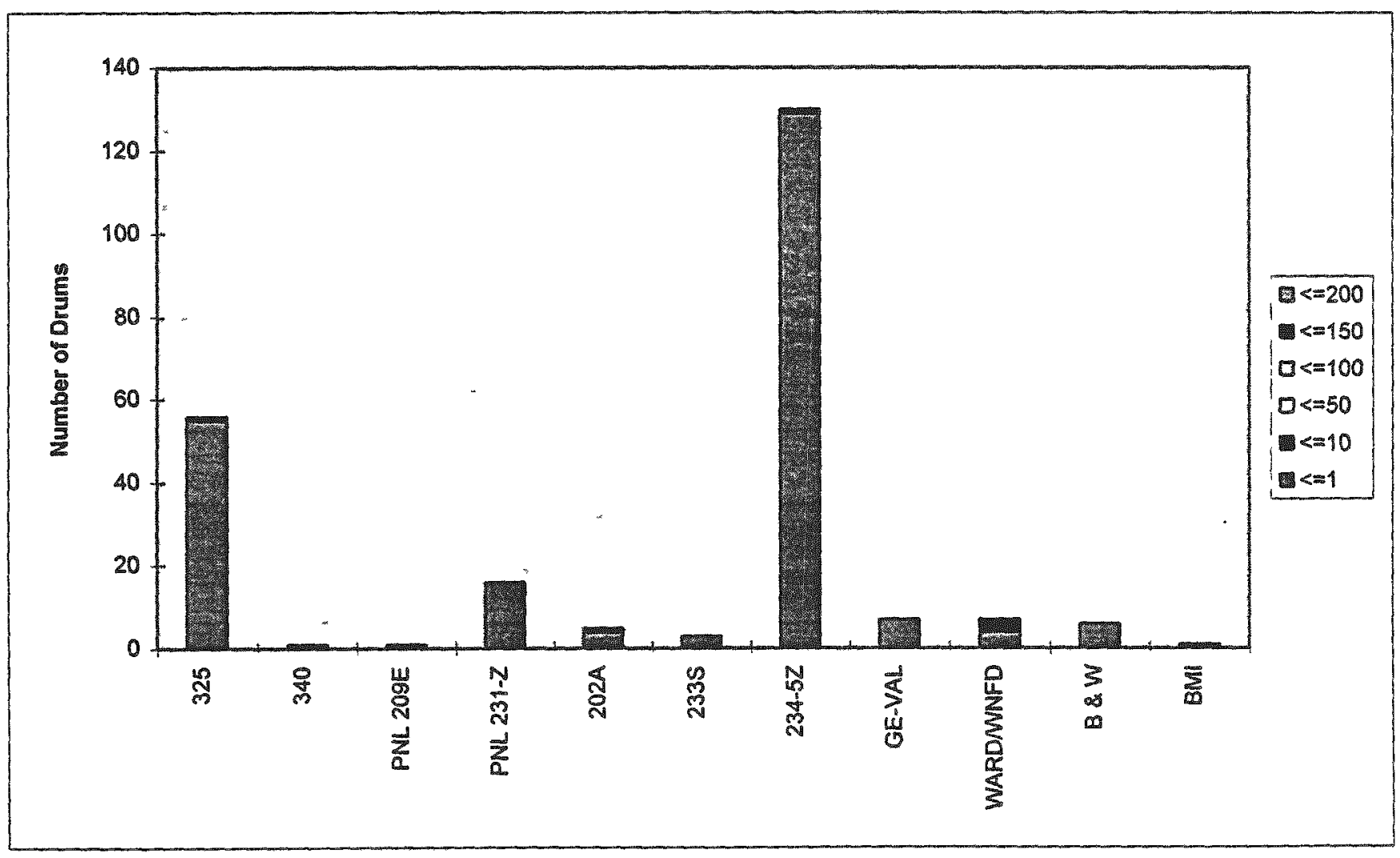




\subsubsection{Neutron Dose}

The WIPP waste acceptance criteria required that neutron contributions of greater than 20 mrems/hour be separately documented. Records from SWITS database list no drums in Trench 4C-04 that approach this limit. Only 2 drums in this trench list a neutron dose rate. Both drums are from 234-5Z and list a neutron dose rate of $1 \mathrm{mrem} / \mathrm{hr}$. One drum is stored in Module 2 and one in Module 3.

\subsubsection{Thermal Power}

Thermal (wattage) limits for individual waste packages are contained in the TRUPACT-II Safety Analysis Report for Packaging. The TRUPACT design limit is 40 watts per cubic foot. Table 5.5-1 shows that no drums in Trench 4C-04 are recorded above 0.1 watts per cubic foot.

Table 5.5-1. Drums in Trench 4C-04 With Thermal Power Listed.

\begin{tabular}{|c|c|c|c|}
\hline \multirow[t]{2}{*}{$\begin{array}{l}\text { Module } \\
\text { Number }\end{array}$} & \multirow[t]{2}{*}{ Generator } & \multicolumn{2}{|c|}{$\begin{array}{l}\text { Number of Drums } \\
\text { with Listed Thermal } \\
\text { Powers }\end{array}$} \\
\hline & & $\begin{array}{l}0.01 \\
\text { watts } / \mathrm{ft}^{3}\end{array}$ & $\begin{array}{l}0.1 \\
\text { watts } / \mathrm{ft}^{3}\end{array}$ \\
\hline 19 & $234-5 z$ & & 1 drum \\
\hline 17 & $234-5 Z$ & & 4 \\
\hline \multirow[t]{4}{*}{15} & WAROMNFD & & 48 \\
\hline & Babcock \& Wilcox & & 28 \\
\hline & 340 & & 13 \\
\hline & 234.52 & & 129 \\
\hline \multirow[t]{5}{*}{14} & WARD WNFD & & 29 \\
\hline & Babcock \& Wilcox & & 85 \\
\hline & 340 & & 8 \\
\hline & $234-5 z$ & & 188 \\
\hline & $202 \mathrm{~A}$ & & 29 \\
\hline 13 & WARDMNFD & & 55 \\
\hline \multirow[t]{2}{*}{9} & 340 & & 1 \\
\hline & $234-5 z$ & & 1 \\
\hline \multirow{2}{*}{$\begin{array}{l}\text { Unknown } \\
\text { Module }\end{array}$} & $234-5 z$ & & 2 \\
\hline & WARDNWND & 1 & 2 \\
\hline
\end{tabular}




\subsubsection{Isotope and Quantity}

There are several WRAP I and WIPP requirements that apply to the radionuclide content of waste containers in the trench.

Since WIPP accepts only TRU waste, it must be separated from LLW in WRAP Module 1. To meet WIPP acceptance criteria waste each container must hold greater than $100 \mathrm{nCi}$ of TRU per gram, exclusive of added shielding, rigid liners, and the waste containers. The $100 \mathrm{nCi} / \mathrm{g}$ TRU includes all alpha contaminated wastes handed as TRU under DOE Order 5820.2A. Table 5.5-2 and Figure 5.5-21 show the number of drums in each module that contain potentially non-TRU waste. Figures 5.5-22 through 5.5-42 show this data separately for each generator. 
WHC-SD-W026-TI-009, Rev. O

Table 5.5-2. Drums of Potentially TRU and Non-TRU Wastes in Each Module by Generator.

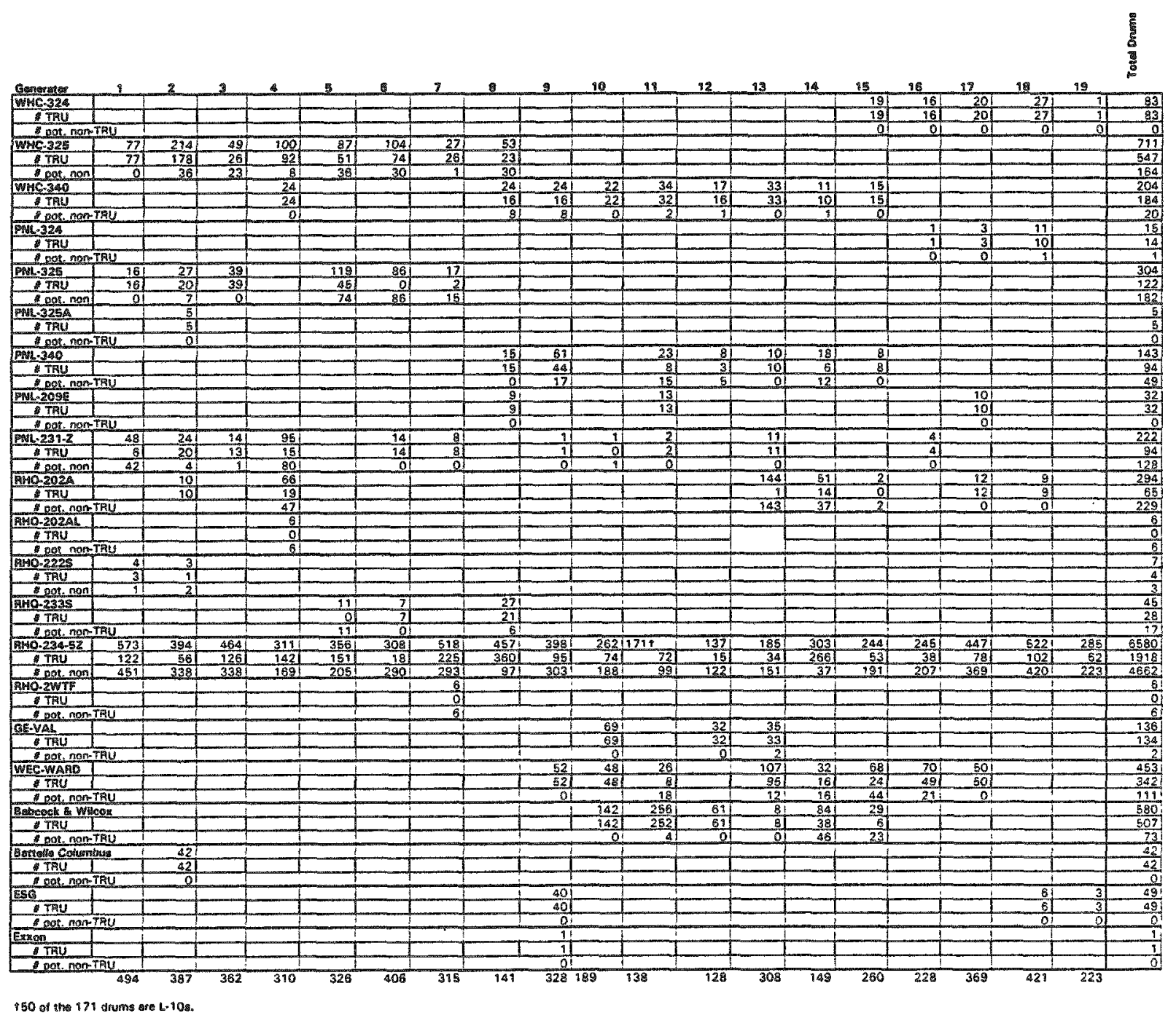




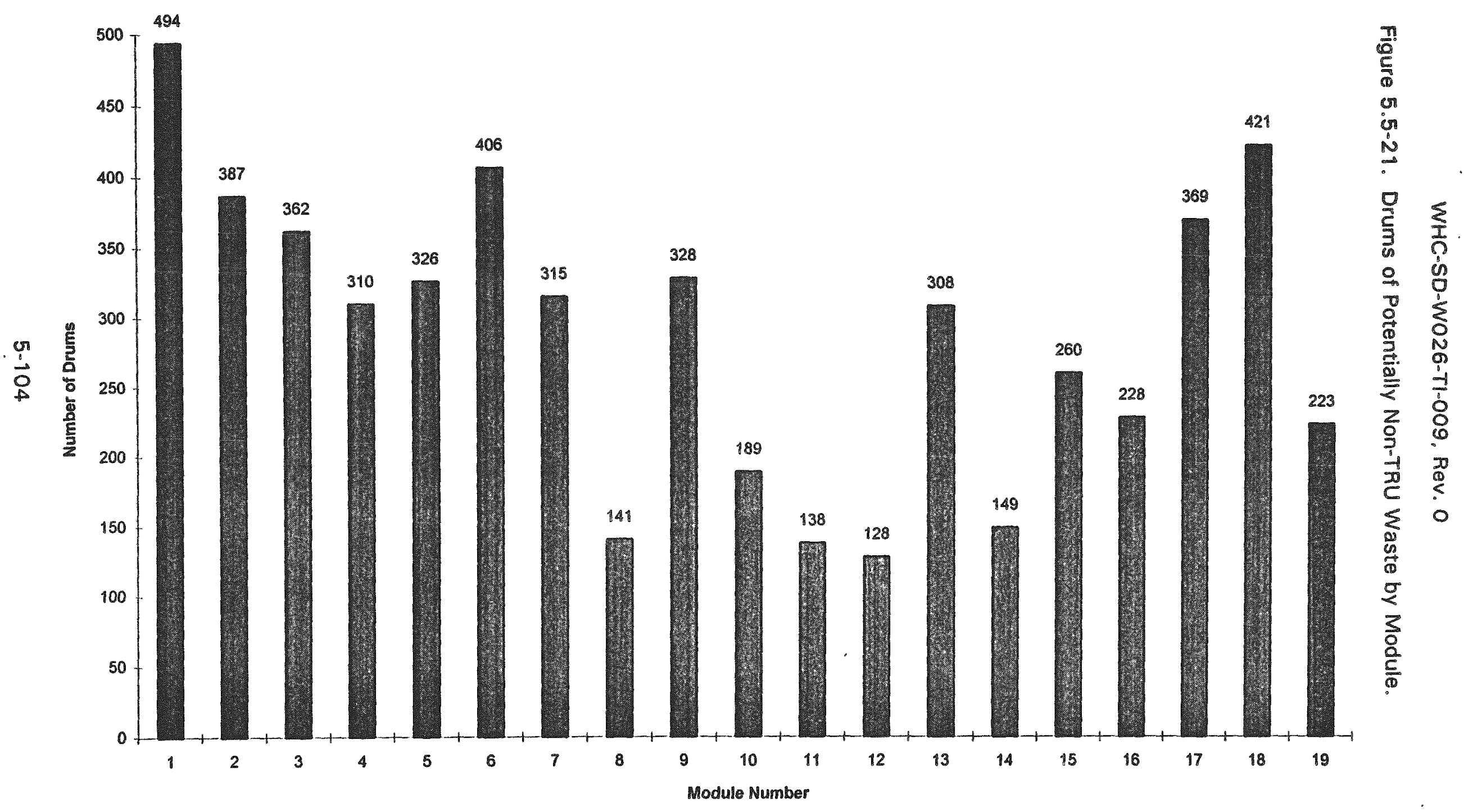




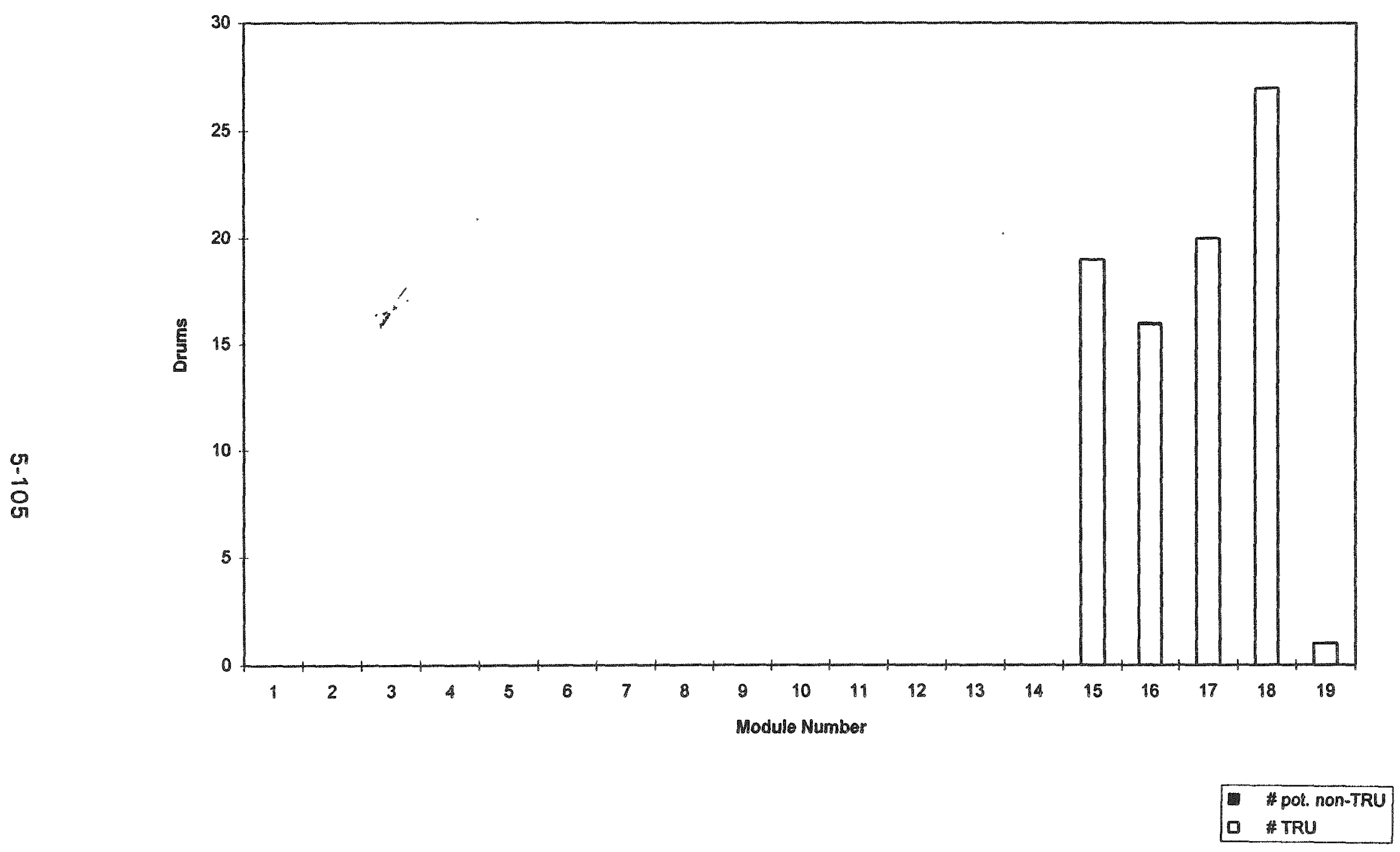

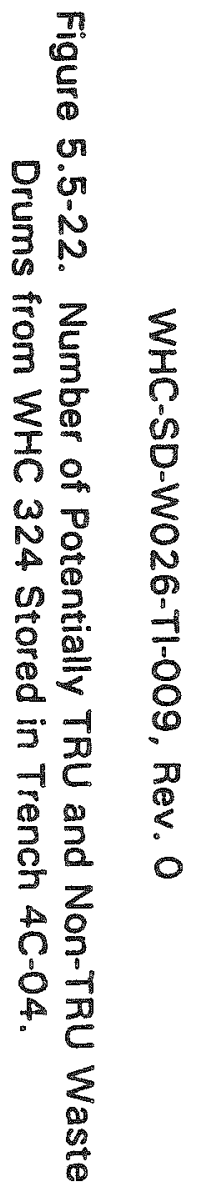


$\frac{0}{0}$
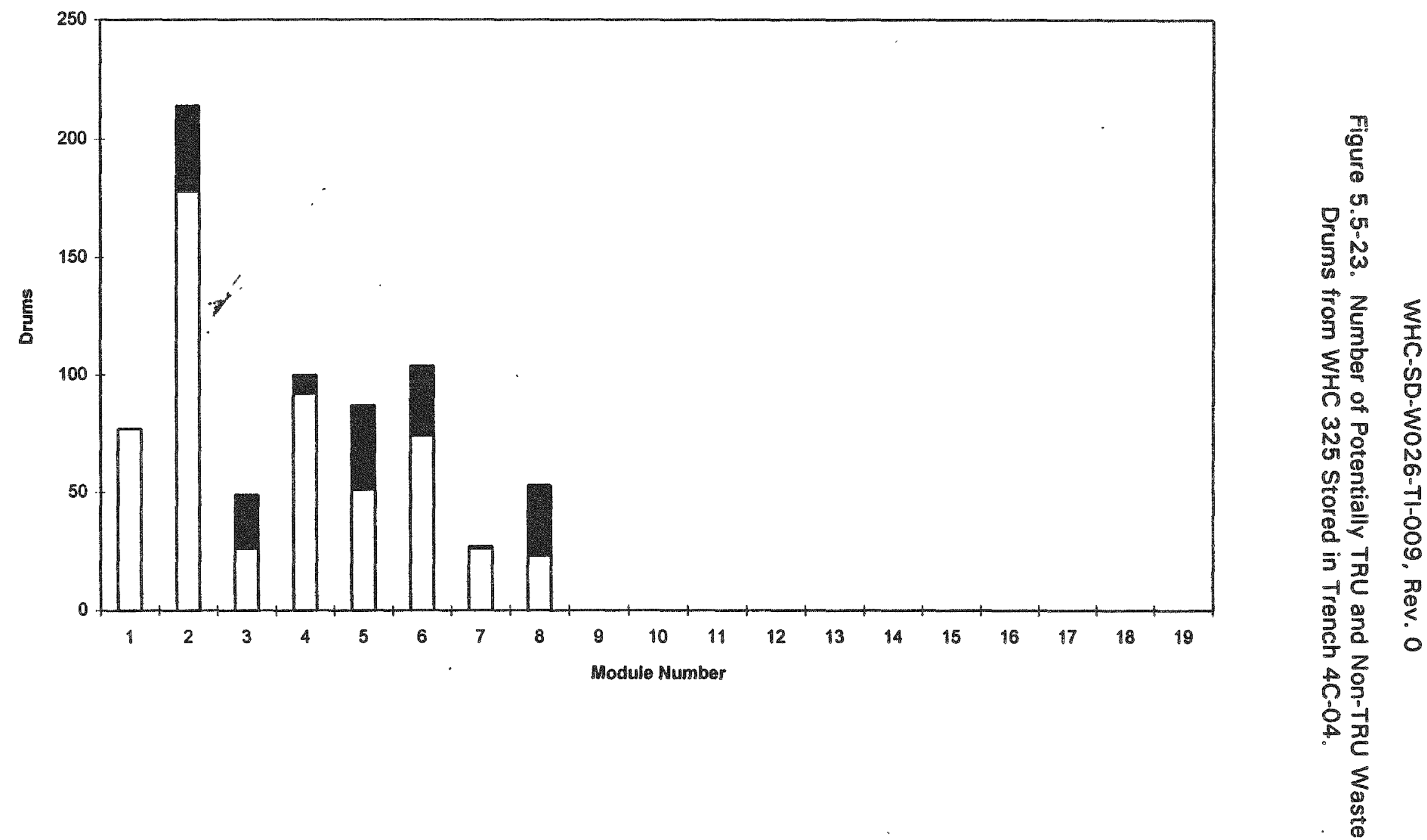
$\stackrel{g}{0}$

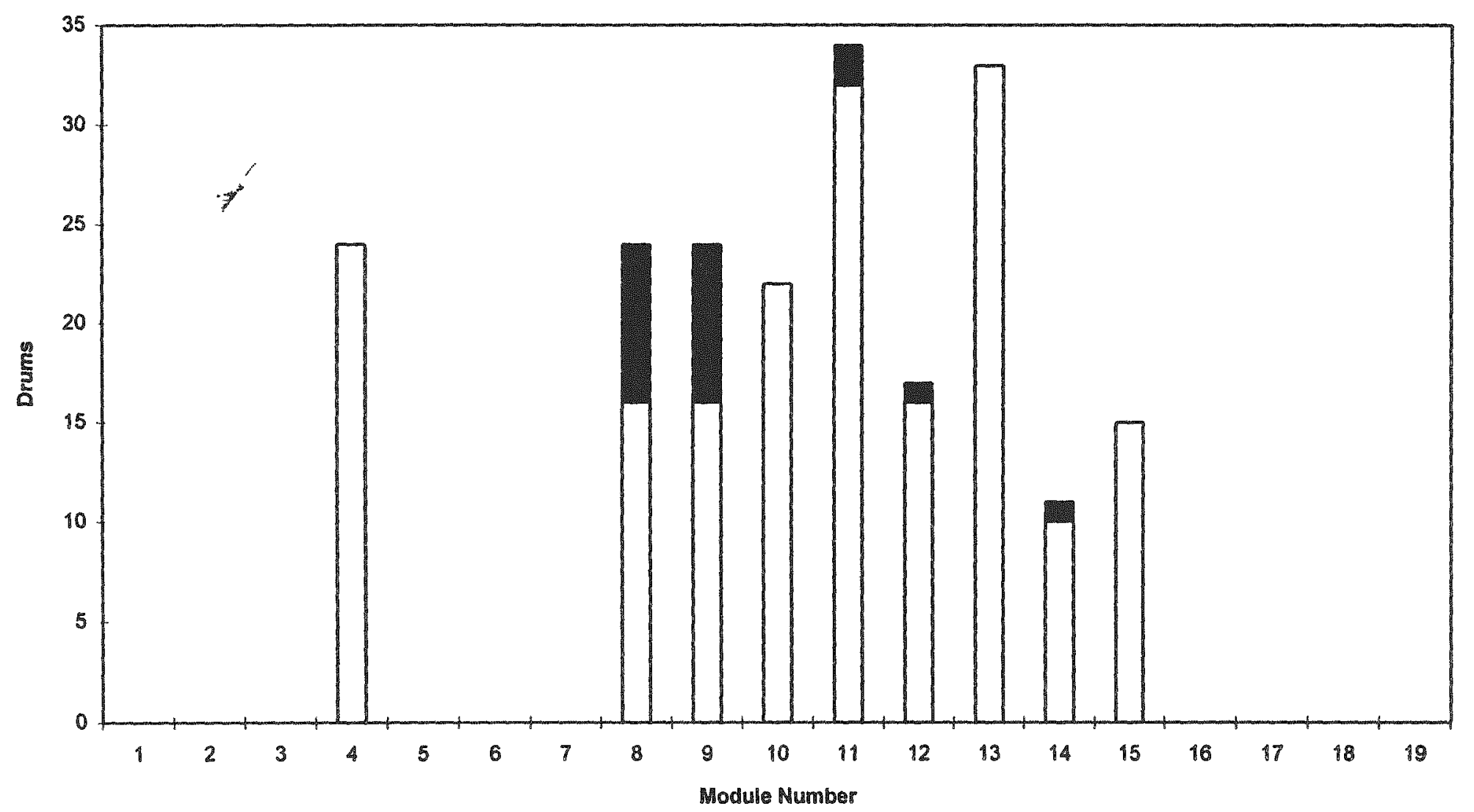

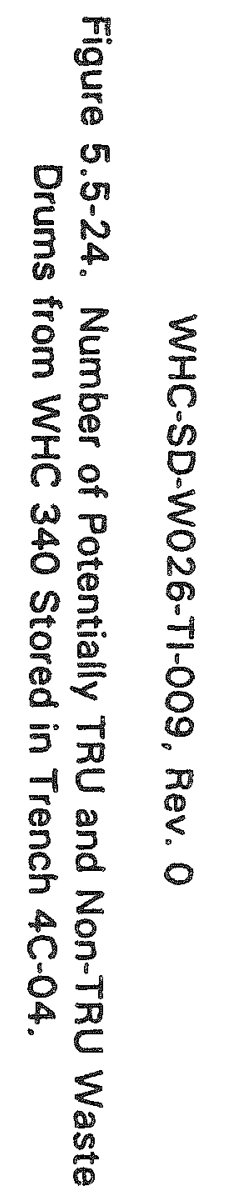

" pot.non-TRU
a TRU 

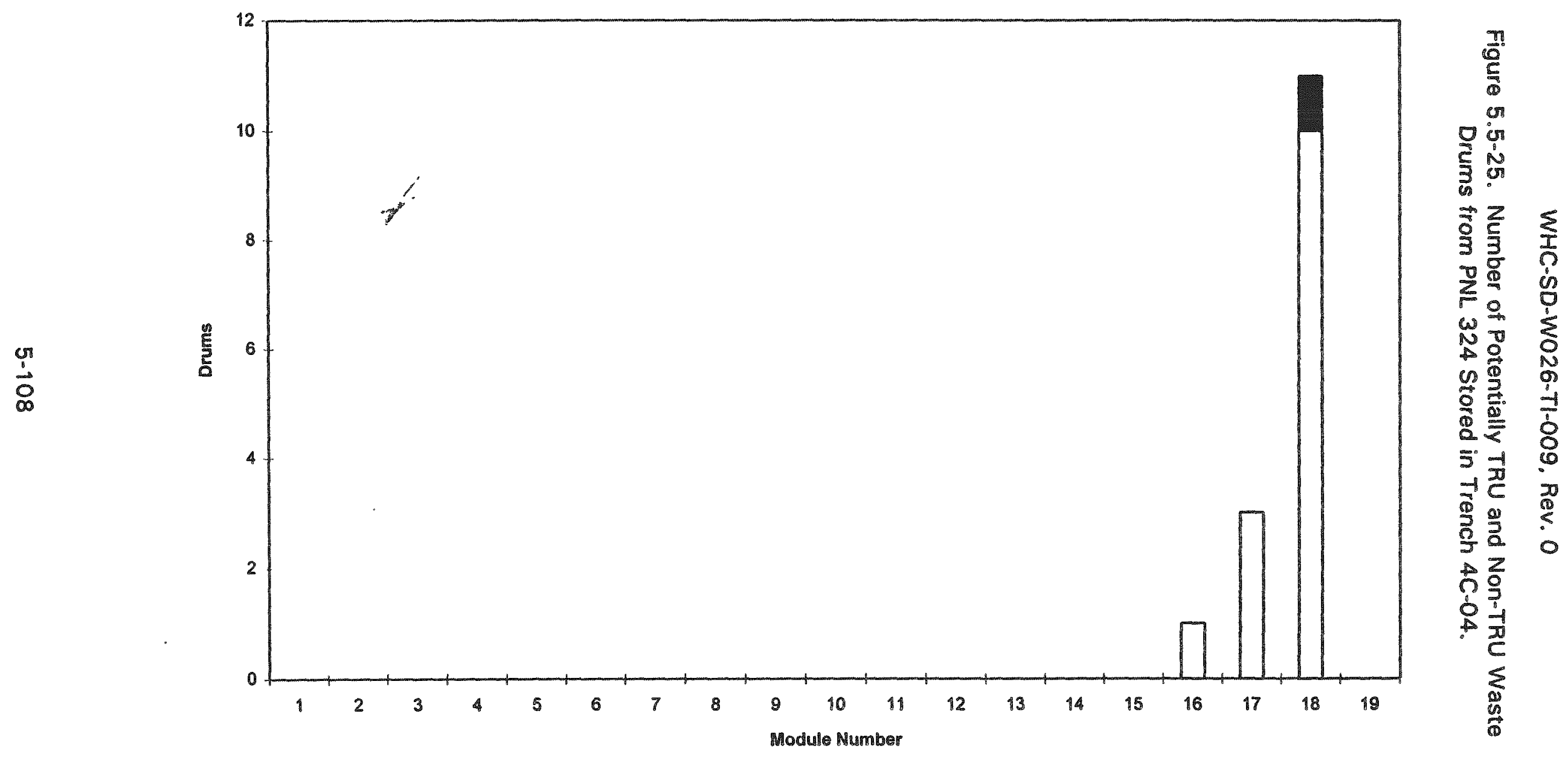

" pot. non-TRU

o MRU 

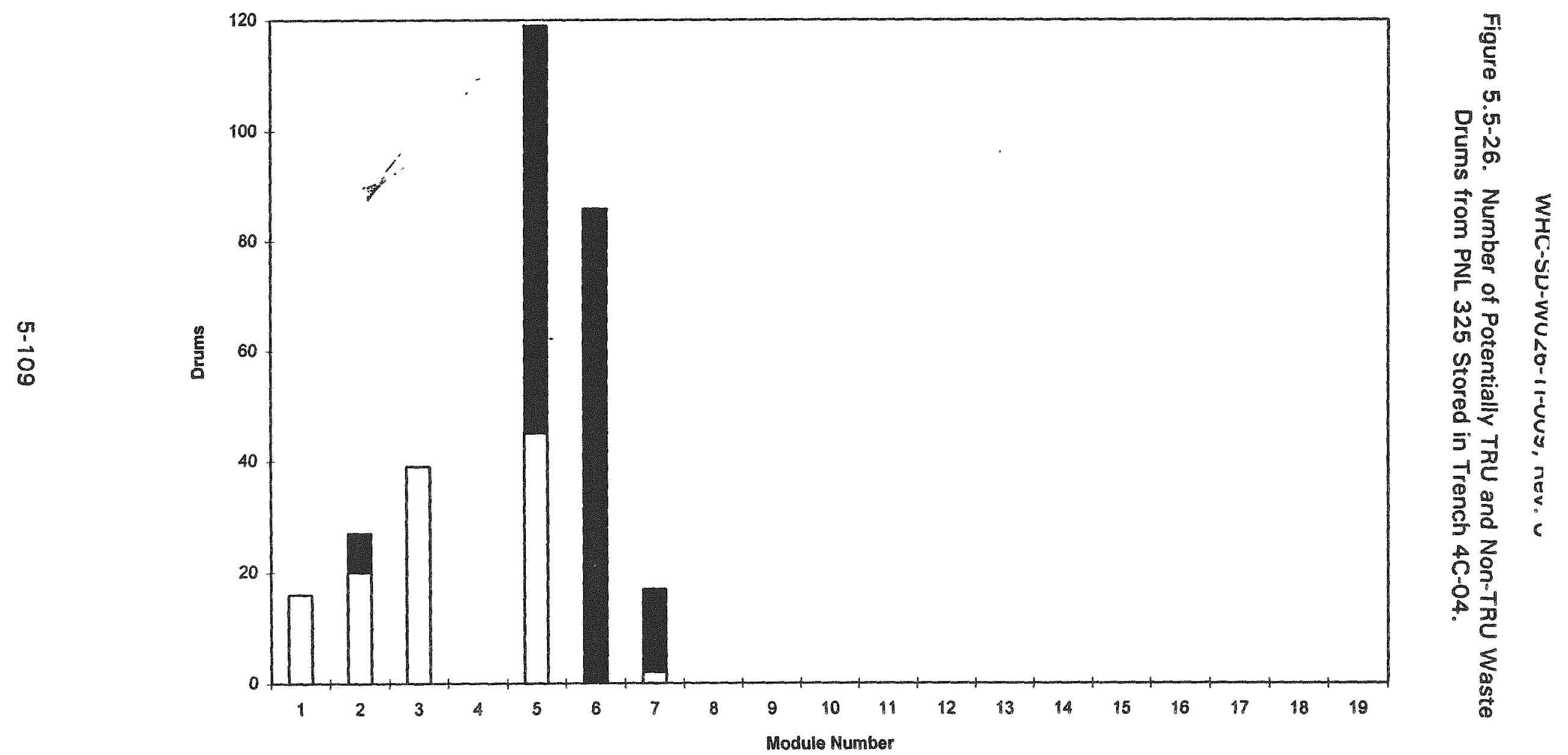

pot non-TRU 

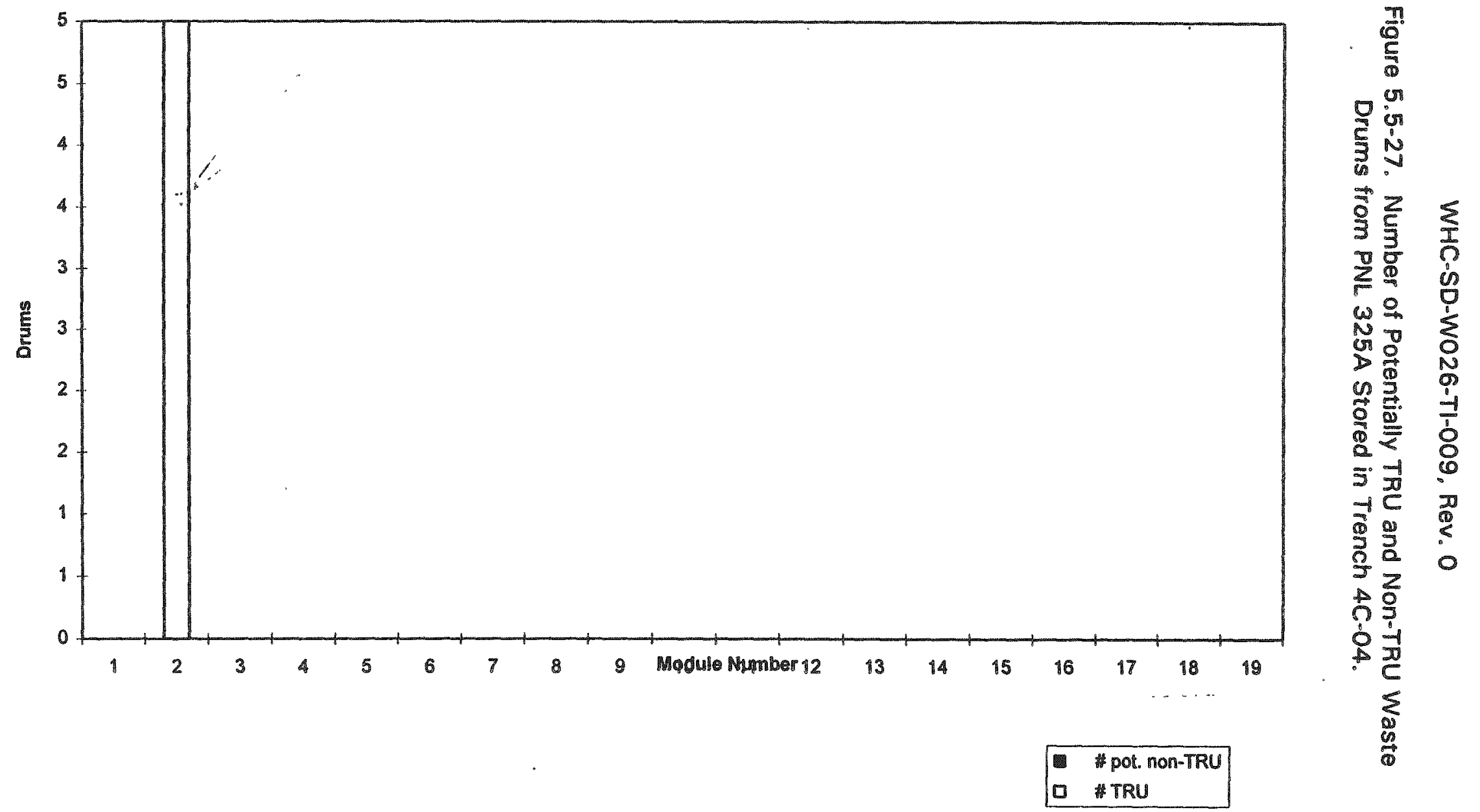


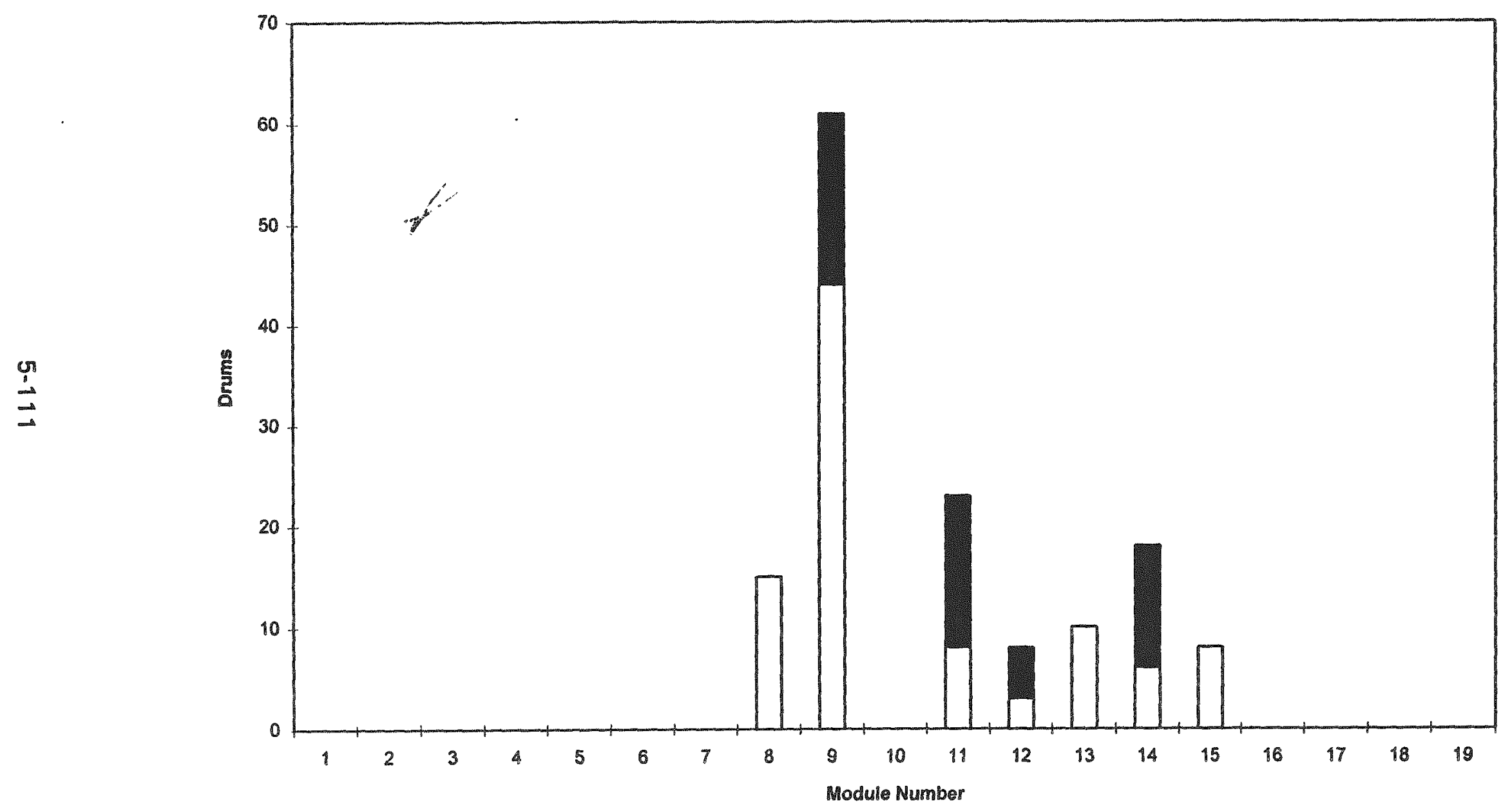

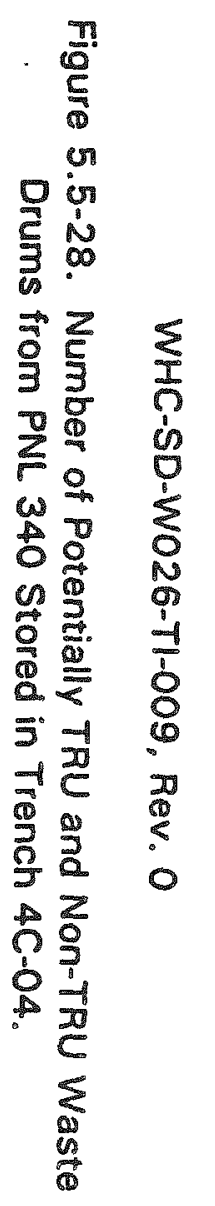

pot. non-TRU

o ARU 
$\underset{n}{\square}$
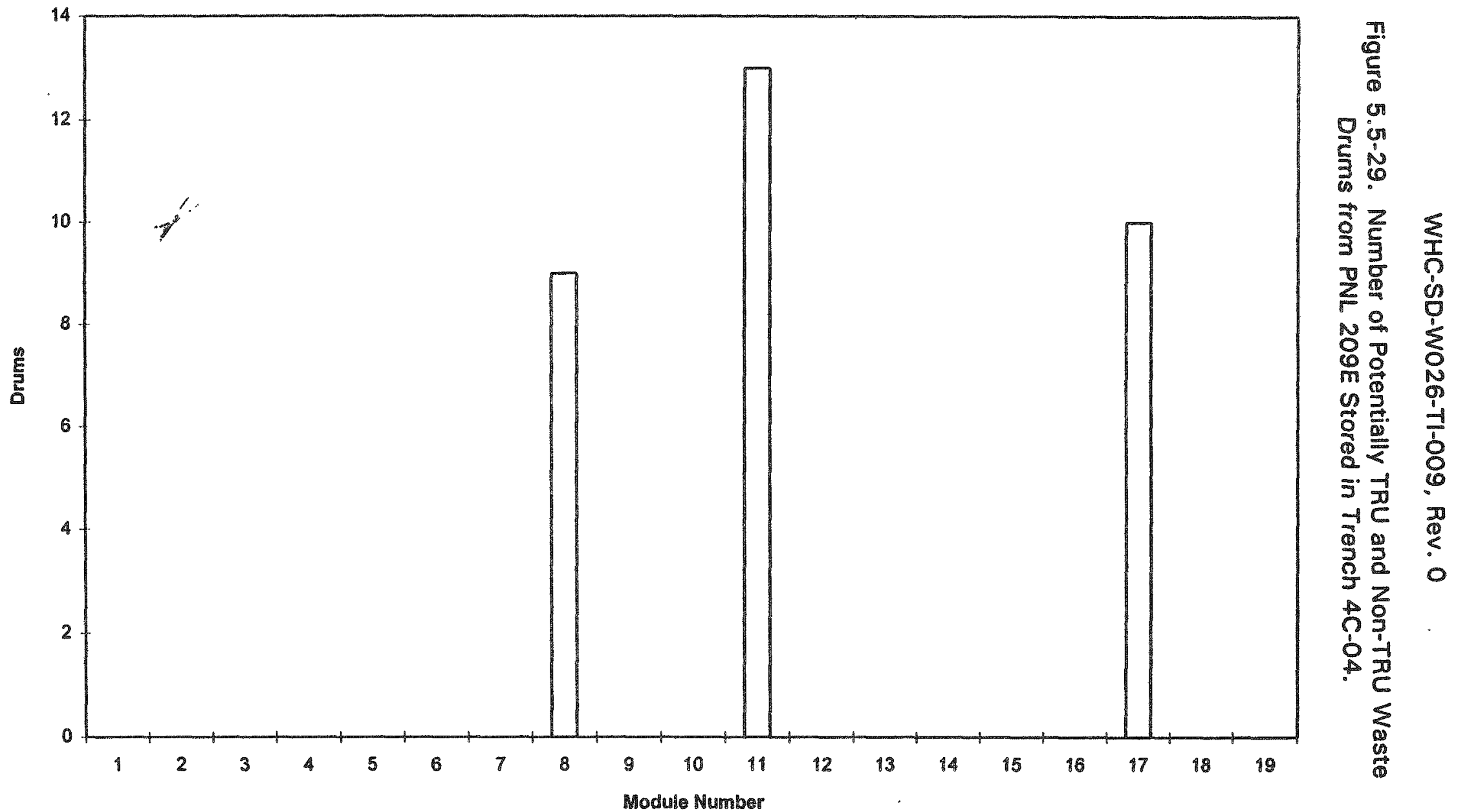

pot. non-TRU 

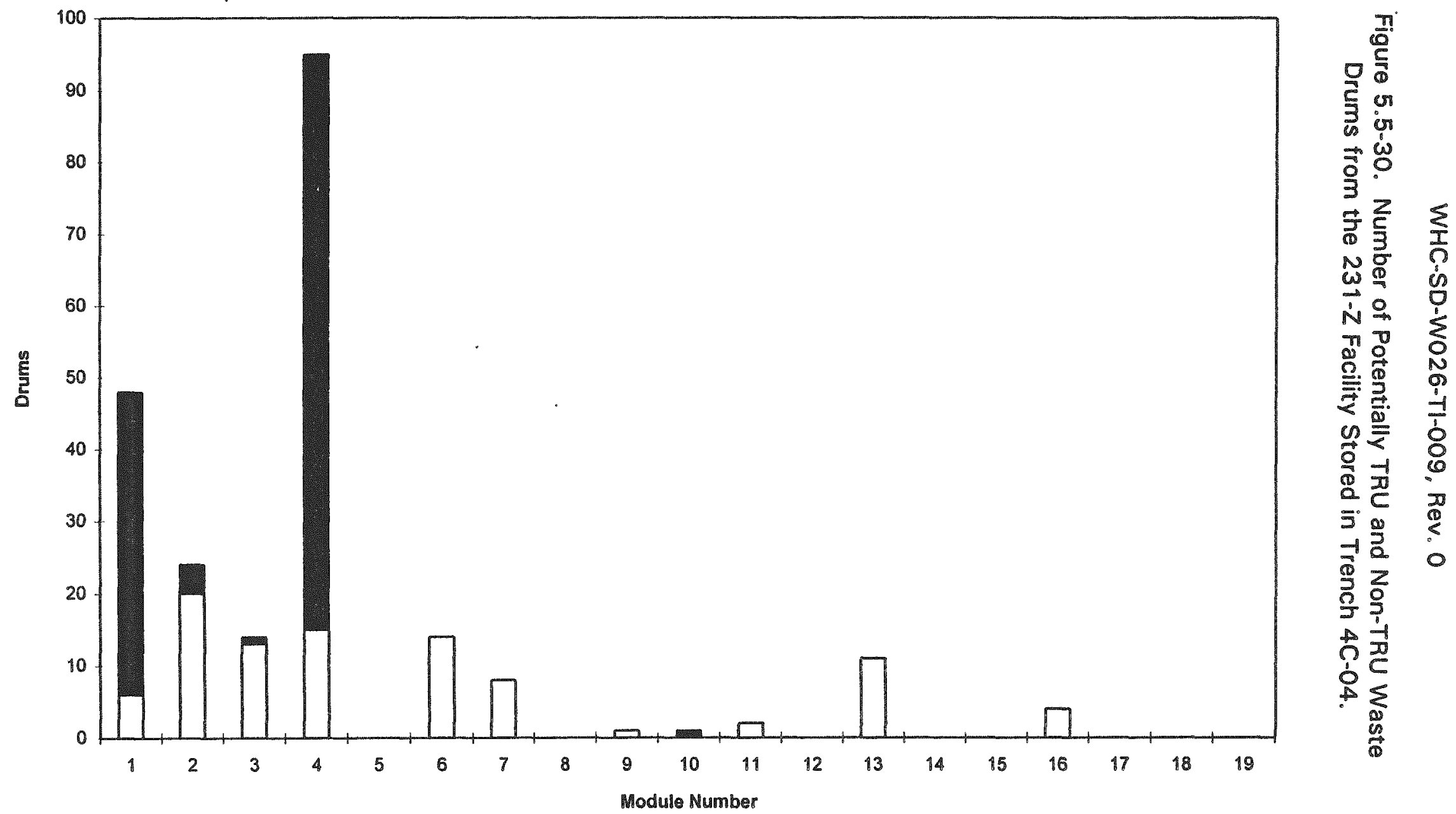

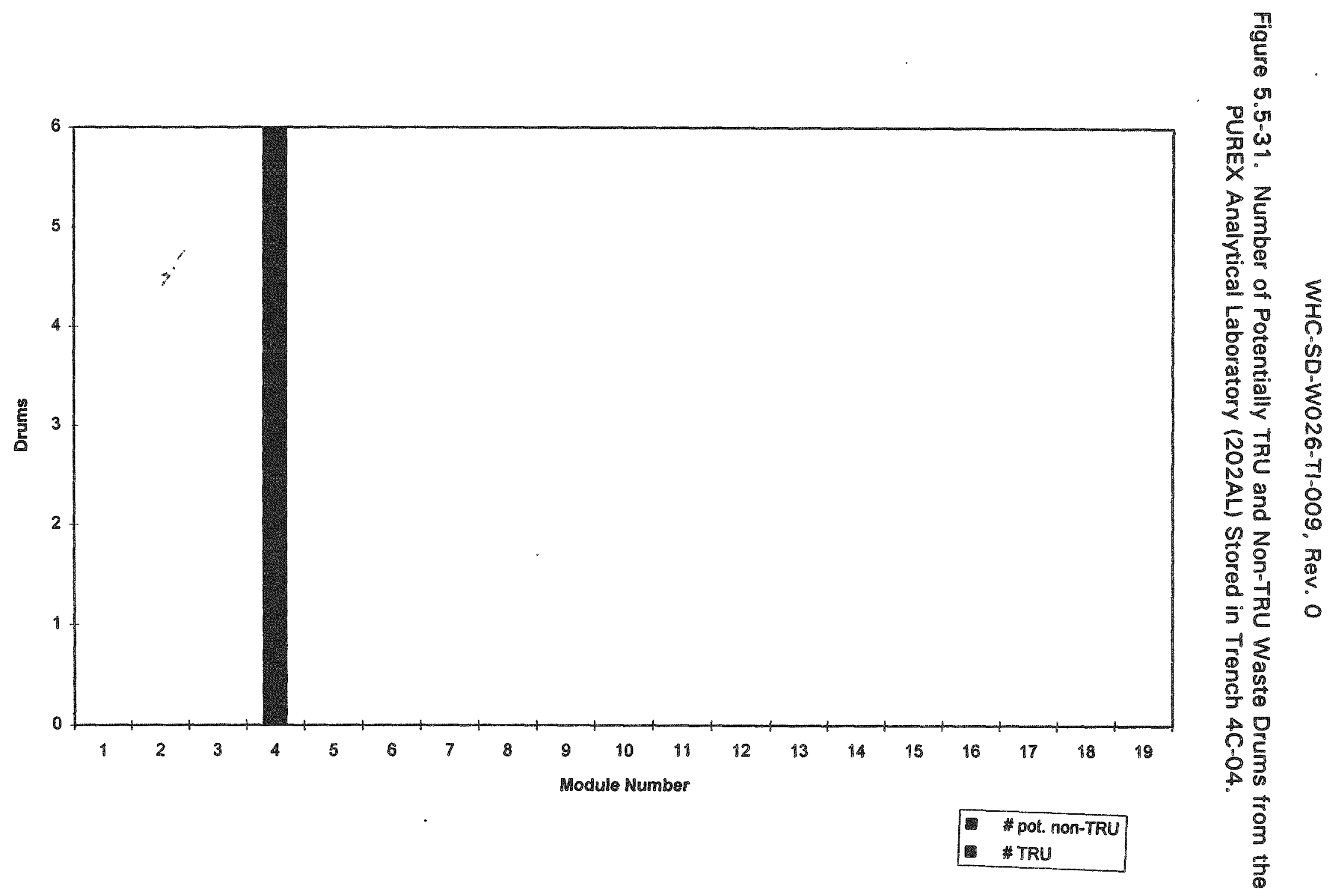

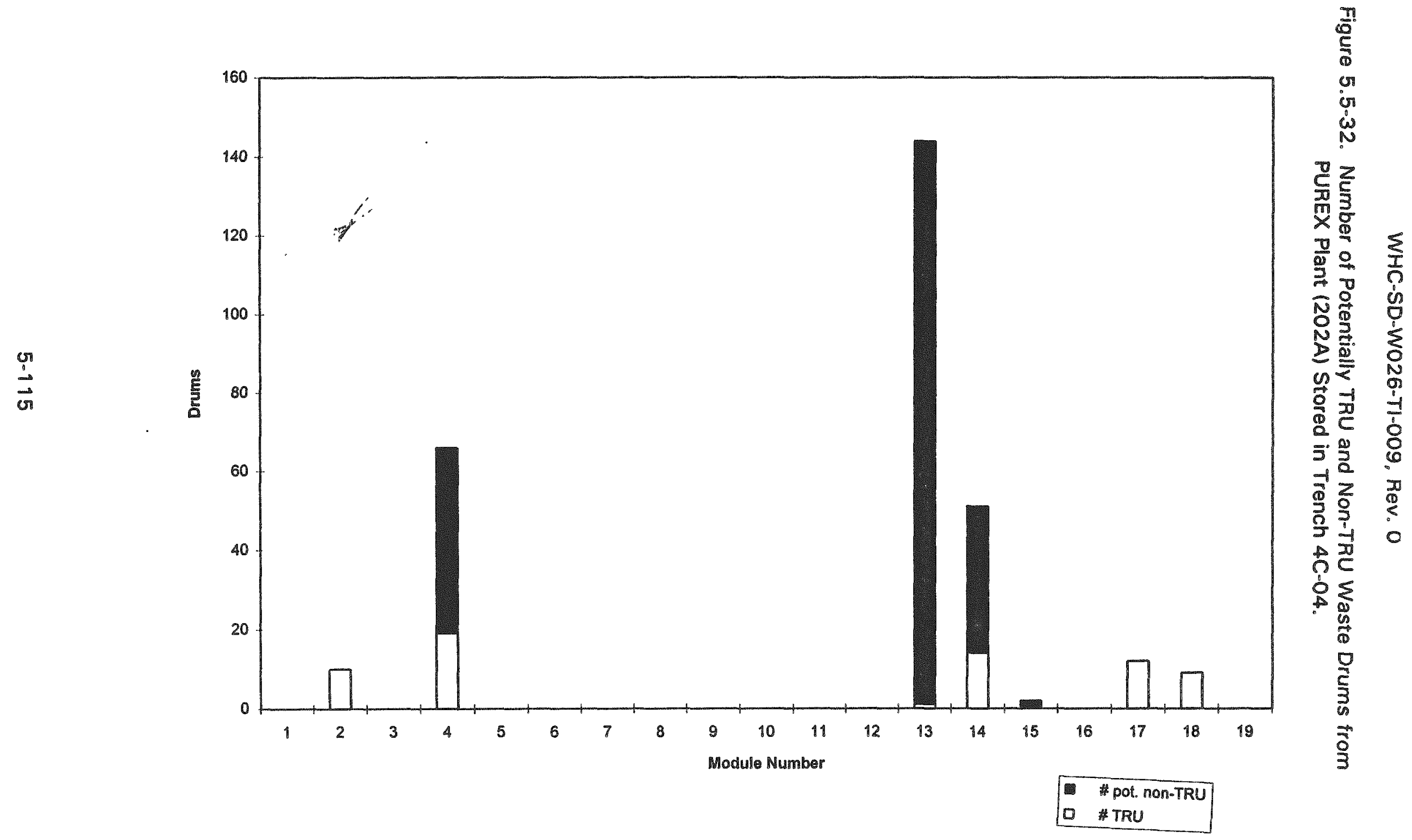
$\stackrel{\overrightarrow{0}}{\overrightarrow{0}}$

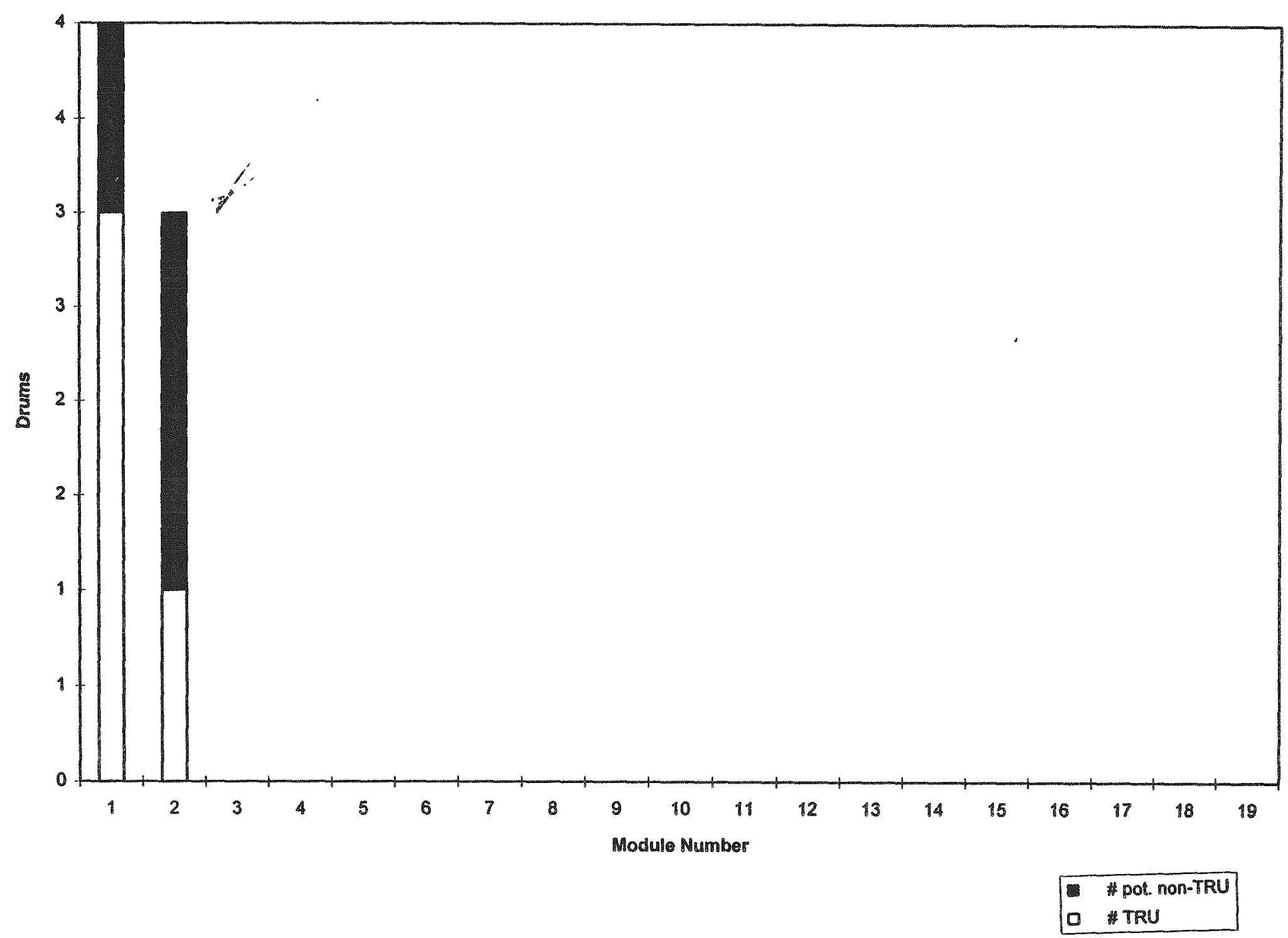

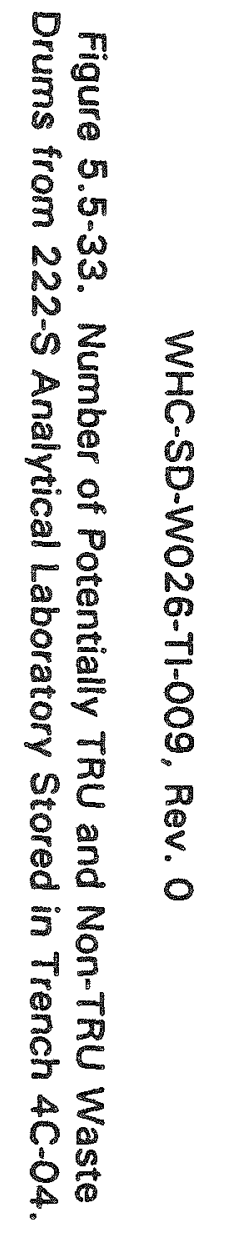




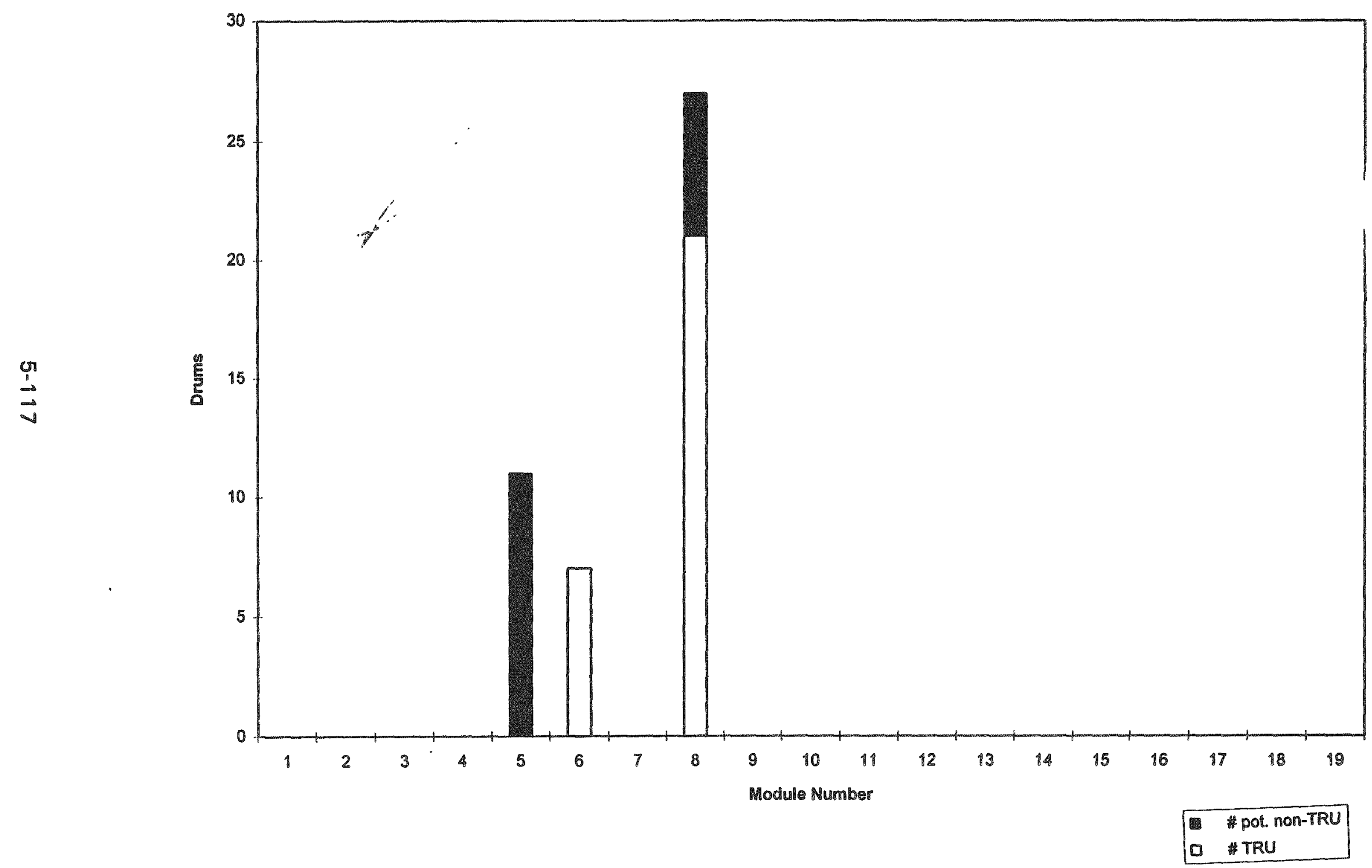

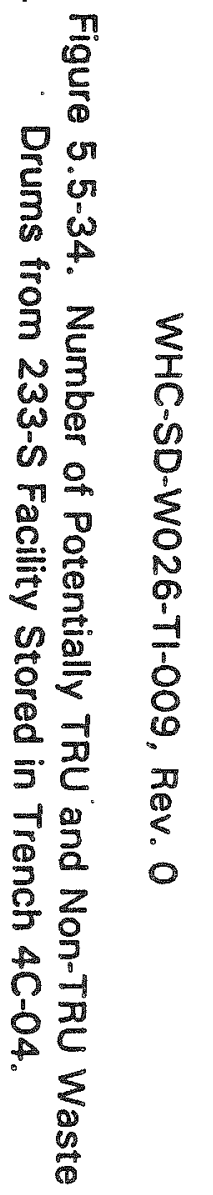




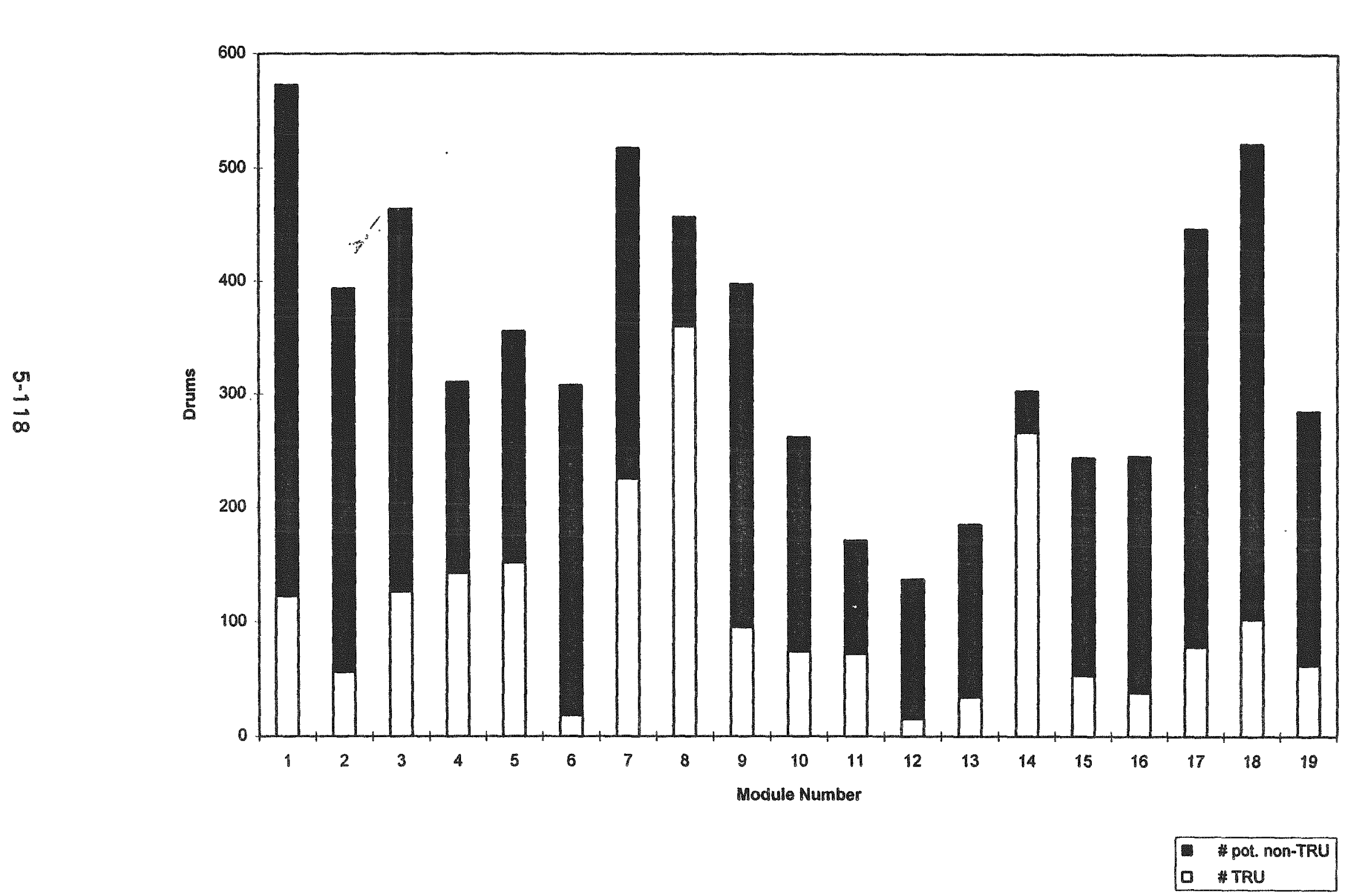

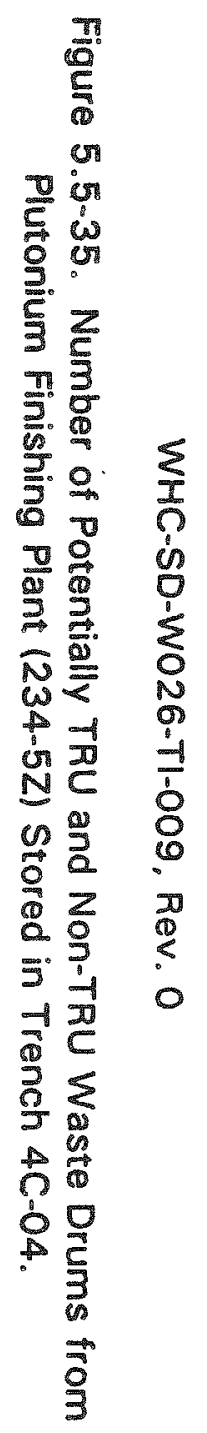



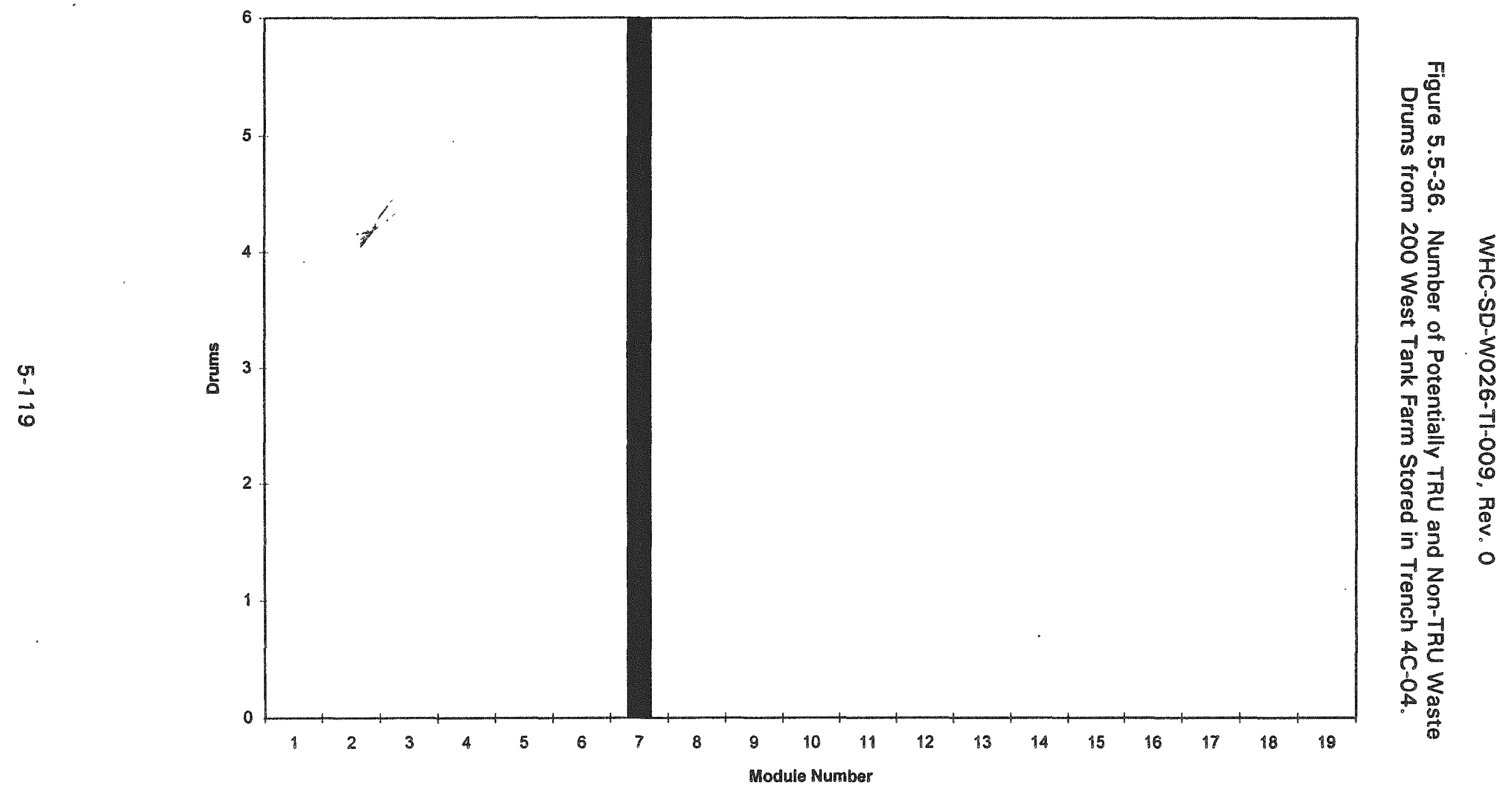

pot. non-TRU 


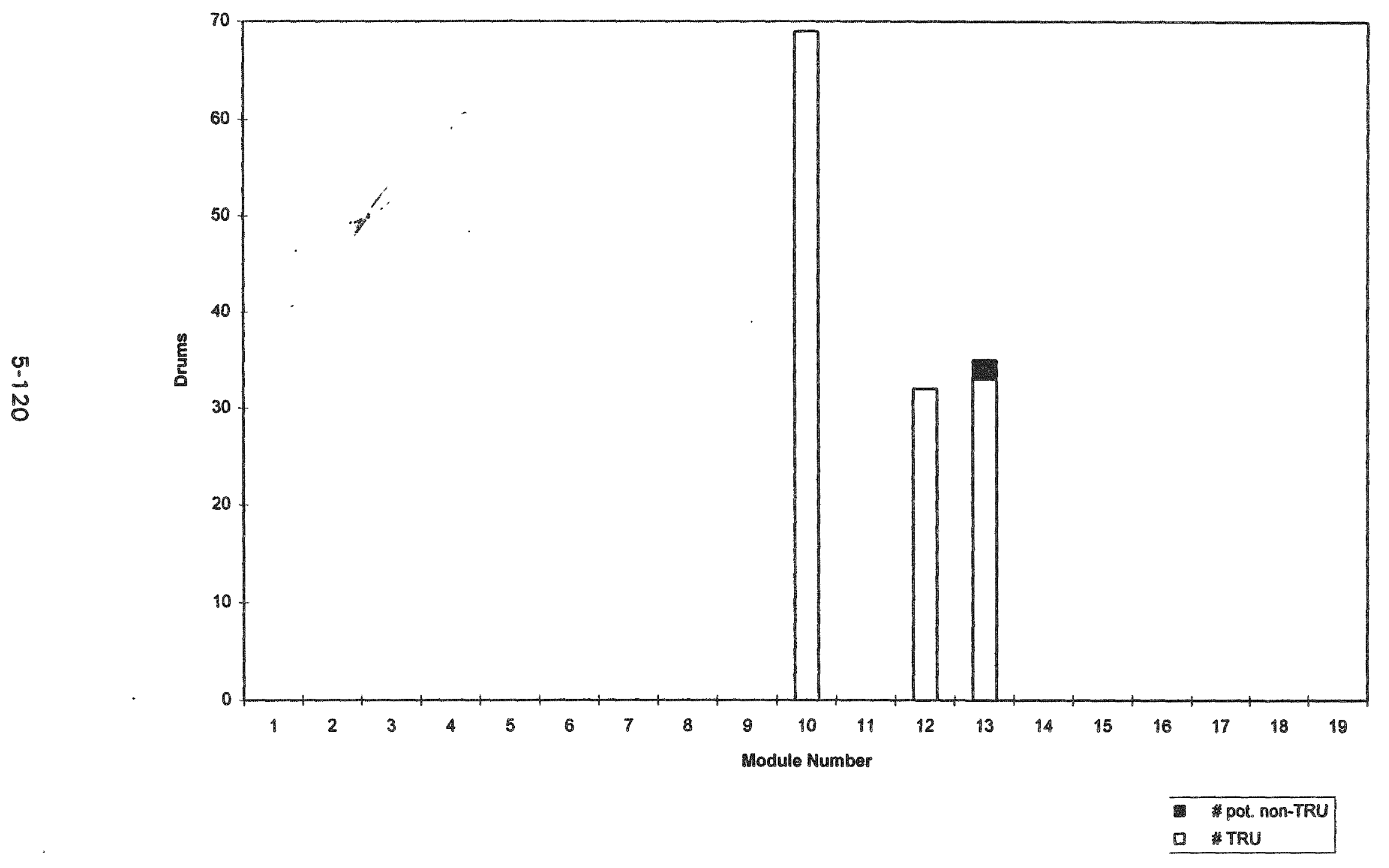

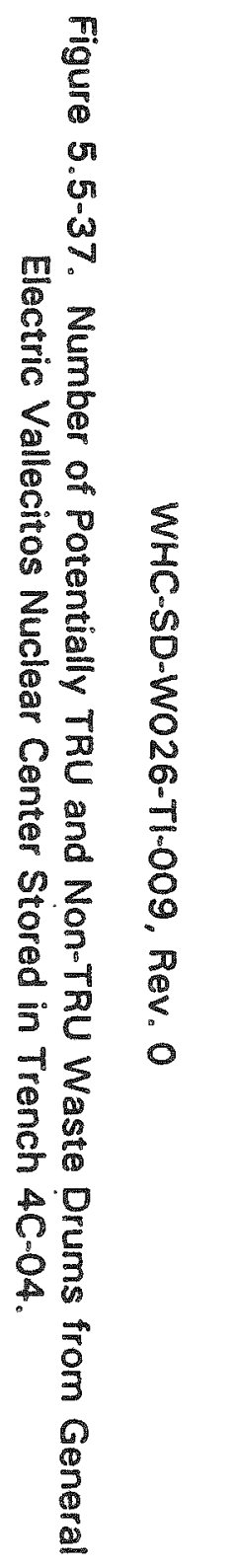



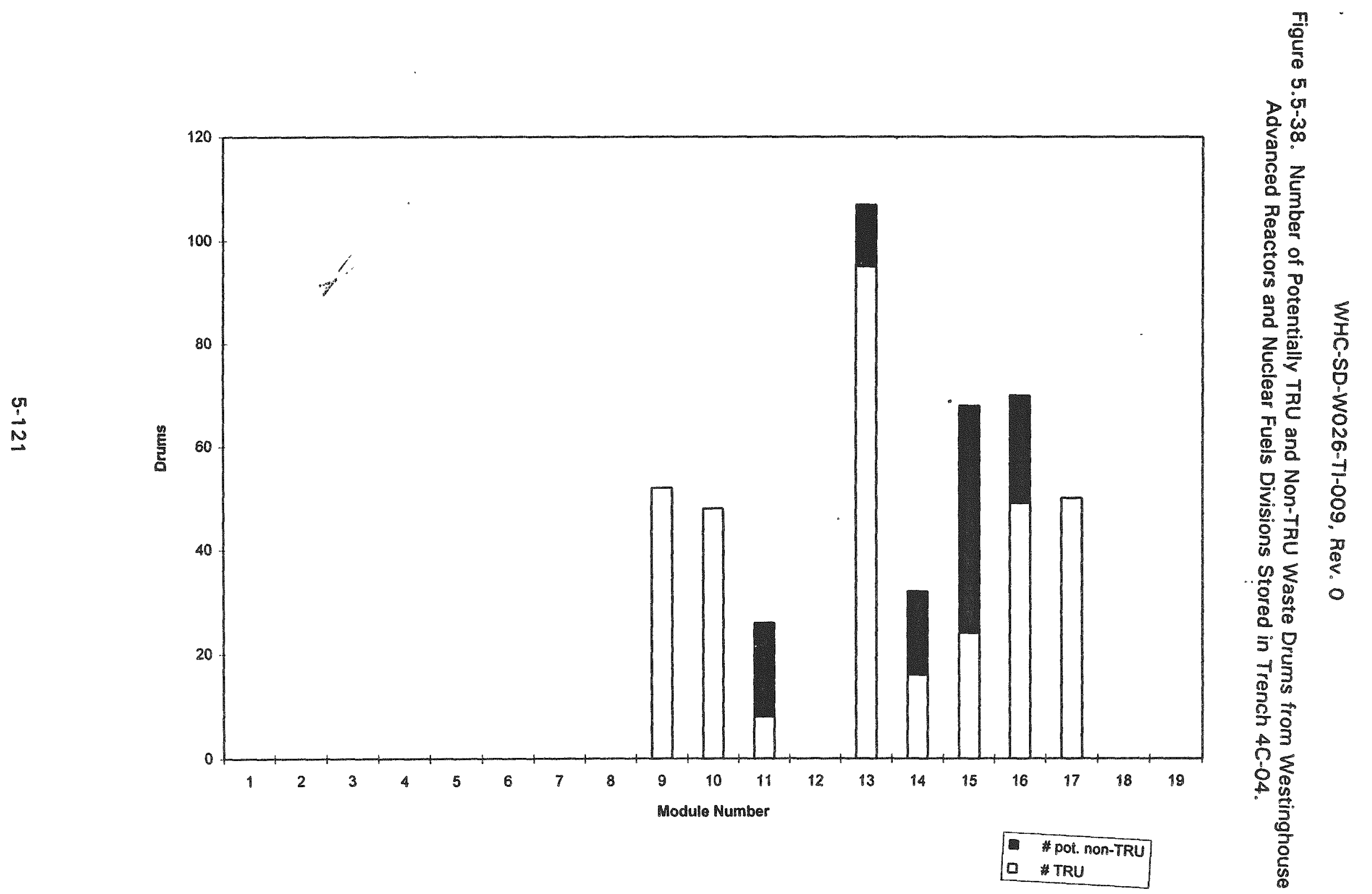

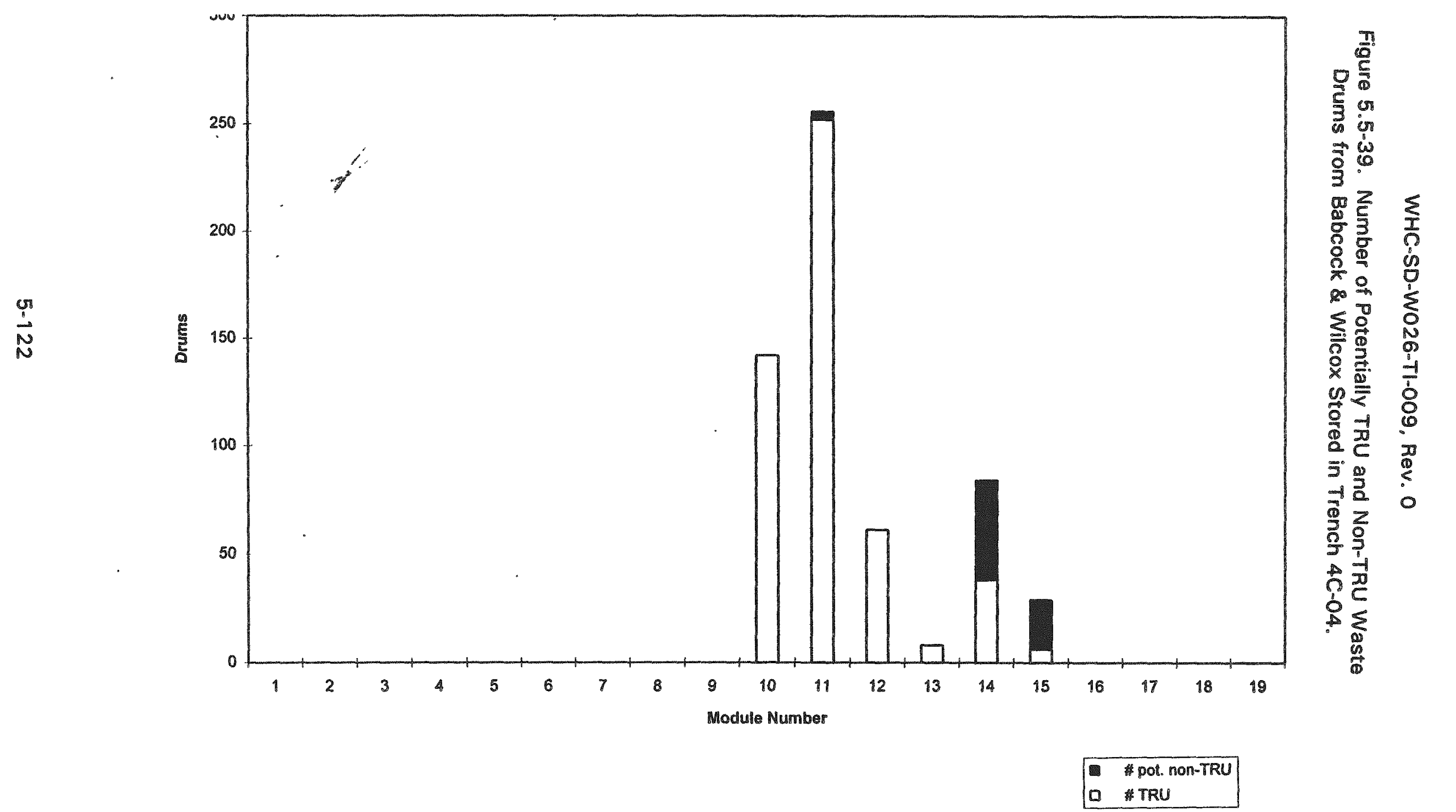

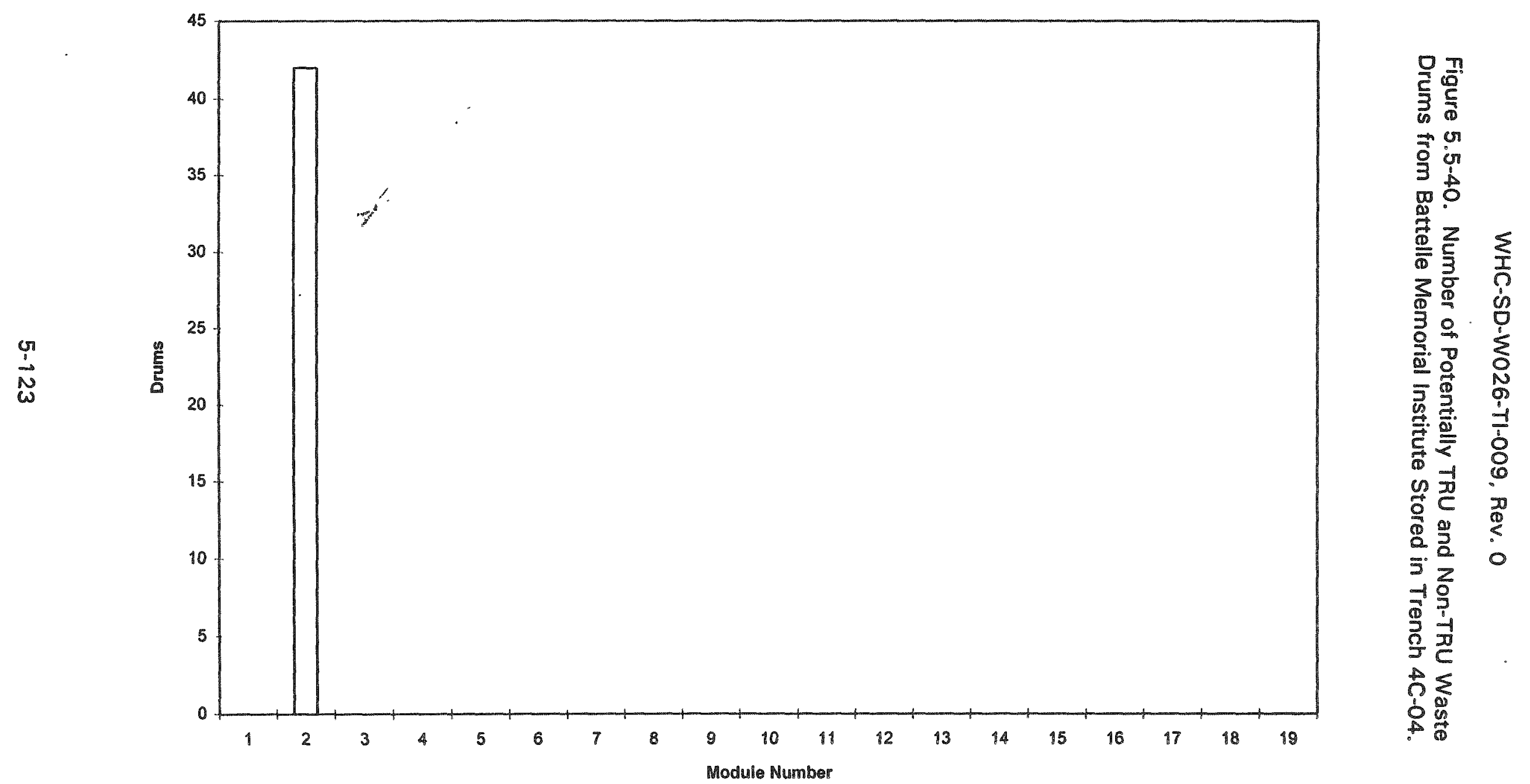

\begin{tabular}{ll|}
\hline * pot. non-TRU \\
O TRU
\end{tabular} 
$\frac{\square}{D}$
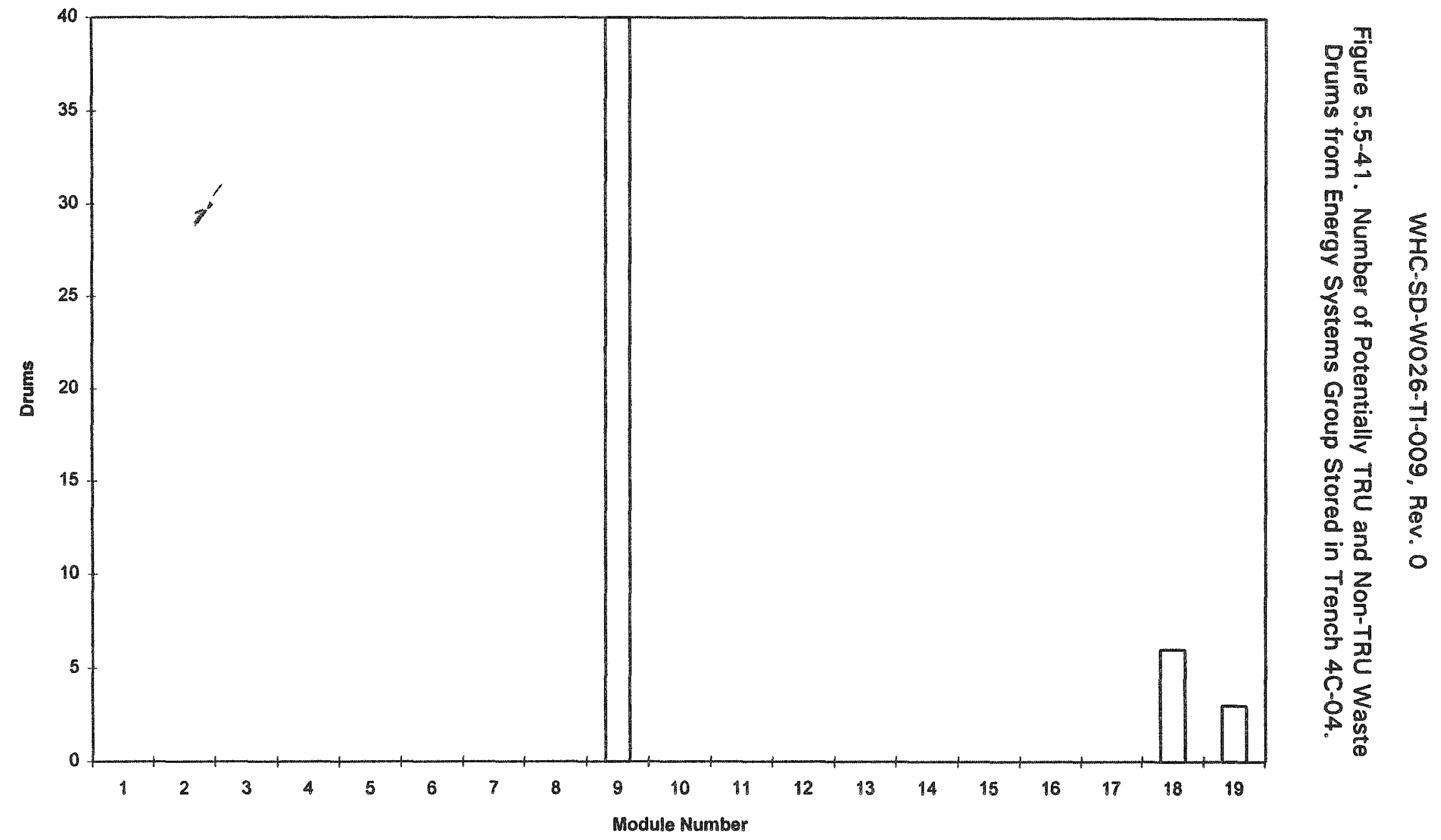

pot. nON-TRU

HRU 
$\stackrel{M}{N}$
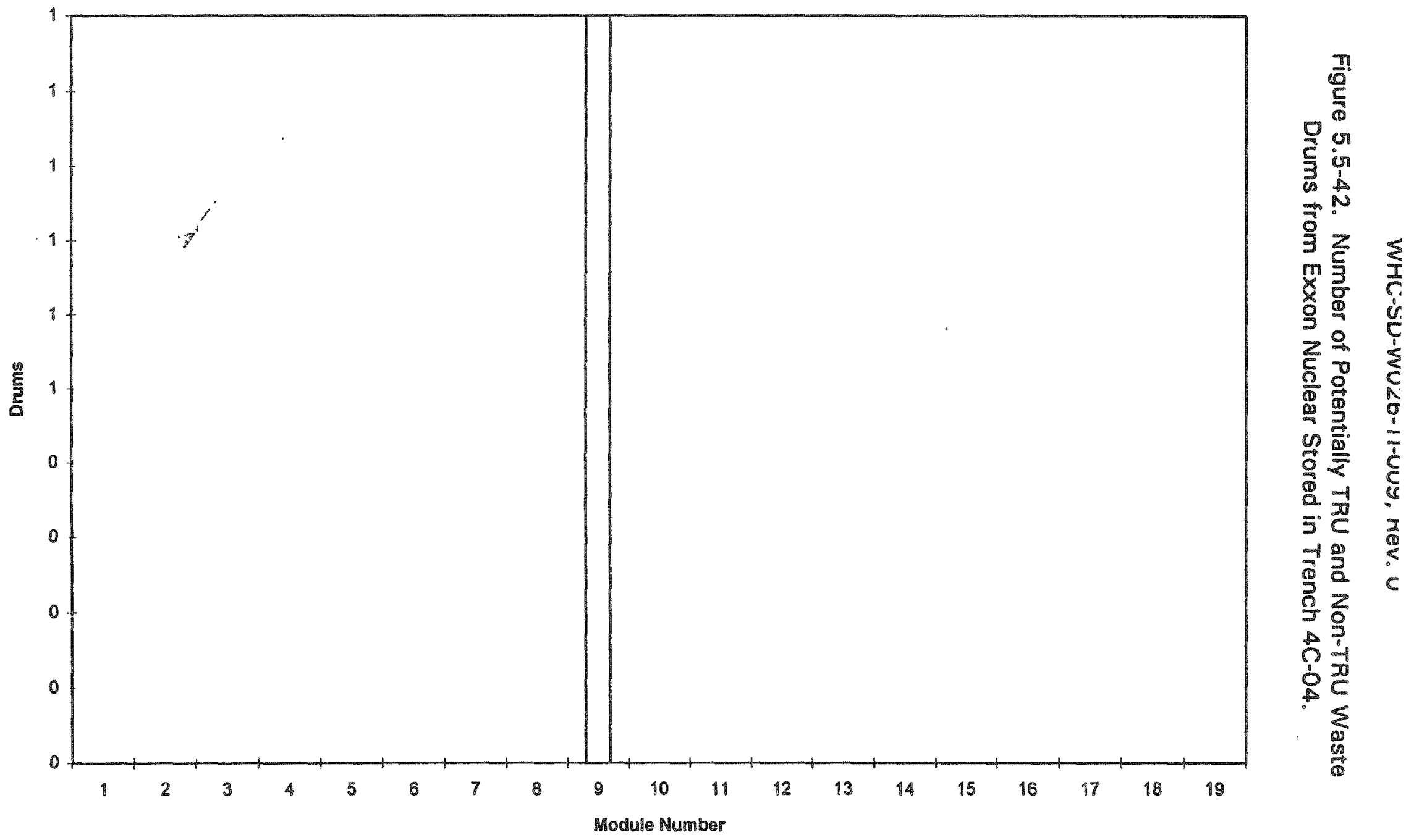

" pot. non-TRU 


\section{Grams of Pu per Module}

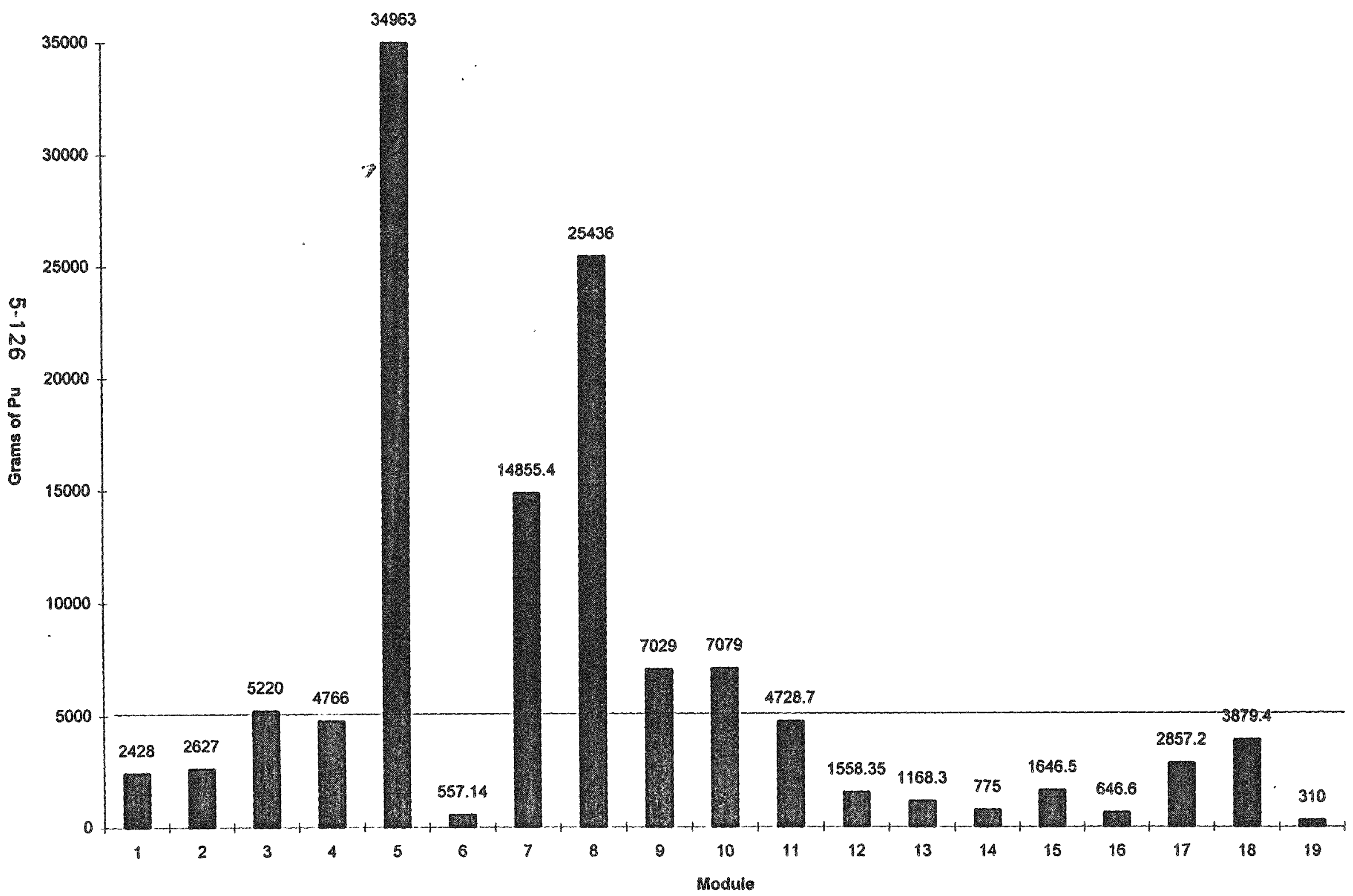


Both the WRAP I facility and WIPP require that the TRU gram loading of each drum by less than 200 grams. Burial records list the highest gram loaded drum of each module. Module 7 is the only module to exceed this limit, with a maximum gram loading of 219 grams. In addition, batches submitted to WRAP I must contain a total of less than 200 grams TRU waste. Using available records of the gram loadings of individual drums, batches must be created that will not exceed these limits. Table 5.5-3 lists the weight of the highest gram loading drum in each module. Figure $5.5-43$ shows the total grams of Pu in each module.

Table 5.5-3. Drums with Highest TRU Gram Loading in Each Module.

\begin{tabular}{|l|l|l|}
\hline Module & Highest Plutonium Loaded Drum $(\mathrm{g})$ & Generator of Drum \\
\hline 19 & 127.9 & WHC-324 \\
\hline 18 & 187 & $234-5 Z$ \\
\hline 17 & 148 & $209 E$ \\
\hline 16 & 77 & $234-5 Z$ \\
\hline 15 & 117 & $234-5 Z$ \\
\hline 14 & 193 & $234-5 Z$ \\
\hline 13 & 72.5 & WHC 340 \\
\hline 12 & 82 & $234-5 Z$ \\
\hline 11 & 140 & $209 E$ \\
\hline 10 & 191 & - \\
\hline 9 & 197 & - \\
\hline 8 & 270 & $234-5 Z$ \\
\hline 7 & 219 & $234-5 Z$ \\
\hline 6 & 94 & WHC 325 \\
\hline 5 & 198 & $234-5 Z$ \\
\hline 4 & 150 & WHC 325 \\
\hline 3 & 189 & $234-5 Z$ \\
\hline 2 & 179 & WHC 325 \\
\hline 1 & 94 & - \\
\hline
\end{tabular}


Records from the SWITS database list the radionuclide present in the waste along with the mass (in grams). Specifically identified are the TRU radionuclides, which at Hanford was often broadened to include U-233 and Radium in addition to the transuranium elements. Criticality specifications for drums were non-existent prior to 1975. Between 1975 and 1978 TRU constituents were limited to 250 grams per drum. After 1978, this limit was reduced to 200 grams.

It is believed that of all the Hanford waste in the Phase 1 Retrieval trench, only the waste from 202A/AL and 234-5Z received at the trench during 1984 could possibly be contaminated with Pu from N-Reactor spent fuel discharged after the 1972 Purex shutdown (reprocessed after the 1983 PUREX restart). There should be no Pu from 1983 reprocessing (or later) in any of the other waste in the trench. The waste from the Babcock \& Wilcox facility at Apollo, PA where mixed oxide cores for the FFTF were fabricated using $\mathrm{PuO}_{2}$ produced at PFP should contain only pre 1972 reprocessed Pu. Therefore, rather than the majority of the waste being contaminated with plutonium from reprocessed fuel used for power generation (typically about $12 \%{ }^{240} \mathrm{pu}$ ), waste will contain contamination from weapons grade plutonium ( $6 \%{ }^{240} \mathrm{Pu}$ ) as well as fuels grade plutonium from both $\mathrm{N}$ Reactor reprocessed fuel and from reprocessed Al clad slugs from K-Basin, etc.

By the start of Project W-113, circa 1998, the Hanford Plutonium to be retried, except possibly the 1984 PUREX or PFP waste receipts, will have aged a minimum of 26 years since "purification" through reprocessing. The "cool down" period from reprocessing for the Plutonium in Trench 4C-04 probably ranges from weeks for fuels reprocessed before PUREX shutdown in 1972 to about 12 years for the waste contaminated with Pu from processing after re-start which may have wound up in Trench 04. This is significant mainly for decay of the 15 year half-life ${ }^{241}$ Pu prior to starting buildup to the current level of its daughter product, ${ }^{241} \mathrm{Am}$ - which was removed when the spent fuel was reprocessed.

$N$ Reactor changed operations from co-generation in 1970 to straight power generation. According to the published fuels reprocessing history for PUREX, none of this fuel was reprocessed prior to the 1972 shutdown. Prior to this period, the reactor was operated for production of fuel grade Pu or for power production (both operations producing Pu with about $12 \%{ }^{240} \mathrm{Pu}$ ) with spent fuel stored until PUREX restart. As noted above we assume that only the 1984 waste receipts from PUREX and PFP could contain significant quantities of this $12 \%{ }^{240} \mathrm{Pu}$.

Prior to 1972, among the fuels reprocessed at PUREX were enriched metals and oxides as well as mixed oxide scrap, resulting in a variety of Pu isotopics. Some of these are located in the Phase 1 trench, 4C-04. Waste from PFP containing concentrations by weight of over $12.9 \%{ }^{240} \mathrm{Pu}$ (taken from the records of ${ }^{240} \mathrm{Pu}$ greater than $12 \%$ ) are listed in the storage modules summaries that follow. To date no further breakdowns have ben identified for PFP Or PUREX.

The 231-Z facility (PNL) normal Pu consisted of $6.3 \%{ }^{240} \mathrm{Pu}$ and $0.6 \%{ }^{241} \mathrm{Pu}$. The characterization report (WHC-EP-0659) shows that special AEC lease Plutonium ()at $22.35 \%$ ${ }^{240} \mathrm{Pu}$ and $4.21 \%{ }^{241} \mathrm{Pu}$ ) and $\mathrm{PuO}_{2}$ for production of cubes (some also containing high 240 and $241)$ existed in the facility. The waste from these, however, would have mostly been generated from 1960-1971, with a small amount in 1974. By 1978, none of the waste 
contaminated with anything other than the normal PU should exist in anything ut the FRP burial boxes containing the equipment used for earlier operations with the high 240 isotopics. None of these are located in Trench 4C-04. Figure 1 is included to show the timeline of major Hanford evens related to the characterization of Trench $4 \mathrm{C}-04$ wastes.

Because of the various roles of support to the FFTF fuels development and the Breeder Reactor Program from the 300 Area facilities (308, 324, 325, and 340 Buildings), it is assumed that the waste in Trench $4 \mathrm{C}-04$ from these facilities are nominally $12 \%{ }^{240} \mathrm{Pu}$.

The 209-E facility (PNL) produced Pu contaminated waste with $9 \%{ }^{240} \mathrm{Pu}$.

The 233-S facility waste was from D \& D operations in 1979 with plutonium contamination probably from weapons grade material.

It is a reasonable assumption that the remainder of the Hanford waste is in the trench. PUREX or PFP related, is a half and half mix of $6 \%$ and $12 \%{ }^{240} \mathrm{Pu}$.

About $92 \%$ of the containers in Trench 4 C- 04 were one mrem/hr, or less, surface does when placed in the trench. Another $5 \%$ were $5 \mathrm{mrem} / \mathrm{hr}$. Of the remainder, $2 \%$ ( $213 \mathrm{drums}$ ) were between 5 and $25 \mathrm{mrem} / \mathrm{hr}$ and there was one drum reading $75 \mathrm{mr} / \mathrm{hr}$ with 25 between 100 and $200 \mathrm{mrem} / \mathrm{hr}$ (5 at or close to $200 \mathrm{mrem} / \mathrm{hr}$ ).

Many of the lower readings probably reflect background rather than drum contents, especially for PFP, where investigation has shown that the gamma emitters in the waste are not fission/activation products other than a very small buildup of fission product from spontaneous fission.

For almost all waste form PFP and most waste form PUREX, the gamma radiation should ba almost totally from the ingrowth of ${ }^{241} \mathrm{Am}$ as the daughter product from the decay of ${ }^{241} \mathrm{Pu}$. It is possible that some waste from PFP could be contaminated entirely by Americium form separations processing, and it is probable that some waste from PUREX will be from material contaminated by direct of indirect contact with liquid or slurries containing fission and activation products as well as Pu. Other on-site and off-site waste containing fission product activity are form hot cell activities in facilities such as the 324 Building at Hanford; the waste consists of contaminated tools, fixtures, cuttings (non-fuel), cladding pieces, and other items associated with irradiated material examinations, etc.

Nine of the higher does drums contain lead and concrete shielding.

For the drums containing unmeasurable $\mathrm{Pu}$, it is reasonable to assume that any ingrowth of ${ }^{241} \mathrm{Am}$ will be negligible with respect to increased gamma dose. For drums with high loadings of TRU an increase of a couple mrem/hr surface dose might be excepted by the time the drums are retrieved. For drums with the higher does rates initially, it appears the major contributors to the dose would be fission/activation products, or separated americium. These activities will have been decaying since placement in the trench, and the decay impact on drum dose rates should be greater than ingrowth of americium or fission/activation products from spontaneous fission. 
WHC-SD-W026-T1-009, Rev. O

Table 5.5-4 lists the amount for each radioisotopes that is present in each module in Trench 4C-04. Figure 5.5-44 and 5.5-45 show the relative abundance of the most common radionuclides and the least common radionuclides in each module, respectively.

Table 5.5-4. Number of Grams of Specific Radionuclides

Present in Trench $4 \mathrm{C}-04$ by Module.

WRAP 1 Batch Analysis

Radionuclides per Module

\section{W-4C Trench 04 Module Data}

\begin{tabular}{|c|c|c|c|c|c|c|c|c|c|c|c|}
\hline & $\mathrm{Pu}$ & Pu-238 & U & U.233 & $\operatorname{dep} U$ & Am & Th & $\mathrm{Np}$ & $\mathrm{Cm}$ & $\mathrm{CP}$ & TOTAL \\
\hline 1 & 2428 & & 7859 & & & & 1531 & & & & 11818 \\
\hline 2 & 2627 & & 4018 & & & & 1000 & & & & 7645 \\
\hline 3 & 5220 & & 10695 & & & 0.5 & 990 & & & & 16905.5 \\
\hline 4 & 4766 & & & & 3000 & & & & & & 7766 \\
\hline 5 & 34963 & & 11187 & & & & 492 & & & & 46642 \\
\hline 6 & 557.14 & & 532 & & & 8 & 393 & & & & 1490.14 \\
\hline 7 & 14855.4 & & 14570 & & & & 7 & $\therefore$ & & & 29432.4 \\
\hline 8 & 25436 & & 35687 & & & & 2212 & & & & 63335 \\
\hline 9 & 7029 & & 4795 & & & & 391 & & & & 12215 \\
\hline 10 & 7079 & & 49134 & & & 3.43 & & & & & 56216.43 \\
\hline 11 & 4728.7 & & 20818 & & & 6.31 & & & & & 25553.01 \\
\hline 12 & 1558.35 & & 8114 & & & & 640 & & & & 10312.35 \\
\hline 13 & 1168.3 & 1.25 & 22613 & & & 0.87 & & & & & 23783.42 \\
\hline 14 & 775 & & 2957 & 1.14 & & 48 & & 1.14 & 4.11 & & 3786.39 \\
\hline 15 & 1646.5 & & 32892 & & & 0.38 & 635 & 0.045 & & 2.1 & 35176.03 \\
\hline 16 & 646.6 & 1.4 & 2150 & & & 0.06 & & & & & 2798.06 \\
\hline 17 & 2857.2 & & 10863 & & & & 457 & & & & 14177.2 \\
\hline 18 & 3879.4 & & 9142 & & & & 732 & & & & 13753.4 \\
\hline 19 & 310 & & 420 & & & & & & & & 730 \\
\hline TOTAL & 122530.6 & 2.65 & 248446 & 1.14 & 3000 & 67.55 & 9480 & 1.185 & 4.11 & 2.1 & 383535.3 \\
\hline
\end{tabular}


Figure 5.5-44. Number of Grams of the Most Common Radionuclides Present in Trench 4C-04 by Module.

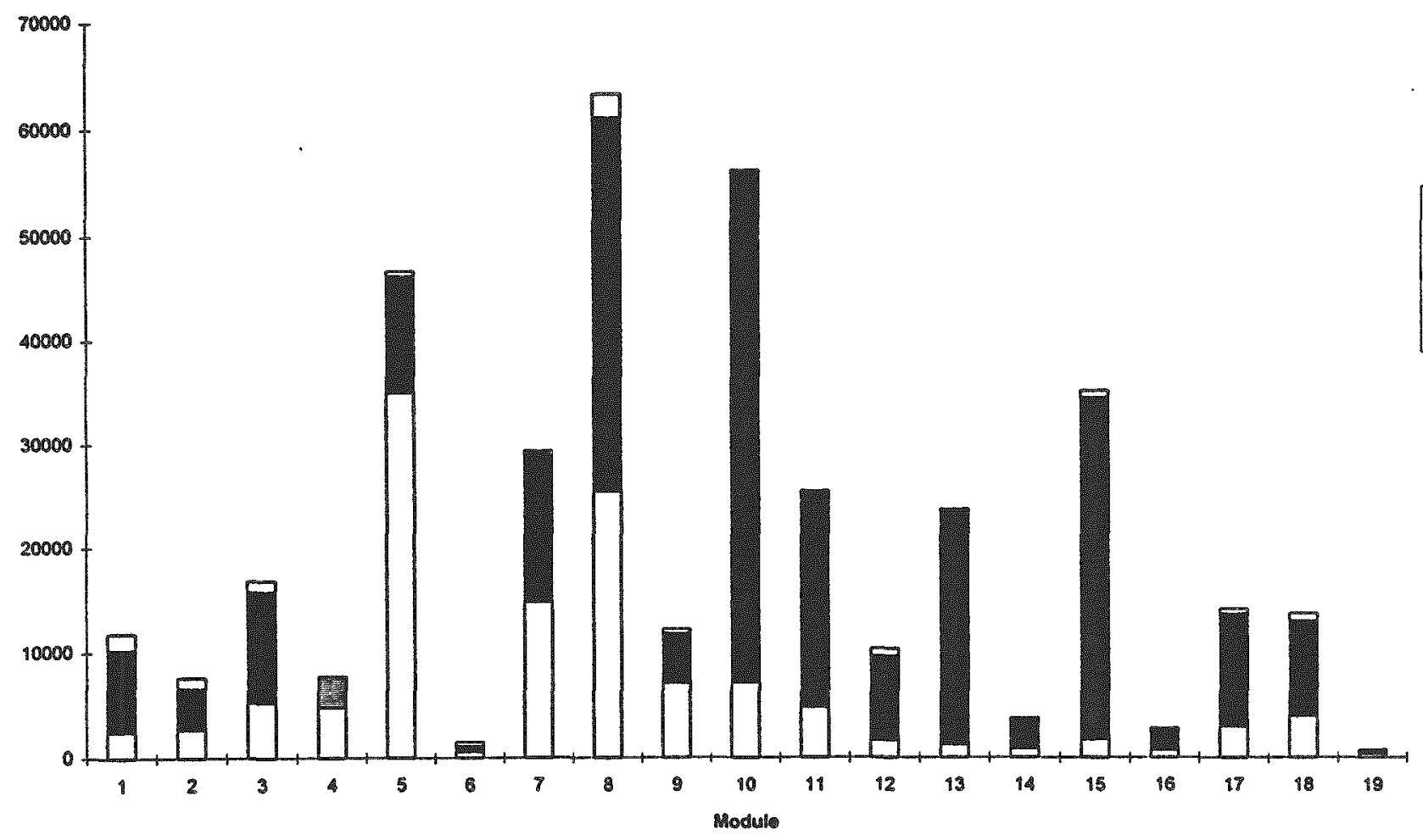


WHC-SD-W026-TI-009, Rev。O

Figure 5.5-45. Number of Grams of the Least Common Radionuclides Present in Trench $4 \mathrm{C}-04$ by Module.

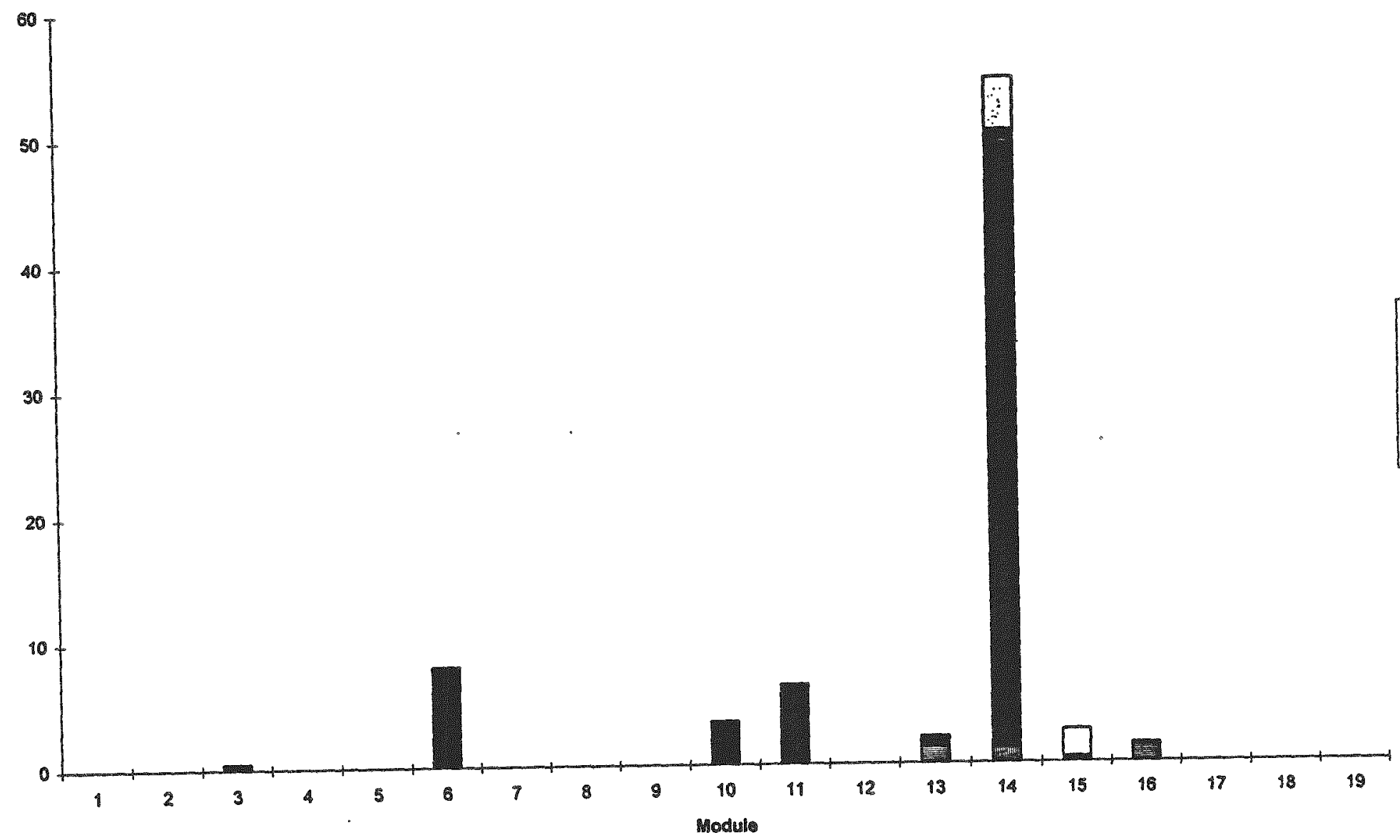


Table 5.5-5 provides a summary of the radionuclides and their quantities present in each module by generator. Figures 5.5-46 through 5.5-64 show the relative distribution of the radioisotopes present in waste drums from each of generators by module.

Table 5.5-5. Summary of the Radionuclides Present in

Fach Module by Generstr?

Mra 11 Satch Anahysis

\begin{tabular}{|c|c|c|c|c|c|c|c|c|c|c|c|c|c|c|c|c|c|c|c|c|c|}
\hline Genorazae & 9 & 2 & 3 & 4 & 5 & c & 7 & $\approx$ & 9 & 10 & 19 & 12 & 13 & 94 & 15 & 96 & 17 & 18 & 19 & & \\
\hline WHC.324 & & & & & & & & & & & & & & & 19 & 16 & 20 & 27 & 3 & 83 & \\
\hline grams Pu & & & & & & & & & & & $\therefore$ & & & & 487 & 139 & 245 & 565 & 128 & & 3.564 \\
\hline roms U & & & & & & & & & & & & & & & 30.979 & 8,696 & 90,604 & 9,142 & 420 & & 52,841 \\
\hline grams $\mathrm{m}$ & & & & & & & & & & & & & & & 635 & & 457 & 732 & & & 1.824 \\
\hline grams Am & & & & & & & & & & & & & & & & 0.06 & & & & & 0.06 \\
\hline WHC.325 & 77 & $\overline{214}$ & 49 & 100 & 87 & 104 & 27 & 53 & & & & & & & & & & & & 311 & \\
\hline grams Py & 680 & 2,250 & 750 & 2,676 & 452 & 378 & 563 & 596 & & & & & & & & & & & & & 8,331 \\
\hline grams $u^{\circ}$ & 7,859 & 3,785 & 10,505 & & 9,187 & 436 & 275 & 77 & & & & & & & & & & & & & 32,124 \\
\hline grsms Th & 1.539 & 8.000 & 990 & & 492 & 393 & 7 & & & & & & & & & & & & & & 4,413 \\
\hline WHC-3405 & & & & 24 & & & & 24 & 24 & 22 & 34 & 17 & 33 & 11 & 15 & & & & & 204 & \\
\hline grams Pu & & & & 318 & & & & 279 & 188 & 120 & 380 & 90 & 586 & 188 & 1144 & & & & & & 2.293 \\
\hline grambus U & & & & & & & & 8.287 & & 25.900 & 10.756 & 3.874 & 21.239 & 744 & 1108 & & & & & & 71,908 \\
\hline grams $\mathrm{m}$ & & & & & & & & 912 & & & & 640 & & & & & & & & $\ldots$ & 1,552 \\
\hline grams An & & & & & & & & & & & & & 0.48 & & & & & & & & 0.48 \\
\hline PNA-324 & & & & & & & & & & & & & & & & 1 & 3 & 11 & & 15 & \\
\hline grams Pu & & & & & & & & & & & & & & & & 7.9 & 4.2 & & & & 12.1 \\
\hline grams P 14.238 & & & & & & & & & & & & & & & & 1.4 & & & & & 1.4 \\
\hline PNL-325 & 76 & 27 & 39 & & 119 & 86 & 97 & & & & & & & & & & & & & 304 & \\
\hline grams Pin & 16 & 33 & 0 & & 428 & 0 & 5.4 & & & & & & & & & & & & & & 482.4 \\
\hline grams U & & & 190 & & & 96 & 6,260 & & & & & & & & & & & & & & 6,546 \\
\hline grams Am & & & 0.5 & & & 8.0 & & & & & & & & & & & & & & & 8.5 \\
\hline PNL.325A & & 5 & & & & & & & & & & & & & & & & & & 5 & \\
\hline grams pu & & 5 & & & & & & & & & & & & & & & & & & & 5 \\
\hline PML.3405 & & & & & & & & 15 & 61 & & 23 & 8 & 10 & 18 & 8 & & & & & 143 & \\
\hline groms pus & & & & & & & & 0 & 422 & & 3.6 & 0.35 & 85 & 17 & 32.5 & & & & & & 490 \\
\hline grams Pu-239 & & & & & & & & & & & & & 1.25 & & & & & & & & 1.25 \\
\hline grame $U$ & & & & & & & & 1,300 & 3,252 & & & 749 & & & 0.09 & & & & & & 5,301 \\
\hline grams U-233 & & & & & & & & & & & & & & 1.34 & & & & & & & 8.14 \\
\hline prants $T \mathrm{~h}$ & & & & & & & & 300 & 391 & & & & & & & & & & & & 631 \\
\hline grams Am & & & & & & & & & & & & & & 11 & 0.24 & & & & & 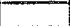 & 11 \\
\hline grams Np & & & & & & & & & & & & & & 1.14 & 0.045 & & & & & & 1.19 \\
\hline grams $\mathrm{Cm}$ & & & & & & & & & & & & & & 4.11 & & & & & & & 4.11 \\
\hline grams Cf & & & & & & & & & & & & & & & 2.1 & & & & & & 2.1 \\
\hline PHL.209E & & & & & & & & 9 & & & 13 & & & & & & 10 & & & 32 & \\
\hline grams Ps & & & & & & & & 21 & & & 247 & & & & & & 560 & & & & 828 \\
\hline PQL-2319.2 & 48 & 24 & 18 & 95 & & 74 & 8 & & 9 & 7 & -2 & & 19 & & & -4 & & & & 222 & \\
\hline grams Pus & & & & 242 & & 0.14 & 14 & & 1 & 0 & 3.1 & & 2.3 & & & 0.7 & & & & & 274 \\
\hline grams dap U": & & & & 3,000 & & & & & & & & & & & & & & & & & 3.000 \\
\hline grams $U$ & & & & & & & & & & 0 & & & & & & & & & & & 0 \\
\hline
\end{tabular}


WHC-SD-W026-TI-009, Rev. 0

Table 5.5-5. Summary of the Radionuclides Present in

Each Module by Generator.

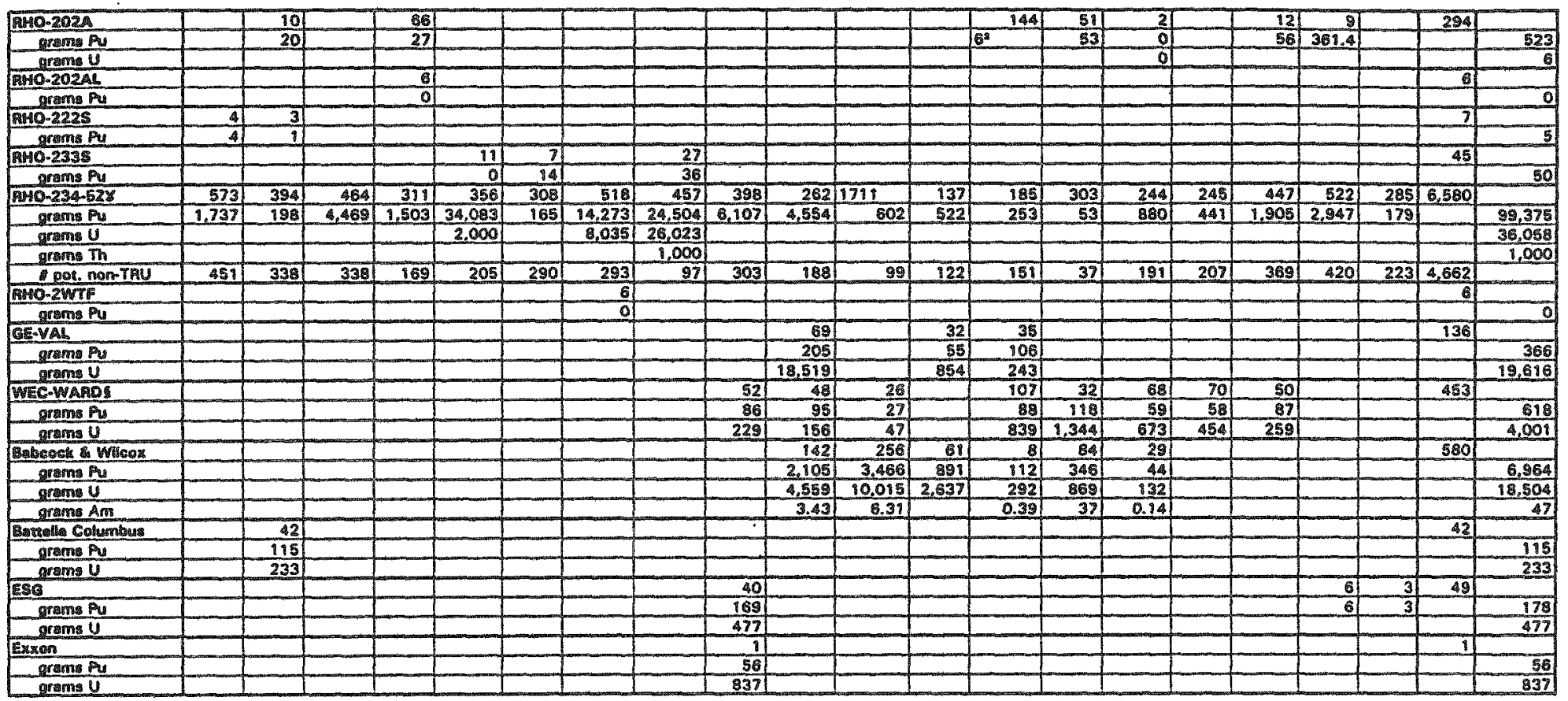

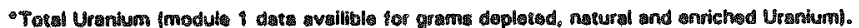

- A All $3,000 \mathrm{~g}$ dapleted U in a single barret.

8All 6.0 . Phe in aniy ons (1) of the 144 barrels.

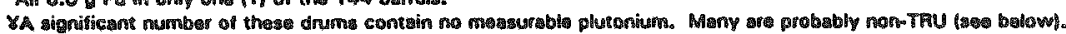

850 of the 171 drums are $1-10 \%$.

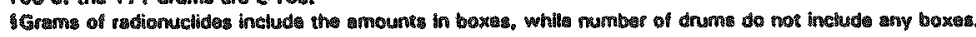




\section{WHC-SD-W026-TI-009, Rev. 0}

Figure 5.5-46. Radioisotope Quantities Present in Drums from WHC 324.

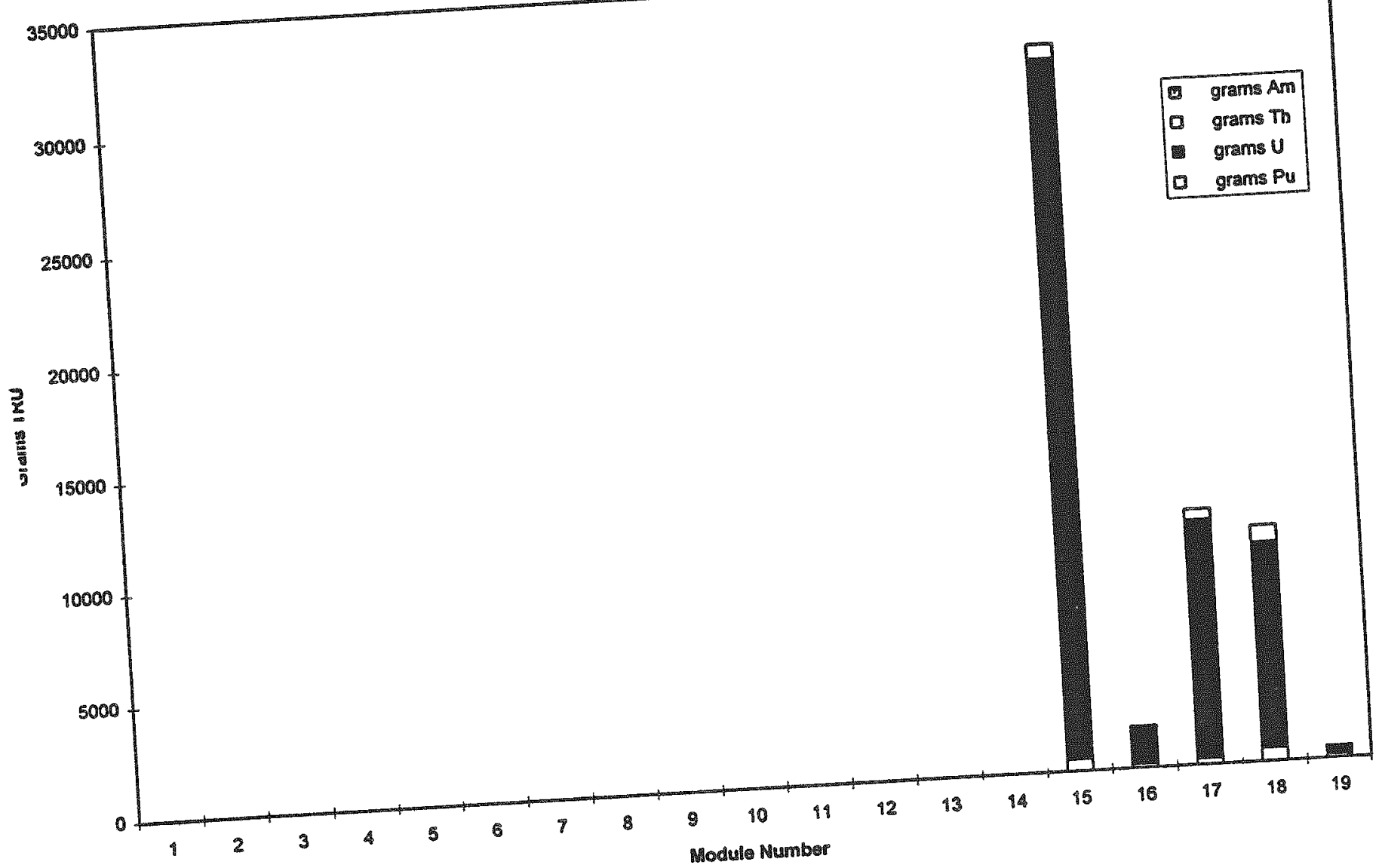


WHC-SD-W026-TI-009, Rev. O

Figure 5.5-47. Radioisotope Quantities Present in Drums from WHC 325.

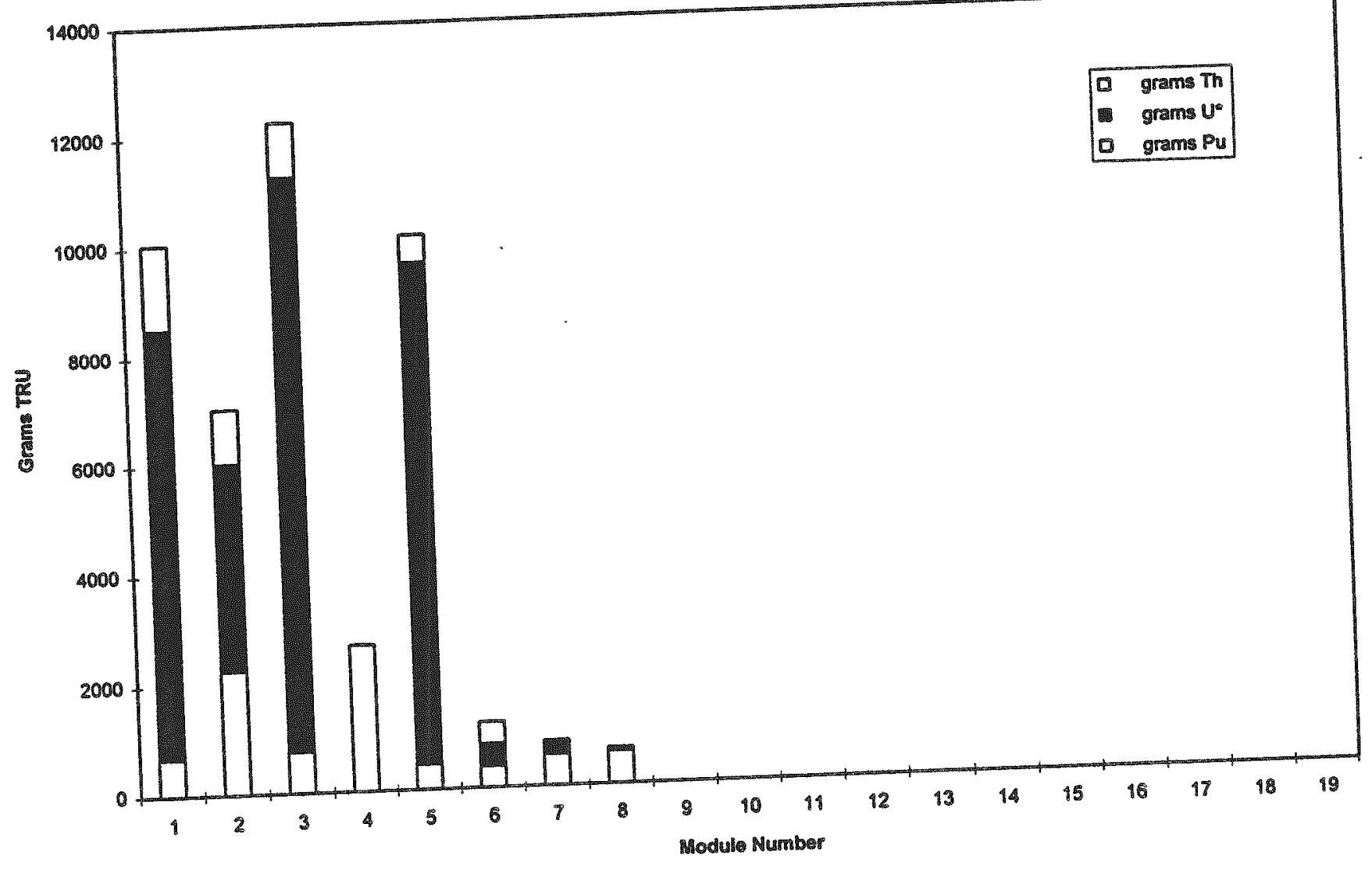


WHC-SD-WO26-TI-009, Rev. O

Figure 5:5-48. Radioisotope Quantities Present in Drums from WHC 340.

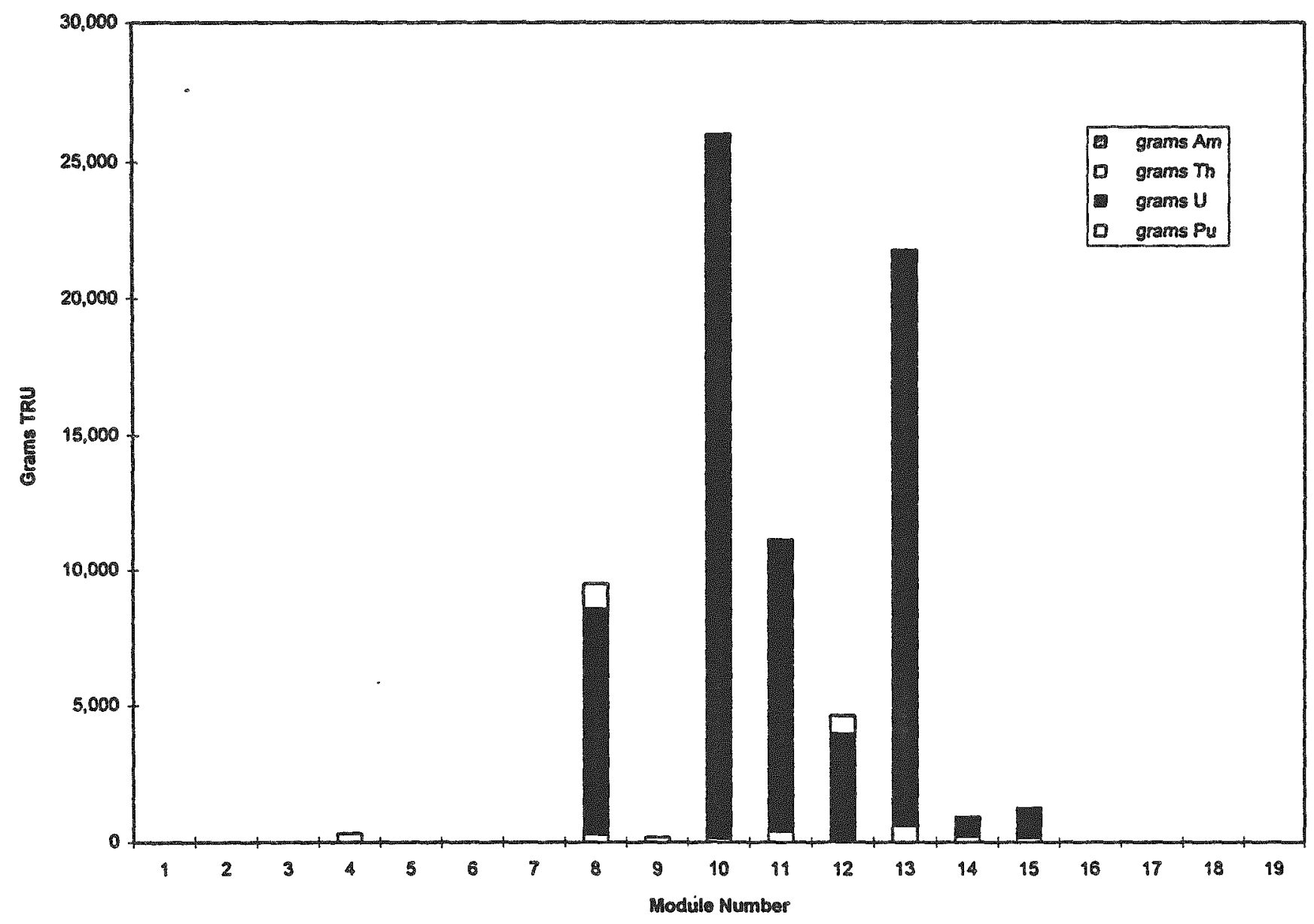


WHC-SD-W026-TI-009, Rev. 0

Figure 5.5-49. Radioisotope Quantities Present in Drums from. PNL 324.

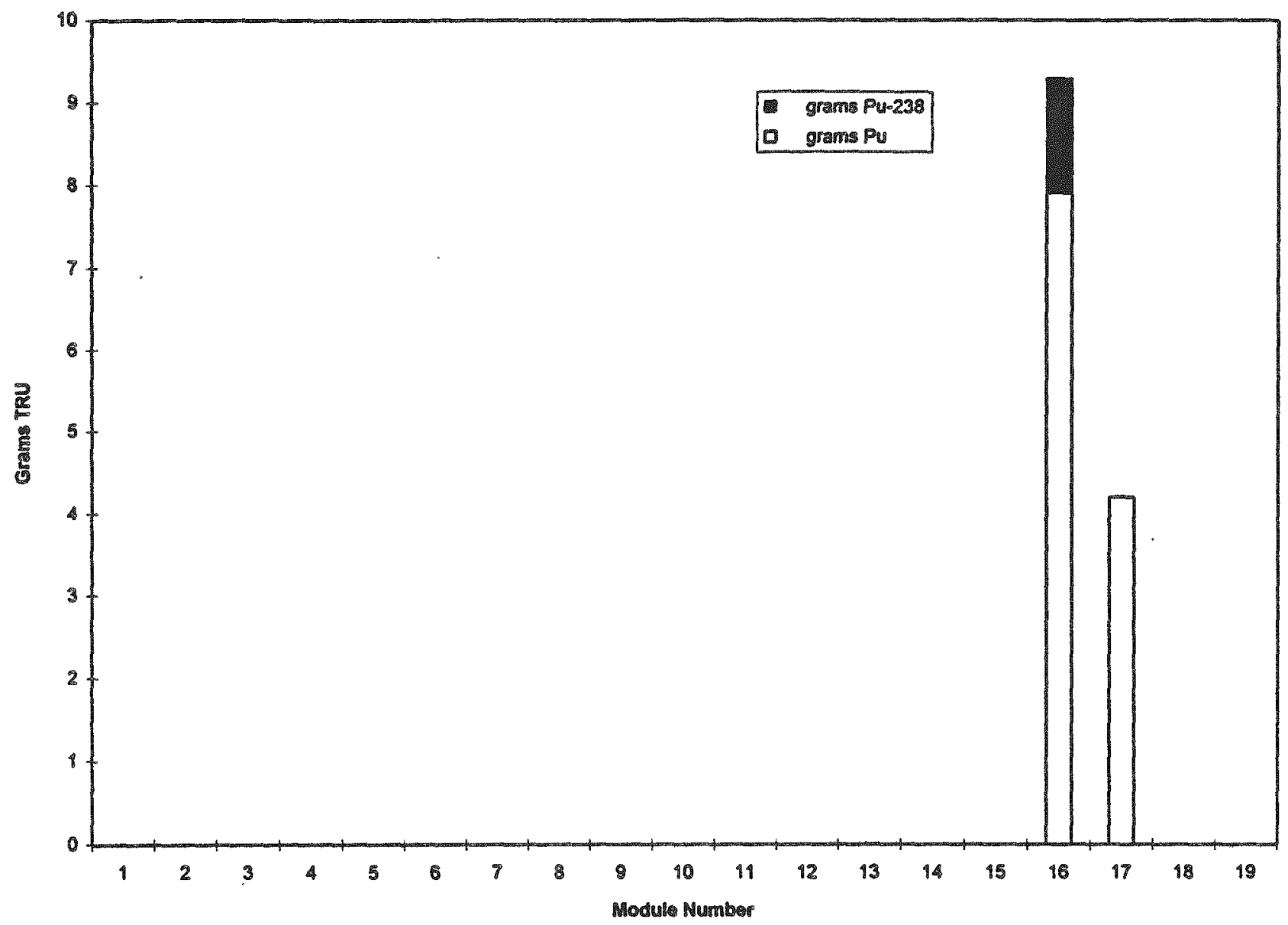


WHC-SD-W026-T1-009, Rev. 0

Figure 5.5-50. Radioisotope Quantities Present in Drums from PNL 325.

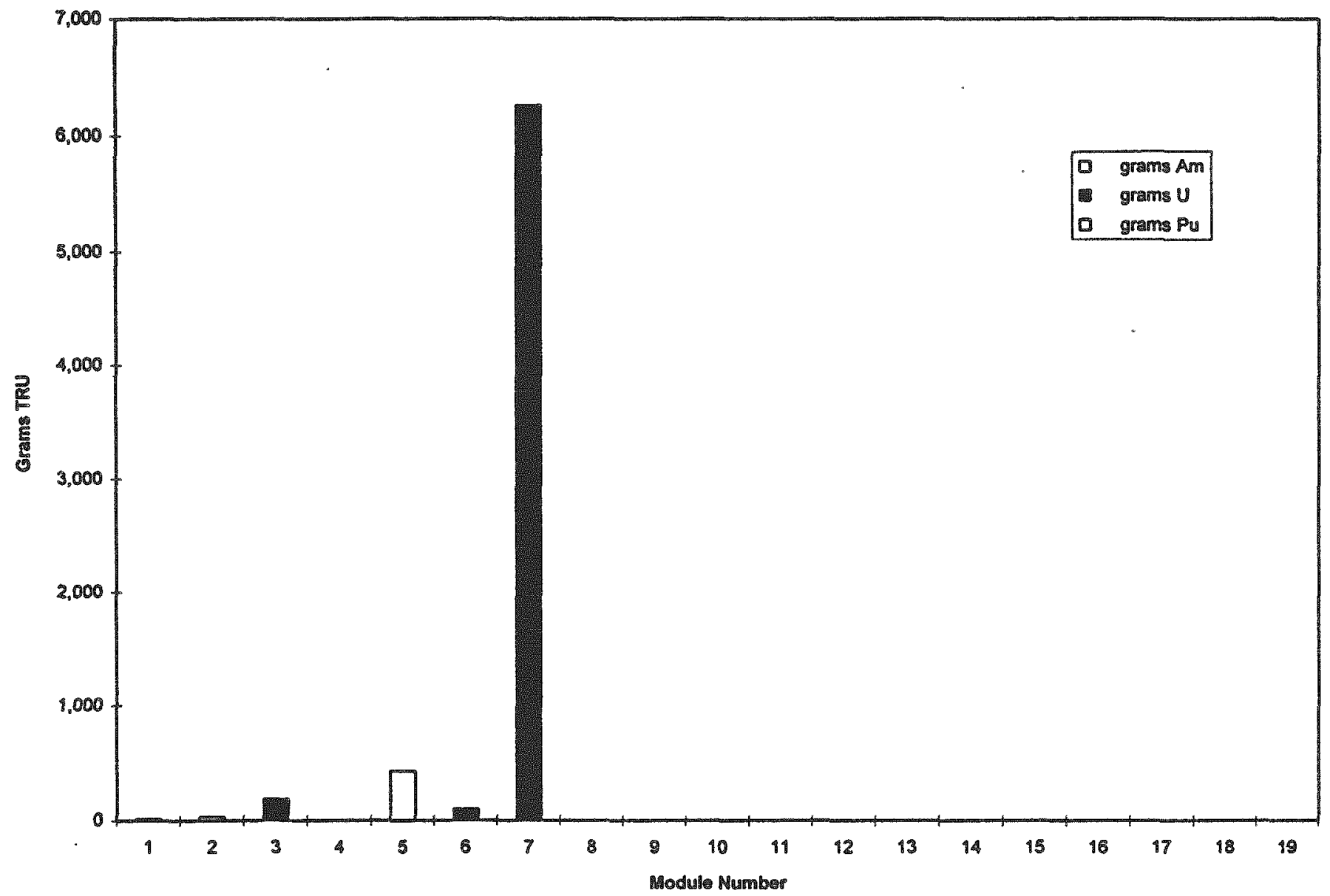


WHC-SD-W026-T1-009, Rev. O

Figure 5.5-51. Radioisotope Quantities Present in Drums from PNL 325A. $s$

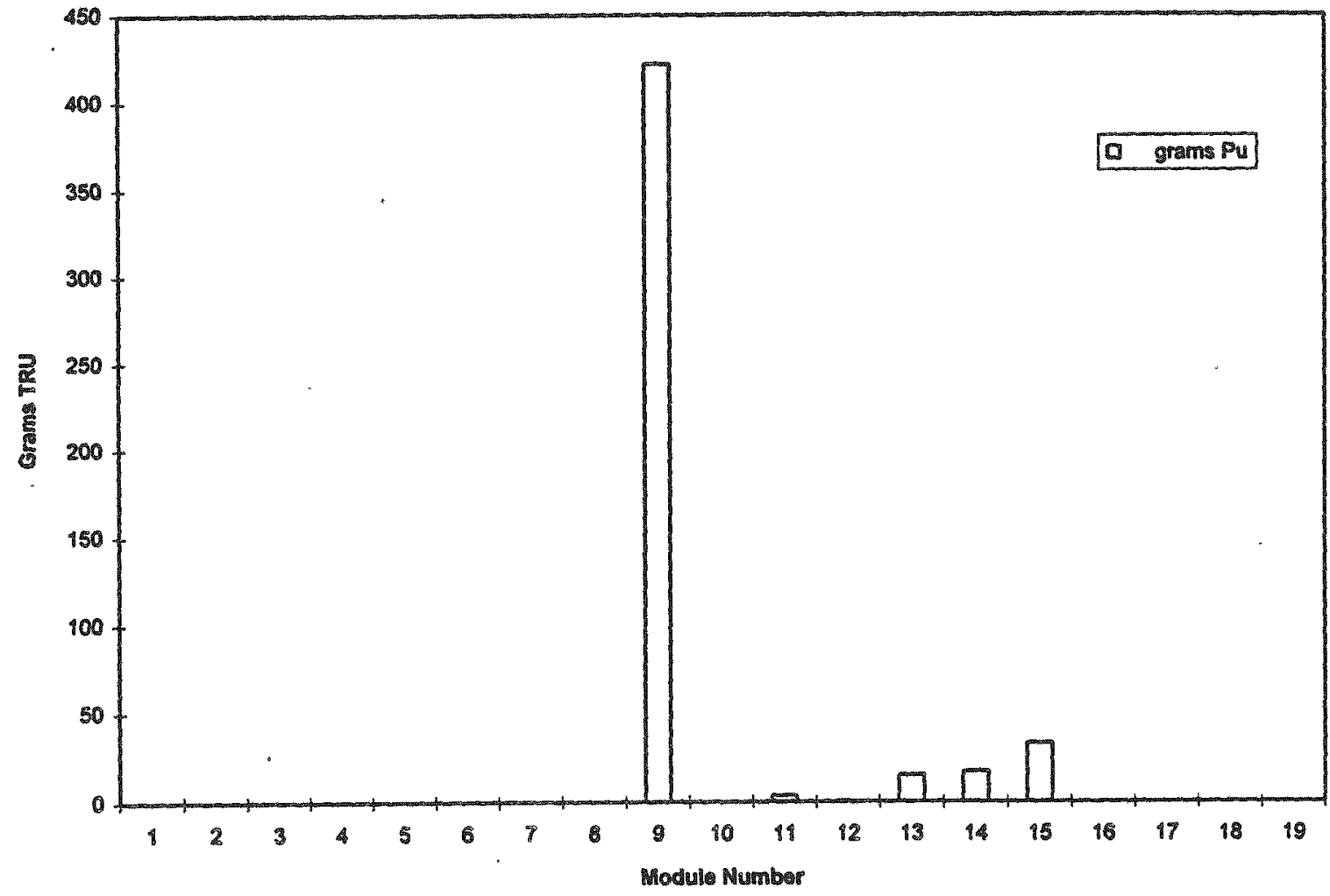


WHC-SD-W026-TI-009, Rev.0

Figure 5.5-52. Radioisotope Quantities Present in Drums from PNL 340.

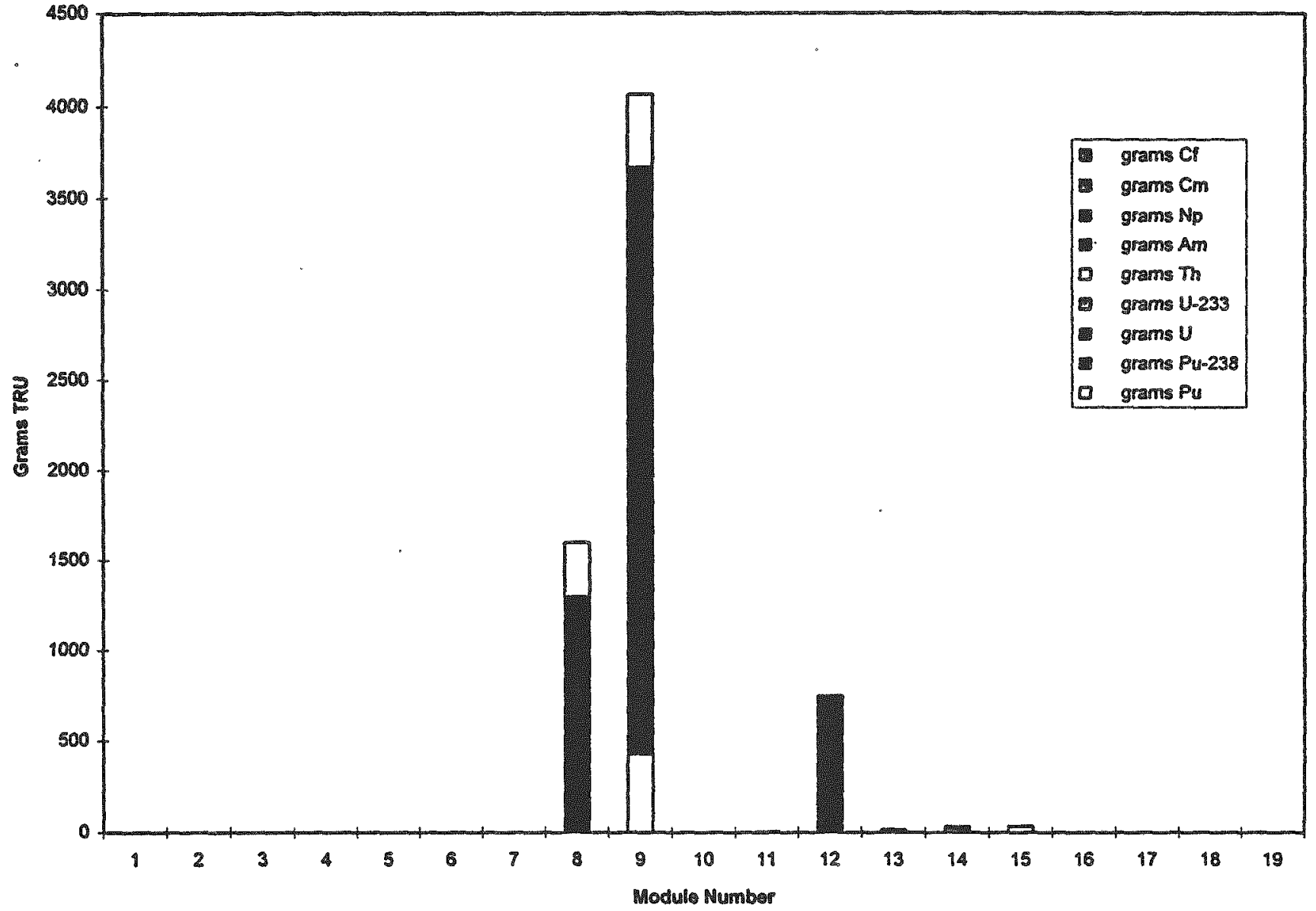


WHC-SD-W026-TI-009. Rev. O

Figure 5.5-53. Radioisotope Quantities Present in Drums from PNL 209E.

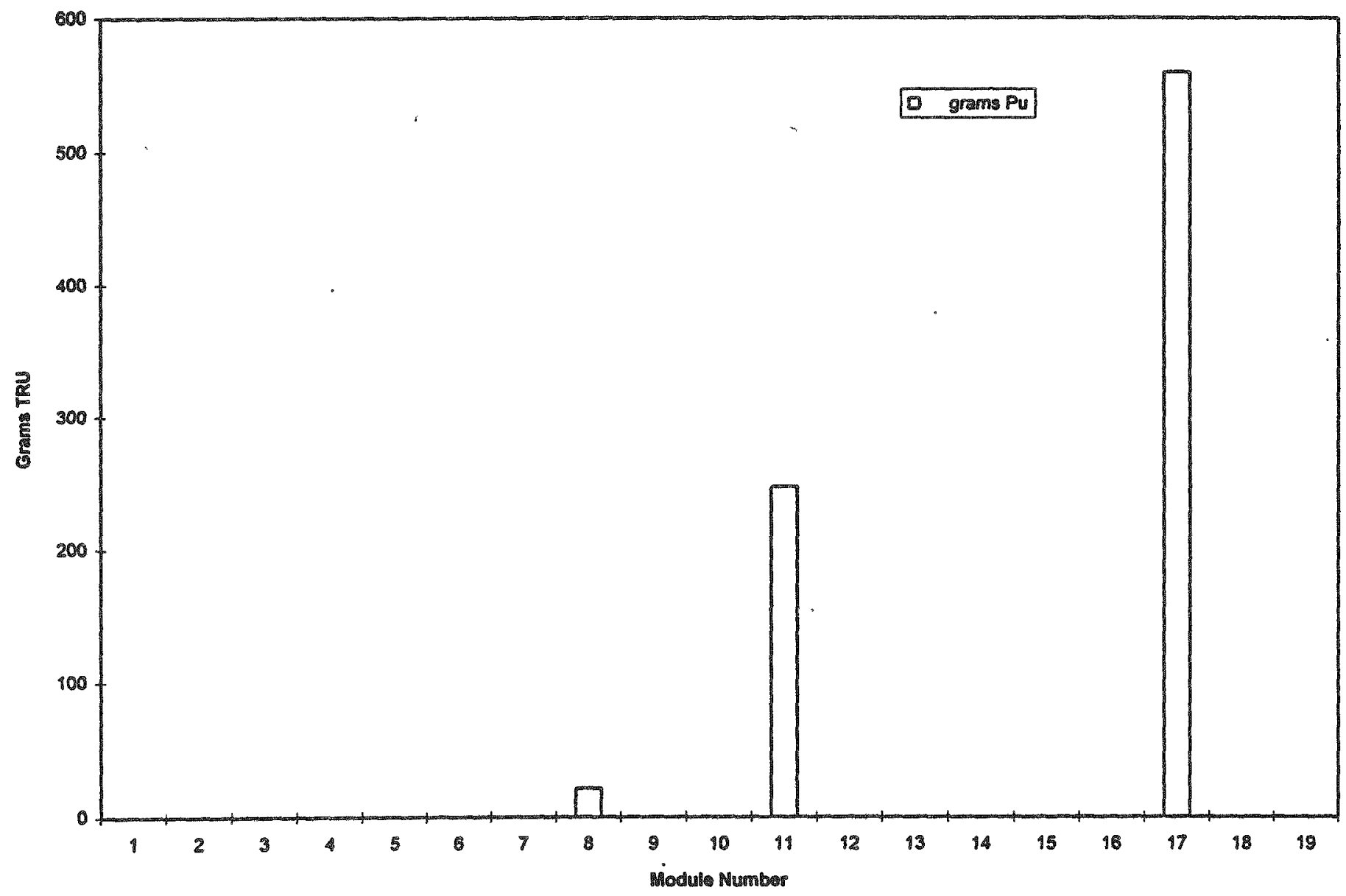


WHC-SD-W026-TI-009.REv.0

Figure 5.5-54. Radioisotope Quantities Present in Drums from PNL 231-Z.

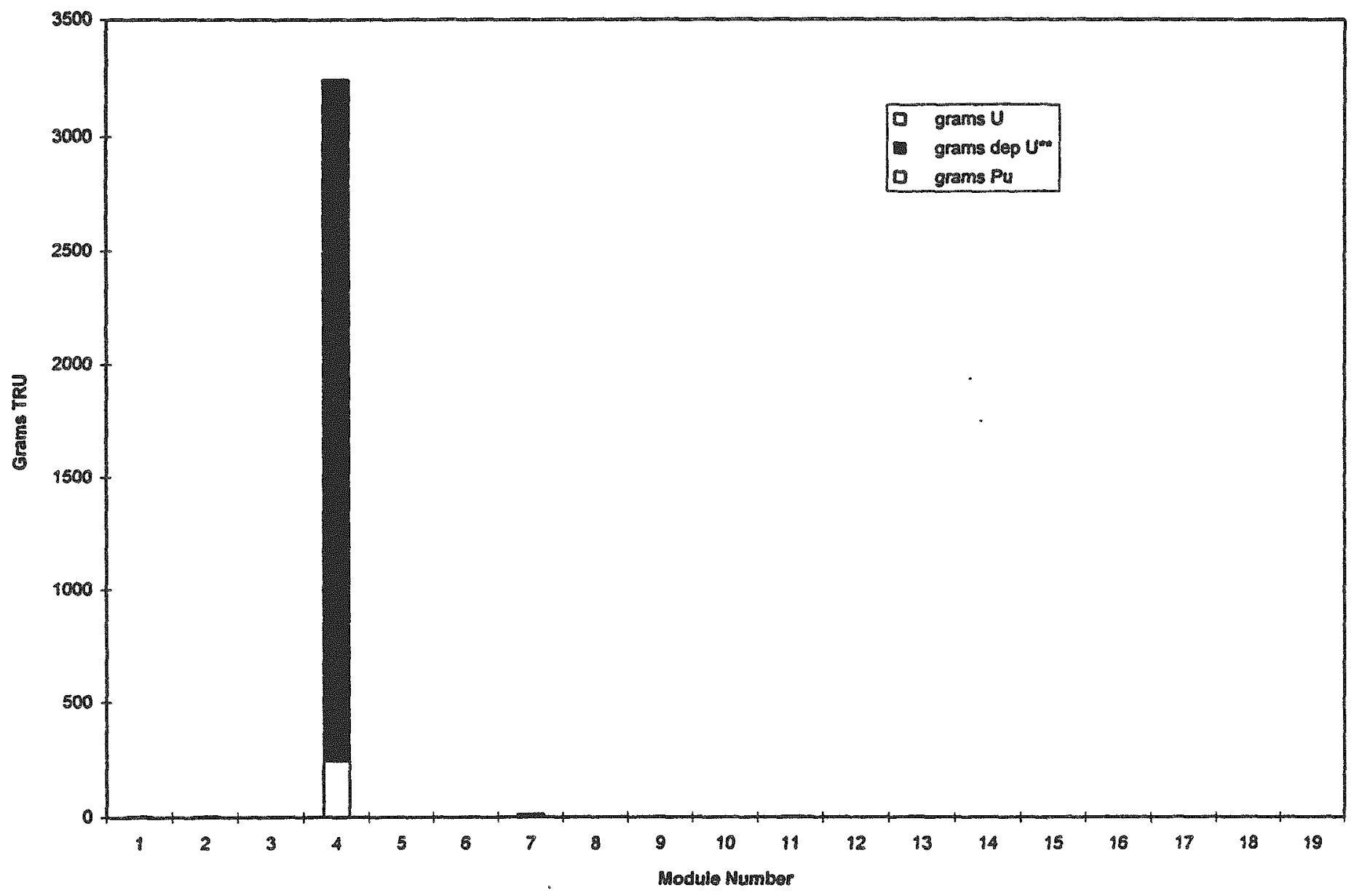


WHC-SD-W026-T1-009, Rev. 0

Figure 5.5-55. Radioisotope Quantities Present in Drums from 202A.

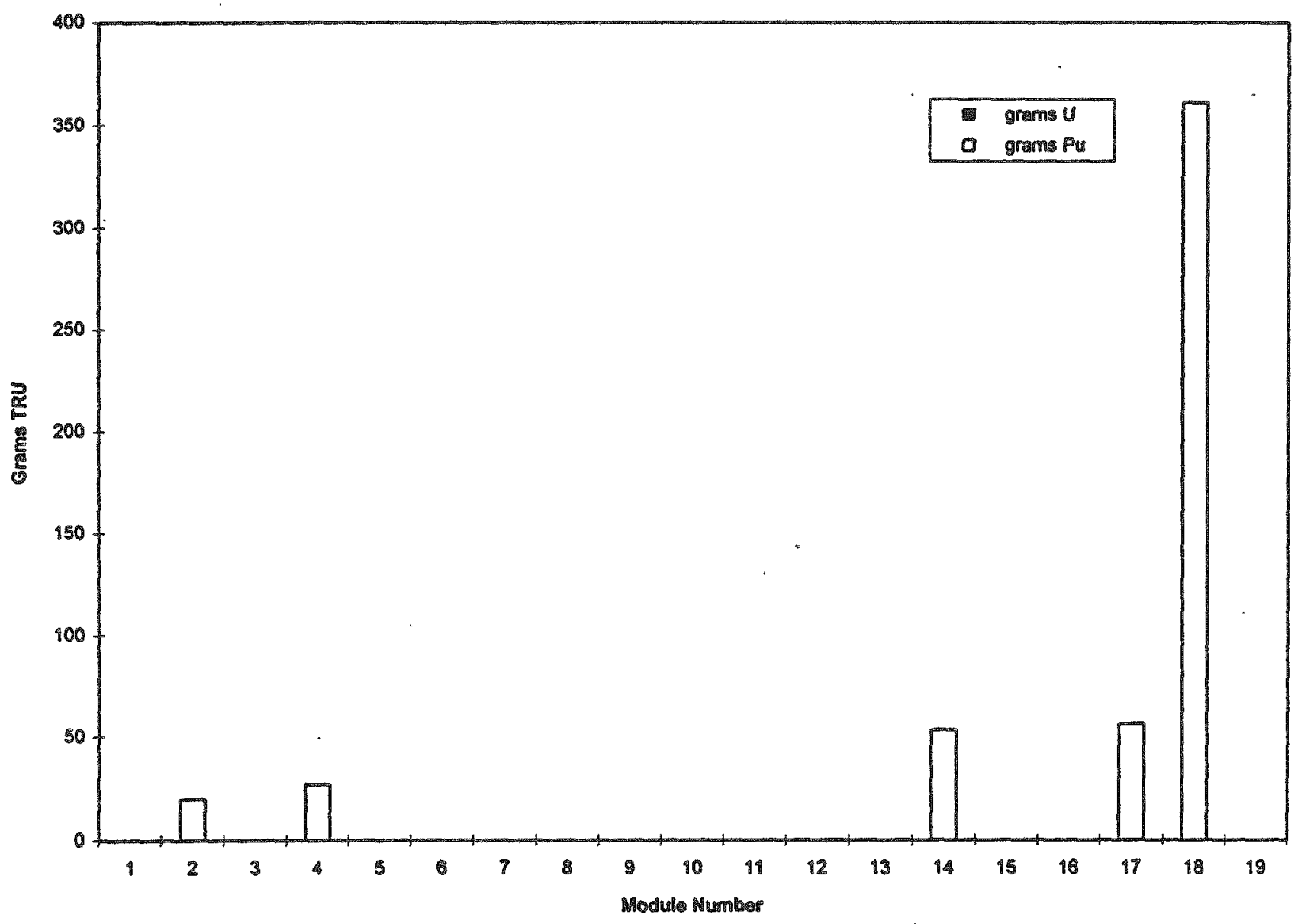

an 
WHC-SD-W026-TI-009, Rev.0

Figure 5.5-56. Radioisotope Quantities Present in Drums from 222 .

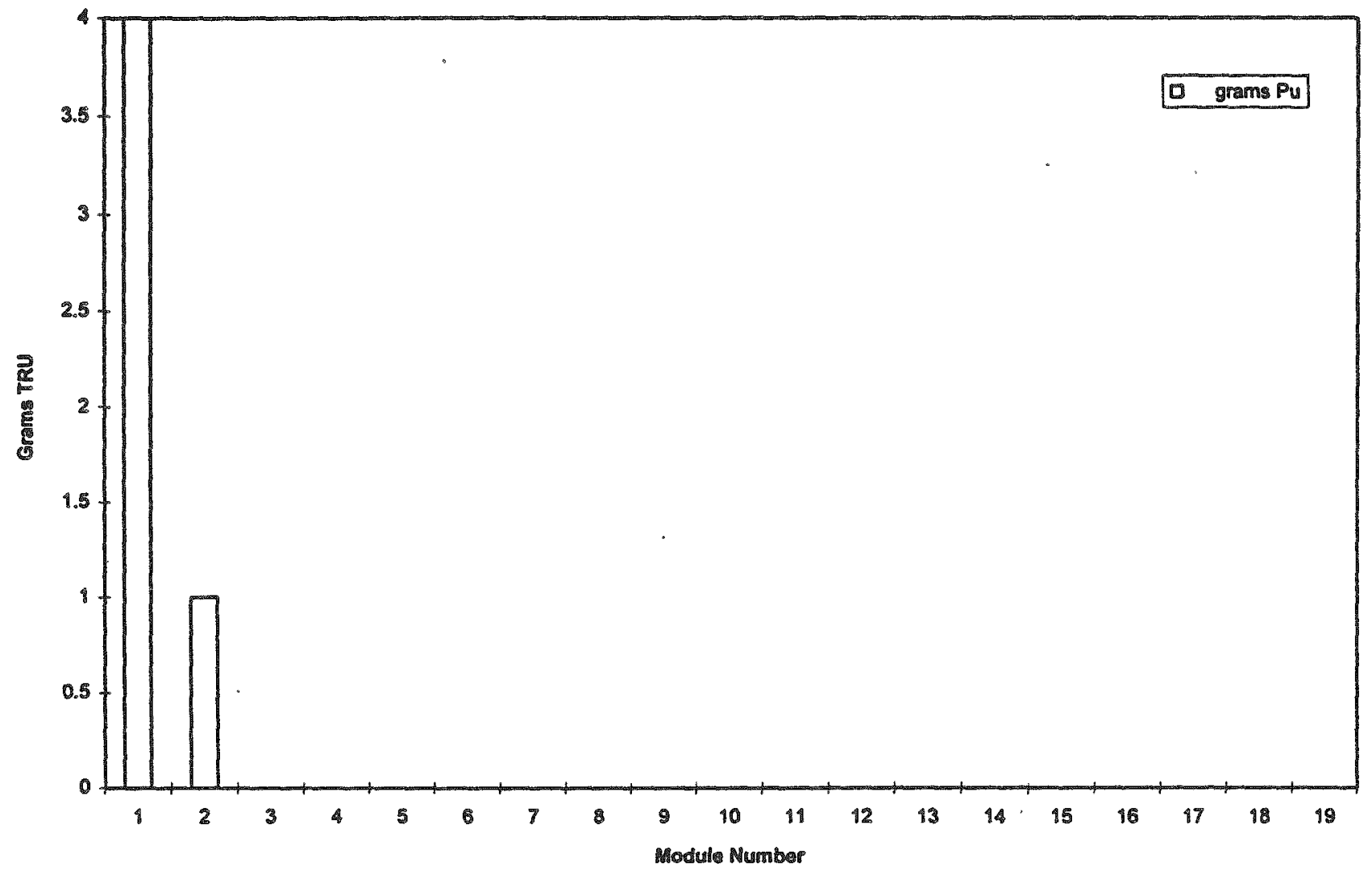


WHC-SD-W026-TI-009,Rev。O

Figure 5.5-57. Radioisotope Quantities Present in Drums from 2335.

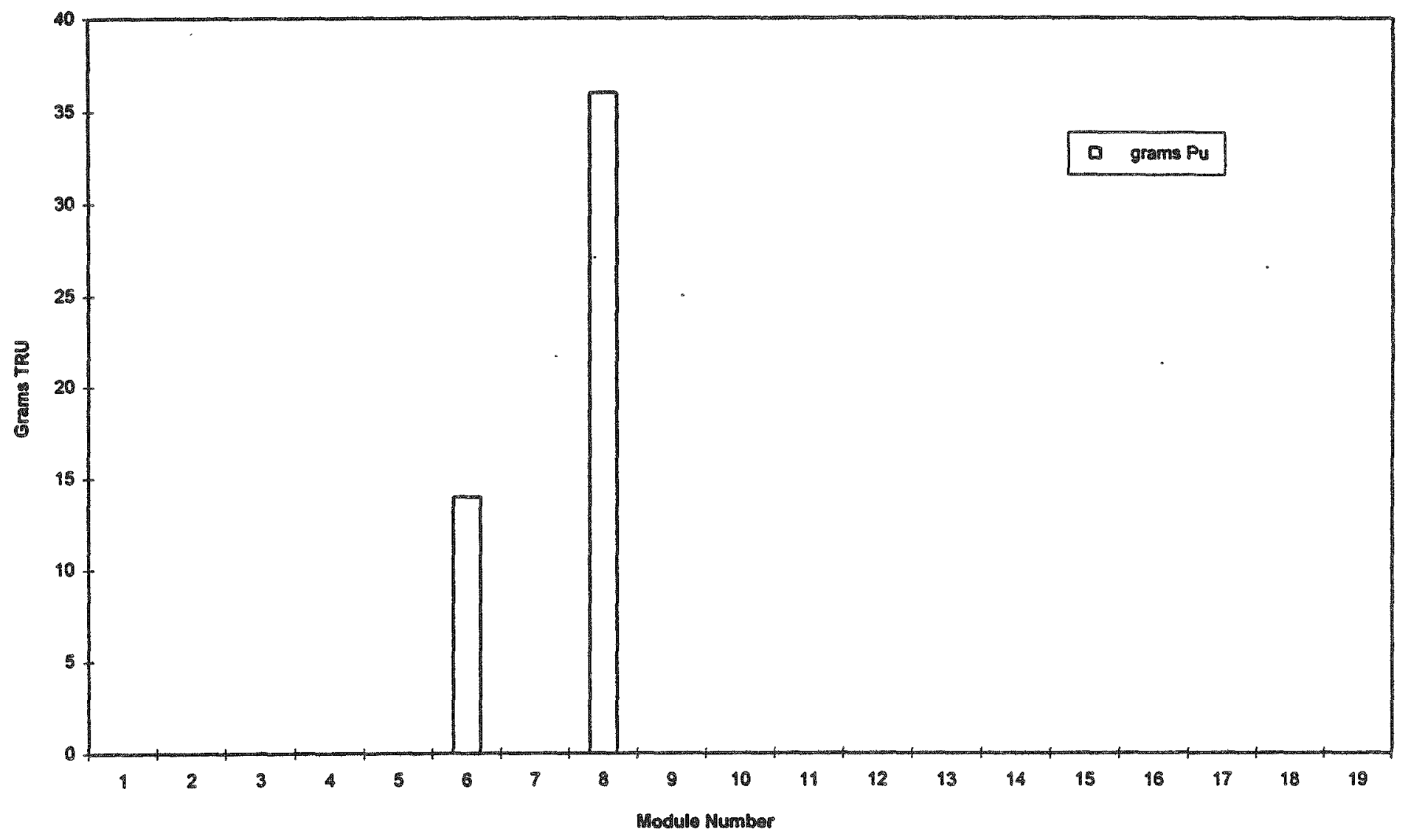


Figure 5.5-58. Radioisotope Quantities Present in Drums from 234-5Z.

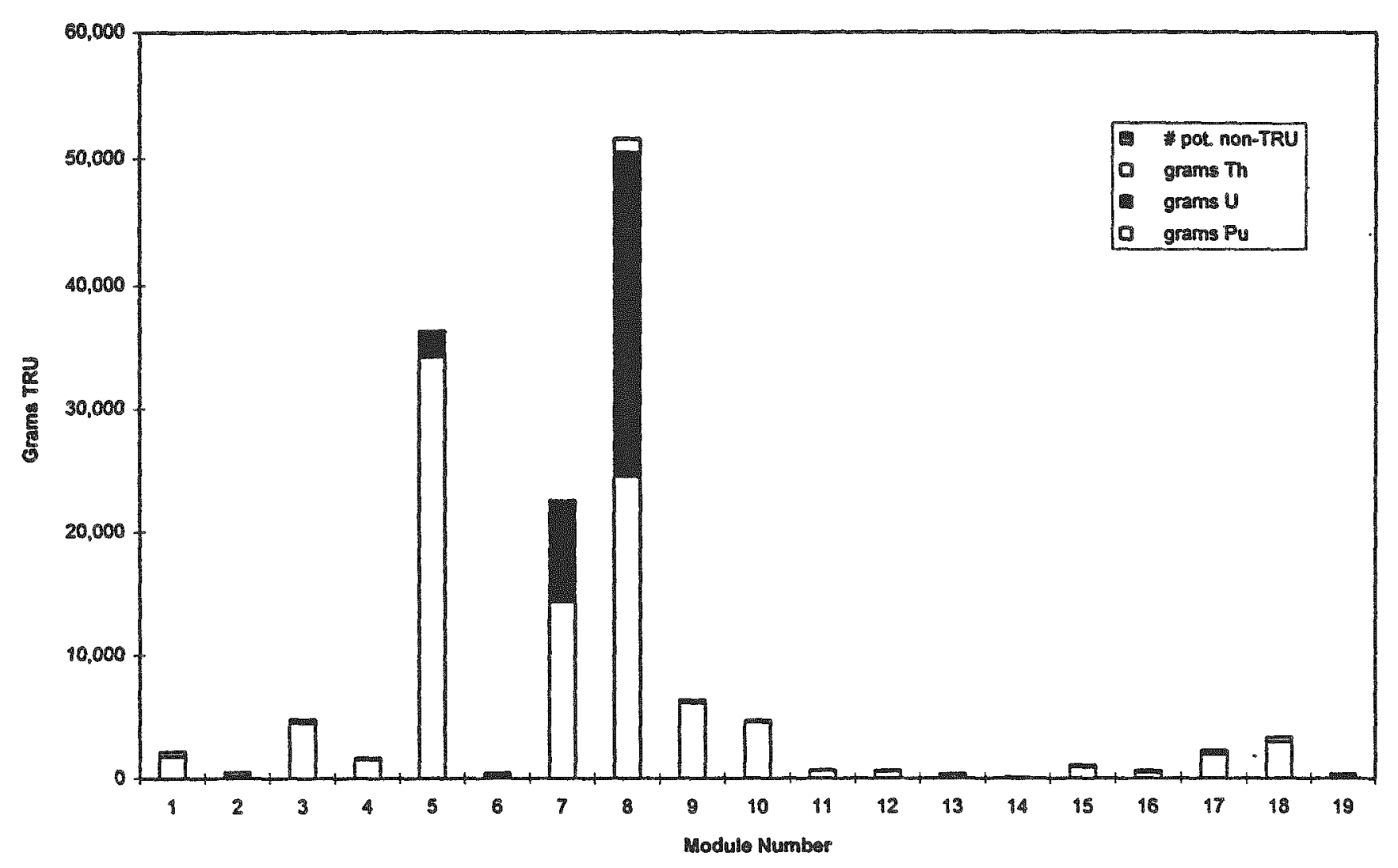


WHC-SD-W026-Tl-009, Rev. O

Figure 5.5-59. Radioisotope Quantities Present in Drums from GE-Vallecitos.

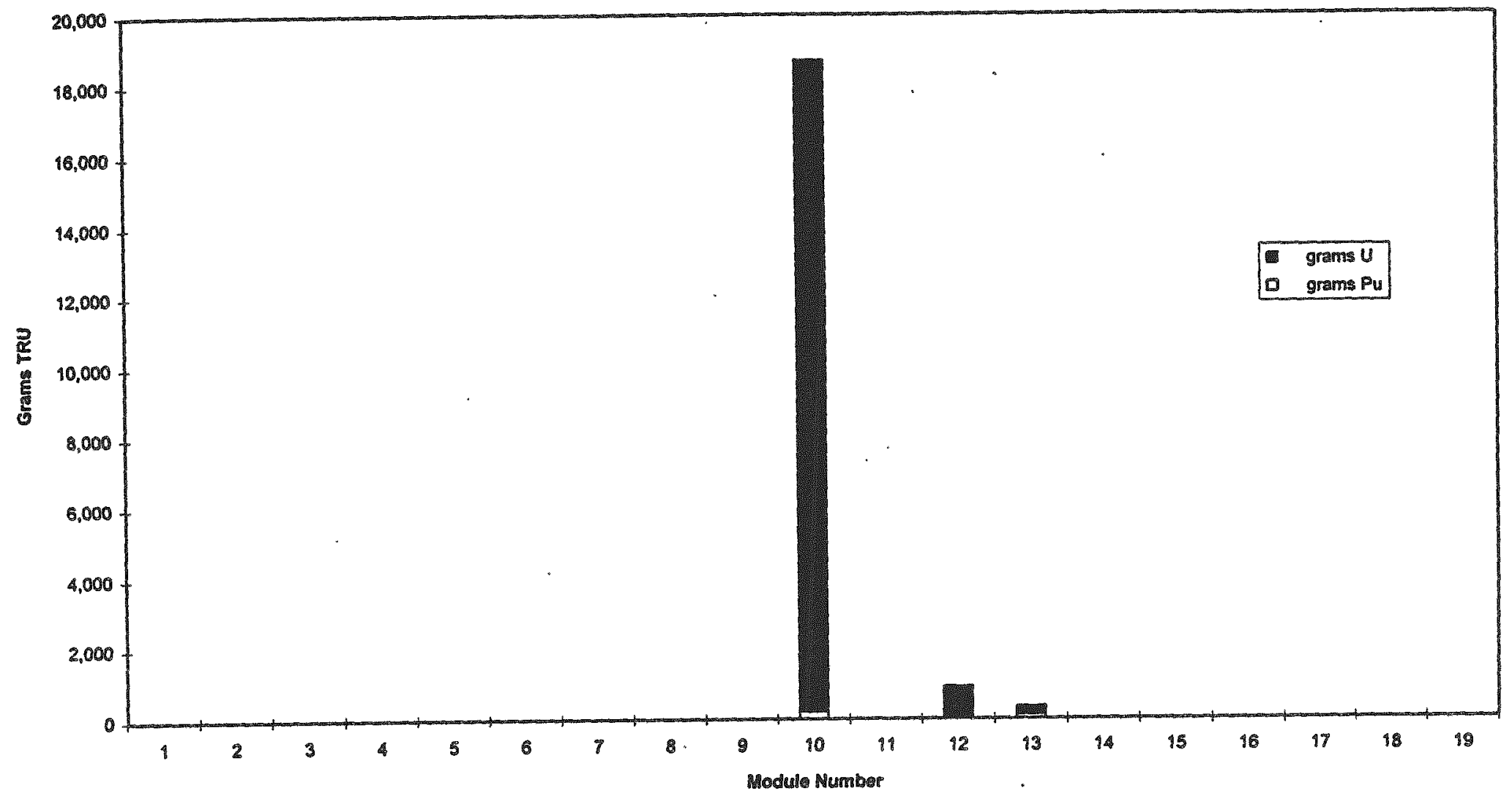


Figure 5.5-60. Radioisotope Quantities Present in Drums from WARDMNFD.

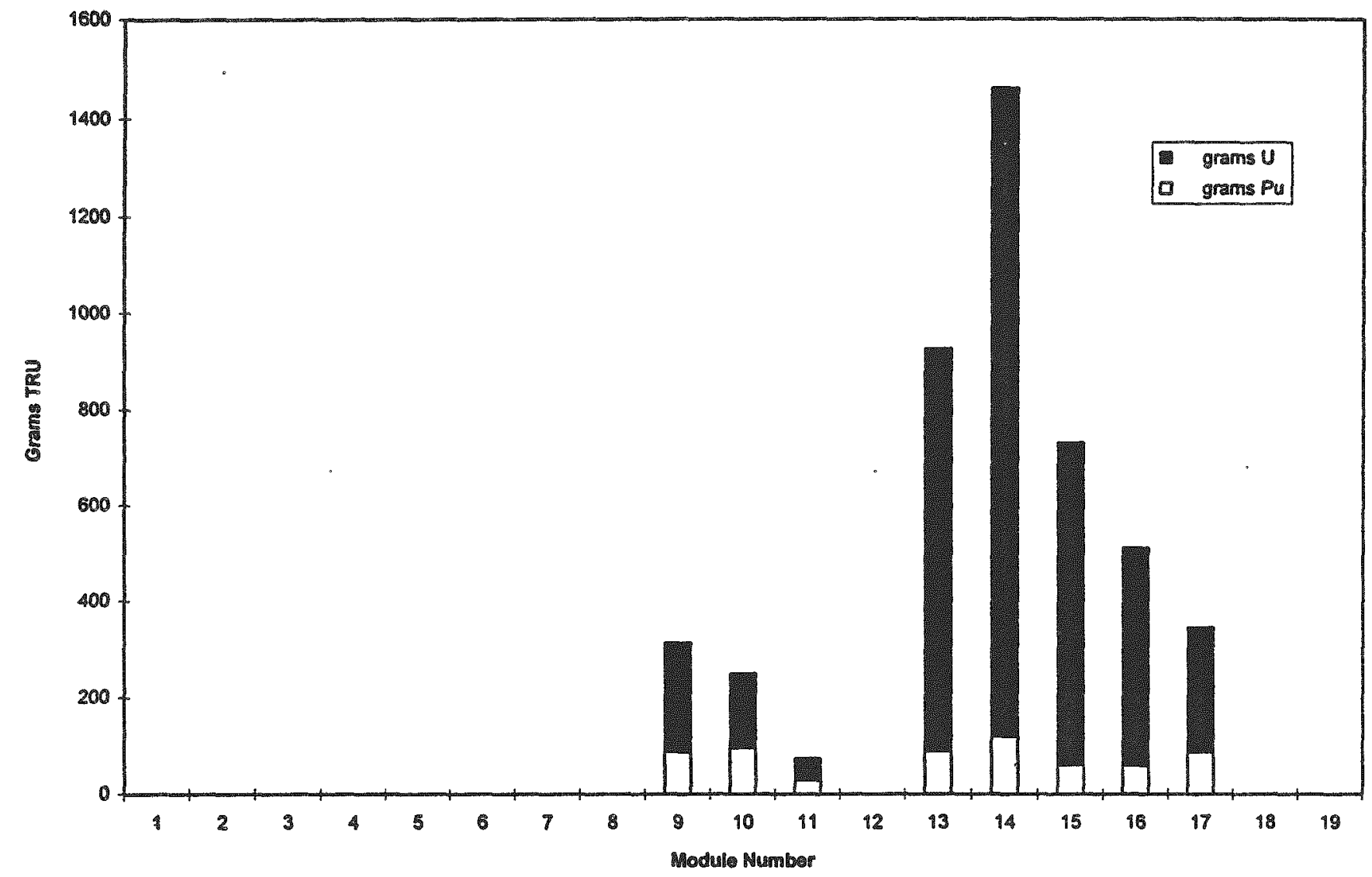


WHC-SD-W026-TH-009, REV. O

Figure 5.5-61. Radioisotope Quantities Present in Drums from Babcock \& Wilcox.

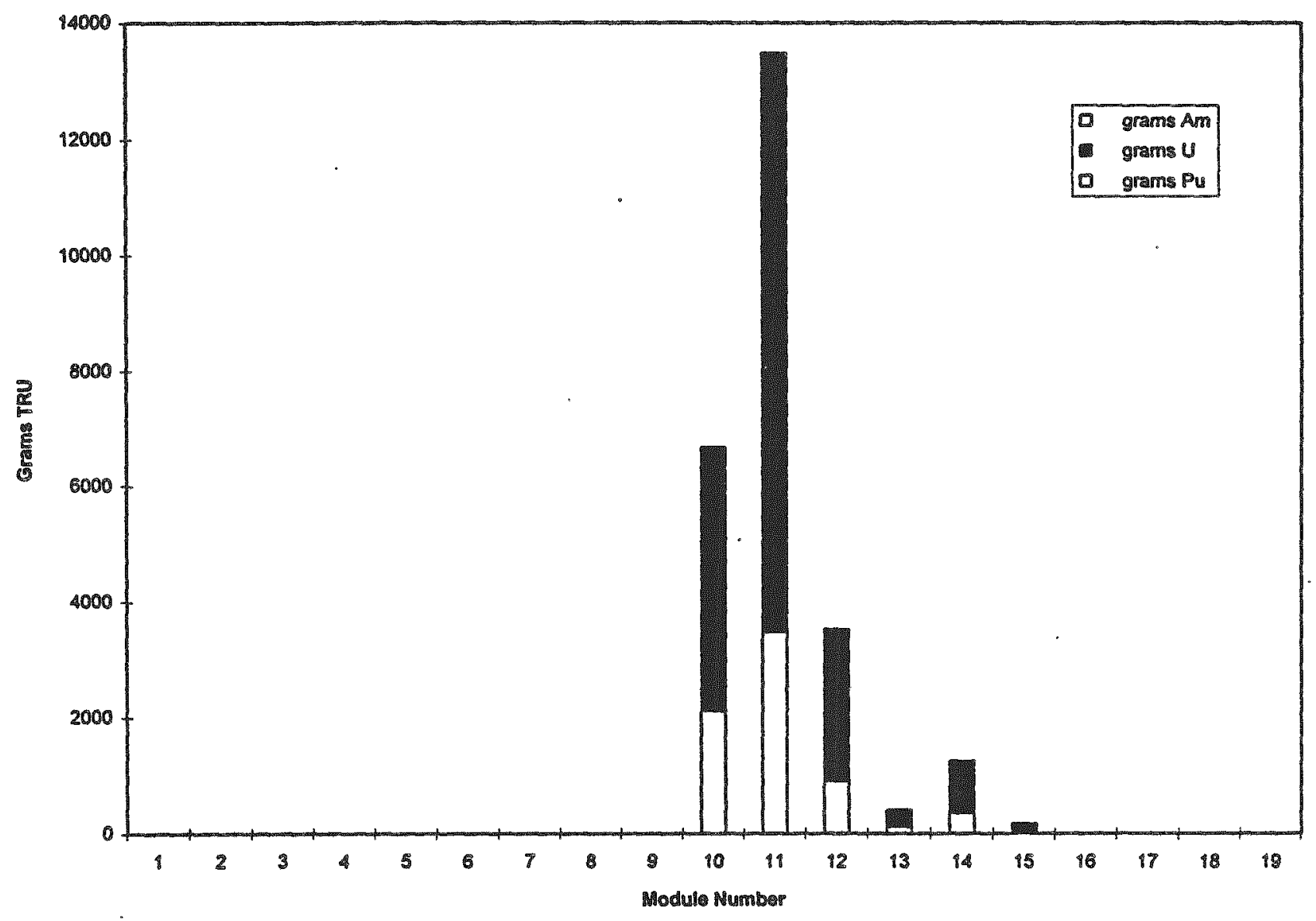


WHC-SD-W026-TI-009, Rev.0

Figure 5.5-62. Radioisotope Quantities Present in Drums from BMI.

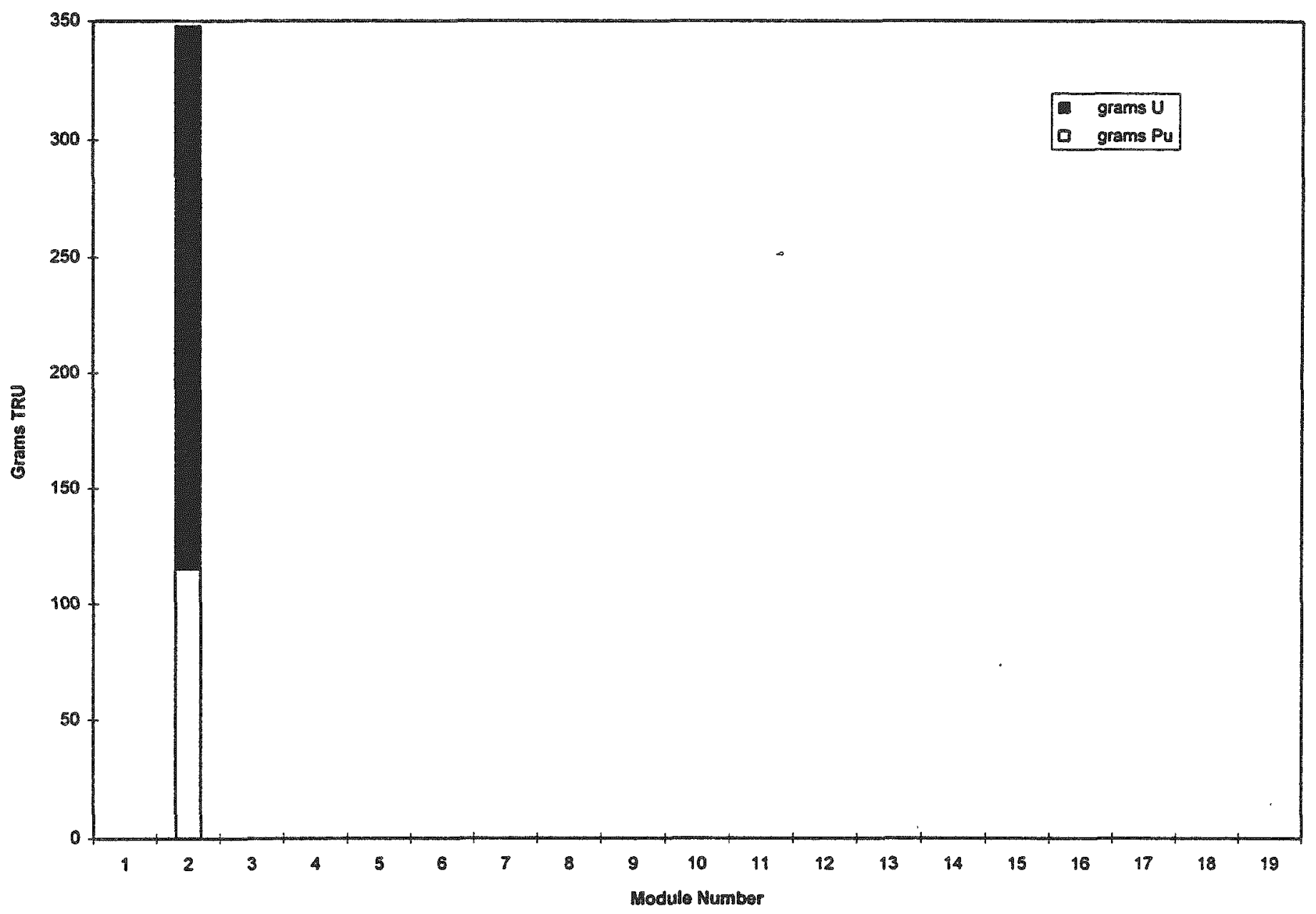


WHC-SD-W026-Tl-009, Rev. O

Figure 5.5-63. Radioisotope Quantities Present in Drums from ESG.

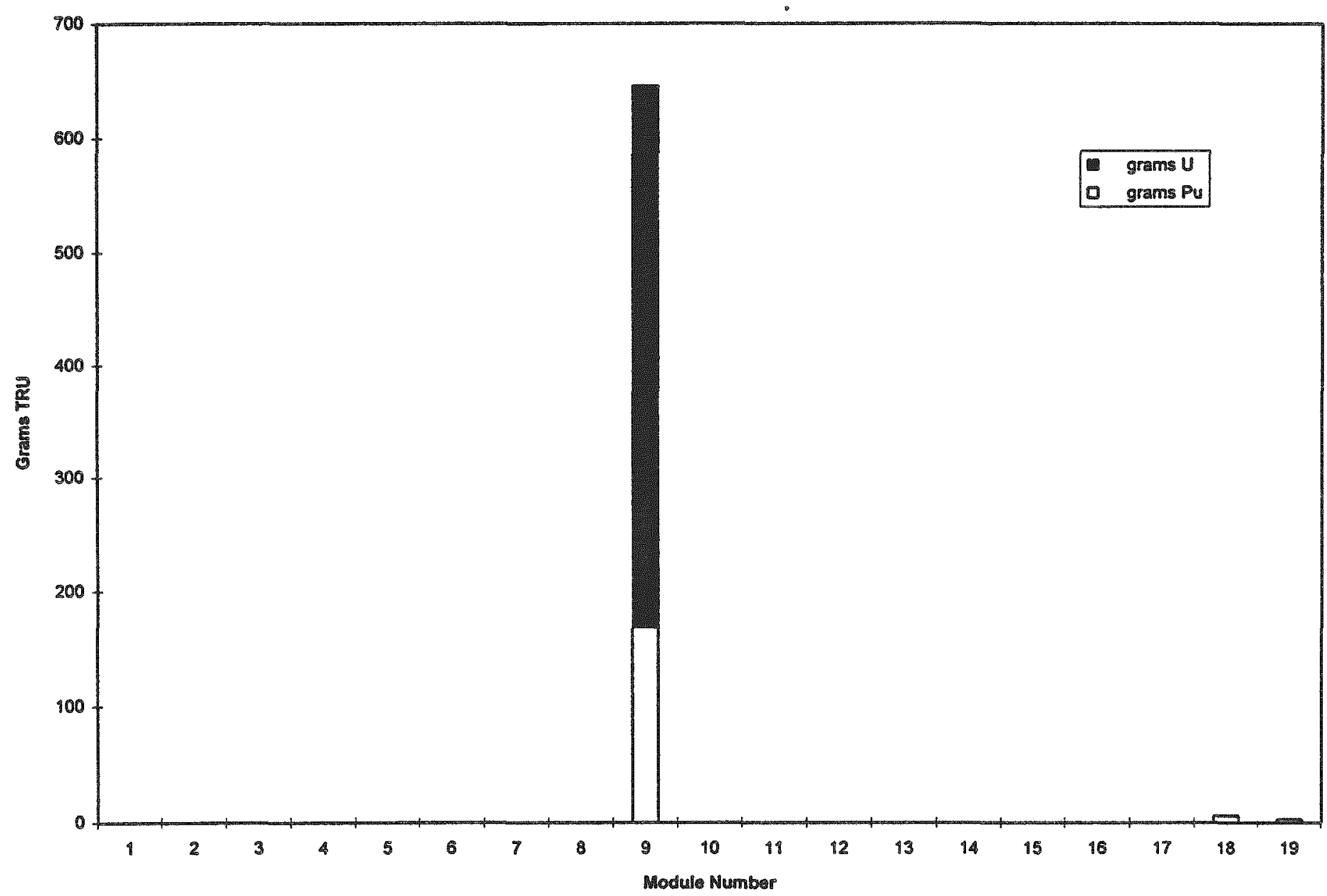


WHC-SD-W026-TI-009, Rev。O

Figure 5.5-64. Radioisotope Quantities Present in Drums from EXXON.

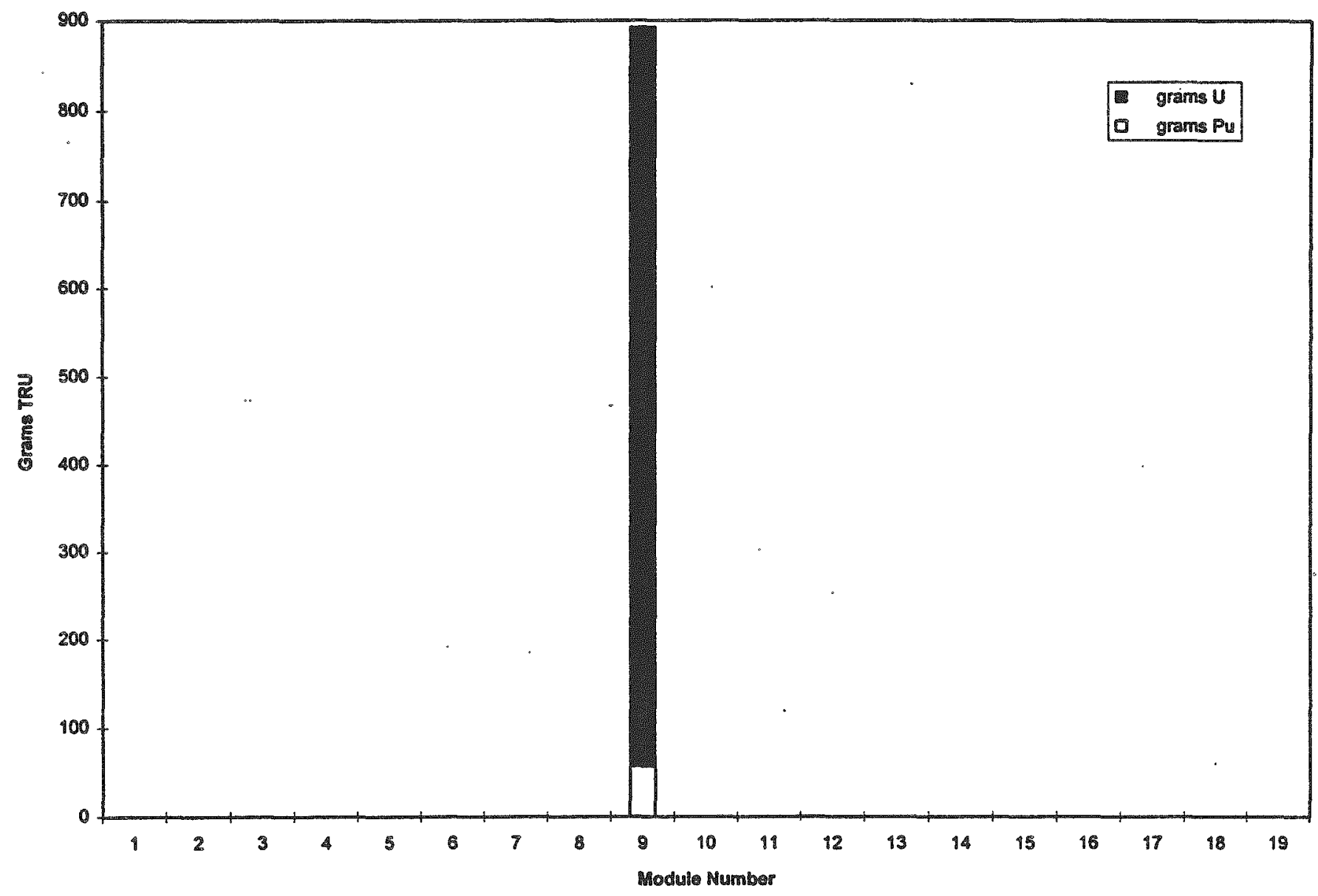




\subsection{DRUM WEIGHT}

Batching of waste drums according to their weight may be reasonable in several circumstances. First of all, drums heavier than $454.5 \mathrm{~kg}(1,000 \mathrm{lbs})$ are prohibited from acceptance in WRAP Module 1 as these drums exceed the load rating of the internal waste handling and transport equipment. Second, current waste package limits for WIPP are also set at $454.4 \mathrm{~kg}$. In addition, the TRUPACT-Il payload is limited to a total of $3,302 \mathrm{~kg}$ $(7.265 \mathrm{lbs})$.

Heavy drums also indicate the probable presence of lead or concrete shielding within the drum. Many drums, especially those shipped from off-site, are shielded to reduce the surface does rate for the drum to a safer level.

The data that form the basis for figures in this section are taken from the SWITS database. It is important to keep in mind that drum weight was not recorded on drum records until after 1978. Drums without a recorded weight were assigned an "average" weight of $68 \mathrm{~kg}(150 \mathrm{lb})$. Therefore, all of the modules, especially the earlier ones, will have a significant number of $68 \mathrm{~kg}$ drums. These drums should be considered to have unknown weights.

Figures 5.6-1 through 5.6-19 show histograms of drum weights for each generator with drums stored in Modules 19 through 1 respectively. 
Figure 5.6-1. Number of Drums in Selected Weight Categories for Each Generator in Module 19.

\begin{tabular}{|}
\begin{tabular}{|c|r|r|r|r|r|r|}
\hline Generator & $<68$ & 68 & $69-100$ & $100-150$ & $150-200$ & $>200$ \\
\hline 324 & 1 & & & & & \\
\hline $234-5 Z$ & 240 & 1 & 33 & 10 & & \\
\hline ESG & & & & & & 3 \\
\hline
\end{tabular}
\end{tabular}

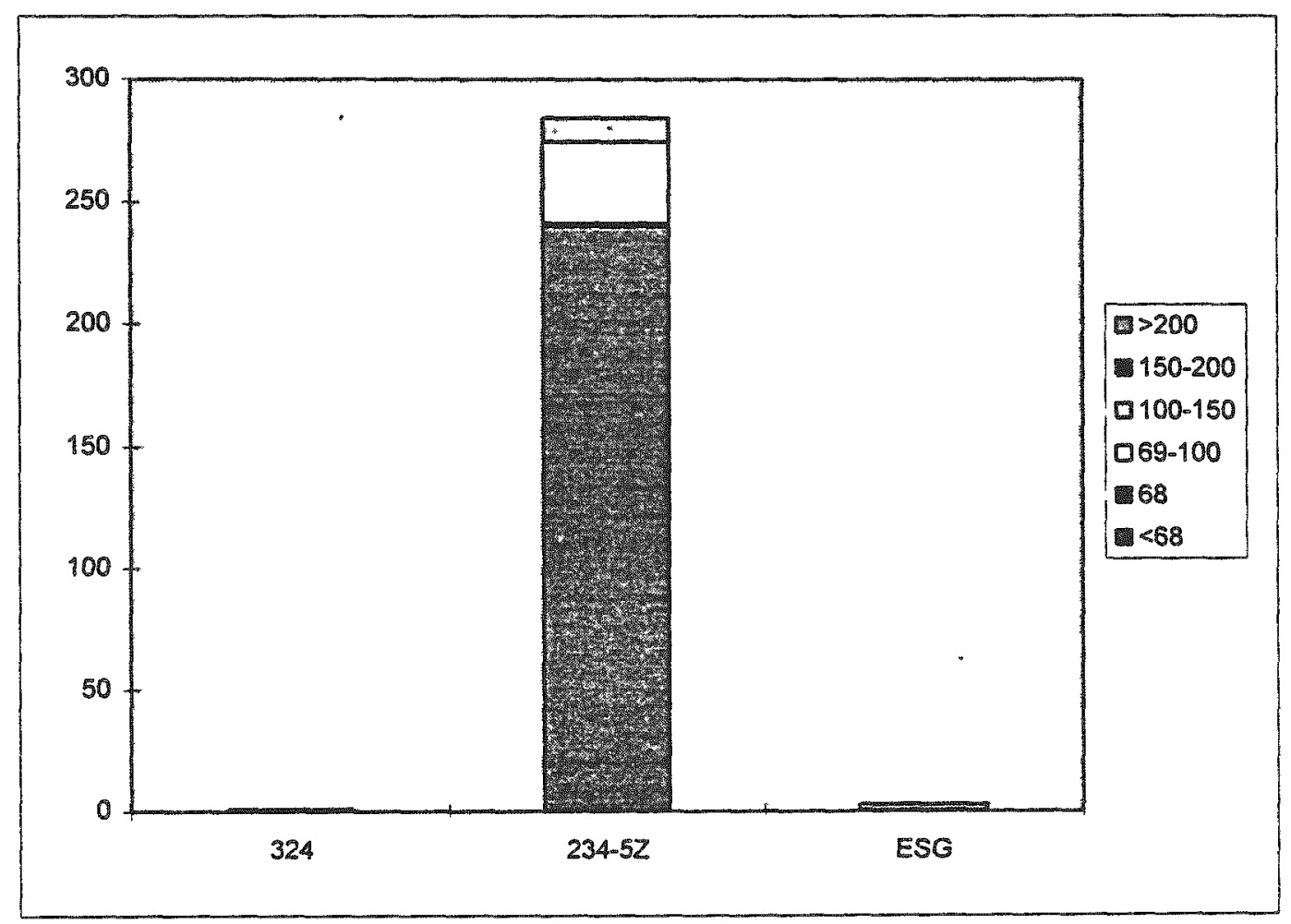


WHC-SD-W026-TI-009,REv. O

Figure 5.6-2. Number of Drums in Selected Weight Categories for Each Generator in Module 18.

WEIGHT

\begin{tabular}{|c|r|r|r|r|r|r|}
\hline Generator & $<68$ & 68 & $69-100$ & $100-150$ & $150-200$ & $>200$ \\
\hline 324 & 7 & & 31 & & & \\
\hline $202 A$ & 9 & & & & & \\
\hline $234-52$ & 449 & & 64 & 2 & & \\
\hline ESG & & & & & & 6 \\
\hline
\end{tabular}

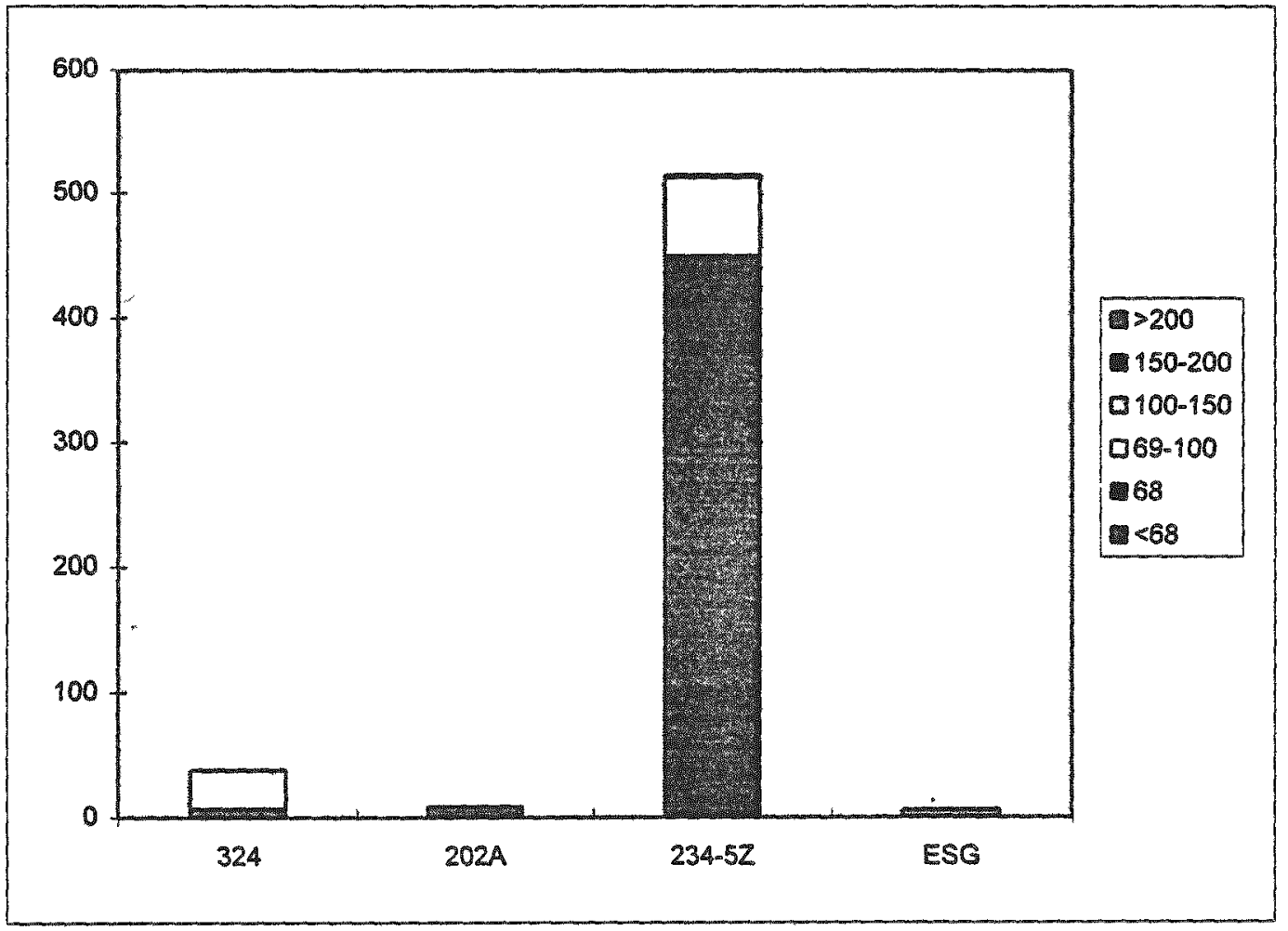


WHC-SD-W026-TI-009, Rev. O

Figure 5.6-3. Number of Drums in Selected Weight

Categories for Each Generator in Module 17.

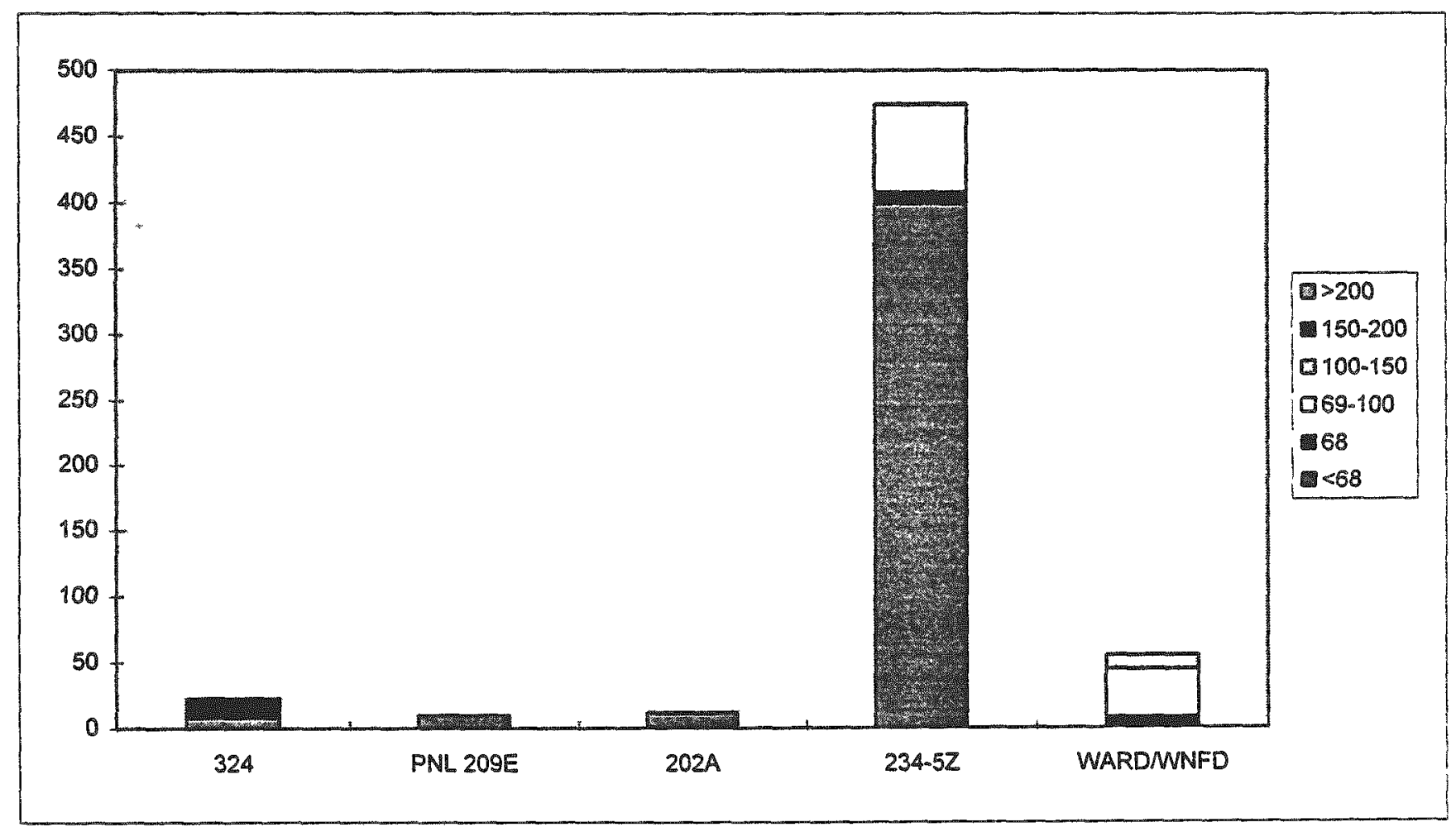


WHC-SD-W026-TI-009, ReV.O

Figure 5.6-4. Number of Drums in Selected Weight

Categories for Each Generator in Module 16.

WEIGHT

\begin{tabular}{|c|r|r|r|r|r|r|}
\hline Generator & $<68$ & 68 & $69-100$ & $100-150$ & $150-200$ & $>200$ \\
\hline 324 & 16 & & 1 & & & \\
\hline PNL 231-Z & & 4 & & & & \\
\hline $234-52$ & 216 & 13 & 12 & & & \\
\hline WARDMNFD & 14 & 11 & 45 & & & \\
\hline
\end{tabular}

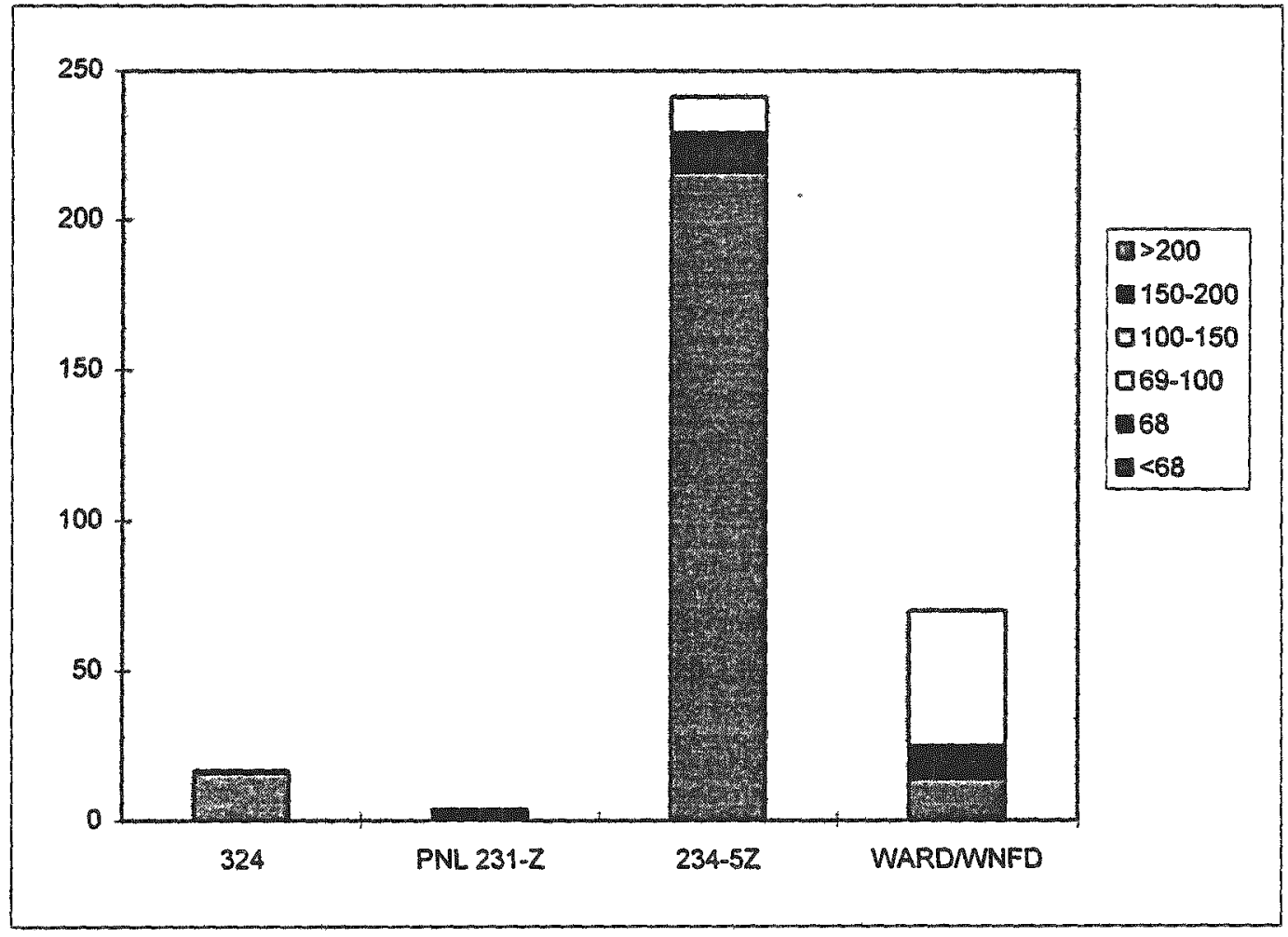


WHC-SD-W026-T1-009, Rev.O

Figure 5.6-5. Number of Drums in Selected Weight

Categories for Each Generator in Module 15.

WEIGHT

\begin{tabular}{|c|r|r|r|r|r|r|}
\hline Generator & $<68$ & 68 & $69-100$ & $100-150$ & $150-200$ & $>200$ \\
\hline 324 & 2 & & 17 & & & \\
\hline 340 & 15 & & 8 & & & \\
\hline PNL $231-Z$ & & 4 & & & & \\
\hline $202 A$ & 2 & & & & & \\
\hline $234-5 Z$ & 215 & & 29 & & & \\
\hline WARDMNFD & 48 & & 20 & & & \\
\hline B \&W & 28 & & & & & \\
\hline
\end{tabular}

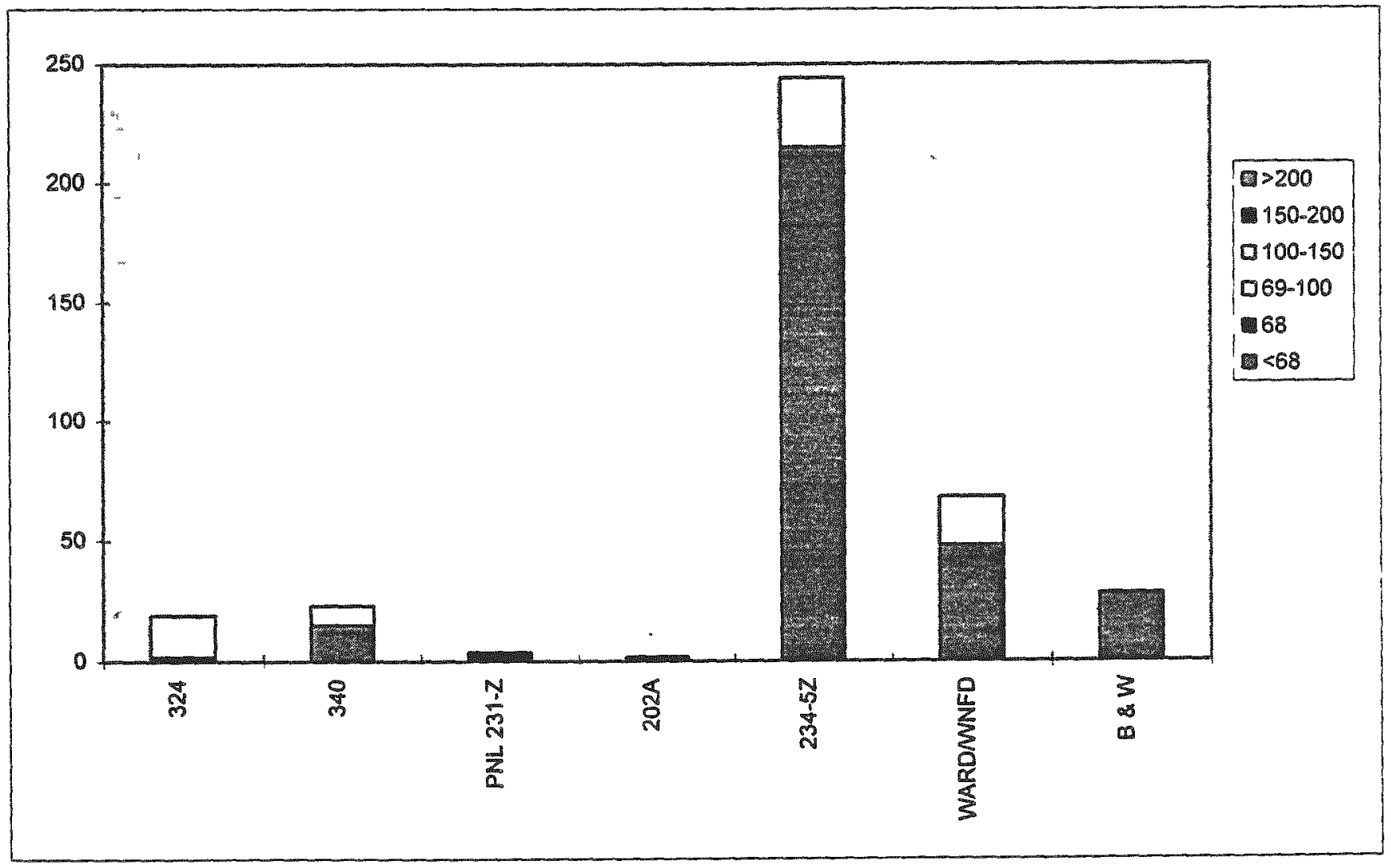


WHC-SD-W026-T1-009, Rev. O

Figure 5.6-6. Number of Drums in Selected Weight

Categories for Each Generator in Module 14.

\begin{tabular}{|c|r|r|r|r|r|r|}
\hline Generator & $<68$ & 68 & $69-100$ & $100-150$ & $150-200$ & $>200$ \\
\hline 340 & 2 & 7 & 20 & & & \\
\hline $202 A$ & & 51 & & & & \\
\hline $234-52$ & 129 & 124 & 38 & & & \\
\hline WARDMNFD & 31 & & & & & \\
\hline B \&W & 85 & & & & & \\
\hline
\end{tabular}

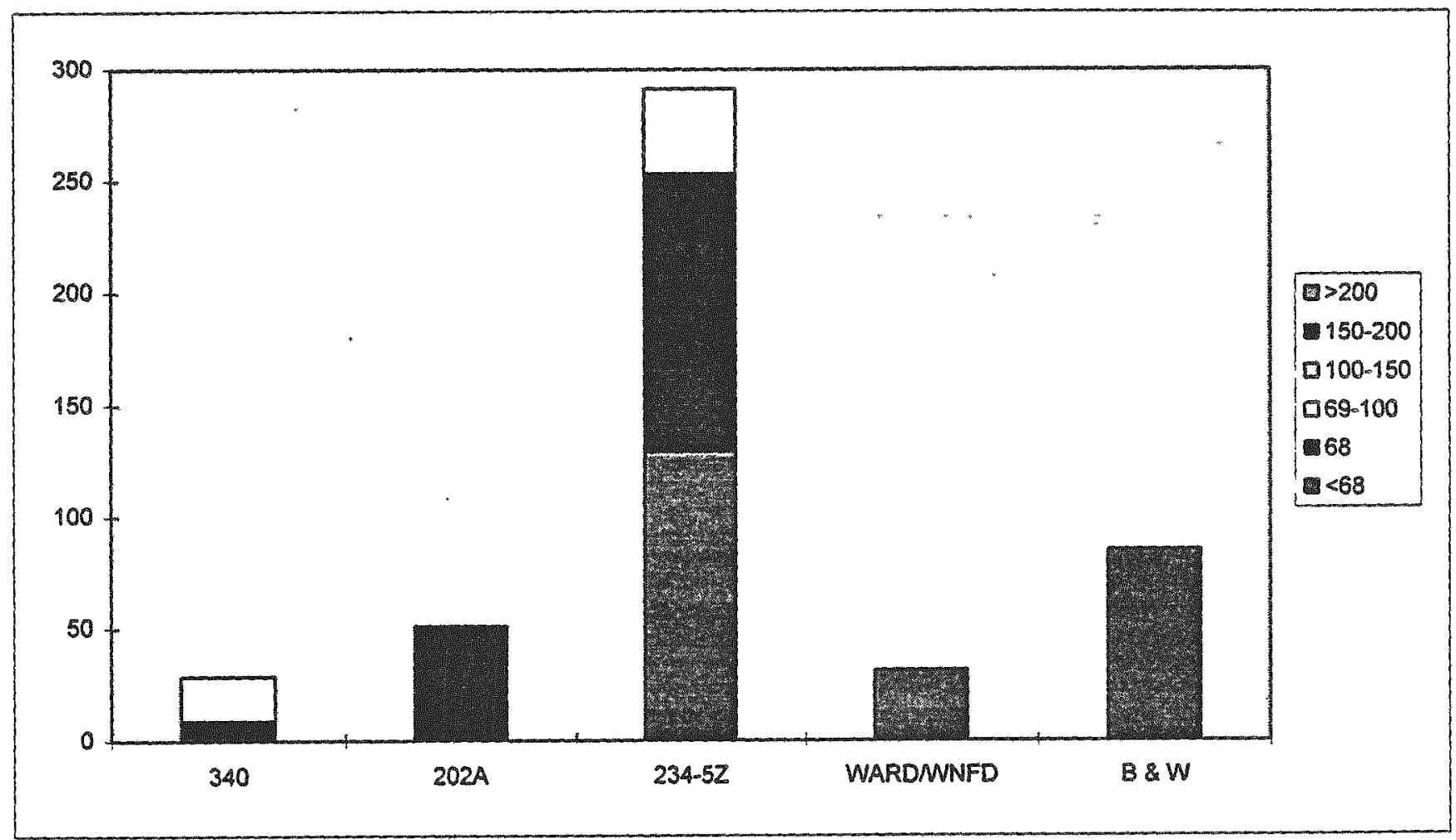


WHC-SD-W026-TI-009, Rev.0

Figure 5.6-7. Number of Drums in Selected Weight

Categories for Each Generator in Module 13.

\begin{tabular}{|c|r|r|r|r|r|r|}
\hline Generator & \multicolumn{1}{|c|}{ WEIGHT } & \multicolumn{1}{|c|}{68} & $69-100$ & $100-150$ & $150-200$ & $>200$ \\
\hline 340 & 11 & 12 & 21 & & & \\
\hline PNL 231-Z & & 11 & & & & \\
\hline $202 A$ & 109 & 22 & 9 & 1 & & \\
\hline $234-5 Z$ & & 185 & & & & \\
\hline GE-VAL & 1 & 1 & 14 & 13 & 3 & 3 \\
\hline WARDMNFD & 96 & & 9 & & & \\
\hline B \&W & 8 & & & & & \\
\hline
\end{tabular}

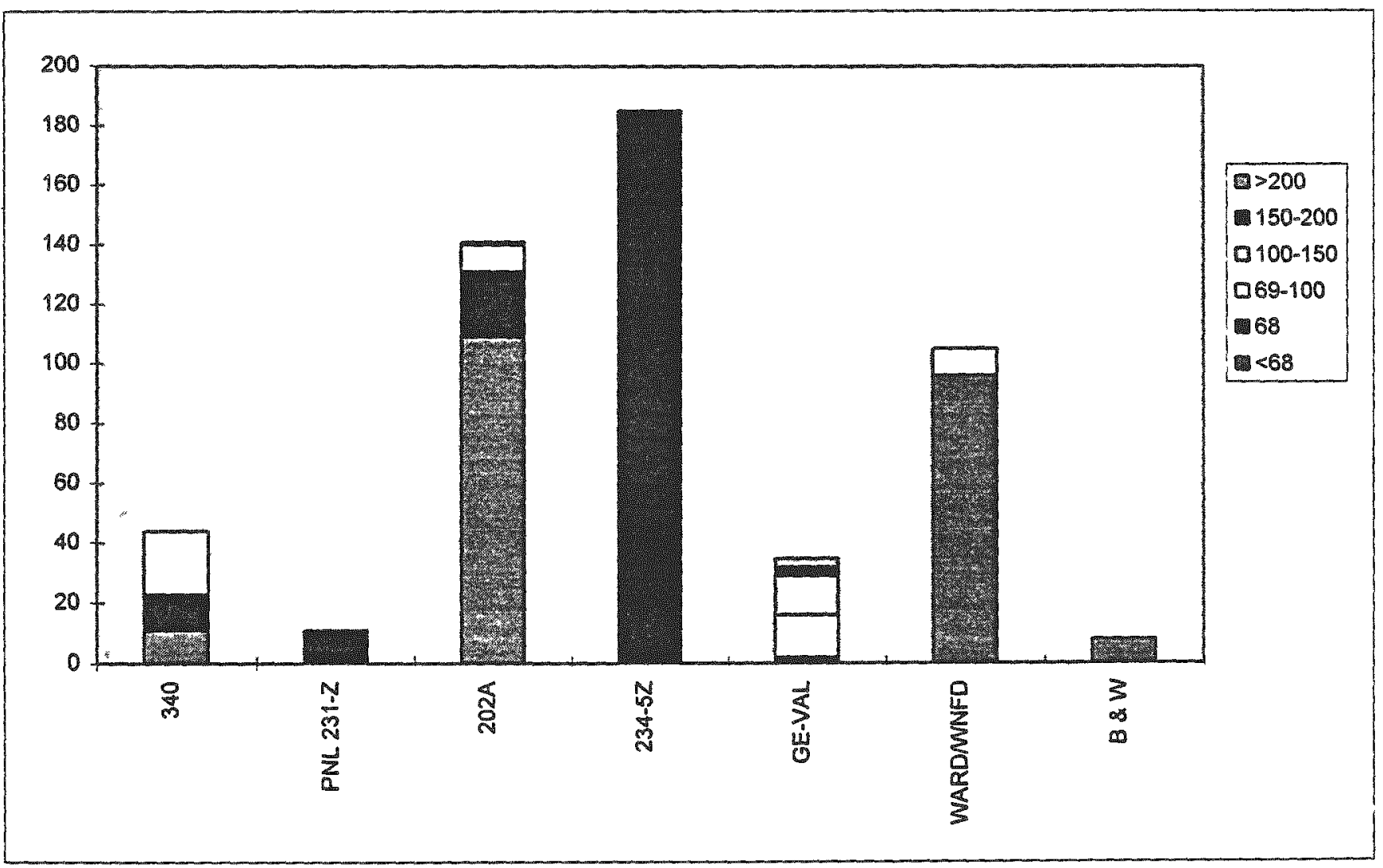


WHC-SD-W026-TI-009, REv.0

Figure 5.6-8. Number of Drums in Selected Weight

Categories for Each Generator in Module 12.

WEIGHT

\begin{tabular}{|c|r|r|r|r|r|r|}
\hline Generator & $<68$ & 68 & $69-100$ & $100-150$ & $150-200$ & $>200$ \\
\hline 340 & 1 & 21 & & & & \\
\hline $234-52$ & & 137 & & & & \\
\hline GE-VAL & 1 & & 19 & 7 & 2 & 3 \\
\hline B \& W & 59 & & 2 & & & \\
\hline
\end{tabular}

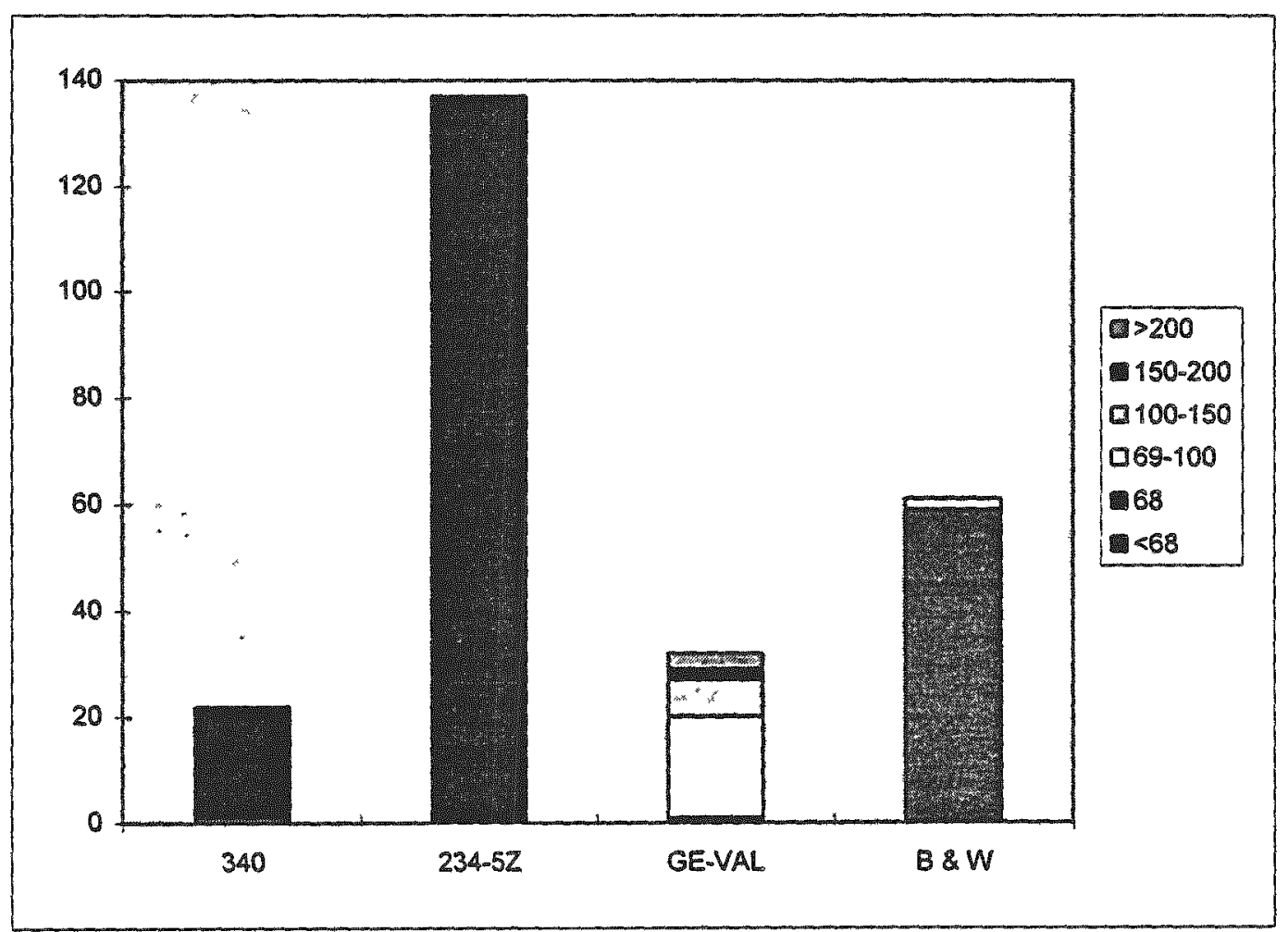


Figure 5.6-9. Number of Drums in Selected Weight Categories for Each Generator in Module 11.

WEIGHT

\begin{tabular}{|c|r|r|r|r|r|r|}
\hline Generator & \multicolumn{1}{|c|}{$<68$} & 68 & $69-100$ & $100-150$ & $150-200$ & $>200$ \\
\hline 340 & 12 & & 41 & 2 & & \\
\hline PNL 209E & & 13 & & & & \\
\hline $234-52$ & & 113 & 7 & & & \\
\hline WARDMNFD & & 26 & & & & \\
\hline B \&W & 249 & 1 & 6 & & & \\
\hline
\end{tabular}

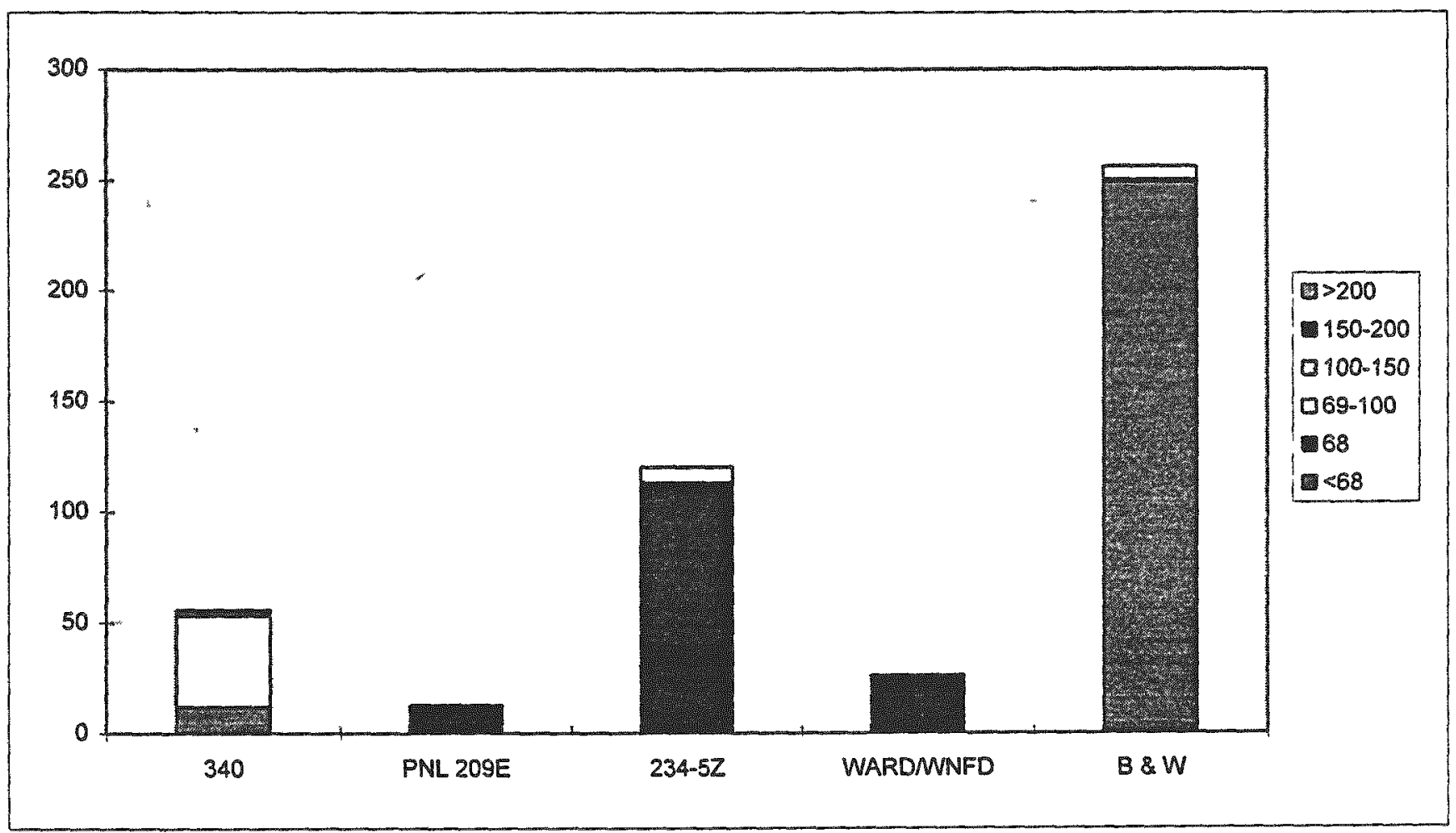


WHC-SD-W026-TI-009, Rev.0

Figure 5.6-10. Number of Drums in Selected Weight

Categories for Each Generator in Module 10.

\begin{tabular}{|c|r|r|r|r|r|r|}
\hline Generator & \multicolumn{1}{|c|}{ WEIGHT } & $68-100$ & $100-150$ & $150-200$ & $>200$ \\
\hline 340 & 17 & & 4 & & & \\
\hline PNL 231-Z & & 1 & & & & \\
\hline $234-5 Z$ & & 261 & & & & \\
\hline GE-VAL & & & 10 & 25 & 21 & 6 \\
\hline WARDMNFD & 42 & & 6 & & & \\
\hline B \&W & 138 & & 3 & & & \\
\hline
\end{tabular}

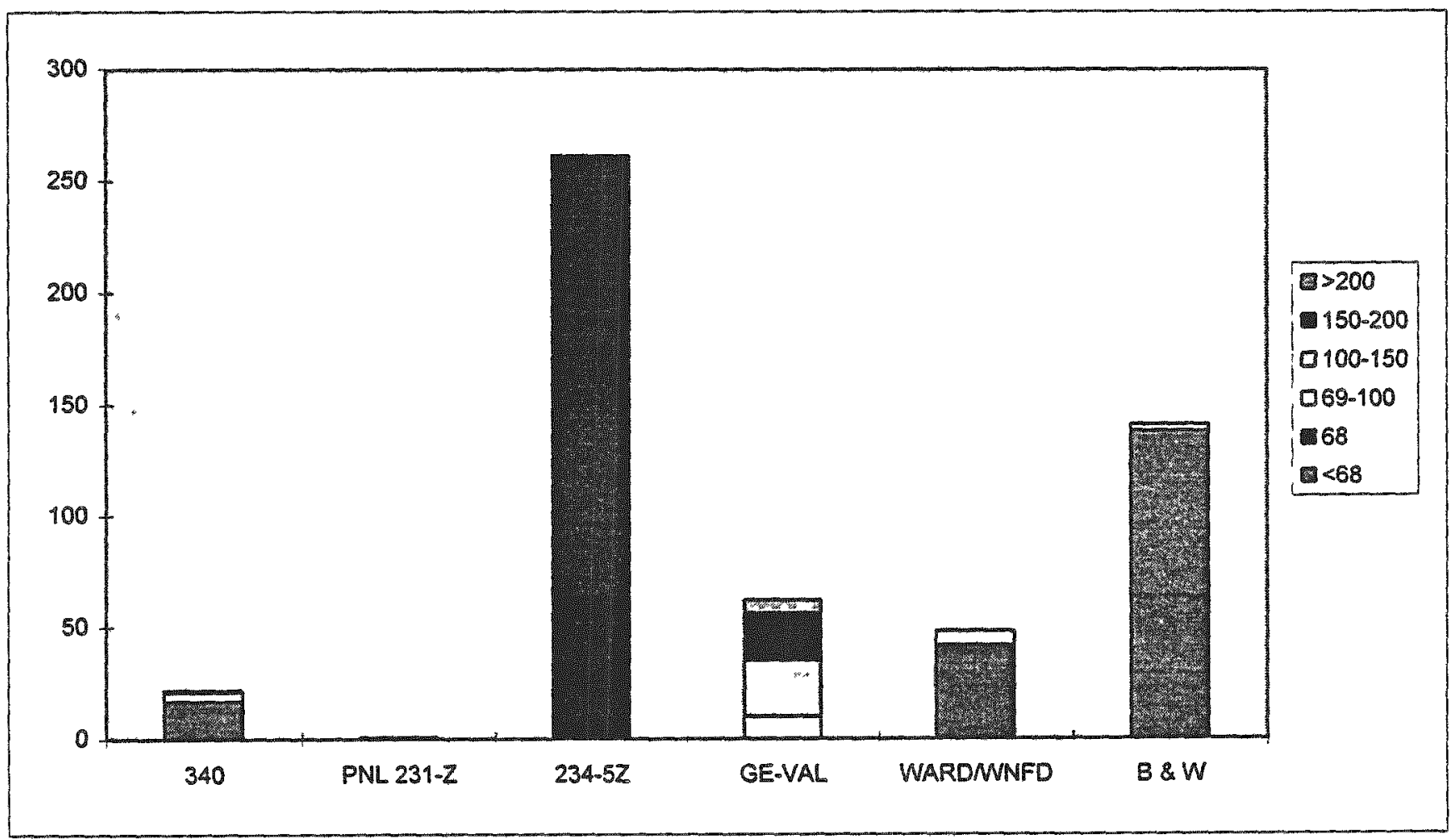


WHC-SD-W026-TH-OO9, Rev. U

Figure 5.6-11. Number of Drums in Selected Weight Categories for Each Generator in Module 9.

WEIGHT

\begin{tabular}{|c|r|r|r|r|r|r|}
\hline Generator & $<68$ & 68 & $69-100$ & $100-150$ & $150-200$ & $>200$ \\
\hline 340 & & 85 & & & & \\
\hline PNL 231-Z & & 1 & & & & \\
\hline $233 S$ & & 1 & & & & \\
\hline $234-5 Z$ & & 392 & & & & \\
\hline WARDMNFD & 48 & 1 & 2 & & & \\
\hline ESG & & 19 & & & & \\
\hline
\end{tabular}

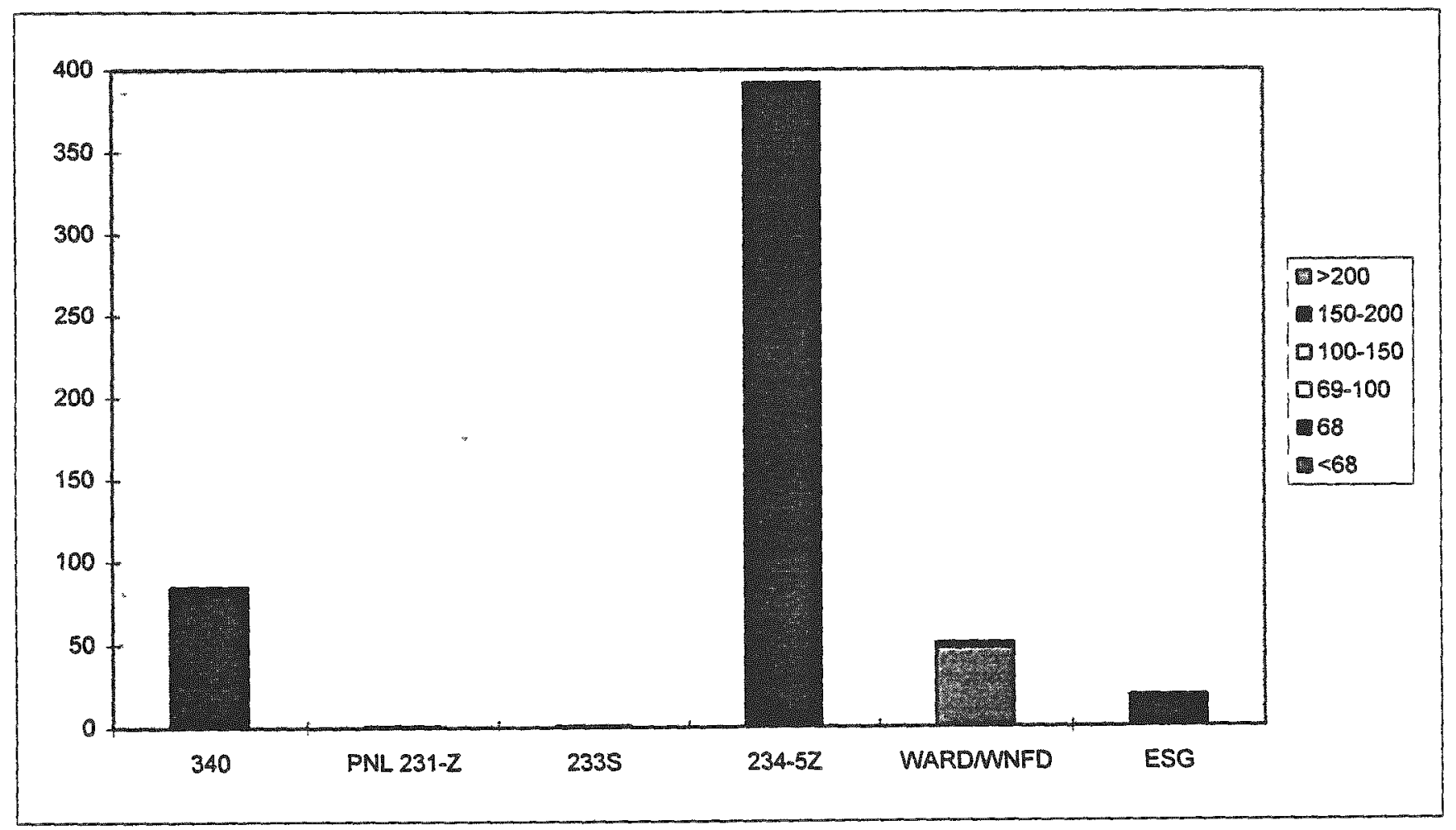


WHC-SD-WO26-TI-009, Rev. O

Figure 5.6-12. Number of Drums in Selected Weight

Categories for Each Generator in Module 8.

\begin{tabular}{|c|r|r|r|r|r|r|}
\hline Generator & $<68$ & 68 & $69-100$ & $100-150$ & $150-200$ & $>200$ \\
\hline 325 & & 53 & & & & \\
\hline 340 & & 39 & & & & \\
\hline PNL $209 E$ & & 9 & & & & \\
\hline 2335 & & 18 & & & & \\
\hline $234-52$ & & 457 & & & & \\
\hline
\end{tabular}

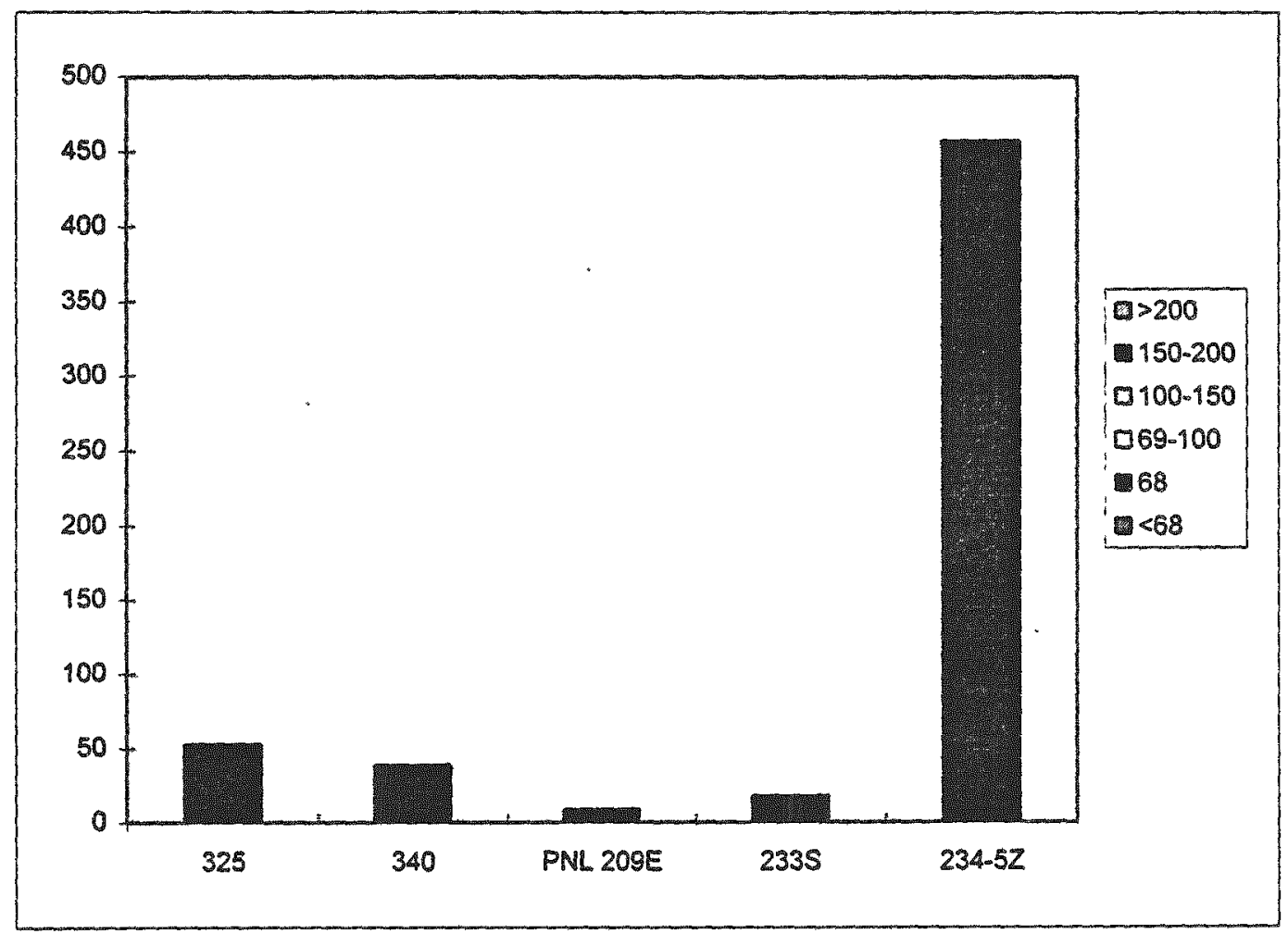


WHC-SD-W026-TI-009, Rev. O

Figure 5.6-13. Number of Drums in Selected Weight Categories for Each Generator in Module 7.

\begin{tabular}{|c|r|r|r|r|r|r|}
\hline Generator & $<68$ & 68 & $69-100$ & $100-150$ & $150-200$ & $>200$ \\
\hline 325 & & 44 & & & & \\
\hline PNL 231-Z & & 8 & & & & \\
\hline $234-52$ & 1 & 516 & & & & \\
\hline 2WTF & & 6 & & & & \\
\hline
\end{tabular}

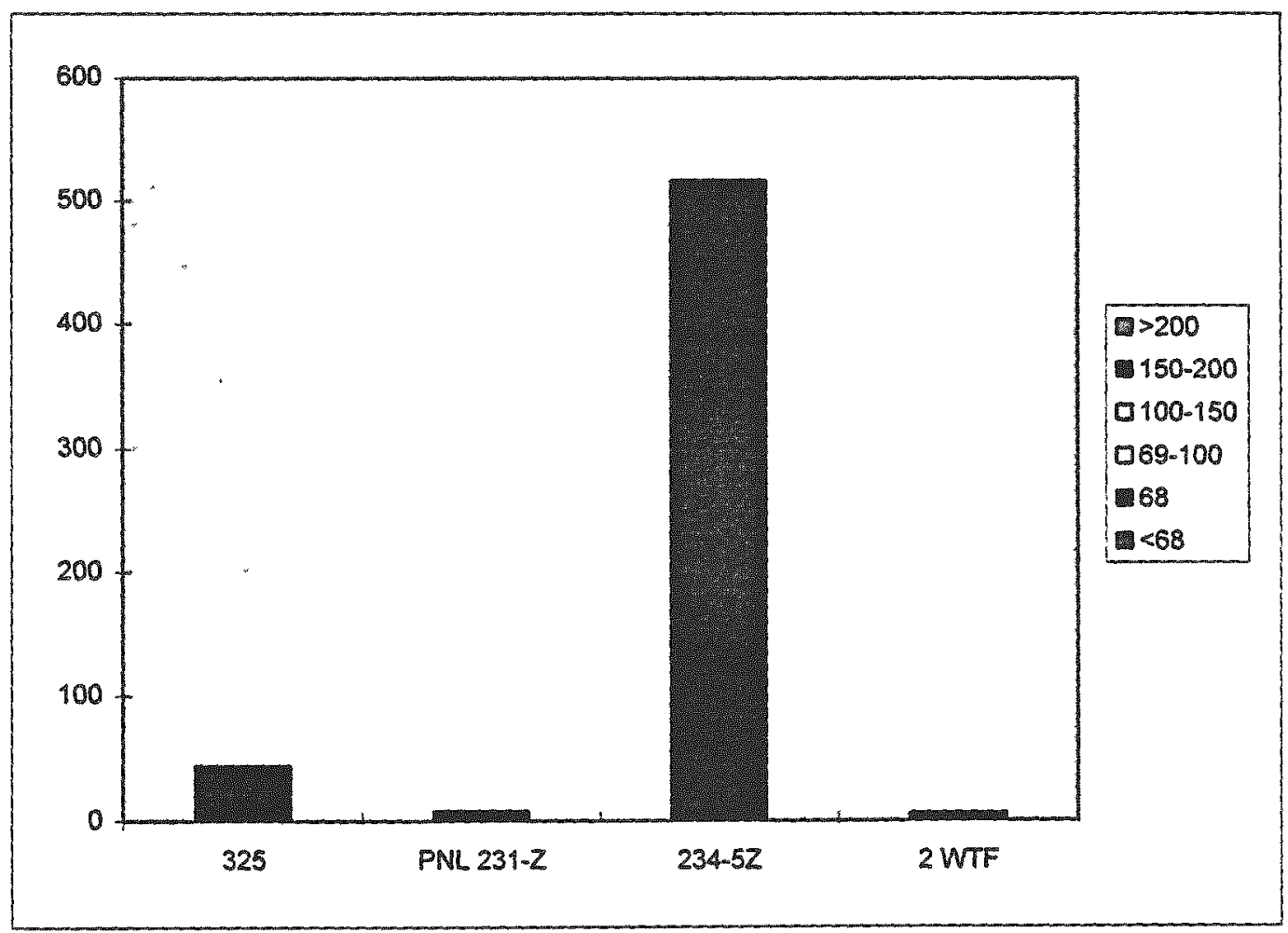


WHC-SD-W026-TI-009, ReV. 0

Figure 5.6-14. Number of Drums in Selected Weight

Categories for Each Generator in Module 6.

\begin{tabular}{|c|r|r|r|r|r|r|}
\hline Generator & $<68$ & 68 & $69-100$ & $100-150$ & $150-200$ & $>200$ \\
\hline 325 & & 185 & & & & \\
\hline PNL $231-Z$ & & 14 & & & & \\
\hline $233 S$ & & 7 & & & & \\
\hline $234-52$ & 2 & 302 & & & & \\
\hline
\end{tabular}

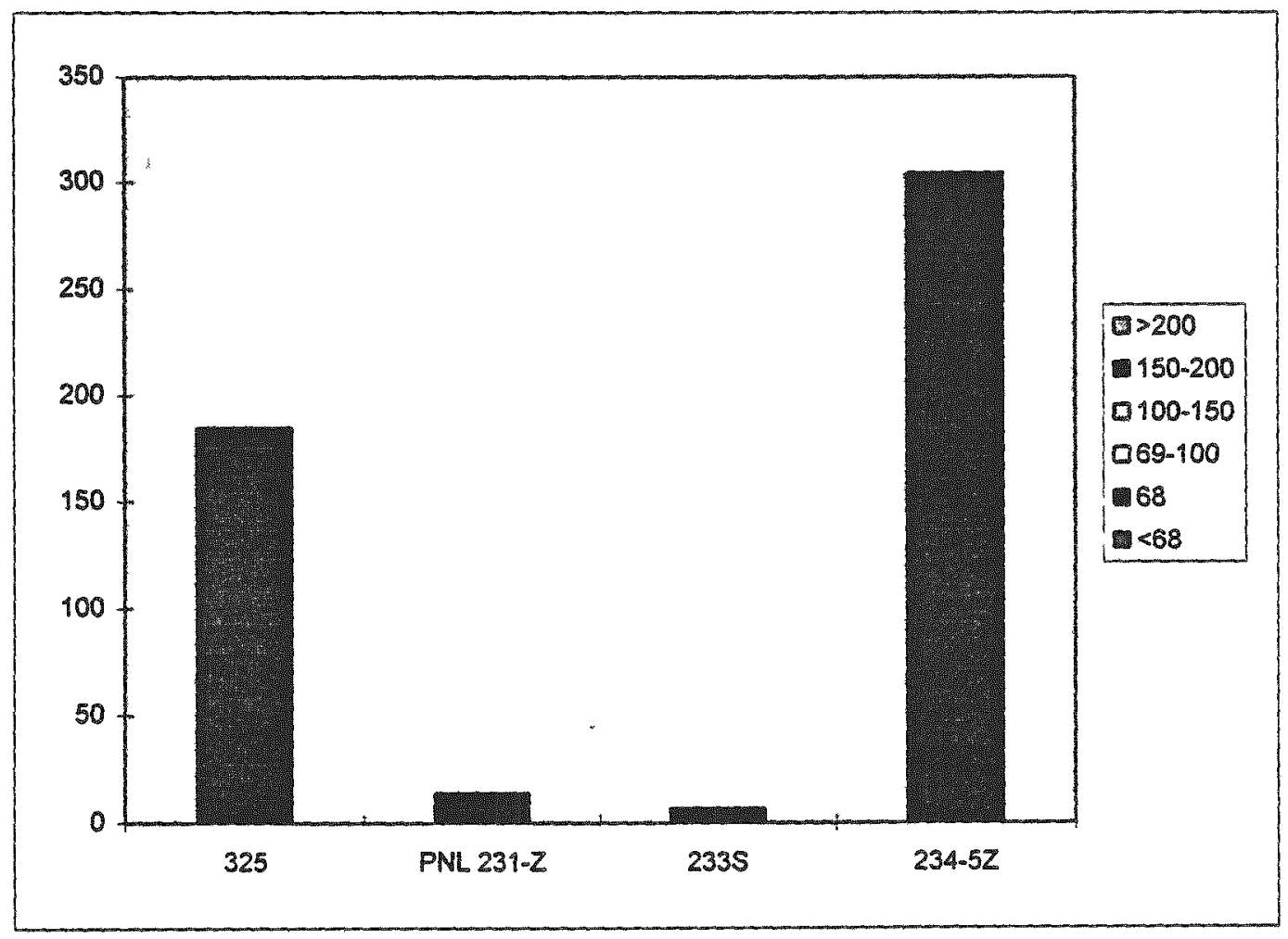


Figure 5.6-15. Number of Drums in Selected Weight Categories for Each Generator in Module 5.

WEIGHT

\begin{tabular}{|c|r|r|r|r|r|r|}
\hline Generator & $<68$ & 68 & $69-100$ & $100-150$ & $150-200$ & $>200$ \\
\hline 325 & & 201 & & & & \\
\hline 2335 & & 8 & & & & \\
\hline $234-52$ & & 337 & & & & \\
\hline
\end{tabular}

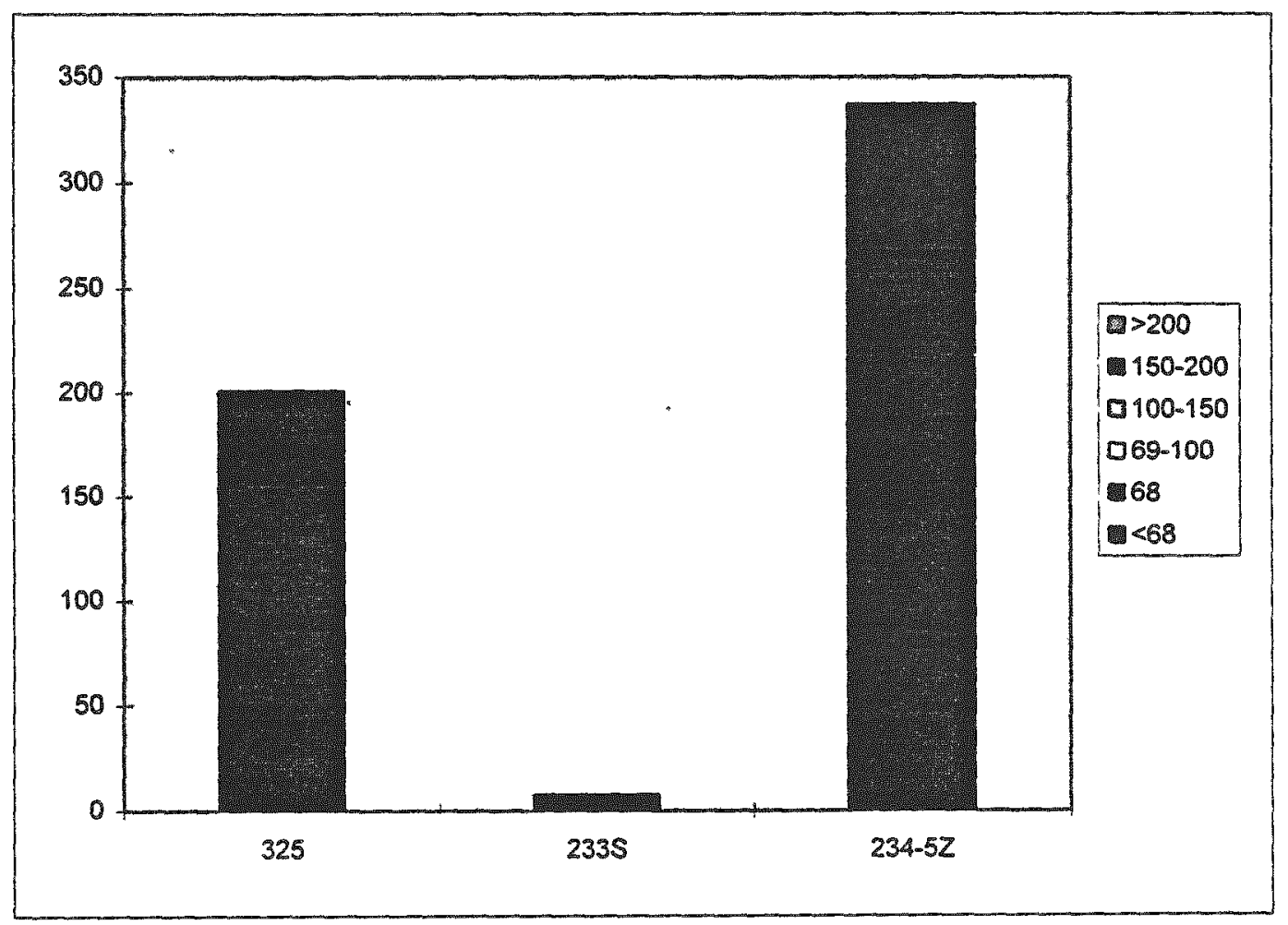


WHC-SD-W026-T1-009, Rev. O

Figure 5.6-16. Number of Drums in Selected Weight Categories for Each Generator in Module 4.

WEIGHT

\begin{tabular}{|c|r|r|r|r|r|r|}
\hline Generator & $<68$ & 68 & $69-100$ & $100-150$ & $150-200$ & $>200$ \\
\hline 325 & & 74 & & & & \\
\hline PNL 231-Z & 1 & 84 & & & & \\
\hline $202 \mathrm{~A}$ & & 64 & & & & \\
\hline $202 \mathrm{AL}$ & & 6 & & & & \\
\hline $234-52$ & & 264 & & & & \\
\hline
\end{tabular}

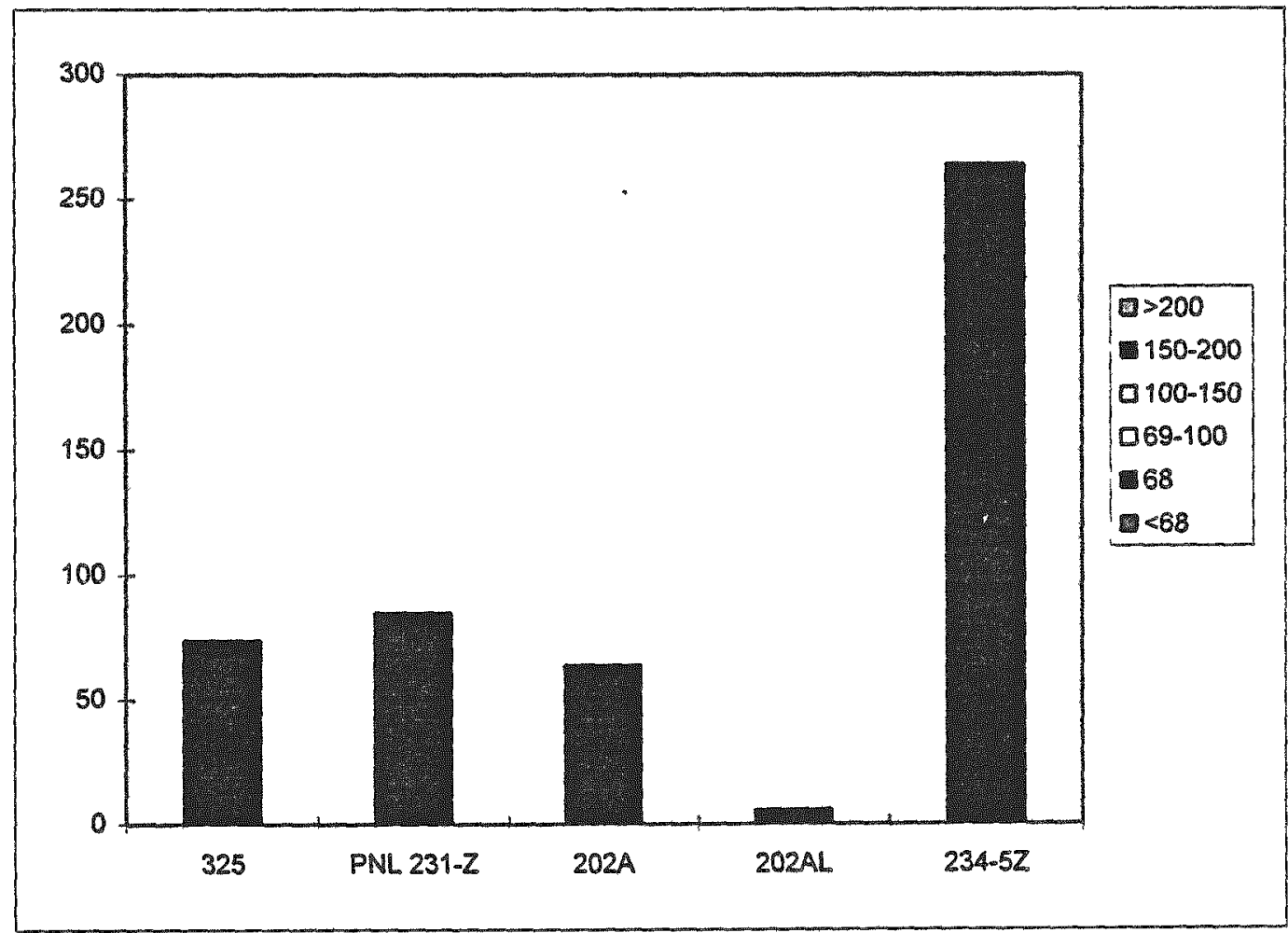


Figure 5.6-17. Number of Drums in Selected Weight Categories for Each Generator in Module 3.

WEIGHT

\begin{tabular}{|c|r|r|r|r|r|r|}
\hline Generator & $<68$ & 68 & $69-100$ & $100-150$ & $150-200$ & $>200$ \\
\hline 325 & & 92 & & & & \\
\hline PNL 231-Z & & 14 & & & & \\
\hline $234-5 Z$ & & 462 & & & & \\
\hline
\end{tabular}

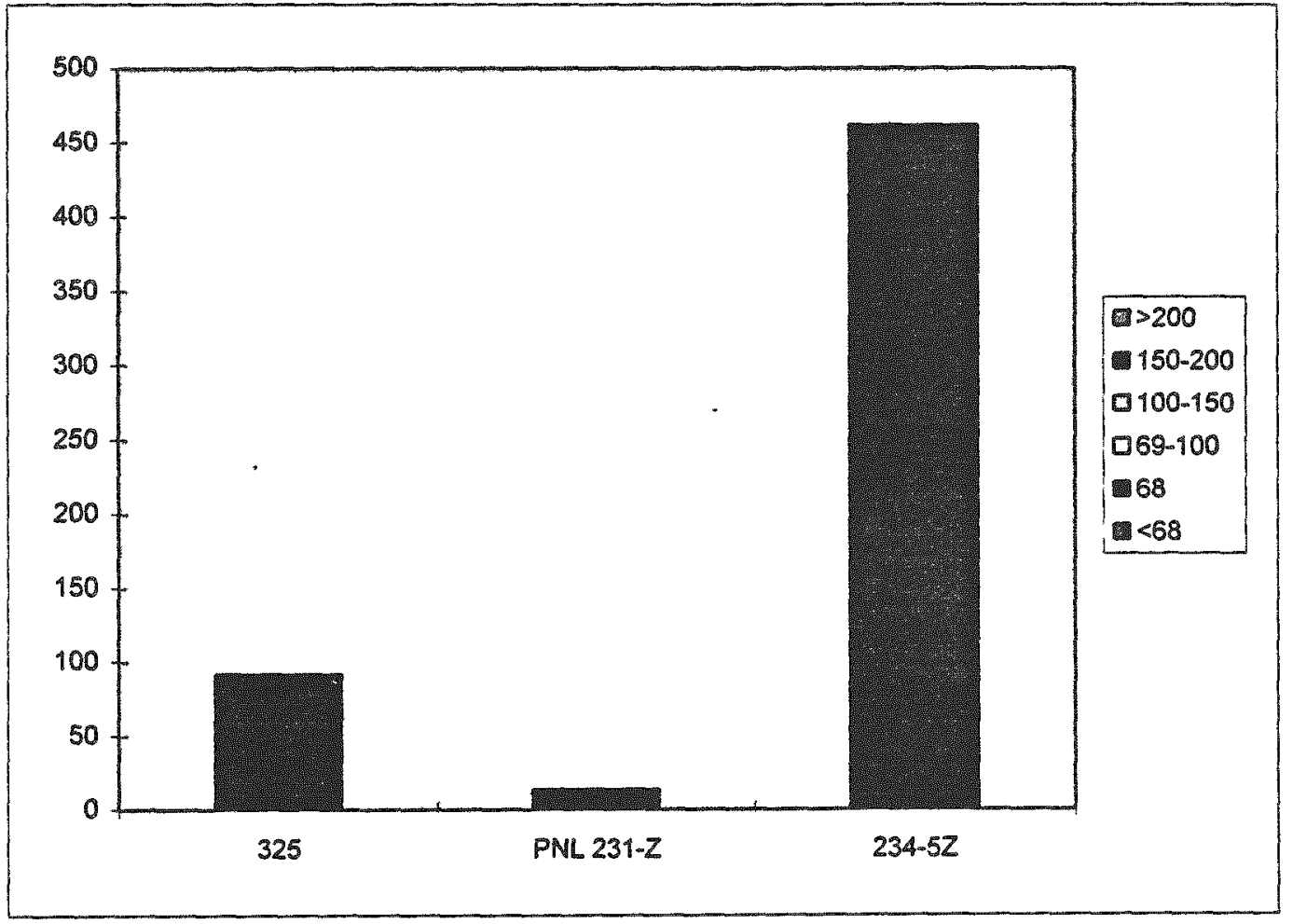


WHC-SD-W026-TI-009, Rev. 0

Figure 5.6-18. Number of Drums in Selected Weight Categories for Each Generator in Module 2.

\begin{tabular}{|c|r|r|r|r|r|r|}
\hline Generator & 668 & 68 & $69-100$ & $100-150$ & $150-200$ & $>200$ \\
\hline 325 & & 223 & & & & \\
\hline $325 A$ & & 5 & & & & \\
\hline PNL 231-Z & & 23 & & & & \\
\hline $202 \mathrm{~A}$ & & 10 & & & & \\
\hline 2225 & & 3 & & & & \\
\hline $234-52$ & & 385 & & & & \\
\hline BMI & 7 & 6 & 27 & 1 & & \\
\hline
\end{tabular}

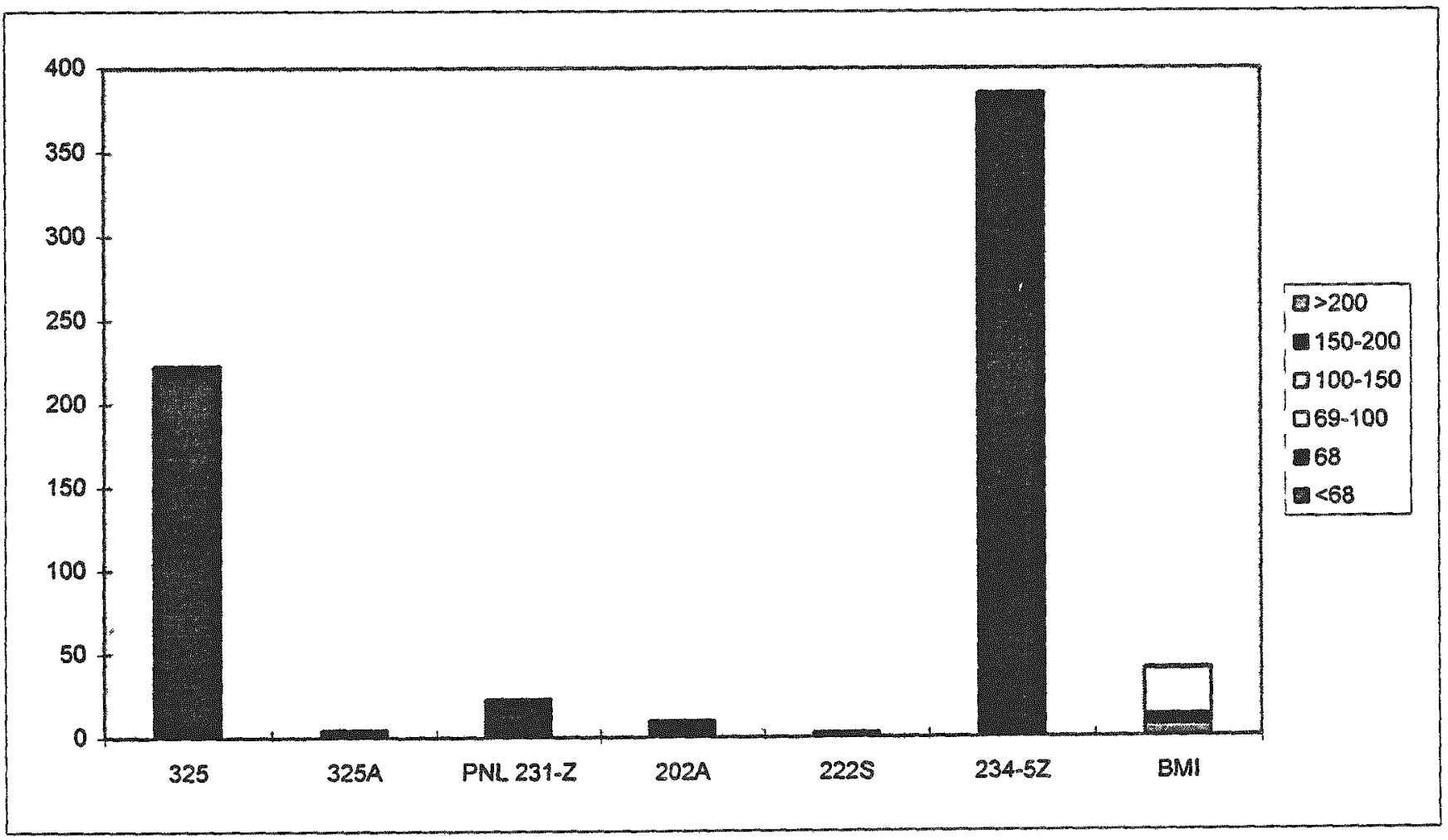


Figure 5.6-19. Number of Drums in Selected Weight Categories for Each Generator in Module 1.

GENERATOR

\begin{tabular}{|c|c|c|c|c|c|c|}
\hline \multicolumn{7}{|c|}{ WEIGHT } \\
\hline & $<68$ & 68 & $69-100$ & $100-150$ & $150-200$ & $>200$ \\
\hline 325 & 14 & 69 & 3 & & 1 & \\
\hline PNL 231-Z & & 42 & & & & \\
\hline $222 S$ & & 4 & & & & \\
\hline $234-5 Z$ & & 564 & & & & \\
\hline
\end{tabular}

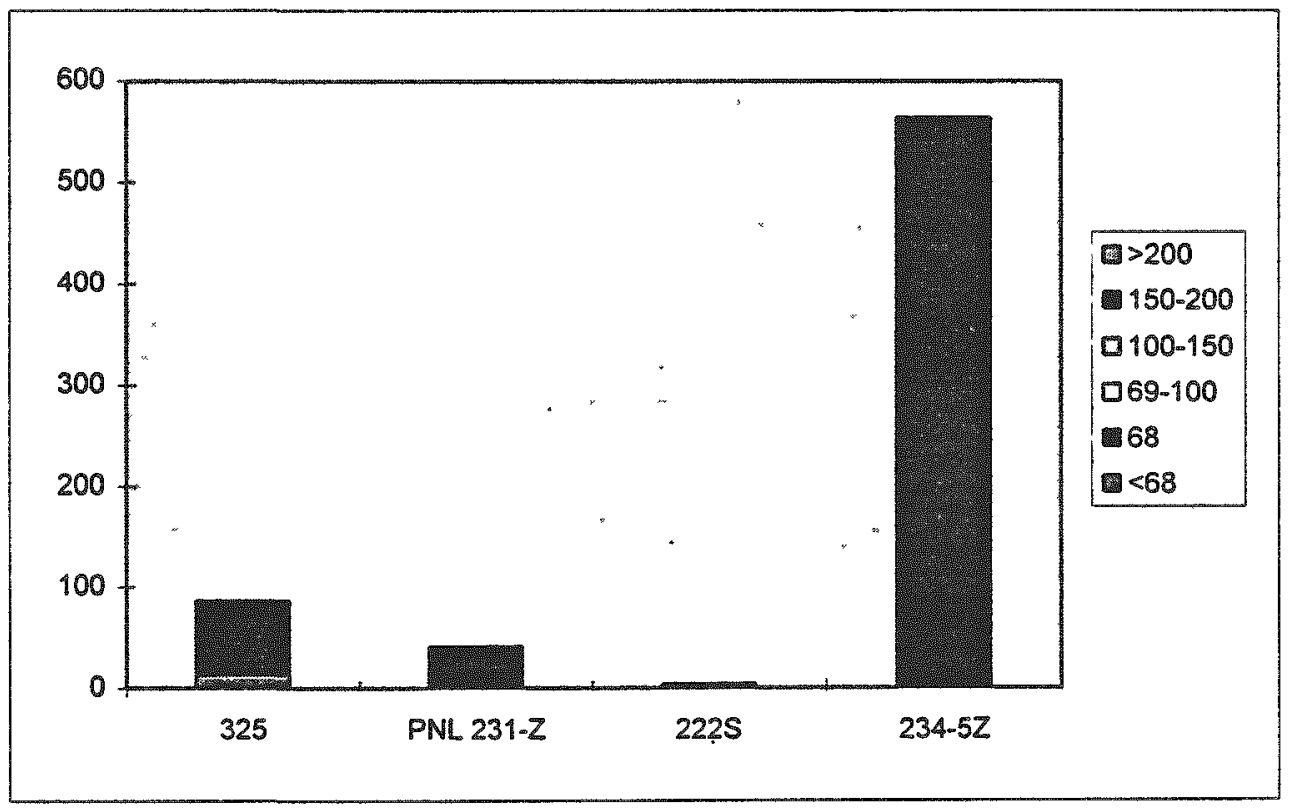




\subsection{SPECIAL WASTE TYPES}

\subsubsection{Soils}

Soils are to be excluded from processing in WRAP Module 1. These drums will be identified by NDE at the trench and will be batched together to exclude them from WRAP Module 1. Module 10 contains 22 drums from GE-Vallecitos with soil in them. Module 9 contains 9 drums from the PFP with soil in them. Module 7 is already known to contain six drums with soil in them. Module 5 contains 6 drums from PNL building 325 with soil in them.

\subsubsection{Animal Carcasses}

Animal carcasses are also excluded from processing in WRAP Module 1. A number of laboratory facilities used animals in radiation research. It is not always possible to tell from records or from NDE which drums contains animal carcasses; however, for containers generated post-1978, animal waste may be listed on the burial record. This is the case in Module 8 , where eight drums from the PNL-340 Building are known to contain animal wastes. 


\subsection{DYNAMIC BATCHING ALTERNATIVE}

Rather than batching all waste by a pre-ordained set of criteria, it may be more practical to build the capability for dynamically batching the waste in response to real-time processing needs. Under this scenario, any of the criteria for batching discussed in the previous section might be used to determine a batch at any given time. The following section discusses how dynamic batching might work.

\subsection{BACKGROUND}

Automated storage and retrieval operations rely on the ability of a computer control system to integrate equipment and information data required to accurately input material, randomly store material, and selectively retrieve material to fulfill customer needs. Retail operations such as K-Mart, JC Penneys, and Wal-Mart have relied on automated operations at their distribution centers to swiftly and accurately receive merchandise from all over the world, temporarily store the merchandise, and then selectively distribute the merchandise to a large number of retail sales stores in their region. The same concept has been used by grocers such as Albertsons, Safeway, and Ralph's Foods to centrally receive and store large volumes of dry goods and perishable produce then retrieve the correct amount of material to fill the orders of the respective retail stores. Manufacturing operations such as Pratt \& Whitney, Revlon, and General Motors have also successfully used this technology to support just-in-time (JIT) delivery of part and pieces for assembly line operations.

For automated storage and retrieval systems to be successful, as a minimum, they must be able to provide for material receipt, storage, and retrieval.

\subsubsection{Material Receipt}

The material being received must be identified to the Automated Storage and Retrieval Computer Control System (ASRCCS). Methods to accomplish this function are:

- Operator input to a video display terminal (VDT), personal computer (PC) or radio frequency (RF) terminal.

- Scanning labels produced by automatic identification (A) methods such as Bar Codes and Optical Character Recognition.

- Electronic data interchange (EDI) can support the remote exchanging of data bases to minimize receipt input operations.

Drums stored in Phase $V$ will have a bar code associated with each drum. These bar codes could be linked to all of the information about that drum in the SWITS database (or in other sources) for ready access to sorting information. 


\subsubsection{Material Storage}

The location where material is being stored must be identified to the ASRCCS. Recognized methods to accomplish this function are:

- Digital communication directly from an automated storage and retrieval machine.

- Operator input via keyboard or scanning of Al produced labels from a man-ride semi-automatic Stacker Retriever Machine using direct connect or RF communication.

\subsubsection{Material Retrieval}

The material being retrieved must exactly match the criteria defined by the requesting party. To successfully complete the retrieval of the requested material, the following elements need to be in place:

- As part of the ASRCCS network a database must be maintained which contains all the relevant characteristics of the material stored and the storage location of each discrete retrieval entity.

- The ASRCCS must be a part of an order processing network allowing the requestor to specify any or all of the material characteristics contained in the data base. The ASRCCS must be able to match the criteria and select the discrete retrieval entities.

- The ASRCCS must communicate the order retrieval to the device or person charged with the retrieval of the material and confirm that the correct material has be retrieved.

\subsection{POTENTIAL OPERATIONAL DESCRIPTION}

Since the Phase $V$ storage facility is an AS/RS, the control system and pallet selection and retrieval system can be designed to dynamically create "on-demand" batches. The following is a high level description of how the control system might function.

\subsubsection{Expected Containers}

Prior to the commencement of Phase 1 or Phase 2 retrieval operations, the known contents of all containers will be entered into a data base. Each record in the database will contain the container identification number, the source of waste as well as the known contents of the container. As containers are removed from the trench, they will have a container bar code label attached. The results of any additional examination, assay, or sampling is done at time of retrieval the results will be added to the data base when available. 


\subsubsection{Material Identification and Induction}

The containers will be moved to Phase $V$ storage and the bar code label scanned to identify the container identification number (CIN) to the ASRCCS. The ASRCCS will match the CIN to the data base and if their is a match, the container will be released to storage. If there is no match, the data base will be marked with an unknown container flag and the material released to storage.

\subsubsection{Material Storage}

The Automated Material Handling System (AMHS) will move the material to Phase $V$ storage, place the material in the rack and report the storage location to the ASRCCS.

\subsubsection{Order Processing}

WRAP Module 1 or WRAP Module 2A operations personnel will prepare the retrieval orders to support their operational needs. They can select a particular container or they can specify the particular characteristics that are of concern to them in their operations. A single container can be selected or all containers meeting the specified criteria can be selected. For example, the operator may want to sample all containers created at PUREX in 1982 containing rags. The order would be entered into the ASRCCS, which would search the data base, select those containers which match the criteria and schedule the retrieval of the containers from Phase $V$ storage.

\subsubsection{Material Retrieval}

Upon receipt of the retrieval order the AMHS will locate and move the material from Phase $V$ storage to the destination specified in the retrieval order. Possible delivery destinations could be a sampling station in WRAP Module 1, a workstation in WRAP Module 2A or a packaging and shipping area. Upon delivery of the container to its destination, the ASRCCS will delete the storage record in Phase $V$ storage and link the material to the delivery destination.

\subsection{POTENTIAL BENEFITS}

Dynamic batching uses the power and flexibility of database manipulation and provides:

- Random storage of material

- Minimizes staging of material

- Maximum flexibility of batch types

- Customer control of their work

- Supports complete tracking of containers and their contents. 


\subsection{REFERENCES}

AEC, 1970, Immediate Action Directive 0511-21, U.S. Atomic Energy Commission, Washington, D.C.

Bergeson, C.B., et al., 1994, WRAP Module 1 Sampling Strategy and Waste Characterization Alternatives Study. WHC-SD-W026-ES-013. Westinghouse Hanford Company, Richland, WA

Carlson, A.B., D.M. Caum, D.C. DeRosa, D.R. Duncan, K.L. Hladek, P.H. Jacobsen, R.S. Kelley, B.A. Mayancsik, and W.L. Willis, 1994, Solid Waste Program Technical Baseline Description, WHC-SD-WM-RPT-060, Rev. O, Westinghouse Hanford Company, Richland, WA.

DOE, 1982. Management of Transuranic Material, DOE Order 5820.1, U.S. Department of Energy, Washington, D.C.

DOE, 1987. Radioactive Waste: Byproducts Material Final Rule, 10 CFR 962, Federal Register, 52 FR 159397-1592, U.S. Department of Energy, Washington, D.C.

DOE, 1988, Radioactive Waste Management, DOE Order 5820.2A, U.S. Department of Energy, Washington, D.C.

Duncan, D.R., B.A. Mayancsik, J.A. Pottmeyer, E. Vejvoda, J.A. Reddick, K.M. Sheldon, and M.l. Weyns, 1993, Characterization of Past and Present Waste Streams from the Plutonium Finishing Plant, WHC-EP-0621, Westinghouse Hanford Company, Richland, WA.

Duncan, D.R., 1994, Radioactive Waste Shipments to Hanford Retrievable Storage from Babcock and Wilcox, Leechburg, PA. WHC-EP-0719. Westinghouse Hanford Company, Richland, WA.

Duncan, D.R., J.A. Pottmeyer, M.I. Weyns, K.D. Dicenso, and D.S. DeLorenzo, 1994, Radioactive Waste Shipments to Hanford Retrievable Storage from Westinghouse Advanced Reactors and Nuclear Fuels Divisions, Cheswick, Pennsy/vania, WHC-EP-0718, Westinghouse Hanford Company, Richland, WA.

EPA, 1986. Test Methods for Evaluating Solid Waste, SW 846, Third Edition, U.S. Environmental Protection Agency, Office of Solid Waste and Emergency Response, Washington, D.C.

Olson, W.W., et al., 1994, Waste Receiving and Processing Facility Module 1 (WRAP 1) Preliminary Safety Analysis Report, WHC-SD-W026-SAR-001, Rev. 1, Westinghouse Hanford Company, Richland, WA.

Pottmeyer, J.A., M.l. Weyns, D.S. DeLorenzo, E. Vejvoda, and D.R. Duncan, 1993a, Characterization of Past and Present Waste Streams from the Plutonium-Uranium Extraction Plant, WHC-EP-0646, Westinghouse Hanford Company, Richland, WA. 
Pottmeyer, J.A., D.S. DeLorenzo, M.I. Weyns-Rollosson, D. Berkowitz, E. Vejvoda and D.R. Duncan, 1993b. Characterization of Past and Present Waste Streams from 231-Z. WHC-EP-0659. Westinghouse Hanford Company, Richland, WA.

Pottmeyer, J.A. M.I. Weyns-Rollosson, M.K. Dicenso, D.S. Delorenzo, and D.R. Duncan, 1993c, Characterization of Past and Present Waste Streams from the 325 Radiochemistry Building. WHC-EP-0696. Westinghouse hanford company. Richland, WA.

WHC. 1991. Engineering Siudy for the Solid Waste Retrieval, Project W-113. WHC-SD-W113-ES-001, Revision 0. Westinghouse Hanford Company, Richland, WA.

Vejvoda, E., J.A. Pottmeyer, D.S. DeLorenzo, M.I. Weyns-Rollosson, and D.R. Duncan, 1993, Radioactive Waste Shipments to Hanford Retrievable Storage from the General Electric Vallecitos Nuclear Center, Pleasanton, California, WHC-EP-0719. Westinghouse Hanford Company, Richland, WA. 
WHC-SO-WO26-TI-009, ReV.O

\section{APPENDIX A}

Queries Used to Generate Data from SWITS Database

$A \cdot O$ 
DON'T SAY IT - WrIt It!

Date:

To:

From: Solid Waste Engineering Data Management Group N3-II $6-4394 / 6-4020$

Re: SWITS DATA REQUEST

Atrached for your information and use is the data which you cequested. This data represents best available information regarding wastes currenty in storage at the Hanford site. I trust the information will be suitable to your needs.

Requests for information from the solid Waste Information and Tracking System (SWITS) are normaly relatively limited in scope, requesting specific data Fialds or summary data. The responses to these requests undergo review during data sollection, summary and response preparation.

The response to this request represents a simple reproduction of the swI Database. Transmittal of this information is made with the following discladmers:

1) The information contained in this transmittal is raw data, and represents information provided to solid Waste Engineering (SWE) on burial records or other documents. This data has not been validated.

2) The information contained in this transmittal is subject to change without notice. Continual update of swITs information and improvement of the software syster make it imposibible to ensure consistency of this data with the database after transmittal.

3) This infomation is current as of $7-1-94$. $+n_{n}$

If I can be of Eurther assistance to you, do not hesitate to call me. 


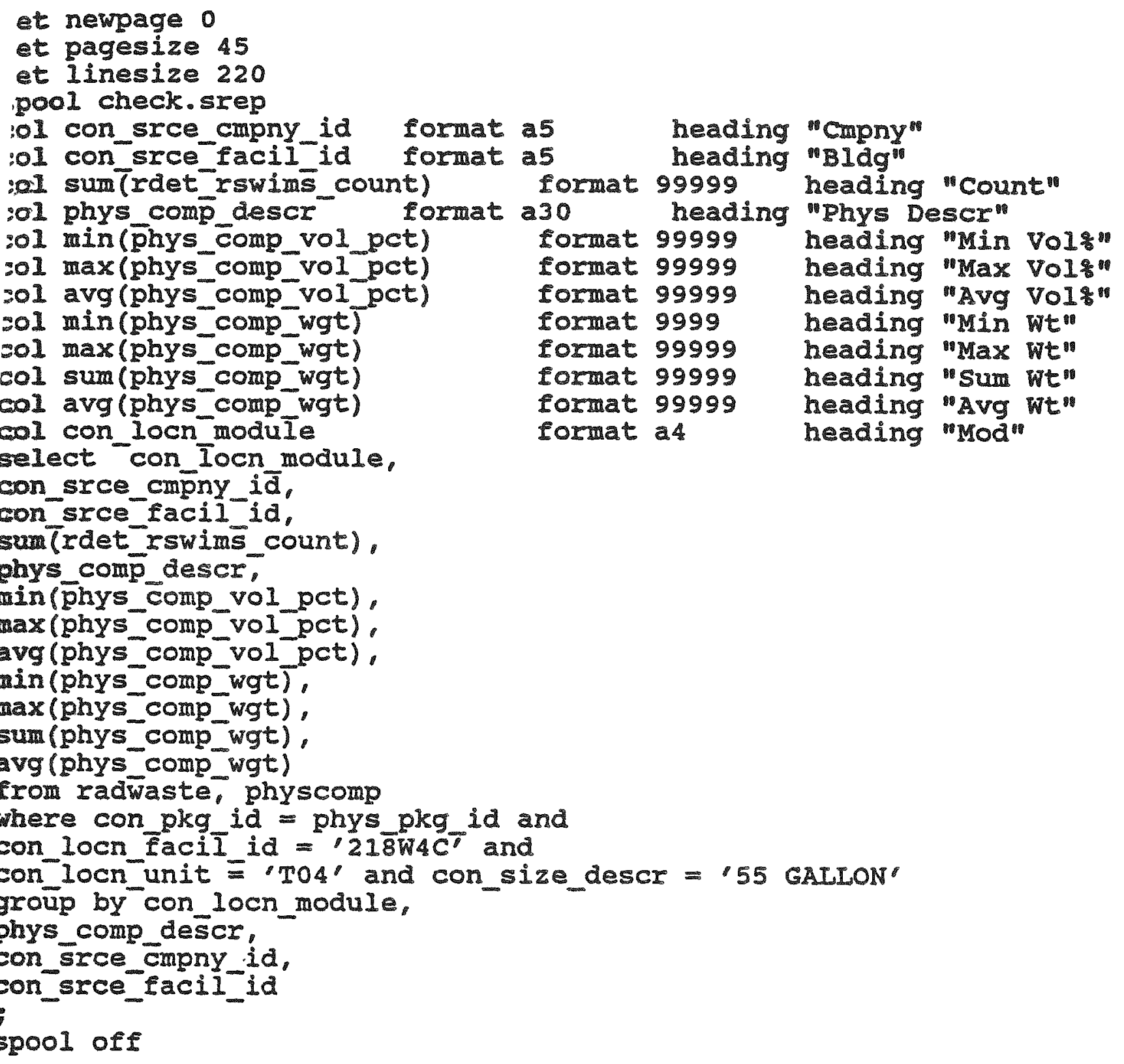




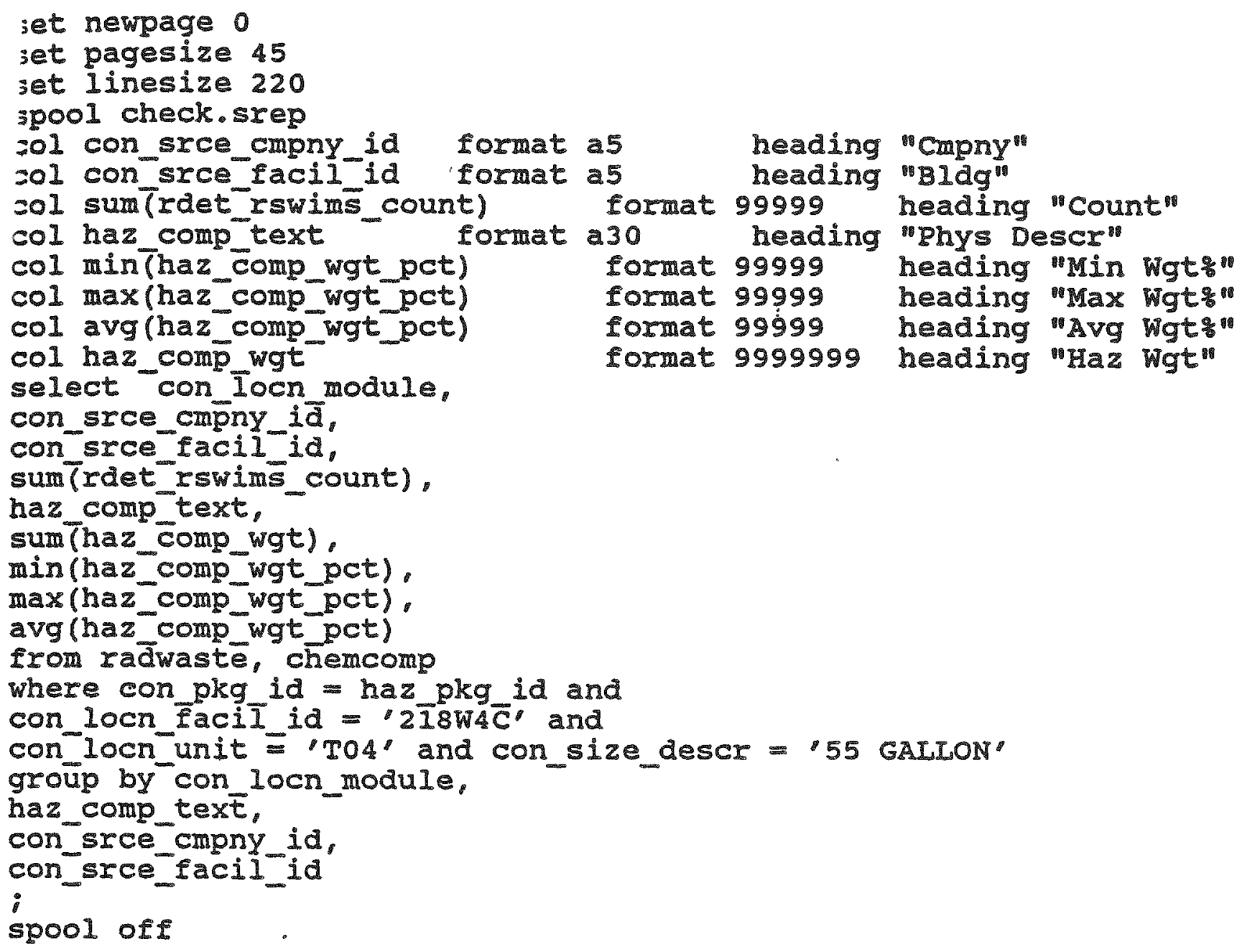


WhC-SD-W026-TI-009, BeV. O

set newpage 0

iet pagesize 45

set linesize 220

spool check. srep

:ol con_srce_cmpny_id format as heading "Cmpny"

sol con srce facil-id format as heading "BIdg"

sol sum(rdet rswims count) format 99999 heading "Count"

select con Iocn module.

consrce facil id,

rdeE_bg_äose rāte.

sum( (rdet_rswims_count)

from radwaste

where

con_locn_facil_id $=' 218$ W4 C' and

con_locn_unit $=$ 'TO4' and con_size_descr $=55$ GALLON'

group by con locn module,

consrce facil_id,

rdeE_bg_dose rāte

orde $\bar{r}$ by con $10 \mathrm{cn}$ module.

consrce facil id,

rdet bg dose rāte

:

spool off 
WHC-SD-WO26-TI-009, ReV.O

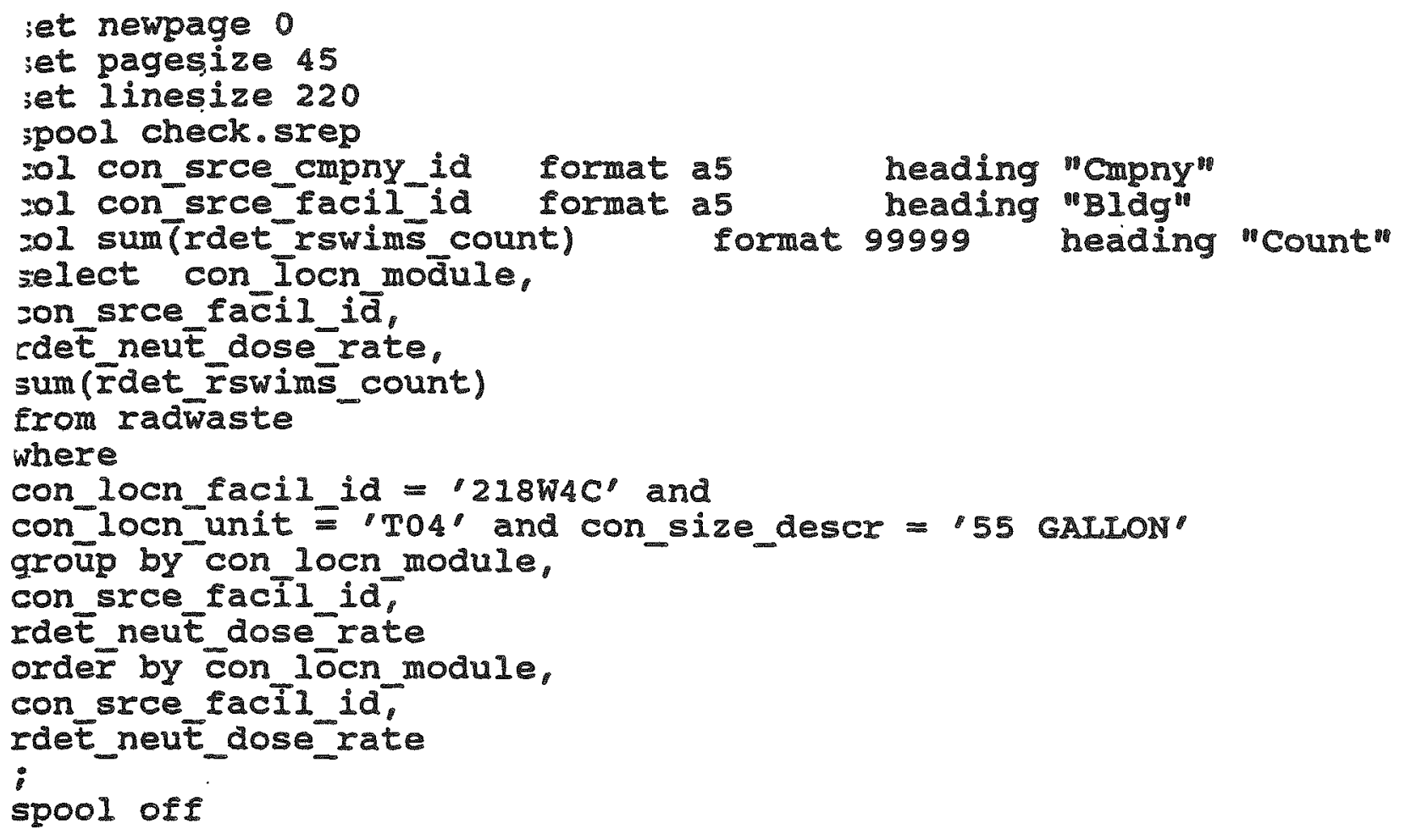




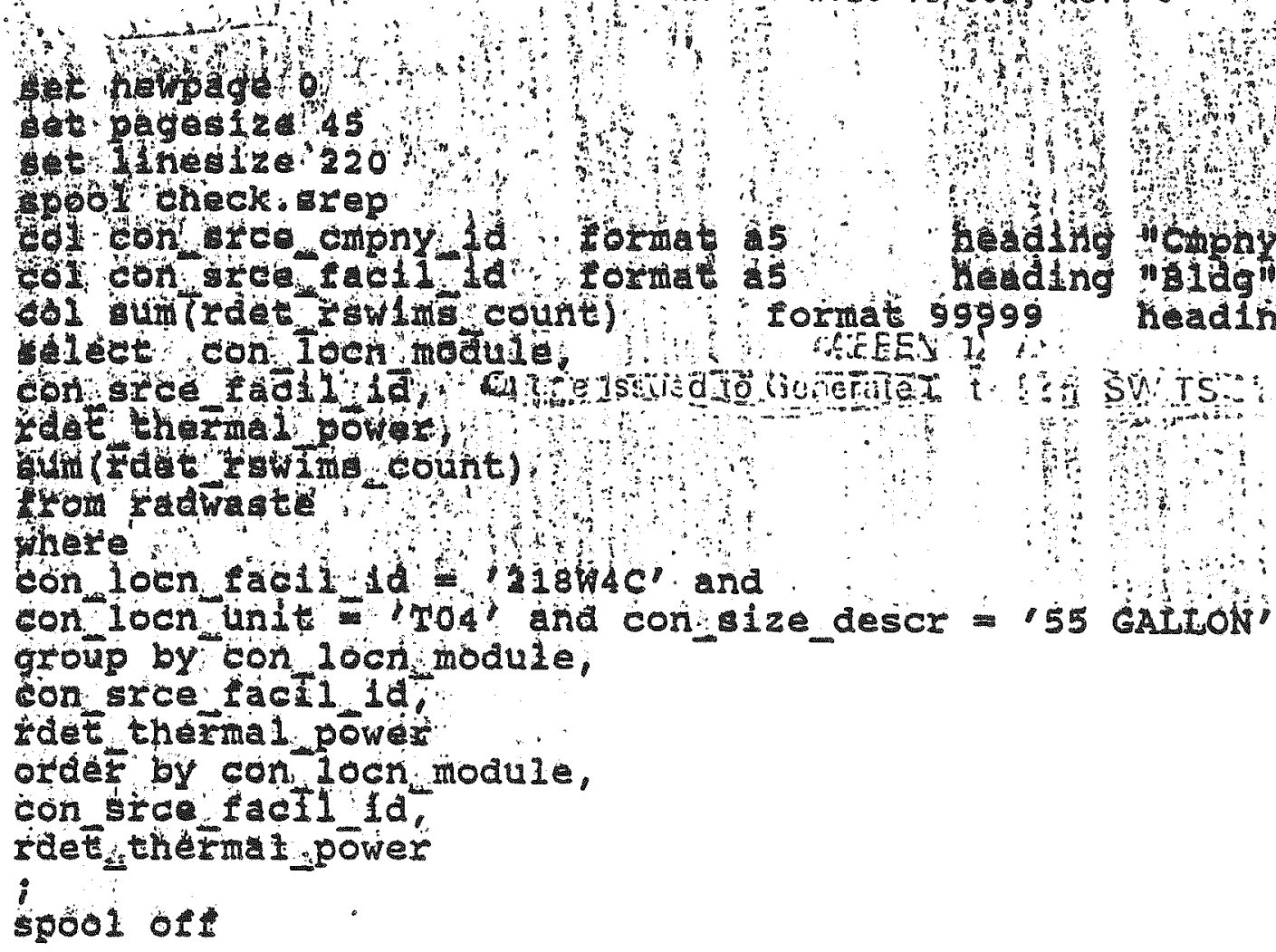




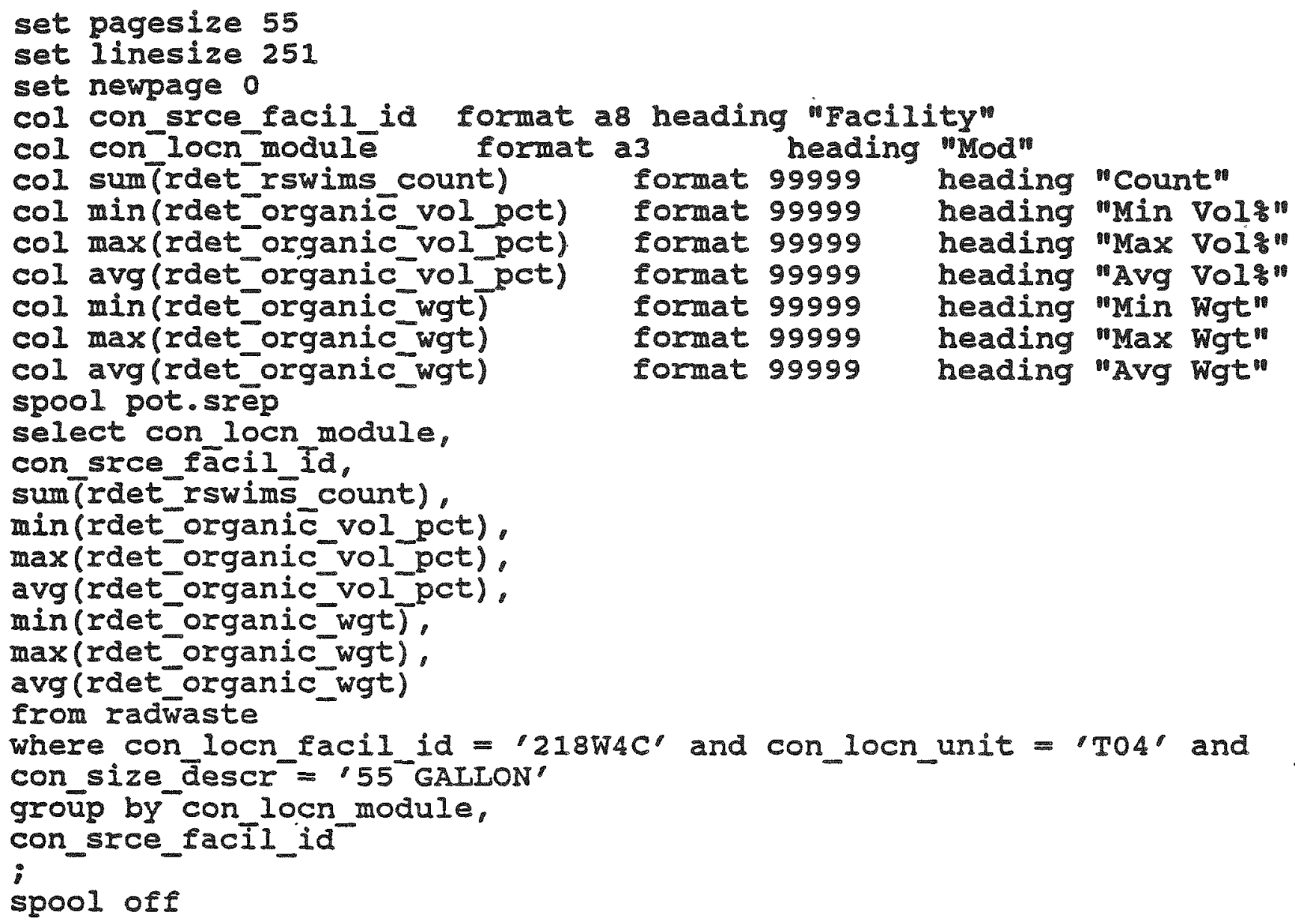




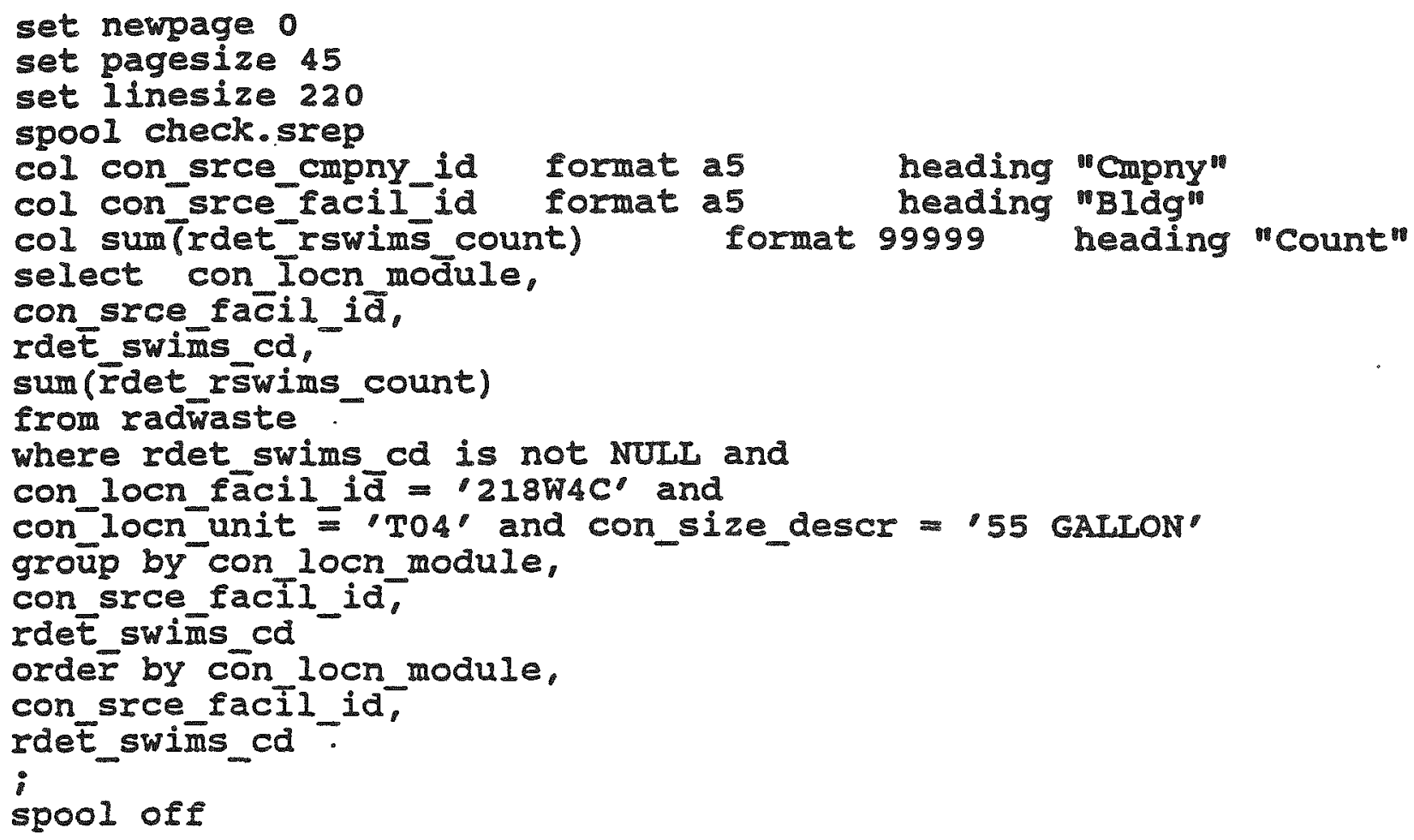




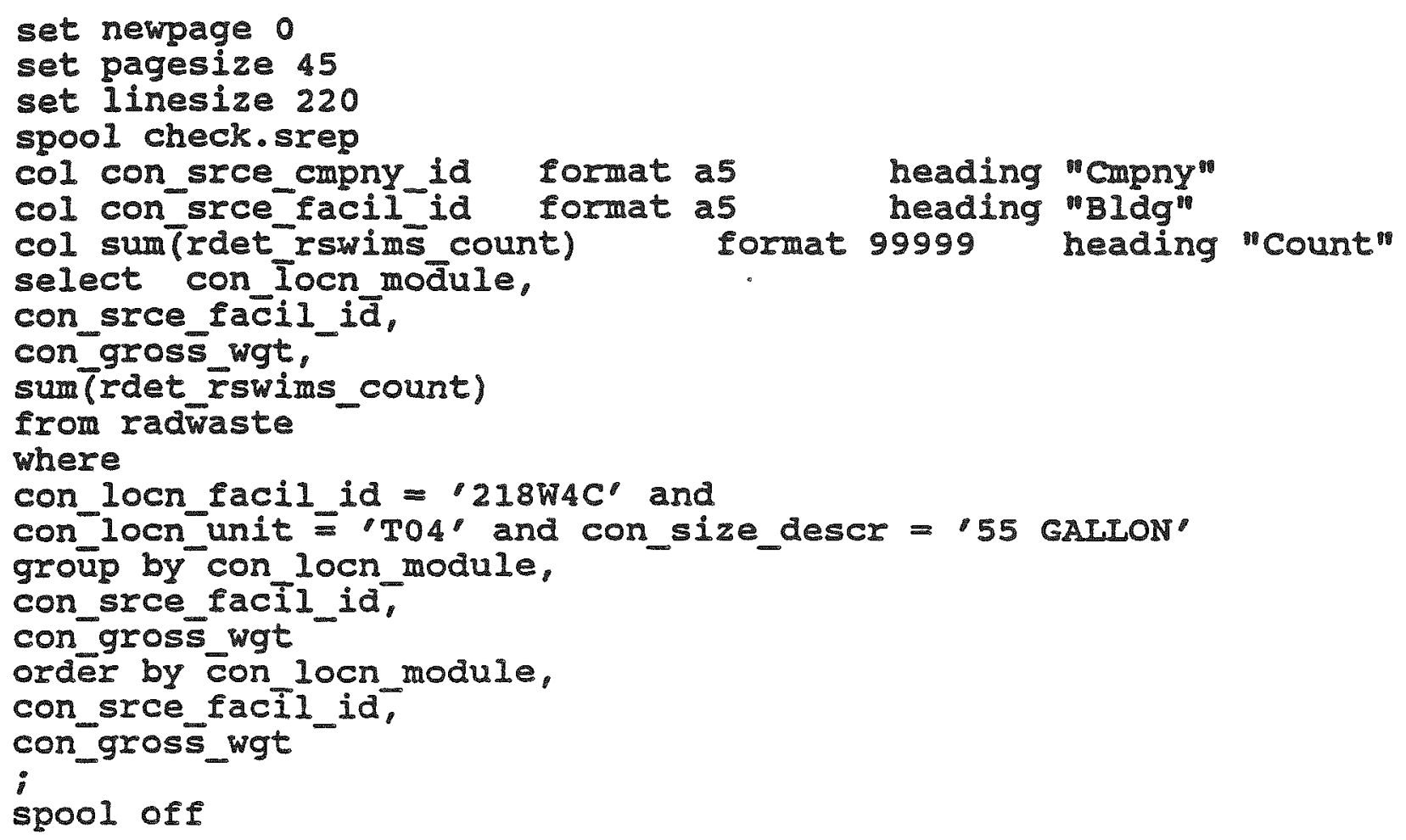

